\title{
Hydroacoustic Evaluation of Fish-Passage Efficiency at Bonneville Dam in 2001
}

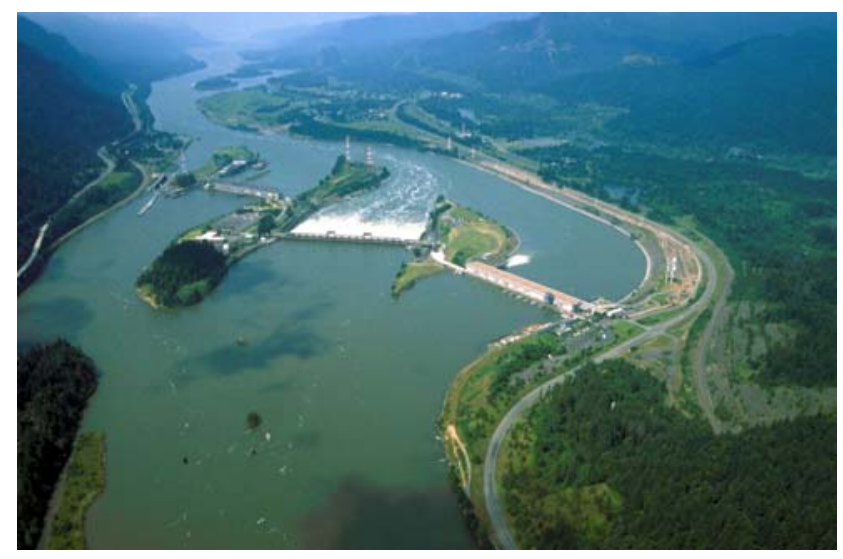

G. R. Ploskey

Pacific Northwest National Laboratory

C. R. Schilt, M. E. Hanks, P. N. Johnson, and J. Kim MEVATEC Corp.

J. S. Skalski

University of Washington

D. S. Patterson

Dyntel

W. T. Nagy

Fisheries Field Unit, USACE, Portland

L. R. Lawrence

Engineering Research and Development Center, USACE

September 2002

Prepared for the

U.S. Army Corps of Engineers

Under a Related Services Agreement

With the U.S. Department of Energy

Contract DE-AC06-76RLO1830

\section{Pacific Northwest National Laboratory}

Operated by Battelle for the

U.S. Department of Energy 


\section{DISCLAIMER}

This report was prepared as an account of work sponsored by an agency of the United States Government. Neither the United States Government nor any agency thereof, nor Battelle Memorial Institute, nor any of their employees, makes any warranty, express or implied, or assumes any legal liability or responsibility for the accuracy, completeness, or usefulness of any information, apparatus, product, or process disclosed, or represents that its use would not infringe privately owned rights. Reference herein to any specific commercial product, process, or service by trade name, trademark, manufacturer, or otherwise does not necessarily constitute or imply its endorsement, recommendation, or favoring by the United States Government or any agency thereof, or Battelle Memorial Institute. The views and opinions of authors expressed herein do not necessarily state or reflect those of the United States Government or any agency thereof.

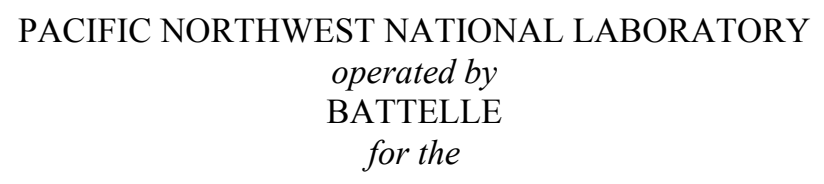

UNITED STATES DEPARTMENT OF ENERGY

under Contract DE-AC06-76RL01830

Printed in the United States of America

Available to DOE and DOE contractors from the Office of Scientific and Technical Information, P.O. Box 62, Oak Ridge, TN 37831-0062;

ph: (865) 576-8401

fax: (865) 576-5728

email: reports@adonis.osti.gov

Available to the public from the National Technical Information Service, U.S. Department of Commerce, 5285 Port Royal Rd., Springfield, VA 22161 ph: (800) 553-6847

fax: (703) 605-6900

email: orders@ntis.fedworld.gov

online ordering: http://www.ntis.gov/ordering.htm 


\title{
Hydroacoustic Evaluation of Fish-Passage Efficiency at Bonneville Dam in 2001
}

\author{
G. R. Ploskey \\ (Pacific Northwest National Laboratory) \\ C. R. Schilt \\ M. E. Hanks \\ P. N. Johnson \\ J. Kim \\ (MEVATEC Corporation) \\ J. S. Skalski \\ (University of Washington) \\ D. S. Patterson \\ (Dyntel)
}

W. T. Nagy

(Fisheries Field Unit, USACE, Portland)

L. R. Lawrence

(Engineering Research and Development Center, USACE)

September 2002

Prepared for

the U.S. Army Corps of Engineers

under a Related Services Agreement

with the U.S. Department of Energy

Contract DE-AC06-76RLO1830

Pacific Northwest National Laboratory

P.O. Box 999

K6-85

Richland, Washington 99352 



\section{Abstract}

The Portland District of the U.S. Army Corps of Engineers requested that scientists with the Pacific Northwest National Laboratory (PNNL) and the U.S. Army Engineer Research and Development Center (ERDC) conduct fish-passage studies at Bonneville Dam using hydroacoustic evaluation methods. The ERDC also contracted with MEVATEC Corporation and Dyntel to provide staff ranging from scientists to technicians for the study. This study supports the Portland-District goal of maximizing fish passage efficiency (FPE) and obtaining 95\% survival for juvenile salmon passing the Bonneville Project.

This report presents results of two hydroacoustic studies of juvenile salmonids conducted in 2001 at Bonneville Dam in an extensive summary, in the main body of the report, and in appendices. Appendix E on the accompanying compact disk includes hourly estimates of forebay elevation and route-specific water discharge, fish passage, and associated variances and covariances.

One study was a project-wide evaluation of fish-passage efficiency, and the other was a more narrowly focused study of the approach, vertical distribution, and fish-guidance efficiency (FGE) of fish at Unit 15, where the Portland District extensively modified the gatewell and vertical barrier screen to improve gatewell flow and FGE. The goal of the larger of the two studies was to provide project-wide estimates of FPE, spill efficiency, and spill effectiveness for run-of-river fish passing the Bonneville Project during the 2001 out-migration. This type of study also provides estimates of the horizontal, vertical, and diel distributions of fish passage and FGE by turbine unit. These data will provide a baseline for evaluating the performance of future management efforts to improve juvenile fish passage. The goal of the second study was to assess the effect of gatewell and vertical-barrier-screen modifications on the FGE of Unit 15. 
Hydroacoustic Evaluation of FPE at Bonneville Dam in 2001 


\section{Executive Summary}

The Portland District of the U.S. Army Corps of Engineers requested that scientists with the Pacific Northwest National Laboratory (PNNL) and the U.S. Army Engineer Research and Development Center (ERDC) conduct the hydroacoustic fish-passage studies described in this report. The ERDC also contracted with MEVATEC Corporation and Dyntel to provide staff ranging from scientists to technicians for the study. This study supports the Portland District goal of maximizing fish passage efficiency (FPE) and obtaining 95\% survival for juvenile salmon passing the Bonneville Project. Project FPE is the percent of all juvenile salmon passing the project by non-turbine routes. Estimation of Project FPE and survival requires estimates of the proportion of juvenile salmon that pass through every major passage route.

This report presents results of two hydroacoustic studies of juvenile salmonids. One was a Projectwide study of fish-passage efficiency and the other was more narrowly focused upon the approach, vertical distribution, and fish-guidance efficiency (FGE) of fish at Unit 15, where the Portland District extensively modified the gatewell and vertical barrier screen to improve gatewell flow and FGE. The District also funded other parallel research on juvenile salmonids in 2001, including a Project-wide radio telemetry study by the U.S. Geological Survey (USGS) and a netting study of fish-guidance and orificepassage efficiency by the National Marine Fisheries Service (NMFS) at Unit 15.

Common metrics used to describe fish passage at Bonneville Dam are listed below.

- Spill Passage Efficiency (SPE) - the proportion of total fish passing the project that pass through the spillway.

- Spill Passage Effectiveness - SPE divided by percent of total discharge going over the spillway.

- Fish Passage Efficiency (FPE) - the proportion of fish that pass through non-turbine routes i.e., juvenile bypass system and spillway.

\section{Goals}

The goal of the larger of the two studies was to provide project-wide estimates of FPE, spill efficiency, and spill effectiveness for run-of-river fish passing the Bonneville Project during the 2001 outmigration. It is the second full-project hydroacoustic study of fish passage at Bonneville Dam. The first was conducted in 2000 (Ploskey et al. 2002a). This type of study also provides estimates of the horizontal, vertical, and diel distributions of fish passage and FGE by turbine unit. These data will provide a baseline for evaluating the performance of future management efforts to improve juvenile fish passage. The goal of the second study was to assess the effect of gatewell and vertical-barrier-screen modifications on the FGE of Unit 15. 


\section{Objectives}

\section{Project FPE Evaluation}

1. Estimate the proportion of smolt-sized fish that pass the project above and below in-turbine screens, sluiceway openings with water depths $>1 \mathrm{~m}$, and the spillway each season.

2. Estimate spill efficiency and effectiveness by season and for spill periods.

3. Characterize the vertical and lateral distributions of smolt-sized fish passing through Powerhouses 1 and 2 and the spillway.

4. Describe day-night changes in vertical and lateral distributions of smolt-sized fish passing Powerhouses 1 and 2 and the spillway.

\section{Unit 15 Evaluation}

1. Determine average trajectories of juvenile salmon by elevation and distance upstream of trash racks through three successive hydroacoustic sample volumes aligned in a downstream-upstream direction.

2. Determine the vertical distribution of smolts from the top of the intake to the bottom of the forebay within three successive hydroacoustic sample volumes to determine how distributions change as fish approach the trash racks.

3. Use in-turbine up- and down-looking hydroacoustic beams to determine the vertical distribution of fish downstream of trash racks and to provide independent estimates of FGE from NMFS netting effort at the same unit.

4. Determine whether the distribution and behavior of fish upstream and downstream of the trash racks explain why FGE decreases from spring through summer.

\section{Site Description and Conditions in 2001}

From the Oregon shore north toward Washington, the project is composed of a navigation lock, a 10unit Powerhouse 1, Bradford Island, an 18-gate spillway, Cascades Island, and an 8-unit Powerhouse 2. Principal passage routes include the spillway and two powerhouses, but within each powerhouse, fish passage can be through ice/trash sluiceways, turbines, or the juvenile bypass system (JBS). Smolts enter the JBS after they encounter screens in the upper part of turbine intakes and are diverted to gatewell slots and orifices opening to a bypass channel.

In a typical water year, the goal of maximizing FPE largely influences operation of the project. Large volumes of spill are presumed to be necessary to compensate for the low FGE of screens at both powerhouses, particularly in summer. In a typical year, spill volumes are limited to between 50,000 and $75,000 \mathrm{cfs}$ during the day and are typically higher at night (100,000-140,000 kcfs) as long as total dissolved gas saturation does not exceed $120 \%$ (i.e., the gas cap). The Northwest had an unusually dry year in 2001 and that, combined with high generation demand, led to unusually low spill volumes. Total project discharge in spring was roughly half (46\% in spring and 54\% in summer) of what it was in 2000 . In 2001 , the project spilled $16 \%$ of the total discharge in spring and $11 \%$ in summer, down $31 \%$ and $50 \%$, respectively, from the percent spilled in 2000. Total spill volume in 2001 was less than a quarter (23\%) in spring and less than an eighth (12\%) in summer of what it was in 2000. 


\section{Materials and Methods}

\section{Equipment}

We sampled Powerhouse 1 turbines with four hydroacoustic systems, the spillway with three systems, and Powerhouse 2 turbines and forebay with four systems. Each system consisted of an echosounder, cables, transducers, an oscilloscope, and a computer system. An echosounder generates electric signals of specific frequency and amplitude and at the required pulse durations and repetition rates, and cables conduct those transmit signals from the echosounder to transducers and return data signals from transducers. Transducers convert voltages into sound on transmission and sound into voltages after echoes return to the transducer. Oscilloscopes were used to display echo voltages and calibration tones as a function of time, and the computer system controlled echosounder activity and recorded data to a hard disk. The $420 \mathrm{kHz}$, circular, single- or split-beam Precision Acoustic Systems (PAS) transducers were controlled by PAS 103 echosounders and Hydroacoustic Assessments' HARP software running on Pentium-class computers.

\section{Calibrations}

Before deployment, all hydroacoustic equipment was transported to Seattle, Washington, where PAS electronically checked the echosounders and transducers and calibrated the transducers using several standard transducers. After calibration, we calculated receiver gains to equalize the output voltages among transducers for on-axis targets ranging in hydroacoustic size from -56 to $-36 \mathrm{~dB} \| 4 \pi \mathrm{m}^{2}$. Lengths of fish corresponding to that acoustic size range would be about 1.3 and 12 inches, respectively, for fish insonified within $21^{\circ}$ of dorsal aspect (Love 1977).

\section{Sampling Powerhouse 1}

In turbine units 1 through 10, we sampled one randomly selected intake slot out of three per unit. We mounted one upward- and one downward-angled $6^{\circ}$ transducer in each of the selected slots to monitor guided and unguided passage, respectively. The lateral location of both transducers within the same intake was randomly selected to be on the north, center, or south side of the trash rack so that some of the lateral variation in passage within intakes would be captured in the variance estimate for the entire powerhouse.

Transducers deployed in units 5 and 10 were $6^{\circ}$ split beams to provide target strength data for detectability modeling. Sampling the 40-ft-long extended submerged bar screen (ESBS) at Unit 8 required a different deployment of transducers. Fish passing above and below the ESBS of Unit 8 were sampled with upward- and a downward-angled, $6^{\circ}$, single-beam transducers to estimate guided and unguided numbers, respectively, but the down-looking transducer was mounted on the downstream side of the ESBS instead of on a trash rack. Therefore, fish passage at Unit 8 could differ from estimates at other Powerhouse 1 units for a variety of reasons, e.g., screen type, unit location, intake selected for sampling, and differences in detectability among deployments. Our modeling of and correction for differences in detectability among deployments should have minimized the last effect. Paired transducers in every intake were fast multiplexed to acquire 201 -minute samples from each intake per hour. The pulse repetition rate was 15 pings per second for every transducer. At Powerhouse 1, we examined the vertical distribution of fish detected by split-beam transducers sampling inside Intake 10 $\underline{\mathrm{b}}$. 


\section{Sampling the Spillway}

Spill bays $2,4,5,6,7,8,10,12,14$, and 15 were each sampled with one down-looking, $10^{\circ}$, singlebeam transducer, and Spill Bay 17 was sampled with one down-looking, $12^{\circ}$, split-beam transducer.

Bays were selected to allow interpolation of fish passage to bays that were not sampled and to emphasize sampling at gates that would pass the most water according to the 1999 Fish Passage Plan. Transducers were mounted $28 \mathrm{ft}$ below the tops of spill gates and aimed upstream $8^{\circ}$ (single beams) or $15^{\circ}$ (split-beam transducer at Bay 17). Transducers were at EL $59 \mathrm{ft}$ when operators opened a gate about $3 \mathrm{ft}$, which was the maximum opening observed in 2001. The lateral location of both transducers within a bay was randomly selected to be on the north, center, or south side so that some of the lateral variation in passage within bays would be captured in the variance estimate for the entire spillway. Transducers were sampled sequentially to allow a pulse repetition rate of 30 pings per second during each of 121 -minute samples collected by each transducer per hour.

\section{Sampling Powerhouse 2}

At Powerhouse 2, one out of three intakes at every turbine unit was randomly selected for sampling, and at Unit 15 we sampled both the $\underline{b}$ and $\underline{\mathrm{c}}$ intakes. The lateral locations of transducers within intakes also were randomized among north, center, and south locations so that some of the lateral variation in passage through intakes would be incorporated in the total variance for the powerhouse. In each intake, we mounted a pair of transducers on the downstream side of the trash racks. One transducer of each pair was mounted near the bottom of the uppermost trash rack and aimed downward to sample unguided fish passing below the traveling screen. The second transducer of each pair was mounted near the bottom of the fourth trash rack from the top and aimed upward to sample fish passing above the screen. The two transducers deployed in Unit 18 were split beams to provide target strength data. Each transducer transmitted sound pulses at 15 pings per second, and both transducers of a pair usually were sampled simultaneously (i.e., fast multiplexed). Fast multiplexing allowed us to estimate covariances for the simultaneous samples of guided and unguided fish, and allowed us to collect 301 -minute samples at

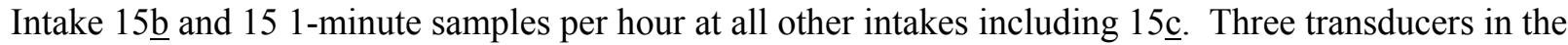
forebay were for sampling vertical distributions and the azimuth direction of travel of fish upstream of Intake $15 \underline{b}$. They consisted of down-looking $6^{\circ}$ split-beam transducers deployed on a steel beam lowered to a depth of $70 \mathrm{ft}$ MSL in the trash-rack slot. They were aimed 6, 12, and 18 degrees off the upstream plane of the trash racks.

At Powerhouse 2, we examined the vertical distribution of fish detected upstream and downstream of the trash racks at Intake $15 \underline{b}$, where the gatewell and vertical barrier screen had been modified to increase flow up into the gatewell. We also examined the direction of travel of detected fish through three splitbeams to better characterize the behavior of fish approaching trash racks and the effect on FGE in spring and summer.

\section{Fish Tracking and Filtering Criteria}

Since the hydroacoustic sampling effort on Bonneville Dam was so extensive and generated such a large volume of data in 2001, we could not manually process enough data to make reliable fish-passage 
estimates with available staff. Therefore, we relied on autotracking software developed over the last four years by the Corp's Fisheries Field Unit, the Corps Waterways Experiment Station (WES), and PNNL to process raw data into tracked fish observations.

During most of spring and early summer, we reviewed samples of the autotracker's performance for every deployment on a fish-by-fish basis to evaluate and fine-tune the autotracker and to develop postprocessing filters for eliminating false traces from the autotracker's output. We released the autotracker to process data for a given deployment only after we determined that it was missing few of the echo patterns that we would have tracked.

Output from the autotracker was filtered extensively to reject non-fish traces that the autotracker selected. Filtering non-fish traces based upon variables like range, slope, and noise level is a critical part of using autotracking software, because the autotracker is more likely to track intermittent series of structural echoes or noise than are technicians. Filters were designed to eliminate echo traces that had a high probability of being from structure, noise, or non-target fish based upon their track statistics.

Although the autotracker was a very efficient tool, we evaluated its performance and post-processing filters in both seasons by comparing counts of fish by the software and by trained technicians. Every technician and the autotracker processed identical Powerhouse 2 data sets acquired early, mid, and late each season, but the abbreviated generation schedule at Powerhouse 1 left few options for data set selection there. We selected spillway samples from throughout the abbreviated spilling seasons. Results from the technicians provided an estimate of inter-tracker error and deployment-specific mean hourly estimates for comparison to the autotracker-based estimates.

We compared human and autotracked counts for each transducer (channel) because there are important differences in passage characteristics, ranges of interest, trace slopes and lengths, and noise conditions for each deployment site and aiming angle. Up-looking-transducer channels sampling guided fish have very different noise regimes from down-looking-transducer channels and the slopes of regression lines fitted to autotracker and mean human counts often differ too. They can even vary in opposite directions, so that up-looking-transducer channels have higher autotracked counts and downlooking transducer channels have higher human-tracked counts.

\section{Adjustments to Fish-Passage Estimates}

After regressing average technician counts on autotracker counts for each deployment, we used slopes of regression lines with intercepts forced through zero to convert autotracker counts into mean technician counts and thereby remove systematic bias in autotracker counts among deployments. Slope multipliers in spring were 0.96 (Powerhouse 1 unguided), 0.83 (Powerhouse 1 guided), 0.833 (Powerhouse 2 unguided), 0.754 (Powerhouse 2 guided), and 0.789 (spillway). Slope multipliers in summer were 0.985 (Powerhouse 1 unguided), 0.953 (Powerhouse 1 guided), 0.841 (Powerhouse 2 unguided), 0.678 (Powerhouse 2 guided), and 0.98 (spillway). Variances were multiplied by the square of the slope factors. Plots of the regressions of mean technician counts on autotracker counts are presented in the Results section of this report.

After the Anadromous Fish Evaluation Program Research Review (13-16 November), where we found that hydroacoustic estimates of fish spill efficiency and effectiveness were considerably higher than 
those from radio telemetry, we examined the azimuth direction of travel of fish through the down-looking split beam at the spillway. We found that 7 to $13 \%$ of the fish in spring and 6 to $10 \%$ in summer were not moving in a downstream direction.

We decided to apply a conservative estimate of the number of fish passing through the spillway, rather than counting only the fraction of fish moving in a downstream direction. We estimated the downstream flux of fish per hour and multiplied hourly counts of fish in all spillway beams by that factor. The fish-flux factor is more conservative than multiplying by the fraction moving downstream because it subtracts the upstream fraction from the downstream fraction. For example, if $90 \%$ of detected fish are moving downstream and $10 \%$ are moving upstream, the flux factor applied would be 0.8 instead of 0.9 . We consider this to be the most appropriate because upstream moving fish have the potential to be counted more than once and should be subtracted from the passage estimate. In reality, all we know is that some fish moving upstream could have been counted more than once and that the flux factor should be somewhere between 0.8 and 0.9 . We could have split the difference and used 0.85 , but we wanted to be certain not to overestimate spillway passage in a drought year. Flux factors applied in spring and summer are described in the Materials and Methods section of the report.

\section{Dam Operations and Fish Passage}

Bonneville Dam operators, who recorded results in a spreadsheet, provided hourly operations data, including discharge by spill bay and turbine unit. Hourly operations data were integrated with fish passage data, and fish passage was set to zero when passage routes were closed. When flow is low at a closed turbine unit or spill bay, a fish can stay in the beam much longer than when the passage route is open. A transducer samples continuously regardless of operations, and samples from closed turbine units and spill bays often include many traces that may be tracked as fish, often multiple times, when a turbine unit is off or a spill bay is closed. It is best to have operations data at 5-minute intervals so that hourly passage estimates are not inflated by multiple fish detections during the fraction of an hour when a turbine was off. For that reason, we set fish passage to zero if hourly discharge through a turbine was less than $65 \%$ of the maximum discharge on a given day. When discharge is less than $65 \%$ of the maximum discharge, there is a high probability that the turbine was off for some part of an hour. Multiple detections of just a few fish wallowing in an out of an acoustic beam when a turbine is off can greatly inflate hourly estimates of guided fish passage and bias estimates of FGE and FPE. We assumed that a turbine with $<65 \%$ of maximum discharge was off the entire hour rather than risk inflation of guided fish counts. These adjustments had little effect on overall fish-passage estimates because they were infrequent and over one half of those occurrences resulted from a turbine running $<10$ minutes / hour.

\section{Missing Data}

All hydroacoustic systems were operated continuously ( $>23$ hours / day), except for about 15 minutes every morning when data were copied from the acquisition computer onto a portable FireWire ${ }^{\mathrm{TM}}$ hard drive or when equipment failed and data from the affected routes were not sampled. Short equipment failures lasting up to 45 minutes were not a problem because fish counts and associated variances could still be estimated from the remaining within-hour samples. Computer lock-ups usually were fixed within an hour because we had staff monitoring systems ever hour, 24 hours per day. Transducer cables failed on units 9 and 11 and both were fixed within a day, as soon as project support or divers became available. 
Missing hourly sums and variances that resulted from equipment outages $>45$ minutes were estimated by temporal linear interpolation for periods $<6$ hours and by spatial interpolation or linear regression for periods $>6$ hours. Occasionally the ratio of guided to unguided numbers at adjacent turbines with similar screens was useful for interpolating estimates of guided or unguided numbers. Regression equations relating hourly variances with hourly sums were sometimes used to estimate missing variance estimates. Two spill bays ( 3 and 16) were not among those sampled and were interpolated from passage estimates for other bays in their respective strata.

\section{Detectability Modeling and Spatial Expansions}

The count of every fish (1) was expanded based upon the ratio of the opening width to beam diameter at the range of detection:

$$
E X P_{-} N U M=\frac{O W}{\left[M I D_{-} R \times T A N\left(\frac{E B A}{2}\right) \times 2\right]}
$$

where OW is opening width in $\mathrm{m}$, MID_R is the mid-point range of a trace in $\mathrm{m}$, TAN is the tangent, and EBA is effective beam angle in degrees.

Effective beam angle depends upon the detectability of fish of different sizes in the acoustic beam and is a function of nominal beam width, ping rate, trace criteria, and fish size, aspect, trajectory, velocity, and range. We modeled detectability for every transducer deployment to calculate effective beam angle as a function of range from a transducer. We obtained target-strength estimates from the average backscattering cross section of fish detected by split-beam transducers and flow-velocity data by $1-\mathrm{m}$ depth strata from a physical or computational fluid design (CFD) model. These data and other hydroacoustic-acquisition data (e.g., beam tilt, ping rate, target-strength threshold, number of echoes, and maximum ping gaps) were entered into a detectability model. Model output consisted of effective beam angle as a function of range from a transducer.

\section{Statistical Methods}

The Material and Methods section of this report contains detailed descriptions of statistical methods used to analyze the hydroacoustic data. Dr. John Skalski developed these methods specifically for this study year.

Our estimates of variation associated with fish passage and efficiency metrics probably are conservative for two reasons. First, we took systematic 1-min samples (usually 12-15) per hour, and treated them as if they were simple random samples. This approach should overestimate the variance. Second, we estimated and added the variation among two or more turbine units to the temporal variation of each unit to provide a very conservative estimate of spatial variation resulting from sampling one out of three intakes per turbine unit. 


\section{Results and Discussion}

\section{Hydroacoustic Detectability}

The motivating force behind efforts to improve detectability modeling is the desire to provide hydroacoustic estimates that are quantitative as well as relative indices to fish passage. Ratio estimators such as fish guidance efficiency only require that the hydroacoustic beams sampling guided and unguided fish have equal detectability so that the ratios of counts, not necessarily the counts themselves, are accurate. Nevertheless, accurate counts estimated by proper expansion of detected fish have the potential to provide estimates with inherent quantitative value as well as providing acceptable relative estimates.

One of the ways to check the adequacy of detectability is to regress numbers of fish per transducer hour on discharge volume and look for negative slopes that might indicate that fish were missed at higher discharge rates. This is one of the quality control checks that we perform every year, and as expected, we found no significant negative regressions between fish counts and discharge.

The closeness of our nighttime (2000-0500 hours) hydroacoustic estimates of FGE for Intake 15 $\underline{b}$ at Powerhouse 2 with 1-2 hour netting estimates (2000-2100 or 2200 hours) by the NMFS indicated that the detectability of transducers sampling guided and unguided fish was similar. The $95 \%$ confidence intervals overlapped in both spring and summer indicating that respective estimates did not differ significantly. In all of spring, nighttime FGE was $73.7 \%$ for hydroacoustic gear and $74.7 \%$ for netting. For summer, nighttime FGE was $54.3 \%$ for hydroacoustics and $56 \%$ for netting.

The closeness of concurrent hydroacoustic and netting estimates of fish passage at Intake 15 $\underline{b}$ in spring and summer verified that our detectability modeling and corrections to expansion factors were reasonable. In spring, the sum of all hydroacoustic and netting estimates of guided fish numbers differed by $22 \%$, and in summer, the estimates did not differ $(<1 \%)$. The sum of all unguided fish by the two methods also were reasonably close and differed by less than $1 \%$ in spring and by about $21 \%$ in summer.

\section{Validation of Autotracking Hydroacoustic Data}

Mean hourly counts of fish by human trackers were very highly correlated with hourly autotracker counts for each deployment. This year, we used human trackers only to verify and adjust the results of the autotracker. Although the agreement among technicians tracking the same data was better than it has sometimes been, the cumulative difference in passage estimate for the lowest tracker would be only about $72.8 \%$ that of the highest tracker for the 438 channel hours we compared in spring and $68.8 \%$ for the 227 channel hours we compared in summer. The slopes of regressions were used to correct our autotracked results downward to offset the tendency of the autotracker to overestimate passage. This approach is not only more economical but also qualitatively superior to assigning technicians to process data from different deployments because of known inter-tracker bias. 


\section{Major Passage Metrics}

\section{Project and Powerhouse FPE}

The drought of 2001 provided a unique opportunity to evaluate Project FPE during spill and non-spill periods in the same year. Project FPE was 15 and 35\% higher during 50,000 cfs spill periods in spring and summer, respectively, than it was during non-spill periods. In 2000, continuous spill at 75,000 or $120,000 \mathrm{cfs}$ throughout spring and summer and the operation of a prototype surface collector at Powerhouse 1 produced Project FPE estimates of $79 \%$ in both seasons. These estimates were 16\% (spring) and 26\% (summer) higher than estimates for spring and summer seasons in 2001, which included spill and non-spill periods rather than continuous spill.

Project-wide FPE was $63 \%$ in spring and 53\% in summer. The FPE estimate for Powerhouse 1 declined from $49 \%$ in spring to $40 \%$ in summer, a drop of $9 \%$. The FPE for Powerhouse 2 declined even more across seasons $(>15 \%)$, with estimates of $57 \%$ and $42 \%$ in the spring and summer, respectively. Project FPE was only about 1\% lower in spring and in summer than FPE calculated for Powerhouse 2 and the spillway alone (without Powerhouse 1). This was not surprising given that Powerhouse 1 passed only about $7.3 \%$ of the water and $6.9 \%$ of the fish in spring and $8.6 \%$ of the water and $7.5 \%$ of the fish in summer.

\section{Spill Efficiency and Effectiveness}

Spill efficiency estimates in spring (14\%) and summer (20\%) 2001 were significantly lower than estimates made in spring (44\%) and summer (49\%) 2000, undoubtedly because of reduced volume and duration of spill during the drought in 2001. For periods of spill, spill efficiency was $33 \%$ in spring and $58 \%$ in summer. Spill effectiveness was 0.84 in spring and 1.83 in summer. For periods of spill, spill effectiveness was 0.93 in spring and 1.6 in summer. Spill effectiveness also was about $38 \%$ lower in spring 2001 than it was the previous spring. In 2000, spill was continuous at about 75,000 cfs during the day and 120,000 cfs at night, but lack of water in 2001 limited spill to about 50,000 cfs for about 21 of 45 days in spring and 10 of 40 days in summer.

Effectiveness seems to be a meaningful metric when differences in flow proportions do not exceed about $30 \%$, which was not the case in comparisons between summer 2000 and 2001. In summer 2001, spill effectiveness was about 55\% higher than the previous year's estimate likely because the proportion of water spilled in summer 2001 was much lower than it was in 2000. The denominator in the spillefficiency calculation (the proportion of water spilled) in summer 2000 was 0.48 whereas was it only 0.11 in summer 2001. The inverse of these proportions shows how much spill efficiency was expanded (i.e., by 2.1 in 2000 and by 9.1 in 2001) to estimate effectiveness. The multiplicative nature of the effectiveness statistic is exemplified by the effectiveness at sluiceways and surface collectors, which are always higher than estimates for a spillway because those small routes pass orders of magnitude less water than a spillway passes. 


\section{Effects of Spill Level}

We found several significant relationships that suggest an optimum spill strategy for future drought years that includes night spill lasting at least 11 hours. There were positive relations between the number of hours of spill per day and FPE and spill-efficiency metrics, and we observed significantly higher fish passage through the spillway at night than during the day, even though the amount of spill was the same during each period. We observed a similar trend in 2000, but nighttime spill discharge was much higher than it was during the daytime, and we could not determine whether the pattern was driven by spill level or day versus night. With constant spill in 2001, we can confidently describe the effect as a diel pattern unrelated to spillway discharge. Spilling at night also has the advantage of eliminating fall back of adult salmonids through the spillway during the day and may reduce fish losses due to visual predators such as birds and fishes in the spillway tailrace. Spill efficiency increased linearly with the number of spill hours per day in spring. We identified two obvious levels of effect. At low-spill durations of 0 to $10 \mathrm{~h} /$ day, average FPE was about $54 \%$ and at high-spill durations of 11 to $24 \mathrm{~h}$ /day average FPE was about $71 \%$.

\section{Comparison with Radio Telemetry Estimates}

The largest differences between hydroacoustic and radio telemetry estimates occurred in spring, including a 14\% difference in Powerhouse 2 FPE during 2\% spill and an $11 \%$ difference in Project FPE, but all other differences in major metrics in spring and summer were $\leq 10 \%$ (Table S.1). In general, the hydroacoustic estimates of major fish-passage metrics were higher than the radio telemetry estimates. Powerhouse 1 FGE in summer was the only exception. The radio-telemetry season started and ended later than did the hydroacoustic season so we recalculated our hydroacoustic estimates based on the USGS's data collection schedule and they did the equivalent recalculation of their data in summer so that we would be comparing the same days each season. The level of agreement between our hydroacoustic and the radio telemetry-based estimates was better for major fish-passage metrics and entire powerhouses than it was for individual units. Differences in FGE estimates for individual units are described later under Comparing FGE Estimates by Different Sampling Methods.

\section{Spatial Trends in Fish Passage}

\section{Horizontal Distributions}

The percentage of discharge through major passage routes was a good indicator of the relative percentage of fish passage among those routes in spring but was less so in the summer. In spring, about $7 \%$ of both fish passage and discharge occurred at Powerhouse $1,14 \%$ of the fish and $16 \%$ of the flow passed through the spillway, and Powerhouse 2 passed $79 \%$ of the fish with $76 \%$ of the flow. Fish and flow percentages also matched up well at Powerhouse 1 in summer (about $8 \%$ of the fish with about $9 \%$ of the flow), but the relative proportions at the other passage routes (the spillway and Powerhouse 2) differed. For the entire summer period, the spillway passed $20 \%$ of the fish in summer with $11 \%$ of the flow and Powerhouse 2 passed about $72 \%$ of the fish with $80 \%$ of the flow. Powerhouse 1 passed about $4 \%$ of all fish in summer in about $7.5 \%$ of the total discharge. During spill days in summer, the spillway passed $58 \%$ of the fish in just $36 \%$ of the flow, while Powerhouse 2 passed $40 \%$ of the fish in $61 \%$ of the flow. 
Table S.1. Comparison of Fish-Passage Metrics Estimated by Hydroacoustics (HA) and Radio Telemetry (RT) at Bonneville Dam in 2001 for May 1-June 9 in Spring and July 1-July 15 in Summer

\begin{tabular}{|c|c|c|c|c|}
\hline Metric & "Season and Spill Conditions & HA & RT & Difference \\
\hline \multirow[t]{3}{*}{ Project FPE $^{(a)}$} & Spring overall & $67 \%$ & $56 \%$ & 111\% (HA>RT) \\
\hline & Spring (about 37\% spill) & $71 \%$ & $64 \%$ & $7 \%(\mathrm{HA}>\mathrm{RT})$ \\
\hline & Spring (about 2\% spill) & $56 \%$ & $47 \%$ & 9\% (HA>RT) \\
\hline PH1 FGE & Spring overall & $47 \%$ & $45 \%$ & $2 \%(\mathrm{HA}>\mathrm{RT})$ \\
\hline \multirow[t]{2}{*}{ (Excluding sluiceways) } & Spring (about 37\% spill) & $39 \%$ & $\mathrm{~N} / \mathrm{A}^{2}$ & \\
\hline & Spring (about 2\% spill) & $50 \%$ & $45 \%$ & $5 \%(\mathrm{HA}>\mathrm{RT})$ \\
\hline \multirow[t]{3}{*}{ PH1 FPE } & Spring overall & $\mathrm{N} / \mathrm{A}^{1}$ & $87 \%$ & \\
\hline & Spring (about 37\% spill) & $\mathrm{N} / \mathrm{A}^{1}$ & $100 \%$ & \\
\hline & Spring (about 2\% spill) & $\mathrm{N} / \mathrm{A}^{1}$ & $86 \%$ & \\
\hline \multirow[t]{3}{*}{ PH2 FPE } & Spring overall & $56 \%$ & $46 \%$ & $10 \%(\mathrm{HA}>\mathrm{RT})$ \\
\hline & Spring (about 37\% spill) & $55 \%$ & $49 \%$ & $6 \%(\mathrm{HA}>\mathrm{RT})$ \\
\hline & Spring (about 2\% spill) & $57 \%$ & $43 \%$ & $14 \%(\mathrm{HA}>\mathrm{RT})$ \\
\hline \multirow[t]{2}{*}{ Spill Efficiency } & Spring overall & $26 \%$ & $16 \%$ & $10 \%(\mathrm{HA}>\mathrm{RT})$ \\
\hline & Spring during spill & $38 \%$ & $30 \%$ & $8 \%(\mathrm{HA}>\mathrm{RT})$ \\
\hline \multirow[t]{2}{*}{ Spill Effectiveness } & Spring overall & 1.21 & 0.70 & $0.51(\mathrm{HA}>\mathrm{RT})$ \\
\hline & Spring during spill & 1.13 & 0.86 & $0.27(\mathrm{HA}>\mathrm{RT})$ \\
\hline Project FPE & Summer overall (about 3\% spill) & $44 \%$ & $40 \%$ & $4 \%(\mathrm{HA}>\mathrm{RT})$ \\
\hline PH1 FPE & Summer overall (about 3\% spill) & $N / A^{(b)}$ & $89 \%$ & \\
\hline PH1 FGE & Summer overall (about 3\% spill) & $47 \%$ & $57 \%$ & $10 \%(\mathrm{RT}>\mathrm{HA})$ \\
\hline PH2 FGE \& FPE & Summer overall (about 3\% spill) & $44 \%$ & $35 \%$ & $9 \%(\mathrm{HA}>\mathrm{RT})$ \\
\hline \multicolumn{5}{|c|}{$\begin{array}{l}1 \text { The radio telemetry FPE estimates include fish that pass by the sluiceway at Powerhouse 1, but there was no hydroacoustic } \\
\text { sampling of Powerhouse } 1 \text { sluiceway passage so there can be direct comparison of Powerhouse } 1 \text { FPE estimates. Since the } \\
\text { Powerhouse } 2 \text { sluiceway was closed in both seasons, Powerhouse FPE and FGE are the same for Powerhouse } 2 \text {. Since the } \\
\text { Powerhouse } 1 \text { sluiceway handled a very small proportion of the total project passage, we neglected this distinction at the project } \\
\text { level. } \\
2 \text { During spring } 37 \% \text { spill, only four radio-tagged fish were tracked through Powerhouse } 1 \text { and they all passed by the sluiceway, } \\
\text { which was not sampled by hydroacoustics. Powerhouse FGE is the proportion of all fish guided divided by the sum of guided } \\
\text { and unguided (turbine) fish. In this case, Powerhouse } 1 \text { FGE would equal 0/0, which is undefined. }\end{array}$} \\
\hline
\end{tabular}

Lateral fish passage patterns that may normally occur during times of full loading of Powerhouse 1 could not occur in 2001 given the drought and a Powerhouse 2 priority for generation. Flow was so low in both spring and summer at Powerhouse 1 that many of the units seldom ran, particularly during periods of spill. Horizontal passage patterns at Powerhouse 1 were consistent between seasons. In spring, about $70 \%$ of the fish that passed at Powerhouse 1 passed through units 9 and 10 , as did $73 \%$ of the Powerhouse 1 discharge. Fish passage and flow were low throughout the rest of Powerhouse 1, with the exception of Units 1 and 2, which passed $8 \%$ of the fish with $14 \%$ of the flow, and $9 \%$ of the fish with $7 \%$ of the flow, respectively. In summer, nearly $75 \%$ of the fish that passed Powerhouse 1 in the summer passed at units 9 and 10 , along with $81 \%$ of the water. Discharge at Powerhouse 1 was very low during the summer and was mostly allocated to units 1,9 , and 10 , and Unit 1 passed about $5 \%$ of the fish in about $10.6 \%$ of the flow. Of the remaining units, significant passage occurred only at Unit 6 , which passed $12.6 \%$ of the fish in less than $3 \%$ of the flow.

The southern skew in the distribution of fish passage at Powerhouse 2 in both seasons was much more noticeable in 2001 than it was in 2000, and it certainly supports the management decision to build a corner collector adjacent to Unit 11. Fish passage through the south half of the second powerhouse was consistently high during both sampling seasons. About $70 \%$ of the fish passing through Powerhouse 2 passed through units 11-14, although these units discharged only slightly more than half of the water 
(52.6\%). Units 11-15 passed roughly similar numbers of fish per volume of water during spring and summer. Unit 17 was off-line all summer. We also observed a southern skew in the passage distribution in summer of 1996 (Ploskey et al. 1998). To better compare fish passage among the individual units of Powerhouse 2, we standardized passage by reporting the density of fish passage in fish per volume of water in both spring and summer. Density was highest at the southern and central units (units 11 through 15), ranging from 531 to 703 fish passed per $\mathrm{M} \mathrm{m}^{3}$ water discharged. Fish passage density was lowest at the three northern units (units 16,17, and 18), ranging from 217 to 321 fish passed per $\mathrm{M} \mathrm{m}^{3}$ water discharged.

Fish passage at the spillway was slightly skewed to the south during both seasons, despite a relatively even distribution of discharge across the spillway. This was mainly due to low passage rates at bays 2 and 3, which passed far fewer fish than bays at the southern end of the spillway, although they discharged about the same amount of water as the bays to the south. Spill discharge was relatively constant in spring and summer at about 50,000 cfs, and the spill pattern (bays and gate openings) varied little. In spring, the highest proportions of the fish that passed the project at the spillway passed through Bay 6 (where $19 \%$ of all spillway passage occurred), Bay 16 (18\% of spillway passage), and Bay 17 (22\% of spillway passage). Spillway discharge was terminated on 15 June, 10 days into the summer sampling season. For the entire summer sampling season, $11 \%$ of all fish passage occurred at the spillway along with $20 \%$ of all discharge. During the ten days that the spillway was operating, however, the spillway passed $58 \%$ of the fish in $40 \%$ of the water.

The exceptional effectiveness of the spillway during the only 10 days of spill in early summer may be explained by a peak in the summer migration, spill at the expense of generation at some Powerhouse 2 units, and the fact that forebay elevations were falling. According to salmonid run-timing estimates by the hydroacoustics and JBS counts, the largest peak in the summer run passed the dam during these early days of summer sampling. When forebay elevations drop, the depth of a bottom ridge upstream of Cascades Island and into the Powerhouse 2 forebay is shallower than it is when pool levels are high. Subyearling fish migrating along the shore upstream of the Powerhouse 2 forebay may guide along the channel edge that separates the Powerhouse 2 forebay from the main channel leading to the spillway, particularly when water levels decrease. In 2001, Powerhouse 2 was the priority powerhouse and usually was fully loaded. However, during the 10 days of spill in early summer, the percent of off hours for Powerhouse 2 turbines was higher than usual (Unit $17=100 \%$; Unit $15=46 \%$; Unit $14=41 \%$; Unit $13=$ $25 \%$; Unit $12=14 \%$; and Unit $11=5 \%$ ).

\section{Vertical Distributions}

\section{Powerhouse 1 - Inside Intake 10므}

The vertical distributions of fish at Unit 10 in spring and summer strongly suggest that installing an ESBS similar to the one installed at Unit 8 would improve FGE in spring, but the benefit would be less in summer. The elevation for classifying detected fish as guided or unguided at an ESBS would be about 21 $\mathrm{ft}$ MSL. According to this cutoff criterion, an ESBS would guide about $68 \%$ of the fish in spring but only about $50 \%$ in summer. In spring 2001 , we classified about $47 \%$ of all fish as guided by the STS, but in summer, that percentage fell to about $36 \%$. In the 2000 passage season we found an estimated FGE of $72 \%$ in spring that fell to $50 \%$ in summer (Ploskey et al. 2002a). 


\section{Powerhouse 2 - Upstream and Downstream of Intake 15므}

Theoretical (expected) FGE based upon the vertical distribution of fish upstream of the trash racks at modified Unit 15 (Intake b) was similar to the estimated in-turbine FGE for all hours sampled in spring but not in summer. Theoretical FGE is defined as expected FGE based upon the upstream vertical distribution relative to an elevation for classifying guided and unguided fish projected upstream parallel to the intake roofline from the elevation used inside the turbine. The FGE of $50 \%$ in summer was $29 \%$ less than the theoretical FGE. In spring, fish detected 16 to $21 \mathrm{ft}$ upstream of trash racks were higher in the water column than fish detected 4 to $9 \mathrm{ft}$ from the racks. A similar pattern was observed in summer, but the peak in the distribution of fish 4 to $9 \mathrm{ft}$ from trash racks was several $\mathrm{ft}$ lower in the water column than the peak for fish 4 to $9 \mathrm{ft}$ from racks in spring. The downward shift in the distribution of fish approaching the trash racks was observed during the day and at night.

Two pieces of evidence indicate that fish approaching trash racks increased in depth and changed behavior, and these factors may make them more or less susceptible to being guided by a STS inside the turbine. First, peaks in vertical distributions of fish located below the elevation of the top of the intake and 4 to $9 \mathrm{ft}$ from trash racks were 9 to $12 \mathrm{ft}$ deeper than peaks in distributions sampled 16 to $21 \mathrm{ft}$ upstream. Second, direction-of-movement and fish-detection statistics show that $70 \%$ of the relatively few detections 10 to $15 \mathrm{ft}$ upstream of trash racks were moving downstream, whereas only about 54\% of detections within 4 to $9 \mathrm{ft}$ of trash racks were moving downstream. In short, we found both higher numbers of fish and lower vertical distributions of fish detected 4 to $9 \mathrm{ft}$ from the racks than of fish detected 16 to $21 \mathrm{ft}$ from the racks. These differences were consistent for both spring and summer. Higher numbers of fish close to the trash racks may indicate that fish paused in their downstream movement as they encountered physical cues relating to the presence of the racks. If fish paused just upstream of the racks, they could easily have been counted multiple times as they passed in and out of the sampling volume, resulting in higher cumulative counts.

Smaller individuals that comprise the summer smolt population likely are less able to maintain their vertical position in the water column when they pause upstream of the trash racks. Fish that pause in their downstream movement just upstream of the trash racks are not only exposed to the downstream component of flow, they also encounter strong downward water velocities. The agreement of theoretical FGE with observed in-turbine FGE during spring may indicate that the spring-migrating smolts were able to maintain both their horizontal and their vertical position in the water column as they paused before going through the trash racks. In summer, the lower vertical distribution of fish detected 4 to $9 \mathrm{ft}$ upstream of the trash racks, as compared to those detected 16 to $21 \mathrm{ft}$ upstream of the racks, was more exaggerated than during spring. In addition, theoretical FGE was significantly higher than observed inturbine FGE in summer.

\section{Temporal Trends in Fish Passage}

\section{Run Timing}

The run timing curve in 2001 based on hydroacoustic estimates shows that the spring peak occurred on 21 April and the summer peaks occurred on 8 and 27 June. The JBS smolt index data at the 
Bonneville Project indicated similar temporal trends as observed with hydroacoustic sampling, with peaks and troughs in general agreement.

\section{Major Fish Passage Metrics}

The 9\% decline in FPE from spring to summer at Powerhouse 1 and the $26 \%$ decline at Powerhouse 2 were similar to but slightly larger than seasonal declines observed in 2000 for Powerhouse $1(6 \%)$ and for Powerhouse $2(19 \%)$. Powerhouse 1 FPE in 2000 was $67 \%$ and $61 \%$ in spring and summer, and these estimates were $18 \%$ and $21 \%$ higher than respective estimates in spring and summer 2001 . The difference most likely resulted from the nearly continuous operation of the PSC and Unit 8 with an ESBS in 2001. In 2001, the PSC units functioned as standard STS units and Unit 8 ran less than 1 day each season because of drought prioritization of operations. Project FPE was about 57\% in spring with no visually obvious trend until spill began on about 15 May when FPE began a gradual increase into early summer. The average FPE during spring spill was about $71 \%$ and $76 \%$ during the 9 days of spill in early summer. Fish passage efficiency dropped down to $34 \%$ on 16 June when spill ended, and it averaged about $40 \%$ with $\pm 10 \%$ fluctuations for the rest of summer.

Powerhouse $1 \mathrm{FPE}$ estimates averaged $49 \%$ in spring and $40 \%$ in summer, but all daily estimates for Powerhouse 1 were much more variable than estimates for Powerhouse 2. Powerhouse 2 estimates averaged $57 \%$ in spring and $42 \%$ in summer, ranging from a high of $65 \%$ on 30 May to a low of $29 \%$ on 14 June.

Spill efficiency varied substantially from day to day but exhibited a general upward trend from 16 May, when spill began, through 15 June, the last day of spill in 2001. Spill efficiency tracked the spill proportion during the first half of the spill season but not during the second half.

\section{Guidance Efficiency at Modified Unit 15}

The spring to summer decline in FGE that we observed at Unit 15 was typical of what we have observed at most units at Bonneville Dam, but the summer FGE estimate was not as low as those from other STS-equipped units at Powerhouse 1 or 2 in the summer of 2000. It was comparable to adjacent Units 14 and 16 in 2001. The nighttime FGE of Unit 15 decreased about 20\%, from $74 \%$ to $54 \%$ from spring through summer in 2001. In 2000, the summer FGE estimate for Powerhouse 1 units running STS and the summer FPE of Powerhouse 2, which had no modified units was about 30\%. Daily estimates of FGE for modified intake $15 \underline{b}$ and $15 \underline{c}$ based upon all hours sampled each day decreased significantly from spring to summer but were highly variable in both seasons.

\section{American Shad Run Timing}

American shad present a problem for hydroacoustic sampling in summer. Almost 2.3 million American shad migrated up through Bonneville Dam in 2001. Shad began arriving at the dam in mid May and were present in large numbers during the third week in May before peaking on 1 June when 144,000 individuals were observed. By 6 June, $50 \%$ of all the migrating shad had already passed the dam. By 30 June, the shad migration was essentially complete with over $98 \%$ of all fish having passed by that day. The Bonneville Dam 2001 shad up migration was nearly twice as large as the 2000 run and it peaked 10 days earlier. 


\section{Diel Trends}

Providing a Powerhouse 2 priority and nighttime spill could significantly improve fish-passage efficiency in spring by as much as $6 \%$ to $12 \%$ during a drought year, while minimizing fallback of adult salmonids through the spillway. Factors contributing to a $6 \%$ to $12 \%$ higher project FPE at night than during the day included significantly higher nighttime fish passage through the project, including the spillway and Powerhouse 2, and higher FGE of Powerhouse-2 turbines at night than during the day.

On an hourly basis, project-wide estimates of FPE in the springtime were higher at night than during the day, and extreme values only differed by $12 \%$. Summertime estimates of FPE were higher at night than they were during 6 or 7 of the daytime hours, although a diel trend was not as obvious in summer as it was in spring.

Estimates of spill efficiency during the spring were low from mid-morning to early evening and were higher at night than during the day. Spill efficiency in the summer was highest from early morning to early afternoon and was at its lowest in early evening. Estimates of spill effectiveness in the spring were slightly higher in the late evening and early morning hours but changed very little throughout the day. Summertime spill effectiveness followed a similar pattern as the spill efficiency in the summer with peaks in the early morning to early afternoon and lows in the early evening.

Project-wide fish passage through all routes in the spring gradually declined through the day, began to slightly increase in the early evening, peaked at 2100 hours, and then declined again through the early morning hours. Numbers of fish spilled in the spring declined through the day then increased sharply at 2100 hours and peaked at 0100 hours. The volume of water spilled differed little among hours in the spring, but a slight increase occurred at 2300 hours, coinciding with an increase in the number of fish spilled. In the summer, the pattern of fish spilled through the day was less defined than in spring, but the decreasing trend during the day and an increase in nighttime hours was still evident. Spill passage during the summer peaked at 0300 hours. There was very little variation in hourly spillway flow in the summer.

We found no significant diel trends in FGE at Powerhouse 1 in spring or summer because variances of estimates were too high, but Powerhouse 2 FGE estimates were generally higher in late afternoon and at night than they were during the day. In spring, the estimates declined slightly from highs at 0100 to 0500 hours to lows from 1200 to 1500 hours. Total fish passage in the spring declined through the morning and into the early afternoon then slightly increased through the remaining afternoon hours then rose sharply and peaked at 2100 hours. During the summer, FGE estimates at Powerhouse 2 dipped to lows in the midmorning and early afternoon hours and peaked staying relatively constant from 1800 to 0400 hours. Total passage through Powerhouse 2 in the summer was similar to the pattern observed during spring except the initial increase started later in the afternoon and the peak occurred at 2200 hours (instead of 2100 hours as in spring).

Hydroacoustic and radio telemetry estimates of hourly trends in fish passage for the project were generally similar, except for a peak in radio telemetry data in the middle of the afternoon (1400 to 1600 hours) that was not evident in the hydroacoustic data. In summer, both hydroacoustics and radio telemetry methods documented a peak in fish passage after sunset. However, the hydroacoustic data show higher passage through the night until about 0900 hours than from 1000 to 1800 hours, whereas the 
radio telemetry data show little if any trend from 0000 to 2000 hours. In summer, the radio telemetry data are for a longer period, which ended July 24, about 9 days after the end of hydroacoustic sampling.

The average hourly percentage of fish passage estimated by hydroacoustics to have passed entire structures (powerhouses or the spillway) or combinations of structures in daytime (0500-2059 hours) were within one percent of radio telemetry results for the same hours in both spring and summer.

Table S.2. Percentage of Fish Estimated by Hydroacoustics (HA) and Radio Telemetry (RT) to Have Passed Bonneville Dam Structures during an Average Daytime Hour (0500-2059 hours) in Spring and Summer of 2001. Data from non-overlapping parts of seasons have been deleted and adjusted appropriately so that the times reported here are the same for both methods. Those dates are May 1-June 9 for spring and July 1-July 15 for summer.

\begin{tabular}{|l|l|l|l|}
\hline Season and Location & HA Percent & RT Percent & Difference \\
\hline Spring PH1 Only & $4.68 \%$ & $3.86 \%$ & $0.82 \%(\mathrm{HA}>\mathrm{RT})$ \\
\hline Spring PH2 Only & $3.77 \%$ & $3.46 \%$ & $0.31 \%(\mathrm{HA}>\mathrm{RT})$ \\
\hline Spring Spillway Only & $3.49 \%$ & $4.04 \%$ & $0.55 \%(\mathrm{RT}>\mathrm{HA})$ \\
\hline Spring PH2 + Spillway & $3.67 \%$ & $3.55 \%$ & $0.12 \%(\mathrm{HA}>\mathrm{RT})$ \\
\hline Spring Full Project & $3.73 \%$ & $3.56 \%$ & $0.17 \%(\mathrm{HA}>\mathrm{RT})$ \\
\hline Summer PH1 Only & $4.72 \%$ & $4.17 \%$ & $0.55 \%(\mathrm{HA}>\mathrm{RT})$ \\
\hline Summer PH2 Only & $3.51 \%$ & $3.18 \%$ & $0.33 \%(\mathrm{RT}>\mathrm{HA})$ \\
\hline Summer Spillway Only & $\mathrm{N} / \mathrm{A}$ & $5.73 \%$ & $\mathrm{~N} / \mathrm{A}$ \\
\hline Summer Full Project & $3.58 \%$ & $3.30 \%$ & $0.28 \%(\mathrm{HA}>\mathrm{RT})$ \\
\hline
\end{tabular}

\section{Comparing the Performance of Fish-Guidance Structures}

For all sample hours in spring, the FGE of submerged traveling screen (STS)-equipped units at Powerhouse 1 ranged from $22 \%$ to $57 \%$, and this was lower than the range observed at Powerhouse 2 (35\% to $72 \%$ ), but in summer the performance of units at both powerhouses was similar. Therefore, provision of a Powerhouse 2 priority may have been a good management tactic in spring. Guidance efficiency ranged from $29 \%$ to $53 \%(\mathrm{FPE}=40 \%$ ) at Powerhouse 1 and from $11 \%$ to $54 \%(\mathrm{FPE}=42 \%)$ in summer. The higher FGE of Powerhouse 2 units may have resulted from the presence of turbine intake extensions (TIEs) at every other intake and the fact that five of nine intakes that we sampled were between TIEs where passage and FGE tended to be higher. We also observed higher FGE in spring at Intake $15 \underline{b}(72 \%)$, which was between two TIEs, than we did at Intake 15ㄷ (59\%), which was behind a TIE. The difference was less in summer (50\% at $15 \underline{b}$ and $48 \%$ at $15 \underline{\mathrm{c}})$. There also was a tendency for FGE to be lower at the ends of Powerhouse 2 than in the middle, but since the intakes we sampled at end units of Powerhouse 2 were behind instead of between TIEs, the effect of unit location could have been masked. Unit 1 had the lowest FGE at Powerhouse 1 in both spring and summer.

In spring, the FGE of the 40-ft-long ESBS at Unit 8 (83\%) was higher than that of any of the units equipped with 20 -ft-long STS, except for modified Unit 15 at Powerhouse 2, but the $38 \%$ ESBS efficiency in summer was comparable to that of average STS units. Unit 8 only ran for about $8 \mathrm{~h}$ in spring and $5 \mathrm{~h}$ in summer, so its FGE estimates were based upon very small data sets and its contribution to Powerhouse 1 and Project FPE was minimal. 
The $72 \%$ to $74 \%$ FGE of modified Unit 15 was higher than that of all other unmodified STS units at Powerhouse 1 and 2 in spring. In summer, it was among the three highest individual Powerhouse 2 units (50\% to 54\%). The FGE of Unit 15 in summer was 4\% less than that observed at Unit 14 (54\%) and statistically the same (50\% to 51\%) as that estimated for Unit 13, although it exceeded the FGE of four other operating units at Powerhouse 2. In summer, Units 2 and 6 at Powerhouse 1 also had high FGE estimates, but they only ran $2 \%$ of the season (20 and 23 hours, respectively). Most $95 \%$ confidence limits on estimates for Powerhouse 1 units were much wider than limits for Powerhouse 2 units because of abbreviated operations that reduced hydroacoustic sample sizes.

\section{Comparing FGE Estimates by Different Sampling Methods}

We had the opportunity to compare our estimates of the FGE of turbine units at Powerhouse 2 with estimates by two other methods. The USGS estimated FGE for every unit at Powerhouse 2 based upon the distribution of passage of radio-tagged fish, and the NMFS estimated FGE for modified Unit 15 by gatewell dipping and fyke netting. Comparison with radio tagging estimates of FGE could be examined for more units, but sampling with the hydroacoustics and radio telemetry was not simultaneous as it was for the hours netted at Unit 15 by the NMFS. Scott Evans (USGS) provided radio telemetry estimates and Bruce Monk (NMFS) provided gatewell and fyke-net estimates presented in this section.

All sampling methods are imperfect and each has unique advantages and disadvantages. Radio telemetry can provide data on movements of known fish and is not limited to the area near the dam. Information on travel time, large-scale trajectories, forebay residency, survivorship, and species or origin and even rearing (wild vs. hatchery) differences is potentially available. However, the power of radio telemetry is diminished when the total number of tagged fish is divided among too many treatments or passage routes, resulting in small sample sizes. Also radio telemetry provides no data on untagged animals. The NMFS continues gatewell dipping and fyke netting single units until the number of guided fish captured is adequate to provide a reliable daily FGE estimate. The average number of guided fish taken in 1 to 2 hours in 2001 was about 600 fish. This is substantially more fish than radio telemetry can detect for a single passage route in an entire season. However, netting is labor intensive and may injure or kill fish, including individuals from endangered populations; therefore, it cannot be used for more than a few hours per day at one or two intakes. The restriction of physical capture to one and at the most two or three samples per day prevents biologists from obtaining daily estimates of sample variance or increased resolution of the temporal and spatial variation in FGE.

While hydroacoustic methods can provide FGE estimates that are very comparable to physical capture based estimates, they can only provide a relative index to fish passage unless calibrated by net sampling and they cannot directly provide species-specific estimates. However, hydroacoustic methods can be economically applied to all intakes $24 \mathrm{~h}$ per day and provide information about variations among intakes and hours of the day. While hydroacoustic sampling requires more than the 1 to 2 hours needed by netting to obtain reliable FGE estimates, it can provide seasonal estimates for single routes that are not limited by the number of fish sampled. Fixed-aspect hydroacoustics provides estimates for untagged fish and can provide reliable estimates for individual passage routes that usually comport with estimates from more intensive netting methods. 


\section{Comparison with Netting Estimates}

Concurrent hydroacoustic and netting (NMFS) samples provided FGE estimates for Intake $15 \underline{b}$ that were very similar in spring and only slightly different in summer (Figure S.1), and estimates were even closer when we estimated hydroacoustic FGE from all nighttime hours instead of just concurrent hours (Figure S.2). Hydroacoustic sampling underestimated the number of guided fish in spring and underestimated the number of unguided fish in summer, according to the lack of overlap in $95 \%$ confidence limits (Figure S.1).

Hydroacoustic estimates of FGE require longer sampling durations than the 1 to 2 hours that are commonly used to estimate FGE by netting because hydroacoustic beams sample only about $5 \%$ of the cross sectional area of an intake compared to near $100 \%$ coverage by netting. In 2001 , we were able to sample throughout the night only when the NMFS was conducting orifice passage efficiency testing, and the unit was operated all night. Abbreviated operations severely limited the number of fish that could be detected by hydroacoustics and the precision and accuracy of hydroacoustic estimates. We made up for this shortcoming by using all available hours of nighttime sampling to make seasonal estimates, but the unit usually was shut down for the night after the netting effort ended. Consequently, many of the additional nighttime samples used to estimate hydroacoustic FGE came from nights of orifice-passage tests rather than nights of FGE netting. For future testing, we recommend that operators restart test units after FGE netting ends so that hydroacoustic estimates can be based upon the maximum number of nighttime samples from the same nights that FGE netting was conducted. The NMFS sampled with nets from about 2000 until 2100 or 2200 hours depending upon the number of fish they collected in the dip basket sampling the gatewell. Sampling duration was only as long as needed to obtain a reliable FGE estimate based upon catches of guided fish and knowledge of FGE ranges that were likely.

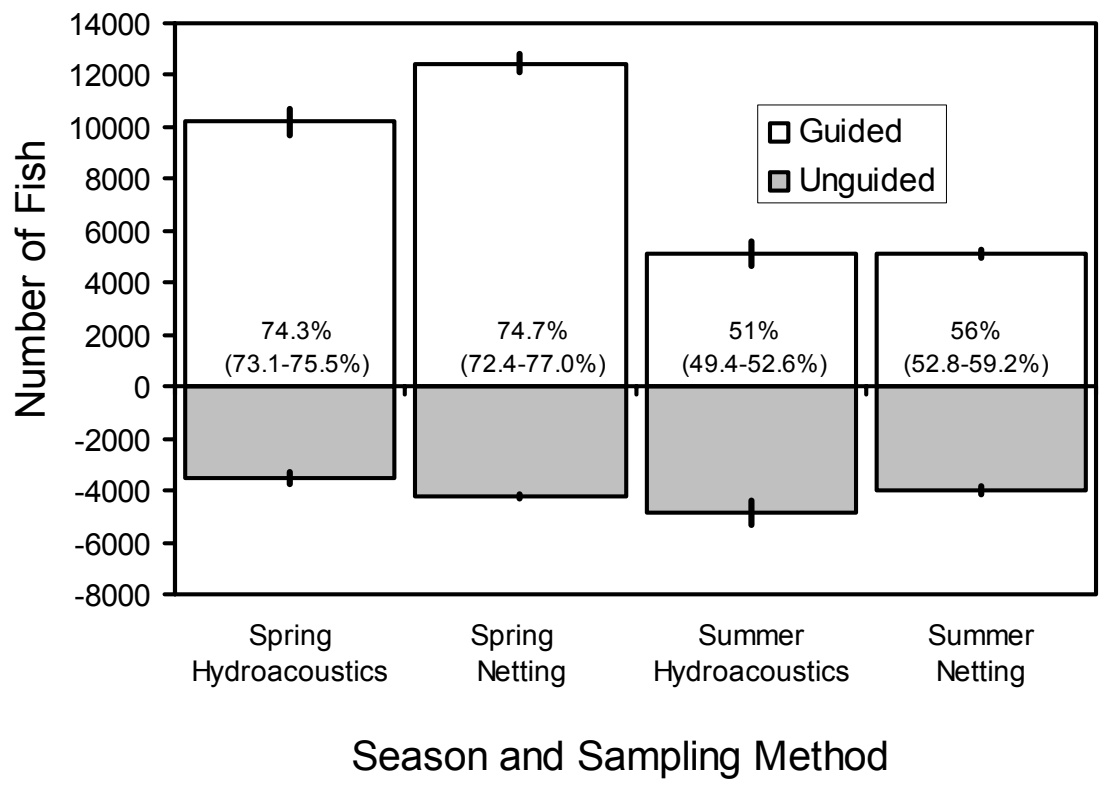

Figure S.1. Plot of the Number of Guided and Unguided Fish Estimated by Concurrent Hydroacoustic Sampling and Netting in Spring and Summer. The percentages inside bars for guided fish are estimates of FGE and numbers in parentheses are $95 \%$ confidence limits. 


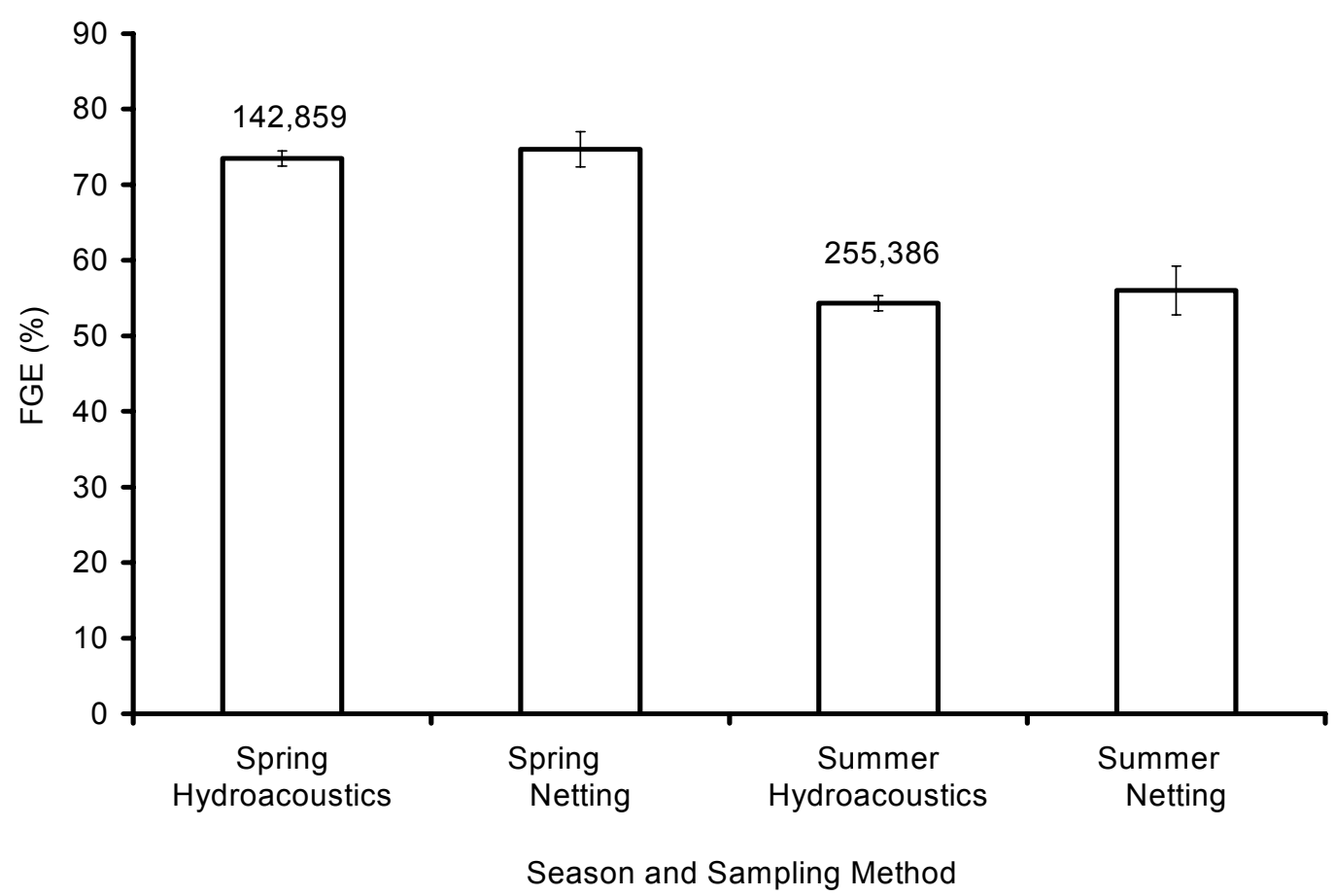

Figure S.2. Plot of FGE Estimates Made from all Nighttime Hours of Hydroacoustic Sampling (20000500) Compared to Estimates Based on Netting from about 2000 to 2100 or $2200 \mathrm{~h}$. Vertical bars are $95 \%$ confidence limits. The expanded numbers of fish upon which FGE estimates were based are shown above the bars for hydroacoustic sampling each season.

Another problem introduced by on and off operation of a turbine unit is that hydroacoustic beams continue to sample and to record multiple traces from fish that are swimming around in the intake of the unit when it is off. At Unit 15, we carefully threw out all fish detected before or after FGE netting based upon start and end times provided by Bruce Monk (NMFS). Operations data reported at 5-minute intervals, like those available in 2000 and earlier years were much better for accurately assigning zero fish counts to samples collected when units are off.

\section{Comparison with Radio Telemetry Estimates}

Our hydroacoustic estimates are reasonably close to radio telemetry estimates, and some of the differences that exist may be attributed to the small sample sizes that are inherent in highly partitioned radio telemetry estimates. Powerhouse unit-specific FGE estimates from radio telemetry were based on from 14 (Unit 18) to 136 (Unit 14) fish in spring and from 15 (Unit 18) to 136 (Unit 14) fish in summer. Inasmuch as those numbers are composed of varying proportions of different species, it is not surprising that radio telemetry estimates sometimes differ. In contrast, unit-specific hydroacoustic estimates are based upon thousands of fish each season. The number of fish captured during 1 to 2 hours of net sampling by the NMFS effort usually is an order of magnitude larger than the number available for radio telemetry estimates for an entire season. 
Similar hydroacoustic and netting estimates of FGE for Unit 15 were both $38 \%$ to $40 \%$ higher than radio telemetry estimates for the same unit in spring, and this may be a function of limited sample sizes of radio-tagged fish. The 38\% FGE estimate by radio telemetry in spring was based on only 19 of 50 detected fish for the entire season, whereas netting estimates usually were based upon $>10$ times that number in just 1 to 2 hours of sampling. The total number of fish counted by concurrent hydroacoustic sampling and netting for spring was 14,687 and 16,651, respectively.

On the unit level, estimates by hydroacoustics were higher than estimates by radio telemetry in five of eight units $(12,13,14,15$, and 16) in spring and in three of four units for which there were radio telemetry estimates in summer (units 12,13 , and 14; Table S.3). The worst case was a $34 \%$ difference at Unit 15 in spring, and the best case was a 1\% difference at Unit 11 in spring. Unit 15 was unusual in that it was very intermittent in its operation during high passage hours due to the NMFS FGE studies there. The next largest differences were at units 12 and 14 in both spring (19\% in both units) and summer (21\% in both units). Hydroacoustic estimates were lower than radio telemetry estimates at units 17 and 18 in spring and at Unit 11 in summer. Estimates were only similar at Unit 11 in spring. Unit-specific differences between the two methods averaged $14.7 \%$ for eight units in spring and $13.7 \%$ for seven units (Unit 17 did not operate) in summer.

Radio telemetry estimates pooled for four adjacent units were within $11 \%$ of similarly pooled hydroacoustic estimates (Table S.3). In spring, the hydroacoustic estimates exceeded radio telemetry estimates by $9 \%$ for units 11 through 14 and by only $2 \%$ for units 15 through 18 . In summer, the hydroacoustic estimates exceeded radio telemetry estimates by $8 \%$ for units 11 through 14 , and by $11 \%$ for units 15 through 18 . 
Table S.3. Hydroacoustic (HA) and Radio Telemetry (RT) Estimates of FGE for Turbines at Bonneville Dam in 2001. Study times were made comparable for both methods by using data only from 1 May to 9 June for spring and 1 July to 15 July for summer.

\begin{tabular}{|c|c|c|c|}
\hline Location & HA Estimate & RT Estimate & Difference \\
\hline \multicolumn{4}{|c|}{ Spring } \\
\hline Unit 11 & $250 \%$ & $51 \%$ & $=1 \%(\mathrm{RT}>\mathrm{HA})$ \\
\hline Unit 12 & $59 \%$ & $40 \%$ & $19 \%(\mathrm{HA}>\mathrm{RT})$ \\
\hline Unit 13 & $67 \%$ & $58 \%$ & $9 \%(\mathrm{HA}>\mathrm{RT})$ \\
\hline Unit 14 & $62 \%$ & $43 \%$ & $19 \%(\mathrm{HA}>\mathrm{RT})$ \\
\hline Units $11-14$ & $58 \%$ & $49 \%$ & $9 \%(\mathrm{HA}>\mathrm{RT})$ \\
\hline Unit 15 & $70 \%$ & $38 \%$ & $32 \%(\mathrm{HA}>\mathrm{RT})$ \\
\hline Unit 16 & $60 \%$ & $48 \%$ & $12 \%(\mathrm{HA}>\mathrm{RT})$ \\
\hline Unit 17 & $48 \%$ & $64 \%$ & $16 \%(\mathrm{RT}>\mathrm{HA})$ \\
\hline Unit 18 & $32 \%$ & $42 \%$ & $10 \%(\mathrm{RT}>\mathrm{HA})$ \\
\hline Units $15-18$ & $51 \%$ & $49 \%$ & $2 \%(\mathrm{HA}>\mathrm{RT})$ \\
\hline All PH2 & $56 \%$ & $46 \%$ & $10 \%(\mathrm{HA}>\mathrm{RT})$ \\
\hline \multicolumn{4}{|c|}{ Summer } \\
\hline Unit 11 & $26 \%$ & $33 \%$ & $7 \%(\mathrm{RT}>\mathrm{HA})$ \\
\hline Unit 12 & $40 \%$ & $19 \%$ & $21 \%(H A>R T)$ \\
\hline Unit 13 & $48 \%$ & $38 \%$ & $10 \%(\mathrm{HA}>\mathrm{RT})$ \\
\hline Unit 14 & $53 \%$ & $32 \%$ & $21 \%(\mathrm{HA}>\mathrm{RT})$ \\
\hline Units11-14 & $39 \%$ & $31 \%$ & $8 \%(\mathrm{HA}>\mathrm{RT})$ \\
\hline Unit 15 & $52 \%$ & $34 \%$ & $18 \%(\mathrm{HA}>\mathrm{RT})$ \\
\hline Unit 16 & $53 \%$ & $46 \%$ & $7 \%(\mathrm{HA}>\mathrm{RT})$ \\
\hline Unit 17 & $\mathrm{~N} / \mathrm{A}$ & $\mathrm{N} / \mathrm{A}$ & \\
\hline Unit 18 & $19 \%$ & $7 \%$ & $12 \%(\mathrm{HA}>\mathrm{RT})$ \\
\hline Unit 15-18 & $50 \%$ & $39 \%$ & $11 \%(\mathrm{HA}>\mathrm{RT})$ \\
\hline All $\mathrm{PH} 2$ & $44 \%$ & $35 \%$ & $9 \%(\mathrm{HA}>\mathrm{RT})$ \\
\hline
\end{tabular}


Hydroacoustic Evaluation of FPE at Bonneville Dam in 2001

xxvi 


\section{Preface}

This report was prepared by the Pacific Northwest National Laboratory (PNNL), Richland, Washington, and the Fisheries Engineering Team (FET), U.S. Army Engineer Research and Development Center (ERDC), Vicksburg, Mississippi, with support from MEVATEC Corporation, 1525 Perimeter Parkway, Suite 500, Huntsville, AL 35806, DynTel, 3530 Manor Drive, Suite 4, Vicksburg, MS 39180, the U.S. Army Corps of Engineers - Portland District, and the University of Washington, Seattle.

\section{Acknowledgments}

Many people made valuable contributions to this study and deserve acknowledgement. Two Portland District biologists, Blaine Ebberts and Dennis Schwartz, provided contract oversight and coordination between the Portland District and the Bonneville Project. Blaine was responsible for the project-wide fish-passage efficiency study, and Dennis oversaw the vertical distribution and fish-guidance-efficiency study at modified Unit 15. Jennifer Sturgill, the Fish Biologist with the Bonneville Project, provided valuable coordination related to Project support, scheduling, and acquisition of dam-operations data, which Project Operators were kind enough to record hourly throughout the study. This study would not have been possible without the support of Project Riggers, who helped with the installation and removal of hydroacoustic equipment.

William Nagy of the Fisheries Field Unit, Portland District, made a major contribution toward the development of standardized processing software that he had developed over the last four years. He provided many hours of advise to Dr. Kenneth Ham and Eric Robinson (both of PNNL), who took the original processing software and developed a new user-friendly interface in Visual BASIC. The new software version consists of a stochastic detectability model, an integrated manual and alpha-beta automated tracker, and a sophisticated query program for developing post-processing filters. These programs not only reduce costs associated with hydroacoustic studies, but also improve the accuracy of fish-passage estimates.

Technicians with MEVATEC, including Kyle Bouchard, Charlie Escher, Chris Holzer, Craig Smith, and Keri Taylor deployed hardware, maintained hydroacoustic systems, and aided with data processing. Charlie Escher also set up and maintained all acquisition computers, and three other MEVATEC technicians (David Steele, John Phillip, and Jose Quevedo) monitored data-acquisition systems throughout the sampling season.

Alan Wirtz of Precision Acoustic Systems in Seattle, Washington, calibrated all hydroacoustic equipment, helped with troubleshooting, and made whatever repairs were required in a timely manner. Schlosser Machine in Hood River fabricated transducer mounts.

Our comparisons of hydroacoustic and radio telemetry estimates of fish passage metrics would not have been possible without estimates and help provided by Scott Evans and Rachel Wardell with the U.S. Geological Survey in Cook, Washington. The radio telemetry and hydroacoustic studies overlapped but also had non-concurrent sample times that had to be eliminated before data could be compared. 
Bruce Monk with the National Marine Fisheries Service graciously provided us with his 2001 netting estimates of guided and unguided fish passage for Unit 15 so we could compare them with hydroacoustic estimates from this study. Bruce also provided us with juvenile bypass screen (JBS) data on run timing of juvenile salmonids.

\section{Acronyms and Abbreviations}

cfs

CFD

ERDC

ESBS

FGE

FPE

$\mathrm{ft}$

$\mathrm{h}$

HA

JBS

$\mathrm{km}$

M

NMFS

PNNL

PSC

RT

$\mathrm{S}$

SPE

STS

TIE

USGS

WES cubic feet per second

computational fluid dynamics

U.S. Army Engineer Research and Development Center

extended submerged bar screens

fish guidance efficiency

fish passage efficiency

feet

hour

hydroacoustics

juvenile bypass system

kilometer

million

National Marine Fisheries Service

Pacific Northwest National Laboratory

Prototype Surface Collector

radio telemetry

second

spill passage efficiency

submerged traveling screens

turbine intake extension

U.S. Geological Survey

U.S. Army Corps of Engineers Waterways Experiment Station 


\section{Contents}

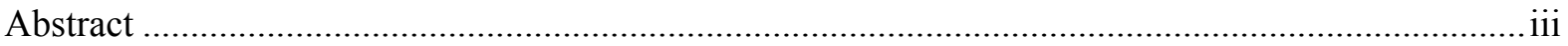

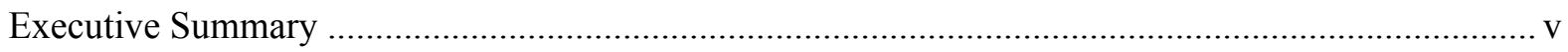

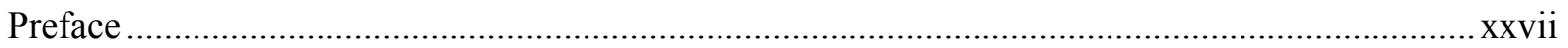

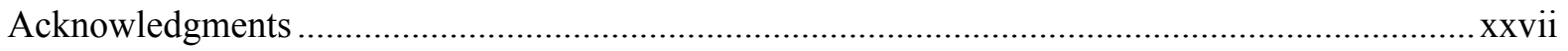

Acronyms and Abbreviations ..............................................................................................

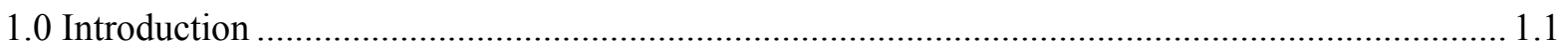

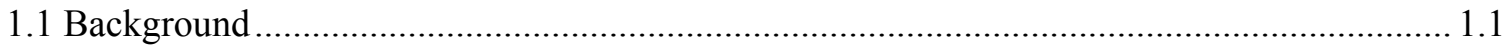

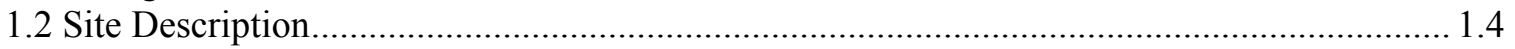

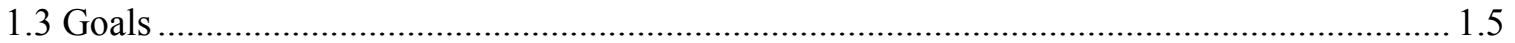

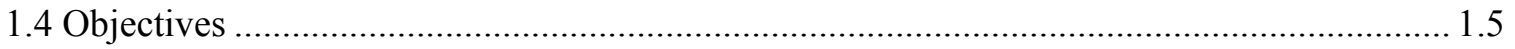

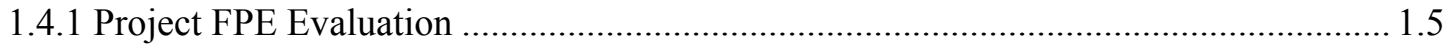

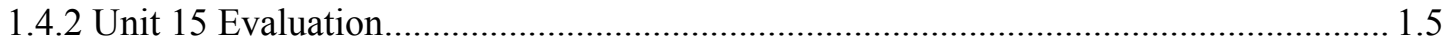

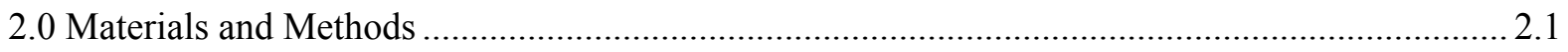

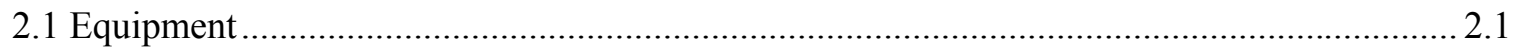

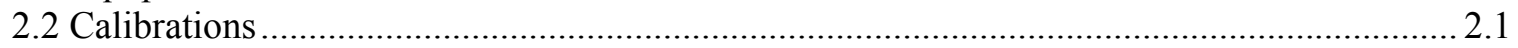

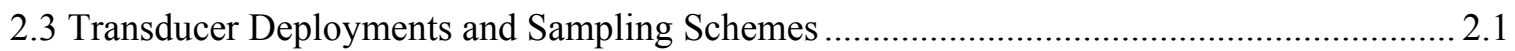

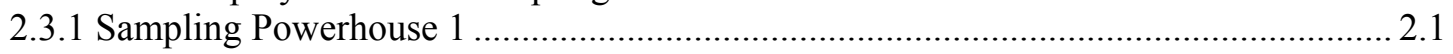

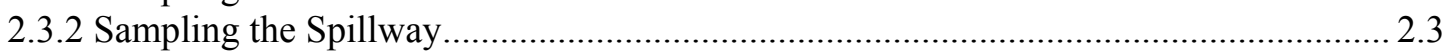

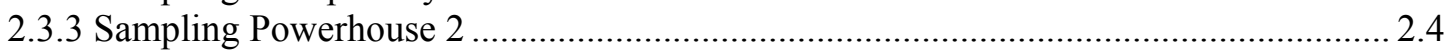

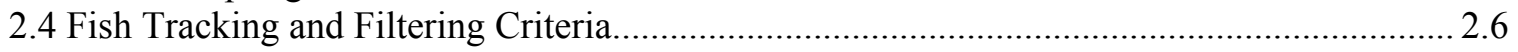

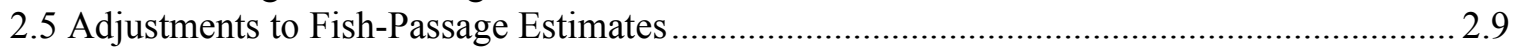

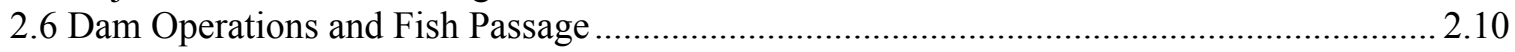

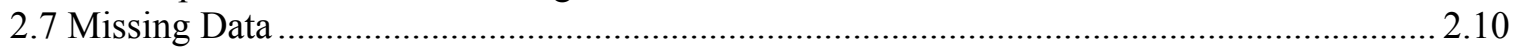

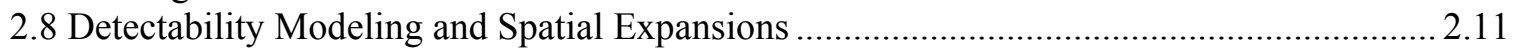

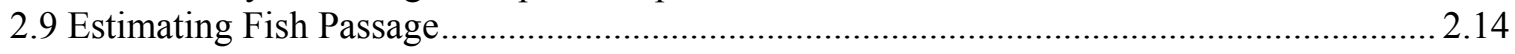

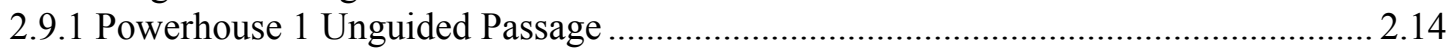

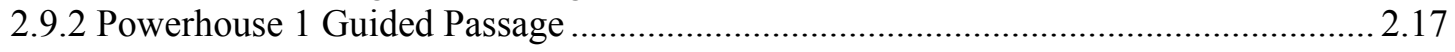

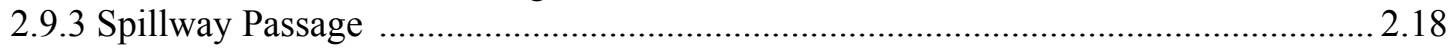

2.9.4 Powerhouse 2 Unguided Passage …..................................................................... 2.20

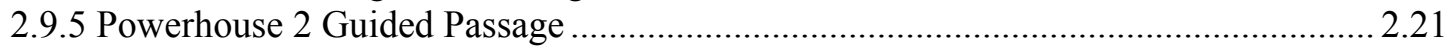

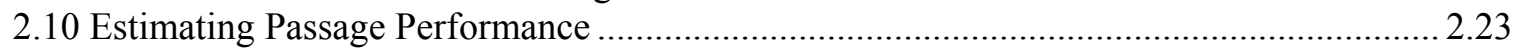

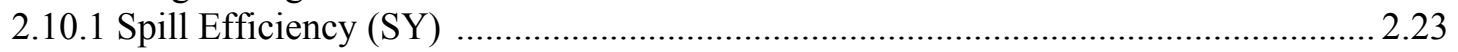

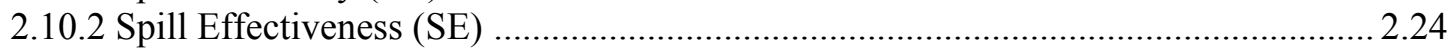

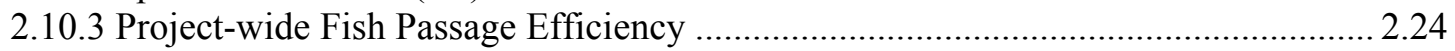

2.10.4 Powerhouse 1 Fish Passage Efficiency (FPE) ……............................................. 2.24

2.10.5 Powerhouse 2 Fish Passage Efficiency (FPE) …................................................ 2.25

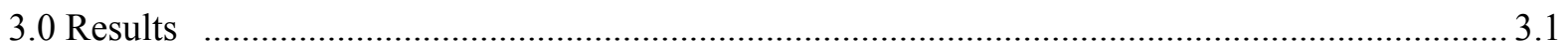

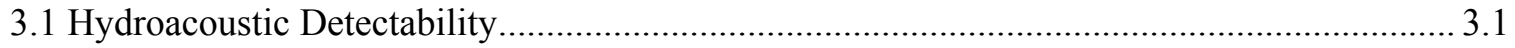

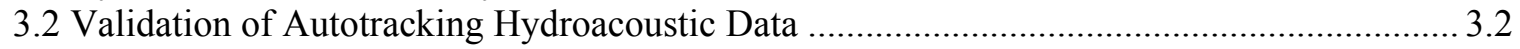

3.2.1 Inter-tracker Error and Human vs. Autotracker Comparisons ..................................... 3.2

3.2.2 Regression Line Slopes for Autotracker Correction .................................................. 3.5

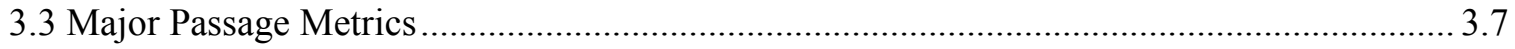

xxix 
3.3.1 Project and Powerhouse FPE............................................................................... 3.7

3.3.2 Spill Efficiency and Effectiveness......................................................................... 3.7

3.3.3 Effects of Spill Level..................................................................................... 3.7

3.3.4 Comparison with Radio Telemetry Estimates ......................................................... 3.8

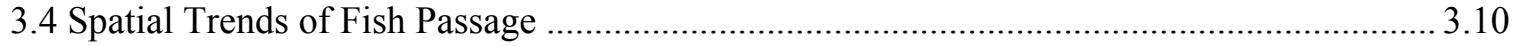

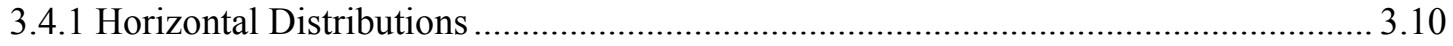

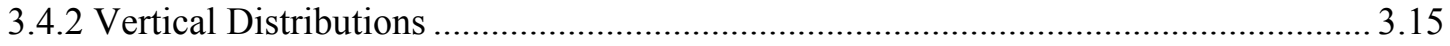

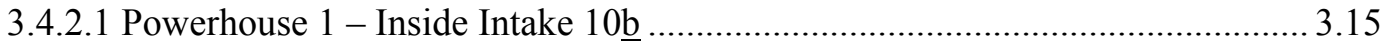

3.4.2.2 Powerhouse 2 - Upstream and Downstream of Intake 15 $\underline{b}$................................. 3.16

3.5 Temporal Trends in Fish Passage .................................................................................20

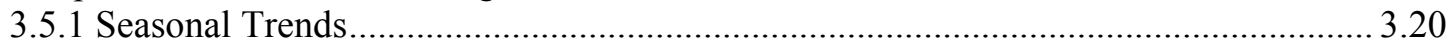

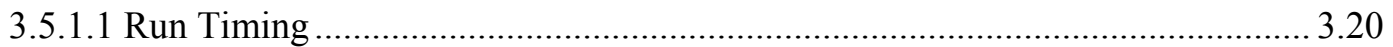

3.5.1.2 Major Fish Passage Metrics ……………………………………………….... 3.21

3.5.1.3 Guidance Efficiency at Modified Unit 15 .......................................................... 3.23

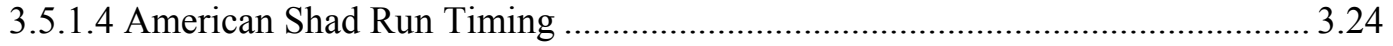

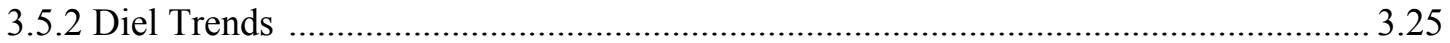

3.5.2.1 Project-Wide Estimates and Spill .................................................................. 3.25

3.5.2.2 Fish Guidance Efficiency and Passage at Turbines ........................................... 3.28

3.5.2.3 Compared to Radio Telemetry Estimates …………………………………....... 3.29

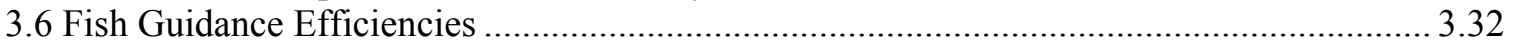

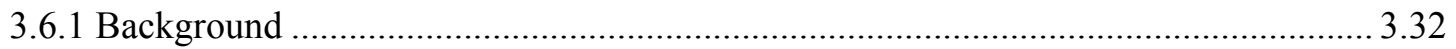

3.6.2 Comparing Performance of Fish Guidance ……………………………………….... 3.32

3.6.3 Comparing FGE Estimates by Different Sampling Methods ........................................ 3.35

3.6.3.1 Comparison with Gatewell Dipping and Fyke Netting Estimates ....................... 3.35

3.6.3.2 Comparison with Radio Telemetry Estimates …………………………………... 3.38

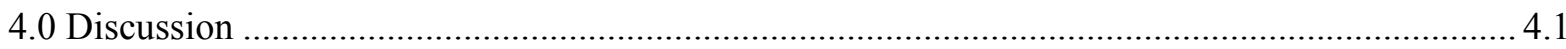

4.1 Hydroacoustic Detectability .................................................................................... 4.1

4.2 Validation of Autotracking Hydroacoustic Data …………………………………….... 4.1

4.3 Major Passage Metrics ................................................................................................ 4.2

4.3.1 Project and Powerhouse FPE................................................................................ 4.2

4.3.2 Spill Efficiency and Effectiveness........................................................................... 4.2

4.3.3 Effects of Spill Level........................................................................................... 4.3

4.3.4 Comparison with Radio Telemetry and Netting Estimates ......................................... 4.4

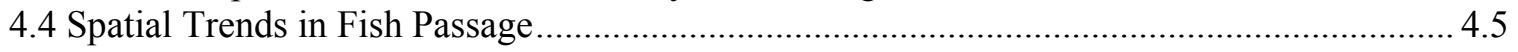

4.4.1 Horizontal Distributions ...................................................................................... 4.5

4.4.2 Vertical Distributions ............................................................................................... 4.7

4.4.2.1 Powerhouse 1 - Unit 10 ................................................................................ 4.7

4.4.2.2 Upstream and Downstream of Modified Unit 15 ................................................. 4.7

4.5 Temporal Trends in Fish Passage .............................................................................. 4.8

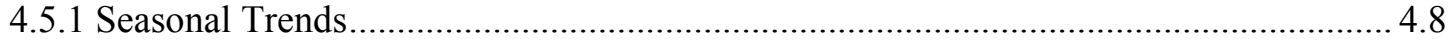

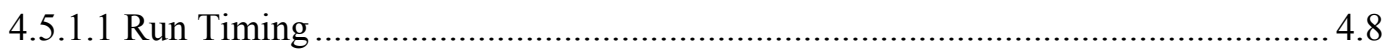

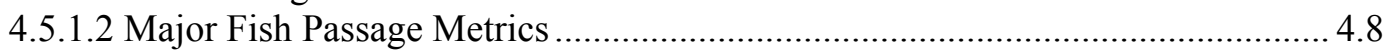

4.5.1.3 Guidance Efficiency at Modified Unit 15 ...................................................... 4.8

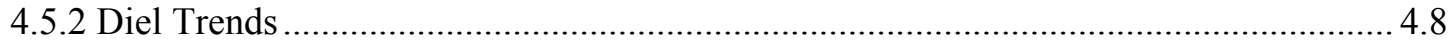

4.6 Fish Guidance Efficiencies ………………………………………………………. 4.10

4.6.1 Comparing Performance of Fish-Guidance Structures.............................................. 4.10

4.6.2 Comparing FGE Estimates by Different Sampling Methods ………………………... 4.10

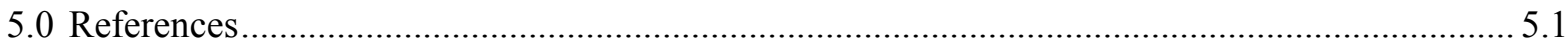


Appendix A - Transducer Calibrations and Receiver Gains....................................................... A.1

Appendix B - Detailed Transducer Locations and Aiming Angles ................................................... 1

Appendix C - Autotracker Definitions and Settings ......................................................................

Appendix D - Statistical Analysis System Code for Filtering Echo Traces Selected by Autotracking

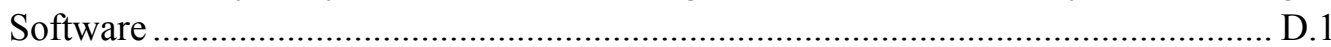

Appendix E - List of Appendix E Tables and Definitions of Variables in Headings of Hourly Fish Passage, Flow, and Forebay Elevation Data on an Accompanying Disk .................... 1

Appendix F - Statistical Analysis System Code for Estimating Effective Beam Angle based Upon

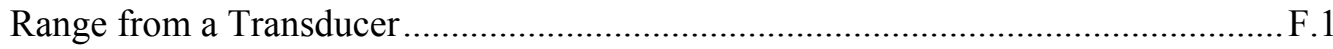




\section{Figures}

Figure 1.1. Plan View of the Bonneville Dam Project..... 1.5

Figure 2.1 Cross-Sectional View through a Powerhouse 1 Intake Like Those Sampled in Units 17,9 , and 10 .

Figure 2.2 Cross-Sectional View through Intake 8b Where Up- and Down-Looking Single-Beam Transducers Were Used to Sample Guided and Unguided Fish, Respectively

Figure 2.3 Cross-Sectional View through a Spill Bay at Bonneville Dam

Figure 2.4 Cross-Sectional View through a Powerhouse 2 Turbine Showing Up- and DownLooking Transducer Beams and Cutoff Ranges for Classifying Fish as Guided and Unguided in Spring and Summer 2001

Figure 2.5 Cross-Sectional View through Intake 15b at Bonneville Dam Powerhouse 2 Showing Three Down-Looking Beams from Split-Beam Transducers.

Figure 3.1 Plots of Effective Beam Angle (EBA) as a Function of Range from Transducers Deployed at Bonneville Dam in Spring 2001

Figure 3.2 Plots of Effective Beam Angle (EBA) as a Function of Range from Transducers Deployed at Bonneville Dam in Summer 2001

Figure 3.3 Cumulative Differences among Human Trackers in Spring and Summer.

Figure 3.4 Regressions of Mean Human Tracker Derived Hourly Passage Estimates and Autotracker-Derived Hourly Passage Estimates by Location (structure) and Deployment (passage route) in Spring

Figure 3.5 Regressions of Mean Human-Tracker Derived Hourly Passage Estimates and Autotracker-Derived Hourly Passage Estimates by Location (structure) and Deployment (passage route) in Summer.

Figure 3.6 Regressions of Autotracker-Based Expanded Hourly Estimates and Mean Human-

Based Expanded Hourly Estimate.

Figure 3.7 Project-Wide Fish Passage Efficiency Estimates for Spring and Summer Seasons at Bonneville Dam in 2001

Figure 3.8 Plot of Project FPE and Spill Efficiency on Hours of Spill per Day at Bonneville Dam in 2001

Figure 3.9 Horizontal Distribution of Fish Passage through Turbines and Spill Bays in Spring

Figure 3.10 Horizontal Distribution of Discharge through Turbines and Spill Bays in Spring.

Figure 3.11 Horizontal Distribution of Fish Passage through Turbines and Spill Bays in Summer..

Figure 3.12 Horizontal Distribution of Discharge through Turbines and Spill Bays in Summer 
Figure 3.13 Horizontal Distribution of Fish Passage Density, in Fish per Millions of Cubic Meters of Water by Turbine Unit at Powerhouse 2 in Spring.

Figure 3.14 Horizontal Distribution of Fish Passage Density, in Fish per Million Cubic Meters of Water, at Powerhouse 2 in Summer.

Figure 3.15 Horizontal Distribution of Fish Passage at Turbines and Spill Bays during the Ten Days that Spill Occurred in Summer.

Figure 3.16 Horizontal Distribution of Discharge at Turbines and Spill Bays during the Ten Days that Spill Occurred in Summer.

Figure 3.17 Vertical Distribution of Smolt-Sized Fish Detected Inside Intake 10b at Powerhouse 1 in Spring 2001.

Figure 3.18 Vertical Distribution of Smolt-Sized Fish Detected Inside Intake 10b at Powerhouse 1 in Summer 2001.

Figure 3.19 Vertical Distributions Upstream (right) and Downstream of the Trash Racks at Modified Unit 15 (Intake b).

Figure 3.20 Vertical Distributions of Fish 4 to 9 and 16 to $21 \mathrm{ft}$ Upstream of Intake 15b Trash Racks in Spring.

Figure 3.21 Vertical Distributions of Fish 4 to 9 and 16 to $21 \mathrm{ft}$ Upstream of Intake 15b Trash Racks in Summer.

Figure 3.22 Distribution of Azimuth Headings of Fish Approaching Trash Racks at Intake 15b in Spring.

Figure 3.23 Distribution of Azimuth Headings of Fish Approaching Trash Racks at Intake 15b in Summer.

Figure 3.24 Patterns of Run Timing through the Spring and Summer Seasons at Bonneville Dam in 2001 Estimated with Hydroacoustics and by Sampling a Smolt Trap in the Juvenile Bypass System.

Figure 3.25 Estimated Project FPE and Spill Efficiency, and Proportion of Water Spilled at Bonneville in 2001

Figure 3.26 Daily Fish Passage Efficiency Estimates for both Powerhouses at Bonneville Dam in 2001 .

Figure 3.27 Daily Spill Effectiveness Estimates and Spill Discharge during the Limited Spill Period at Bonneville Dam in 2001

Figure 3.28 Estimates of Fish Guidance Efficiency (FGE) throughout Spring and Summer at Intake $15 \mathrm{~b}$ and $15 \mathrm{c}$ at Bonneville Dam in 2001

Figure 3.29 Run timing of Up-Migrating American Shad through the Bonneville Project in 2000 and 2001 .

Figure 3.30 Diel Patterns of Fish Passage Efficiency, Spill Efficiency, and Spill Effectiveness during the Spring and Summer at Bonneville Dam in 2001. 
Figure 3.31 Estimates of Diel Trend in Total Fish Passage and Discharge in Spring (top) and Summer through Bonneville Dam in 2001.

Figure 3.32 Estimates of Deil Trend in Spilled Fish and Discharge over the Spillway in Spring (top) and Summer through Bonneville Dam in 2001

Figure 3.33 Diel Estimates of Fish Guidance Efficiency and Total Fish Passage for Powerhouse 1 during Spring (top) and Summer at Bonneville Dam in 2001

Figure 3.34 Diel Estimates of Fish Guidance Efficiency and Total Fish Passage for Powerhouse 2 during Spring (top) and Summer at Bonneville Dam in 2001.

Figure 3.35 Diel Passage Based on Hydroacoustic and Radio Telemetry Sampling at Bonneville Dam in 2001 during the Spring (5/1-6/9) When Both Radio Telemetry and Hydroacoustic Studies Were Ongoing..

Figure 3.36 Diel Passage Based on Hydroacoustic and Radio Telemetry Data at Bonneville Dam in 2001 during the Summer, When Both Radio Telemetry and Hydroacoustic Studies were Ongoing.

Figure 3.37 Comparison of FGE among Combinations of Location and Fish-Guidance Devices or Conditions .

Figure 3.38 Comparison of FGE among Types of Units with STS's at Powerhouse 1, Powerhouse 2, and at Modified Unit 15 by Date.

Figure 3.39 Estimates of FGE and 95\% Confidence Limit for Turbine Units at Bonneville Dam in Spring and Summer.

Figure 3.40 Estimates of the Number of Guided and Unguided Fish and FGE at Intakes 15b (between TIEs) and 15c (behind a TIE) during all Hours the Turbine Was Operated in Spring.

Figure 3.41 Plot of the Number of Guided and Unguided Fish Estimated by Concurrent Hydroacoustics and Net Sampling at Unit 15 in Spring and Summer.

Figure 3.42 Plot of FGE Estimates Made from all Hours of Hydroacoustic Sampling Compared to Estimates Based upon Netting from about 2000 to 2100 or $2200 \mathrm{~h}$.

Figure 3.43 Plot of FGE Estimates Made from all Nighttime Hours of Hydroacoustic Sampling (2000-0500) Compared to Estimates Based upon Netting from about 2000 to 2100 or $2200 \mathrm{~h}$

Figure 4.1 Relation between Fish Passage Efficiency (FPE) and Hours of Spill per Day in Spring 2001

Figure 4.2 Plot of Forebay Elevation during the First 9 D of Summer when Spill Was Occurring in 2001

Figure 4.3 Diel Pattern of Shad Passage through Bonneville Dam in summer 2001

Figure 4.4 Patterns of Discharge of Modified Unit 15 in Spring and Summer 2001 showing the Frequency of On and Off Periods. 


\section{Tables}

Table 2.1 Deployment-Specific Variables that Were Input to a Stochastic Detectability Model for Estimating Effective Beam Angle as a Function of Range from a Transducer.

Table 2.2 Polynomial Inputs or Constants for the Detectability Model for Beam Patterns, Fish Trajectories, and Fish Speeds for Every Deployment.

Table 2.3 Stratification Scheme for Estimating among Intake Variance Components at Powerhouse 1

Table 2.4 Groups of Spill Bays Selected to Form Strata for Calculating Spill Passage and Variances.

Table 3.1 Comparison of Fish-Passage Metrics Estimated by Hydroacoustics (HA) and Radio Telemetry (RT) at Bonneville Dam in 2001

Table 3.2 Percentage of Fish Estimated by Hydroacoustic and Radio Telemetry to Have Passed Bonneville Dam during an Average Daytime Hour (0500-2059 hours) in Spring and Summer of 2001

Table 3.3 Hydroacoustic (HA) and Radio Telemetry (RT) Estimates of FGE for Turbines at Bonneville Dam Powerhouse 2 in 2001. 
Hydroacoustic Evaluation of FPE at Bonneville Dam in 2001

xxxvi 


\subsection{Introduction}

This report presents results of two hydroacoustic studies of juvenile salmonids funded by the U. S. Army Engineers - Portland District and conducted at Bonneville Dam by a team of researchers from Pacific Northwest National Laboratory (PNNL), MEVATEC, University of Washington, Dyntel, and the U.S. Army Corps of Engineers Fisheries Field Unit and Engineer Research Development Center (ERDC). One was a project-wide fish passage efficiency study and the other was a more narrowly focused study of the approach, vertical distribution, and fish guidance efficiency (FGE) of fish at Unit 15. The District extensively modified the gatewell and vertical barrier screen at Unit 15 to determine whether the changes would improve FGE. The District also funded other parallel research on juvenile salmonids in 2001, included a project-wide radio telemetry study by the U.S. Geological Survey (USGS) and a netting study of fish guidance efficiency and orifice-passage efficiency by the National Marine Fisheries Service (NMFS) at Unit 15.

\subsection{Background}

The U.S. Army Corps of Engineers - Portland District is striving to meet the goal, set in the 2000 Biological Opinion, of maximizing fish passage efficiency (FPE) and obtaining 95\% survival for juvenile salmon passing the Bonneville Project. Project FPE is the percent of all juvenile salmon passing the project by non-turbine routes. To estimate project FPE and survival, the proportions of juvenile salmon that pass through all major routes must be estimated.

In a typical water year, the goal of maximizing FPE largely influences operation of the project. Large volumes of spill are presumed to be necessary to compensate for the low fish guidance efficiency (FGE) of screens at both powerhouses, particularly in summer. Spill volumes are, in a typical year, limited to between 50,000 and $75,000 \mathrm{ft}^{3} / \mathrm{sec}$ during the day and up to $120 \%$ of the gas cap set to control total dissolved gas supersaturation. The Northwest had an unusually dry year in 2001 and that, combined with high generation demand, led to unusually low spill volumes. Total project discharge in spring was roughly half ( $46 \%$ in spring and $54 \%$ in summer) of what it was in 2000 . In 2001, the project spilled $16 \%$ of the total discharge in spring and $11 \%$ in summer, down from $31 \%$ and $50 \%$, respectively, in 2000 . Total spill volume was less than a quarter (23\%) in spring and less than an eighth (12\%) in summer of what it was in 2000 .

Spill under 50,000 $\mathrm{ft}^{3} /$ second creates eddies and slack water areas in the spillway tailrace. Excessive predation is assumed in the tailrace where currents do not quickly carry fish downstream. Spill levels above $75,000 \mathrm{ft}^{3} /$ second during the day can lead to high numbers of adult salmon falling back through the spillway, as adults exit the Bradford Island ladder and follow the shoreline around to the spillway forebay. Adult salmon do not pass through the ladder at night, and therefore spill can be increased in an attempt to reach $80 \%$ FPE for a 24 -hour period. However, spill above 120,000 $\mathrm{ft}^{3} /$ second typically causes total dissolved gas (TDG) levels to exceed $120 \%$ saturation. State water-quality standard waivers allow supersaturation up to $120 \%$. Levels of TDG above this may result in greater fish mortality than would occur if spill was reduced and more fish were passed through the turbines. 
The Portland District acquired mobile hydroacoustic data on fish distributions in both powerhouse forebays at Bonneville Dam in 1996 (Ploskey et al. 1998) and 1997 (BioSonics Incorporated 1998). For Powerhouse 1, these data indicated that higher average fish densities occurred upstream of Units 4 through 6 in spring and upstream of Units 4 through 6 and 8 and 9 in summer. For Powerhouse 2, average fish densities were highest upstream of Units 11 through 13 adjacent to the south eddy and sluice chute in spring and in summer. Fish densities also were high upstream of Unit 18 in 1996 but not in 1997. Vertical distribution data showed that most fish were in the upper $15 \mathrm{~m}$ of the water column. The low fish guidance efficiency of many submerged traveling screens at Bonneville Dam would not be expected from an examination of the vertical distribution data collected within $10 \mathrm{~m}$ of the dam. If fish did not alter their vertical distribution from what was observed in forebay areas, data from 1996 and 1997 would suggest that fish guidance efficiency usually would exceed $80 \%$. Data acquired from in-turbine sampling and from fixed up-looking transducers deployed on the bottom of the Powerhouse 2 forebay in 2000 also indicated that FGE estimates were much lower than expected from vertical distributions in the forebay.

Diel (24-hour) patterns of smolt passage are not uniform regardless of whether passage is estimated in sluiceways (Uremovich et al. 1980; Willis and Uremovich 1981) or the juvenile bypass system (JBS) (Hawkes et al. 1991; Wood et al. 1994). Diel passage through the JBS often has a bimodal distribution with a major peak occurring just after dark and a minor peak after sunrise. In contrast, passage through sluiceways usually is higher during the day than at night (Willis and Uremovich 1981). However, patterns apparently are influenced by the operation of sluice gates (Uremovich et al. 1980), flow, unit outages, and species (Willis and Uremovich 1981). Netting required to estimate FGE is intensive but because netting is limited to a few hours per day, it does not provide diel information. Diel patterns of fish passage above and below screens were estimated in spring and summer 1996 for randomly selected intakes of every turbine at Powerhouse 2 and every intake of Units 3 and 5 at Powerhouse 1. Estimates also were made in the spring and summer of 1998 and 2000. These indicate that fish passage through turbines usually is higher at night than it is during the day (Ploskey et al. 2001a; Ploskey et al. 2002a).

Available data indicate that the horizontal distribution of smolt passage among intakes is not uniform. Gatewell sampling has indicated that the number and location of operating units and sluice gates as well as the species of smolt determine lateral distributions of juvenile salmon at Powerhouse 1 (Willis and Uremovich 1981). Interactions among factors may account for a lack of consistency in measures of horizontal patterns by Uremovich et al. (1980), who found fish concentrated at units 6, 7, and 10; Willis and Uremovich (1981), who found variable patterns depending on operations; and Krcma et al. (1982), who observed most passage at units 4 through 6. Much of the FGE data collected at Powerhouse 2 with in-turbine hydroacoustics (e.g., Magne et al. 1989; Stansell et al. 1990) and netting (Gessel et al. 1988; Muir et al. 1989) are of limited value for evaluating the horizontal distribution of passage because they typically focused on one or two units at a time. The Fishery Field Unit attempted hydroacoustic sampling of juvenile salmon passing through several spillway gates in the mid 1980s. Transducers were mounted on the bottom of gates and aimed upward and out from the gate. Apparently, noise generated by sound echoing off of vortices at some gates masked echoes from juvenile salmon and prevented equalized sampling efforts among gates. BioSonics tested several methods for sampling spillway passage in 1997 (BioSonics 1998). Their best approach was to mount their transducers on piers and aim them toward the ogee just upstream of the gates. BioSonics also designed a mount to deploy transducers and estimate passage through the second powerhouse sluice chute. Transducers were placed at the bottom center of the upstream bulkhead slot and aimed vertically and slightly upstream. 
Vertical distributions of juvenile salmon sampled by fixed-aspect hydroacoustics also vary seasonally and daily but this information has not been considered for improving juvenile fish passage at Powerhouse 2. For example, late spring and summer operations at Powerhouse 2 now prioritize the use of turbines 11 and 18 for adult salmon attraction. However, previous studies clearly showed that these units have the lowest FGE for juveniles passing downstream and that juvenile passage through Unit 11 is exceptionally high relative to other units at Powerhouse 2. The FGE of traveling screens was highest at units near the center of the second powerhouse. If Units 11 and 18 did not have turbines or had turbines with much more benign passage conditions than those presently installed, current operations would benefit both adults and juveniles. However, given the low FGE at units 11 and 18 in summer, $85 \%$ to $90 \%$ of the juvenile fish passing Powerhouse 2 go through turbines rather than the bypass.

In the 1980s and early 1990s, hydroacoustics also has been used on limited spatial and temporal scales to evaluate sampling potential or relative passage among a few routes. Thorne and Kuehl (1989) evaluated the effects of noise on hydroacoustic assessment of passage within several turbines of Powerhouse 1. Results showed that acoustic sampling is feasible at the units they tested. Magne et al. (1986, 1989), Magne (1987) and Stansell et al. (1990) made hydroacoustic estimates of FGE for turbine units 11 and 17 and found estimates were closer to netting estimates by the National Marine Fisheries Service (NMFS) when they sampled longer than just a few hours with hydroacoustic gear.

A corner collector is being designed for the south end of the second powerhouse. Ploskey et al. (1998) and BioSonics (1998) found high densities of fish upstream of units 11-13, and Unit 11 had the highest passage of any intake sampled in 1996. Like the Fisheries Field Unit in previous years, BioSonics found that large numbers of fish passed through the sluice chute when that route was available. However, is it not known what contribution the sluice chute or a corner collector could make to guidance at Powerhouse 2 or to project-wide FPE. Data from Ploskey et al. (1998) indicated that the combined FGE of Units 11,12 , and 13 was only $35 \%$. However, operation of the chute increased the combined FGE to $87 \%$ after sluice passage was added to the guided fish terms. This finding could be significant because 1996 mobile hydroacoustic sampling indicated that there was a 2:1 skew in the distribution of fish toward the south end of Powerhouse 2. An important factor contributing to successful fish passage in 1998 was removal of one half of the turbine intake extensions (TIEs), which increased lateral flow toward the sluice chute. When in place, TIES reduce lateral flows along the face of the powerhouse.

At Bonneville Dam First Powerhouse, the Portland District evaluated two distinct smolt bypass approaches, surface flow bypass and extended-length submersible bar screens, from 1998 through 2000. The year 2001 was scheduled for a decision on which complement of smolt passage devices to emphasize for long-term smolt protection at Powerhouse 1. The Corps prepared a special document, called the decision document, to analyze the relative merits of surface bypass and screens at B1.

Research conducted on surface flow bypass from 1998 through 2000 was summarized by Johnson and Carlson (2000). The goal of the surface flow bypass program was to develop and evaluate surface bypass and collection prototype concepts that would lead, if justified by prototype test results, to permanent systems for improving survival of juvenile salmon. In 1998, a prototype surface collector (PSC) was installed at Units 3-6 and was extensively studied (see Johnson and Giorgi 1999 for a review). In 1999, limited research occurred to prepare for tests in 2000. In 2000, the PSC was extended from Units 3-6 to also cover Units 1-2, because a noticeable number of smolts were observed in 1998 and 1999 
to move obliquely from north to south along the face of the PSC. A thorough evaluation of the PSC was conducted in 2000 as part of the Anadromous Fish Evaluation Program (AFEP). The 2000 PSC evaluation emphasized forebay fish behavior as well as PSC performance, i.e., efficiency and effectiveness. It included the following biological research (AFEP study codes in parentheses):

- fixed radio telemetry to determine species-specific PSC performance and movement patterns for yearling chinook salmon and steelhead (SBE-P-95-6)

- acoustic telemetry to study three-dimensional movement patterns and PSC performance on a speciesspecific basis (SBE-P-00-14)

- fixed hydroacoustics to estimate fish passage rates to determine PSC performance for the run-at-large (SBE-P-98-8a)

- multi- and split-beam hydroacoustics to assess fish movements near the PSC (SBE-P-98-8b)

- numerical modeling to integrate hydraulic data from a computational fluid dynamics model with three-dimensional fish movement data (SBE-P-00-13).

A hydroacoustic evaluation was conducted because radio telemetry only provides data on individuals of species and age classes that are chosen for study whereas hydroacoustics samples the run at large. Estimates of FPE can be made by radio telemetry, but only for tagged fish and under the assumption that tagged fish behave like untagged fish. Radio telemetry provides species-specific information, reservoir passage routes and rates, forebay delay times, and other insights that hydroacoustics cannot, but it cannot provide the robust horizontal and vertical distribution information for assessing changes in fish passage or for suggesting improvements in interception facilities. Telemetry sample sizes sometimes are too small when divided among 36 or more passage routes at a project. Hydroacoustic sampling not only provides overall measures of Project performance, but also can indicate where improvements can be made and what kind and how much of a change might be required. For example, vertical distribution data of fish passing through turbines can provide estimates of FGE for existing screens or for proposed screens or surface collectors assuming that the interception point was lower in the water column. The ability to ask such "what if" questions for run-of-river fish is a unique strength of hydroacoustic sampling. In addition, continuous hydroacoustic sampling allows for regression of performance measures (such as spill efficiency) on continuous operations data such as spill volume. These types of regressions can suggest Project operations to optimize juvenile fish passage at a project. Provision of continuous fish-passage data on run-of-river fish is a unique strength of hydroacoustic sampling.

\subsection{Site Description}

Estimation of FPE and quantification of any enhancement by fish guidance devices is difficult because the Bonneville Project is among the most complex on the Columbia River. From the Oregon shore north toward Washington, the project is composed of a navigation lock, a 10-unit Powerhouse 1, Bradford Island, an 18-gate spillway, Cascades Island, and an 8-unit Powerhouse 2 (Figure 1). Principal passage routes include the spillway and two powerhouses, but within each powerhouse, fish passage can be through ice/trash sluiceways, turbines, or the juvenile bypass system (JBS). Smolts enter the JBS after they encounter screens in the upper part of turbine intakes and are diverted to gatewell slots and orifices opening to a bypass channel. In 2000, Units 1-6 at Powerhouse 1 were modified to create a prototype 
surface collector (PSC) for testing the efficacy of deep-slot surface collection (Ploskey et al. 2002a). The PSC was removed before the beginning of the 2001 passage seasons.

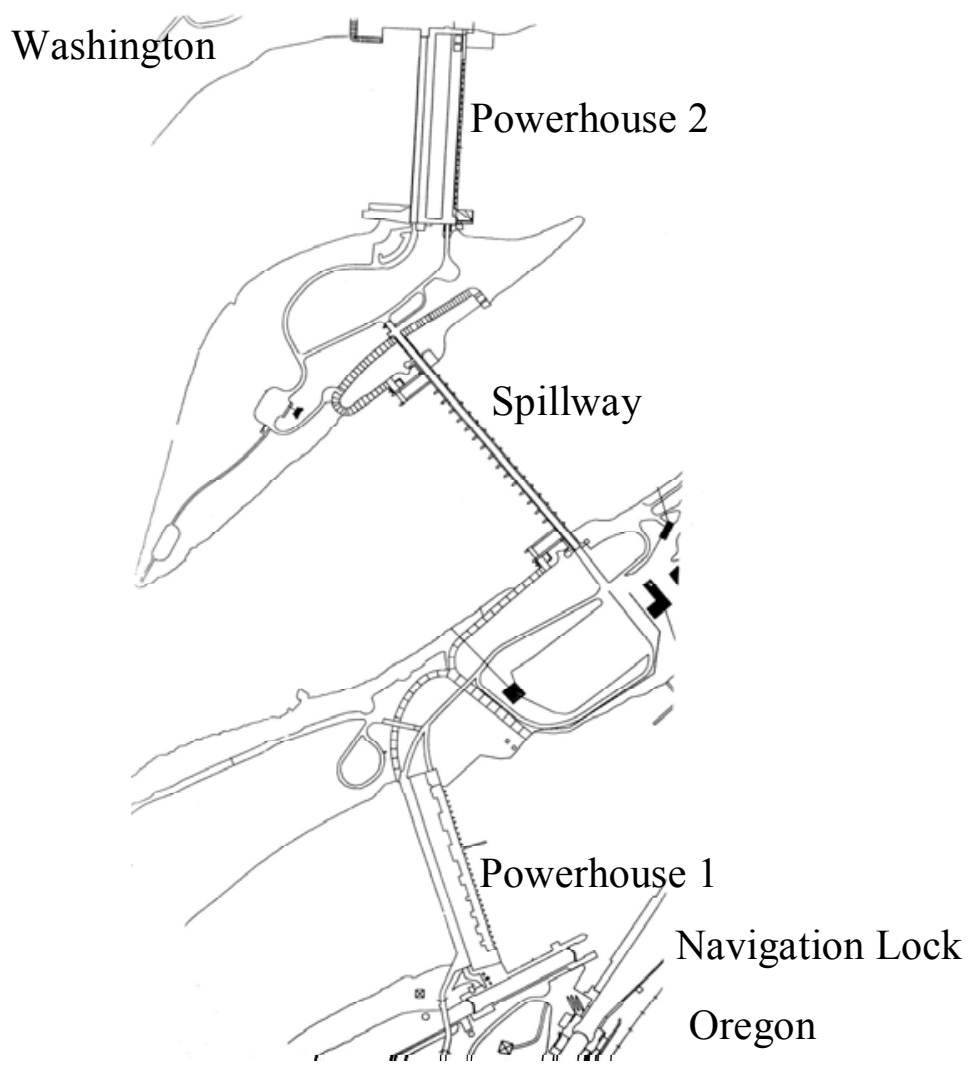

Figure 1. Plan View of the Bonneville Dam Project

\subsection{Goals}

The goal of the larger of the two studies was to provide project-wide estimates of FPE, spill efficiency, and spill effectiveness for run-of-river fish passing the Bonneville Project during the 2001 outmigration. It is the second full-project hydroacoustic study of fish passage at Bonneville Dam. The first was conducted in 2000 (Ploskey et al. 2002a). This type of study also provides estimates of the horizontal, vertical, and diel distributions of fish passage and FGE by turbine unit. These data will provide a baseline for evaluating the performance of future management efforts to improve juvenile fish passage. The goal of the second study was to assess the effect of gatewell and vertical-barrier-screen modifications on the FGE of Unit 15. 


\subsection{Objectives}

Two evaluations were conducted: a project-wide evaluation and a study of Unit 15 .

\subsubsection{Project FPE Evaluation}

1. Estimate the proportion of smolt-sized fish that pass the project above and below in-turbine screens, through sluiceway openings with water depths $>1 \mathrm{~m}$, and via the spillway each season.

2. Estimate spill efficiency and effectiveness by season and for spill periods.

3. Characterize the vertical and lateral distributions of smolt-sized fish passing through Powerhouses 1 and 2 and the spillway.

4. Describe day-night changes in vertical and lateral distributions of smolt-sized fish passing Powerhouses 1 and 2 and the spillway.

\subsubsection{Unit 15 Evaluation}

1. Determine average trajectories of juvenile salmon by elevation and distance upstream of trash racks through three successive hydroacoustic sample volumes aligned in a downstream-upstream direction.

2. Determine the vertical distribution of smolts from the top of the intake to the bottom of the forebay within three successive hydroacoustic sample volumes to determine how distributions change as fish approach the trash racks.

3. Use in-turbine up- and down-looking hydroacoustic beams to determine the vertical distribution of fish downstream of trash racks and to provide independent estimates of FGE from the National Marine Fisheries Service (NMFS) netting effort at the same unit.

4. Determine whether the distribution and behavior of fish upstream and downstream of the trash racks explain why FGE decreases from spring through summer. 


\subsection{Materials and Methods}

\subsection{Equipment}

We sampled Powerhouse 1 turbines with four hydroacoustic systems, the spillway with three systems, and Powerhouse 2 turbines and forebay with four systems. Each system consisted of an echosounder, cables, transducers, an oscilloscope, and a computer system. Each echosounder and computer was plugged into an uninterruptible power supply. An echosounder generates electric signals of specific frequency and amplitude and at the required pulse durations and repetition rates, and cables conduct those transmit signals from the echosounder to transducers and return data signals from the transducers to the echosounder. Transducers convert voltages into sound on transmission and sound into voltages after echoes return to the transducer. The oscilloscopes were used to display echo voltages and calibration tones as a function of time, and the computer system controlled echosounder activity and recorded data to a hard disk. The $420 \mathrm{kHz}$, circular, single- or split-beam Precision Acoustic Systems (PAS) transducers were controlled by PAS 103 echosounders and Hydroacoustic Assessments' HARP software running on Pentium-class computers.

\subsection{Calibrations}

Before deployment, all hydroacoustic equipment was transported to Seattle, Washington, where PAS electronically checked the echosounders and transducers and calibrated the transducers using several standard transducers. After calibration, we calculated receiver gains to equalize the output voltages among transducers for on-axis targets ranging in hydroacoustic size from -56 to $-36 \mathrm{~dB} \| 4 \pi \mathrm{m}^{2}$ (Appendix A). Lengths of fish corresponding to that acoustic size range would be about 1.3 and 12 inches, respectively, for fish insonified within $21^{\circ}$ of dorsal aspect (Love 1977). Inputs for receiver-gain calculations included calibration data (i.e., echosounder source levels and $40 \log$ [range] receiver sensitivities for specific transducers and cable lengths) and acquisition equipment data and settings (installed cable lengths, maximum output voltage, and on-axis target strengths of the smallest and largest fish of interest). In most instances, calibrated and installed cable lengths were identical. When installed cable lengths differed from calibrated cable lengths because we had insufficient cable for a deployment, we used an empirically derived correction factor to compensate for cable length effects on source levels, receiver sensitivity, and receiver gain settings.

\subsection{Transducer Deployments and Sampling Schemes}

This section describes hydroacoustic deployments and sampling schemes with text and figures. We also describe technical details about transducer locations and aiming angles in Appendix B.

\subsubsection{Sampling Powerhouse 1}

In turbine units 1-10, we sampled one randomly selected intake slot out of three per unit. We mounted one upward- and one downward-angled, $6^{\circ}$ transducer in the selected slots to monitor guided and unguided passage, respectively (Figures 2.1 and 2.2). The lateral location of both transducers within the same intake was randomly selected to be on the north, center, or south side of the trash rack 
(Appendix B) so that some of the lateral variation in passage within intakes would be captured in the variance estimate for the entire powerhouse.

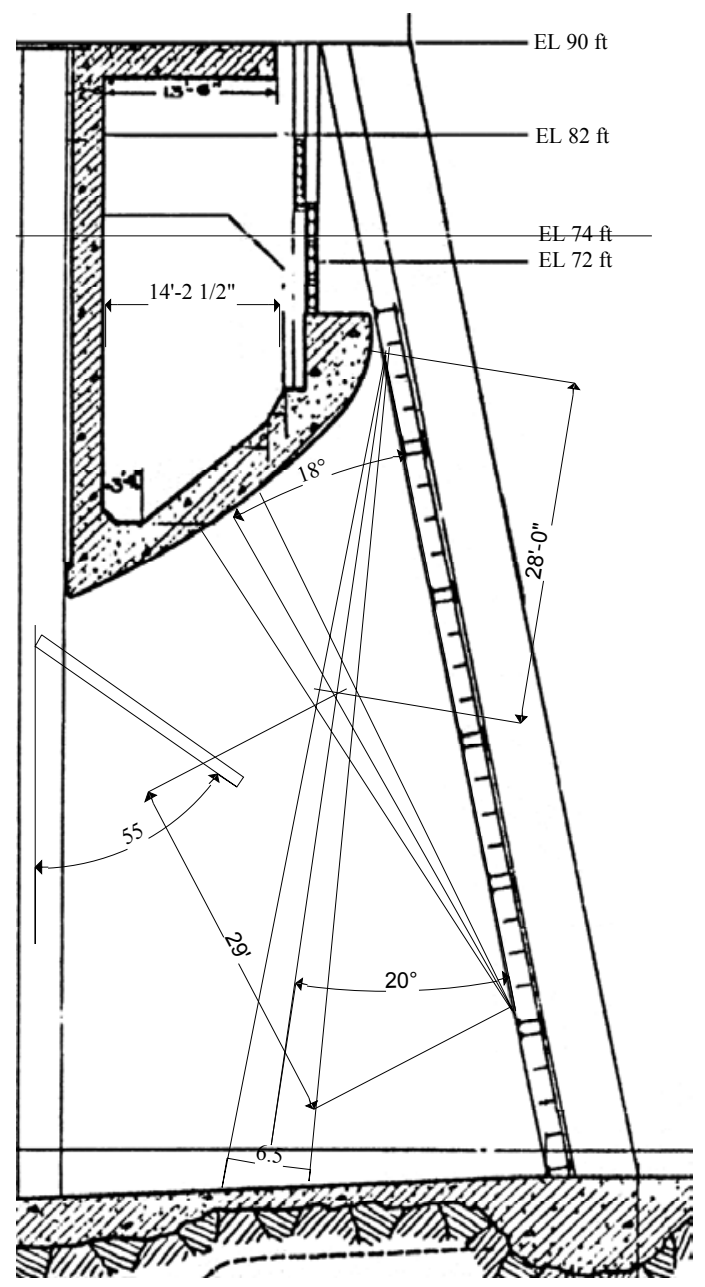

Figure 2.1. Cross Sectional View through a Powerhouse 1 Intake like those Sampled in Units 1-7, 9, and 10. The drawing shows up- and down-looking hydroacoustic beams, aiming angles, and cutoff ranges for sampling guided and unguided fish. Minimum ranges for sampling guided and unguided fish were 8.53 and $8.84 \mathrm{~m}$, respectively.

Transducers deployed in units 5 and 10 were $6^{\circ}$ split-beams to provide target strength data for detectability modeling. Sampling the 40-ft-long extended submerged bar screen (ESBS) at Unit 8 required a different deployment of transducers. Fish passing above and below the ESBS of Unit 8 were sampled with upward- and a downward-angled, $6^{\circ}$, single-beam transducers to estimate guided and unguided numbers, respectively, but the down-looking transducer was mounted on the downstream side of the ESBS instead of on trash racks (Figure 2.2). Therefore, fish passage at Unit 8 could differ from estimates at other Powerhouse 1 units for a variety of reasons, e.g., screen type, unit location, intake selected for sampling, and differences in detectability among deployments. Our modeling of and correction for differences in detectability among deployments should have minimized the last effect. Paired transducers in every intake were fast multiplexed to acquire 201 -minute samples from each intake per hour. The pulse repetition rate was 15 pings per second for every transducer. 


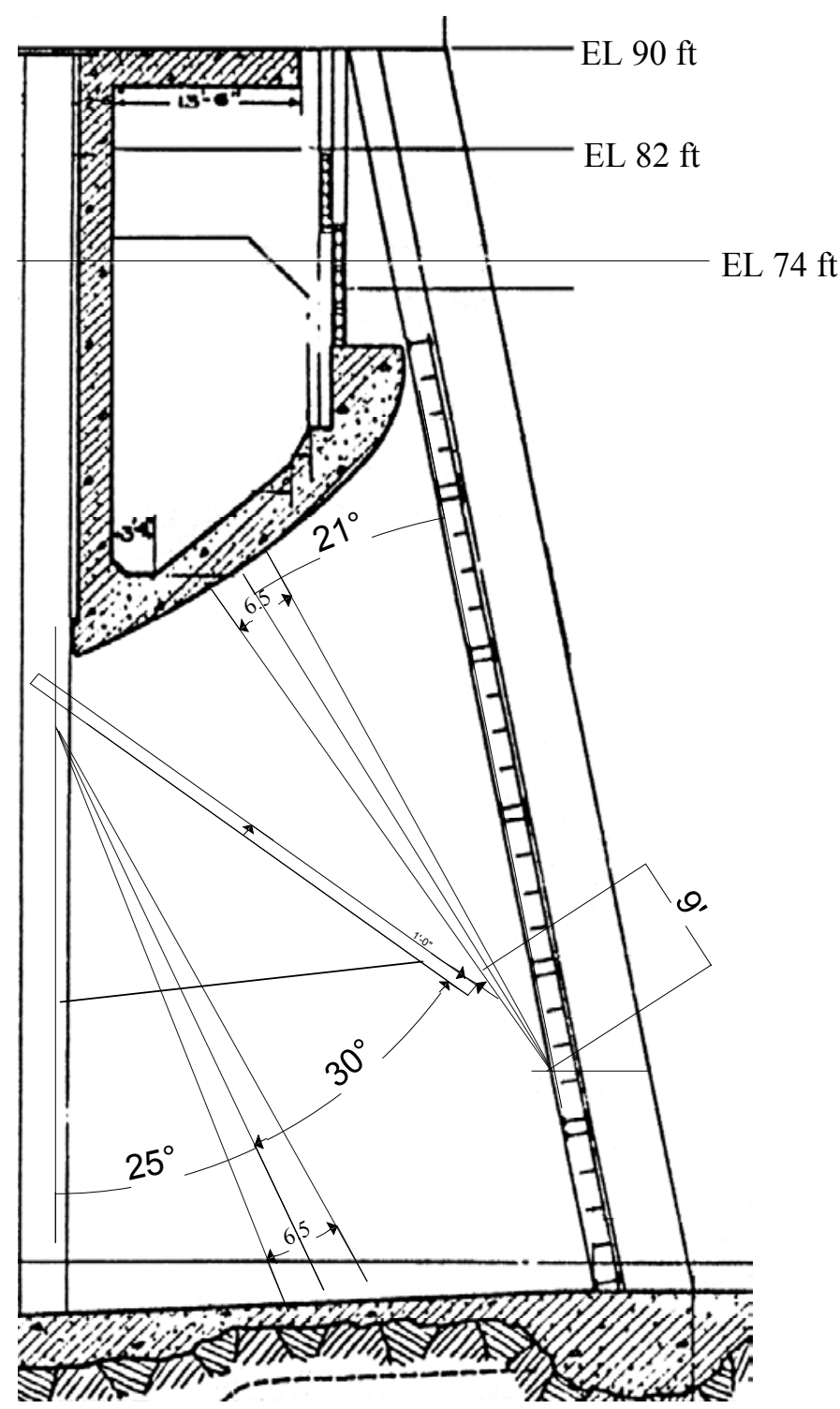

Figure 2.2. Cross-Sectional View through Intake 8b Where Up- and Down-Looking Single-Beam Transducers Were Used to Sample Guided and Unguided Fish, Respectively. Minimum ranges for sampling guided and unguided fish were 3.1 and $2.7 \mathrm{~m}$, respectively.

\subsubsection{Sampling the Spillway}

Spill bays $2,4,5,6,7,8,10,12,14$, and 15 were each sampled with one down-looking, $10^{\circ}$, singlebeam transducer, and Spill Bay 17 was sampled with one down-looking, $12^{\circ}$, split-beam transducer. Bays were selected to allow interpolation of fish passage to bays that were not sampled and to emphasize sampling at gates that would pass the most water according to the 1999 Fish Passage Plan. Transducers were mounted $28 \mathrm{ft}$ below the tops of spill gates and aimed upstream $8^{\circ}$ (single beams; Figure 2.3 ) or $15^{\circ}$ upstream for the split-beam transducer (Appendix B). Transducers were at EL $59 \mathrm{ft}$ when operators opened a gate about $3 \mathrm{ft}$, which was the maximum opening observed in 2001 . The lateral location of each 
transducer within a bay was randomly selected to be on the north, center, or south side so that some of the lateral variation in passage within bays would be captured in the variance estimate for the entire spillway.

Severe drought in 2001 limited the number of spill days each season. When there was spill, it was set at about 50,000 cfs day and night. Transducers were sampled sequentially to allow a pulse repetition rate of 30 pings per second during each of 12 1-minute samples collected by each transducer per hour.

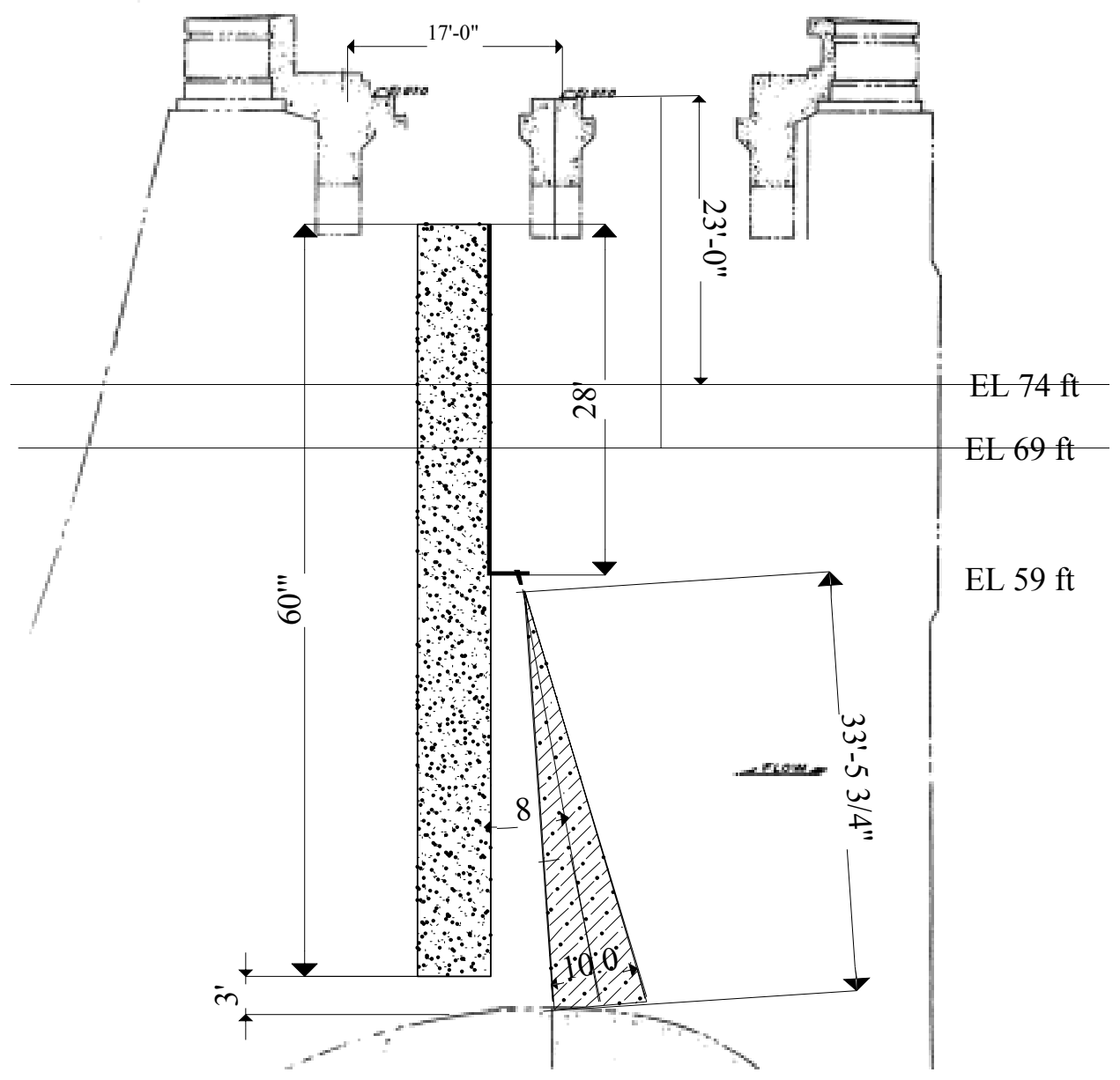

Figure 2.3. Cross-Sectional View through a Spill Bay at Bonneville Dam. The diagram shows a transducer mount on the upstream side of a spill gate and the orientation of the hydroacoustic beam. Flow was from right to left through the beam. The gate opening of about $3 \mathrm{ft}$ was the maximum observed in 2001. The minimum range for sampling spilled fish was $2.4 \mathrm{~m}$ from the transducer.

\subsubsection{Sampling Powerhouse 2}

At Powerhouse 2, one out of three intakes at every turbine unit was randomly selected for sampling, and at Unit 15 we sampled both the $\underline{b}$ and $\underline{\mathrm{c}}$ intakes. Three transceivers and computers were used to control the 18 transducers. The lateral locations of transducers within intakes also were randomized among north, center, and south locations (Appendix B). In each intake, we mounted a pair of transducers on the downstream side of the trash racks (Figure 2.4; Appendix B). One transducer of each pair was mounted near the bottom of the uppermost trash rack and aimed downward to sample unguided fish 
passing below the traveling screen. The second transducer of each pair was mounted near the bottom of the fourth trash rack from the top and aimed upward to sample fish passing above the screen. The lateral location of both transducers within the same intake was randomly selected to be on the north, center, or south side of the trash rack (Appendix B). The two transducers deployed in Unit 18 were split beams to provide target strength data.

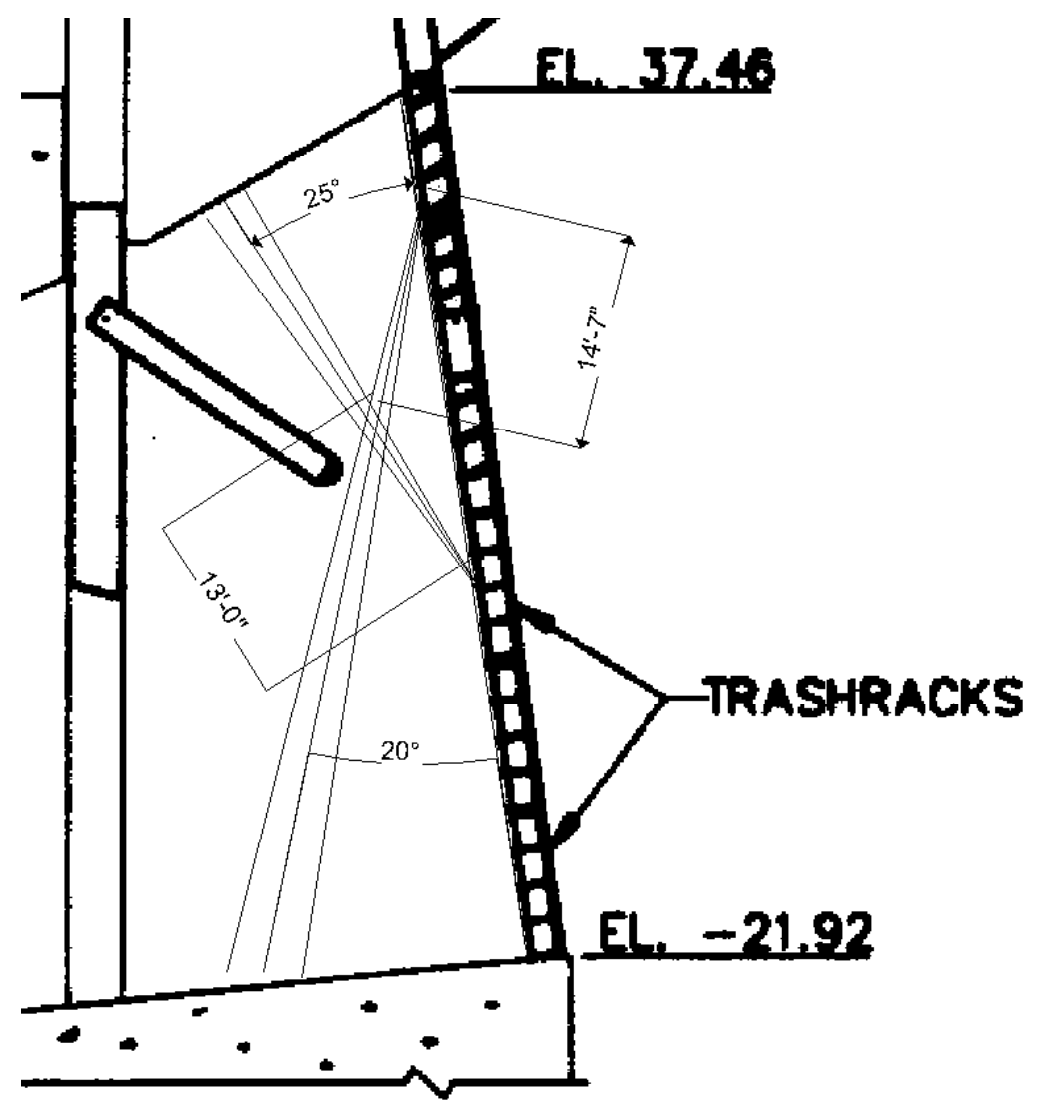

Figure 2.4. Cross-Sectional View through a Powerhouse 2 Turbine Showing Up- and Down-Looking Transducer Beams and Cutoff Ranges for Classifying Fish as Guided or Unguided. Minimum ranges for sampling guided and unguided fish were 3.96 and $4.44 \mathrm{~m}$, respectively.

Each transducer transmitted sound pulses at 15 pings per second, and both transducers of a pair usually were sampled simultaneously (i.e., fast multiplexed). Fast multiplexing allowed us to estimate covariances for the simultaneous samples of guided and unguided fish and to collect 301 -minute samples

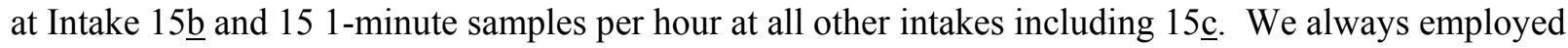
simultaneous sampling on units 15 through 18. We also used simultaneous sampling for units 11 through 14 on days when the NMFS was conducting FGE testing at Unit 15, when we were not trying to operate forebay transducers upstream of Intake 15ㅁ. However, we sampled transducers of each pair in units 11 through 14 sequentially for $30 \mathrm{~s}$ each from 0000 through $1600 \mathrm{~h}$ on days when the NMFS was conducting orifice-passage efficiency (OPE) studies at Unit 15, and we were operating three forebay transducers at Intake $15 \underline{b}$ at the same time (Figure 2.5). 
Slow multiplexing transducers in units 11-14 during OPE tests eliminated extensive interference of acquired signals that we encountered when we first tried fast multiplexing transducers in Units 11 through 14 and slow multiplexing forebay transducers upstream of trash racks at Intake $15 \underline{b}$. The three transducers in the forebay (Figure 2.5) were for sampling vertical distributions and the azimuth direction of travel of fish upstream of Intake $15 \underline{\mathrm{b}}$. They consisted of down-looking $6^{\circ}$ split-beam transducers deployed on a steel beam lowered to a depth of $70 \mathrm{ft} \mathrm{MSL}$ in the trash-rack slot.

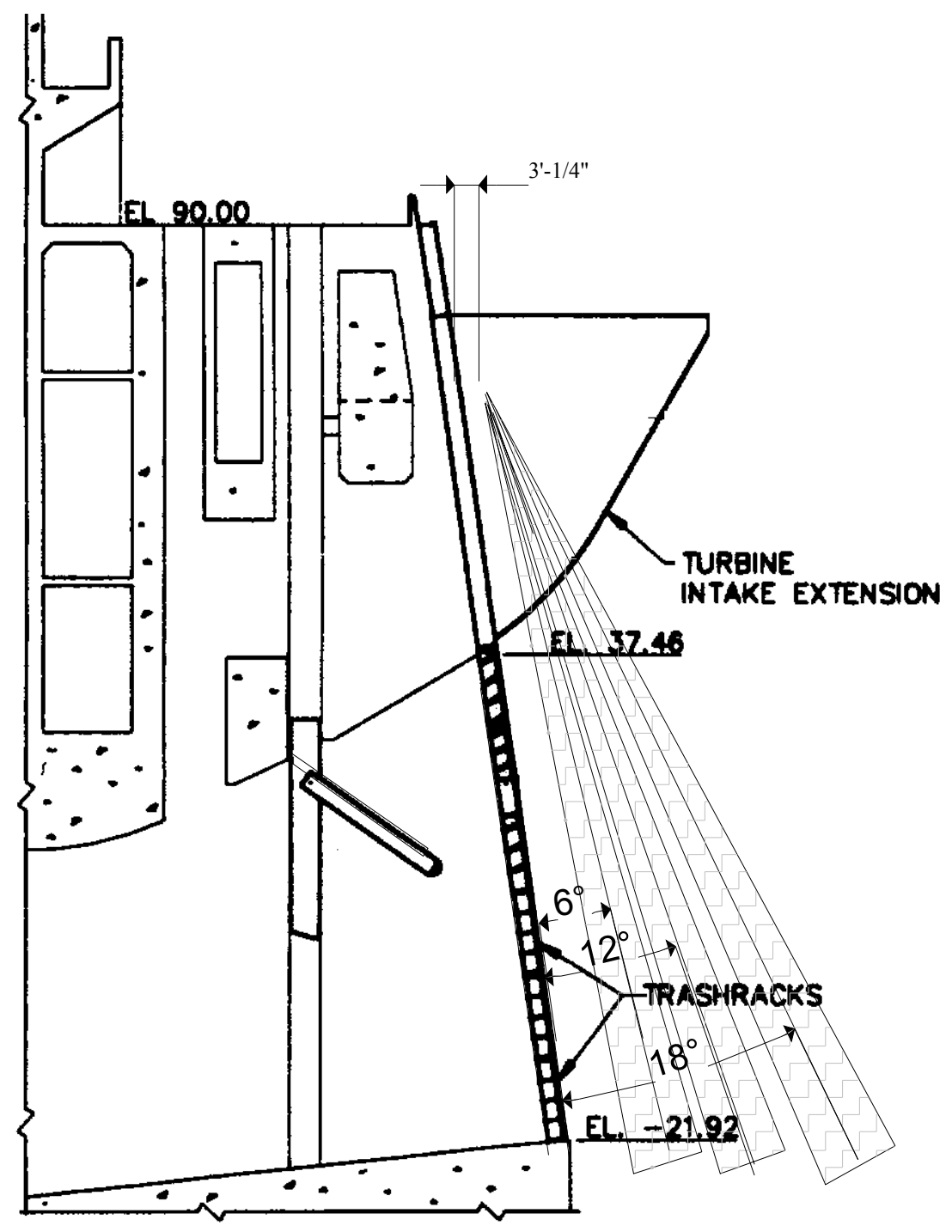

Figure 2.5. Cross-Sectional View through Intake 15b at Bonneville Dam Powerhouse 2 in Spring and Summer 2001 Showing Three Down-Looking Beams from Split-Beam Transducers

\subsection{Fish Tracking and Filtering Criteria}

Since the hydroacoustic sampling effort on Bonneville Dam was so extensive and generated such a large volume of data in 2001, we could not feasibly manually process enough data to make reliable fish- 
passage estimates with available staff. Therefore, we relied on autotracking software developed over the last four years by the Fisheries Field Unit, the Waterways Experiment Station (WES), and PNNL to process raw data into tracked fish observations. The autotracker software tells the processing computer to:

1. Identify and remove echoes at constant range from structure.

2. Find seed echoes for candidate tracks.

Go to every echo.

Define a 10-ping by 1-m window centered on that echo.

Place all echoes in the window into 5-degree angle bins.

If any bin-count $>3$, flag the center echo as a candidate seed.

3. Re-examine candidate seed echoes.

Go to every seed-echo window.

Count echoes in all possible line features (Hough transform).

If no echoes in the window are part of a strong line feature then drop the seed echo (to distinguish between dense noise and dense fish tracks).

4. Initiate alpha-beta tracking.

Track forward, starting at each seed echo.

Track backward from the same seed echo after forward tracking has ended.

Check the track segment against criteria (core criterion; minimum and maximum gap).

5. Link track segments that are collinear into single tracks. This involves projecting the first track segment forward and the second segment backward and linking them into one fish if the ping gap $\leq 20$ pings and the two segments line up and meet a track link criteria.

6. Write out track statistics (echo statistics optional).

We describe and present autotracker parameters and the settings used to process the 2001 data in Appendix C. During most of spring and early summer, we reviewed samples of the autotracker's performance for every deployment on a fish-by-fish basis to evaluate and fine-tune the autotracker and to develop post-processing filters for eliminating false traces from the autotracker's output. We released the autotracker to process data for a given deployment only after we determined that it was missing few of the echo patterns that we would have tracked.

In Appendix D, we describe criteria and present Statistical Analysis System code used to reject nonfish traces that the autotracker selected. In another part of the processing program, we eliminated fish detected at ranges less than those described in legends of Figures 2.1 through 2.3. Filtering non-fish traces based upon variables like range, slope, and noise level is a critical part of using autotracking software, because the autotracker is more likely to track intermittent series of structural echoes or noise than are technicians. Filters were designed to eliminate echo traces that had a high probability of being from structure, noise, or non-target fish based upon their track statistics.

Filtering American shad traces selected by the autotracker in summer was a difficult problem that was pervasive in 2001 because the peak of the American shad run arrived at least two weeks earlier than in most years. In echograms, shad usually can be recognized because they occur in schools, unlike salmon smolts that usually pass through beams as single traces. It is rare to detect more than one or two smolt traces in close proximity in time or space inside turbine intakes. In addition, few of the traces in these schools had ping gaps and the average number of echoes per trace often exceeded 10. In heavy shad 
passage events, it was common to detect $>30$ traces in a 1-min sample. Shad schools were almost never observed in down-looking beams sampling unguided fish, but they were common in up-looking beams sampling guided fish in some turbines.

Our approach to filtering shad schools was to find obvious schools of shad in echograms from uplooking split-beam transducers and statistically characterize the distribution of average target strengths of those fish. Most of the fish in those schools had target strengths $>-49.2 \mathrm{~dB}$ (about a 4-inch-long fish when insonified about $30^{\circ}$ off ventral aspect); thus, these were too big to likely be sub-yearling smolts. Using echo strength to filter shad detected with single-beam transducers is imperfect because large fish on the edge of a beam return lower amplitude echoes that are not adjusted for the fishes' position in the beam. After comparing the central tendency of target and echo-strength distributions, we decided to use an echo-strength filter of $-51.5 \mathrm{~dB}$ to filter shad from single-beam samples of guided fish. This conservative setting may have filtered some larger smolts, but it reduced the probability of sample contamination by shad. Maximum target or echo strengths used to filter shad were deployment specific and depended upon the aiming angle of each transducer. We used Love's (1977) equations relating target strength to fish length and insonification angle to find corresponding maximum target strengths for 4inch-long fish in each deployment. We are working on other ways to filter American shad from summer samples using criteria such as the density of traces in range and time and the number of consecutive echoes without gaps, but for now target strength or a roughly equivalent echo-strength is the filter of choice.

Although the autotracker was a very efficient tool, we evaluated its performance and post-processing filters in both seasons by comparing counts of fish by the software and by trained technicians. Although five of our six human trackers each had from one to three years of previous tracking experience, we did extensive training and testing on raw hydroacoustic data from previous years and from early 2001 data before the 2001 tracking season began. Every technician and the autotracker processed identical Powerhouse 2 data sets acquired early, mid, and late each season, but the abbreviated generation schedule at Powerhouse 1 left few options for data set selection there. We selected spillway samples from throughout the abbreviated spilling seasons. Fish count data, in the form of computer files that include statistics for each trace, were processed the same as are autotracked fish counts to produce temporally and spatially expanded hourly passage estimates. Results from the technicians provided an estimate of intertracker error and deployment-specific mean hourly estimates for comparison to the autotracker-based estimates. We used this approach because fish counts, even for the same files, can vary widely among human trackers (Ploskey et al. 2001b; 2002). Given the demonstrated wide range of interpersonal variation, we compare our autotracker's results to mean human estimates rather than to any one person's estimates.

It is important that autotracker and human-tracker quality control checks be made at the proper level, the transducer channel. We compared human and autotracked counts for each transducer (channel) because there are important differences in passage characteristics, ranges of interest, trace slopes and lengths, and noise conditions for each deployment site and aiming angle. Last year, we discovered that comparing at the system level, which involves several transducer channels with different deployments, could mask error (Ploskey et al. 2002). Up-looking-transducer channels sampling guided fish have very different noise regimes from down-looking-transducer channels and the slopes of regression lines fitted to autotracker and mean human counts often differ too. They can even vary in opposite directions, so that up-looking-transducer channels have higher autotracked counts and down-looking transducer channels 
have higher human-tracked counts. In those cases, comparing at the system level would mask some of the disagreement between the humans and the autotracker.

Each tracker's output, whether from a human or from the autotracker, is processed with a channelspecific software "filter" that automatically rejects traces that do not meet specific criteria. Output files from each human or automatic tracker were post processed identically. Post-processing included deployment-specific "filtering" for trace length, trace slope, echo or target strength, structure, and other regular noise, and other characteristics described in Appendix D. The resulting filtered fish counts on each day were then summed separately by the transducer channel that was sampled. We also compared cumulative temporal deviations among trackers by cumulative counts over time.

\subsection{Adjustments to Fish-Passage Estimates}

After regressing average technician counts on autotracker counts for each deployment, we used slopes of regression lines with intercepts forced through zero to convert autotracker counts into mean technician counts and thereby remove systematic bias in autotracker counts among deployments. Slope multipliers in spring were 0.96 (Powerhouse 1 unguided), 0.83 (Powerhouse 1 guided), 0.833 (Powerhouse 2 unguided), 0.754 (Powerhouse 2 guided), and 0.789 (spillway). Slope multipliers in summer were 0.985 (Powerhouse 1 unguided), 0.953 (Powerhouse 1 guided), 0.841 (Powerhouse 2 unguided), 0.678 (Powerhouse 2 guided), and 0.98 (spillway). Variances were multiplied by the square of the slope factors. Plots of the regressions of mean technician counts on autotracker counts are presented in the Results section of this report.

After the Anadromous Fish Evaluation Program Research Review (13-16 November), where we found that hydroacoustic estimates of fish spill efficiency and effectiveness were considerably higher than were those from radio telemetry, we examined the azimuth direction of travel of fish through the downlooking split beam at the spillway. We found $7 \%$ to $13 \%$ of the fish in spring and $6 \%$ to $10 \%$ in summer not moving in a downstream direction. Some of the percentage of upstream-moving fish could have resulted from error in the way direction of travel was estimated this year. The azimuth estimates were based upon positions of the first and last echoes in a fish trace. This approach has some error associated with it because inaccurate phase data for one or both echoes could result in inaccurate positioning of the echoes in three-dimensional space and an error in the estimated direction of travel. Phase data can be corrupted by having fish echoes near noise echoes, structure, or other fish echoes at the same range. A better approach and the one that will be used in future years would be to determine the direction of travel based upon a line fitted to all echoes in a fish trace. This will be less susceptible to error because it will depend upon position estimates for more than just two echoes.

We decided to apply a conservative estimate of the number of fish passing through the spillway, rather than counting only the fraction of fish moving in a downstream direction. Instead, we estimated the downstream flux of fish per hour and multiplied hourly counts of fish in all spillway beams by that factor. The fish-flux factor is more conservative than multiplying by the fraction moving downstream because it subtracts the upstream fraction from the downstream fraction. For example, if $90 \%$ of detected fish are moving downstream and $10 \%$ are moving upstream, the flux factor applied would be 0.8 instead of 0.9. We consider this to be the most appropriate because upstream moving fish have the potential to be counted more than once and should be subtracted from the passage estimate. In reality, all we know is that some fish moving upstream could have been counted more than once and that the flux factor should 
be somewhere between 0.8 and 0.9 . We could have split the difference and used 0.85 , but we wanted to be certain not to overestimate spillway passage in a drought year. Flux factors applied in spring were 0.74 from 0800 to 1700 hours, 0.86 from 2000 to 0400 hours, and 0.80 during crepuscular hours (05000700 hours and 1800 or 1900 hours). Flux factors applied in summer were 0.80 from 0800 to 1700 hours, 0.88 from 2000 to 0400 hours, and 0.84 during crepuscular hours (0500-0700 hours and 1800 or 1900 hours).

\subsection{Dam Operations and Fish Passage}

Hourly operations data, including discharge by spill bay and turbine unit, were provided by Bonneville Dam operators, who recorded results in a spreadsheet. Hourly operations data were integrated with fish passage data, and fish passage was set to zero when passage routes were closed. When flow is low at a closed turbine unit or spill bay, a fish can stay in the beam much longer than when the passage route is open. A transducer samples continuously regardless of operations, and samples from closed turbine units and spill bays often include many traces that may be tracked as fish, often multiple times, when a turbine unit is off or a spill bay is closed. It is best to have operations data at 5-minute intervals so that hourly passage estimates are not inflated by multiple fish detections during the fraction of an hour when a turbine was off. For that reason, we set fish passage to zero if hourly discharge through a turbine was less than $65 \%$ of the maximum discharge on a given day.

When discharge is less that $65 \%$ of the maximum discharge, there is a high probability that the turbine was off for some part of an hour. Multiple detections of just a few fish wallowing in and out of an acoustic beam when a turbine is off can greatly inflate hourly estimates of guided fish passage and can bias estimates of FGE and FPE. We assumed that a turbine with $<65 \%$ of maximum discharge was off the entire hour rather than risk inflation of guided fish counts. These adjustments had little effect on overall fish-passage estimates because they were infrequent and over one half of those occurrences resulted from a turbine running $<10$ minutes/hour. For example, at units 9 and 10, we set hourly fish passage to zero in only 28 and 31 of 1,103 spring hours $(<3 \%)$, respectively, based upon low hourly discharge. At Unit 14, fish passage was set to zero based upon low discharge in $17(1.5 \%)$ of 1,103 spring hours monitored.

Hourly rates and variances in fish passage and hourly rates of water discharge through various routes at Bonneville Dam are presented in Appendix E on the accompanying compact disk. Tables 1 and 2 of Appendix E describe the variables in the comma-separated variable files.

\subsection{Missing Data}

We made a special effort to make certain that missing samples were accounted for in the spring and summer data sets. First, we created a data set consisting of all possible sample locations and times each season and set an expanded fish variable to missing in every observation. Second, we merged the missing data set with the acquired data set and counts of expanded fish, if present in the acquired data, overwrote missing counts. When a sample was not acquired for whatever reason, there was nothing in the acquired data set to overwrite the missing value for expanded fish. Therefore, the observation was appropriately designated as missing and could be interpolated before data were analyzed.

All hydroacoustic systems were operated continuously ( $>23$ hours/day), except for about 15 minutes every morning when data were copied from the acquisition computer onto a portable FireWire ${ }^{\mathrm{TM}}$ hard 
drive or when equipment failed and data from the affected routes were not collected. Short equipment failures lasting up to 45 minutes were not a problem because fish counts and associated variances could still be estimated from the remaining within-hour samples. Computer lock-ups usually were fixed within an hour because we had staff monitoring systems 24 hours per day. We had transducer cables fail on units 9 and 11 and both were fixed within a day, as soon as project support or divers became available. The failure at Unit 11 was replaced in March before the fish passage season began.

Missing hourly sums and variances that resulted from equipment outages $>45$ minutes were estimated by temporal linear interpolation for periods $<6$ hours and by spatial interpolation or linear regression for periods $>6$ hours. Occasionally the ratio of guided to unguided numbers at adjacent turbines with similar screens was useful for interpolating estimates of guided or unguided numbers. Regression equations relating hourly variances with hourly sums were sometimes used to estimate missing variance estimates. Two spill bays ( 3 and 16) were not among those sampled and were interpolated from passage at the next open bay on either side to produce estimates for horizontal distribution figures.

\subsection{Detectability Modeling and Spatial Expansions}

The count of every fish (1) was expanded based upon the ratio of the opening width to beam diameter at the range of detection:

$$
E X P_{-} N U M=\frac{O W}{\left[M I D_{-} R \times T A N\left(\frac{E B A}{2}\right) \times 2\right]}
$$

where OW is opening width in $\mathrm{m}$, MID_R is the mid-point range of a trace in $\mathrm{m}$, TAN is the tangent, and EBA is effective beam angle in degrees.

Effective beam angle depends upon the detectability of fish of different sizes in the acoustic beam and is a function of nominal beam width, ping rate, trace criteria, and fish size, aspect, trajectory, velocity, and range. We modeled detectability for every transducer deployment to determine effective beam angle as a function of range from a transducer. We obtained target-strength estimates from the average backscattering cross section of fish detected by split-beam transducers and flow-velocity data by $1-\mathrm{m}$ depth strata from a physical or computational fluid design (CFD) model. These data and other hydroacousticacquisition data (e.g., beam tilt, ping rate, target-strength threshold, number of echoes, and maximum ping gaps) were entered into a detectability model. Inputs to the detectability model are presented in Tables 2.1 and 2.2. Model output consisted of effective beam angle as a function of range from a transducer. Polynomials fitted to those data were substituted for EBA in Equation 1 to correct for differences in detectability by range among transducers and locations.

Polynomial regressions were used to describe the relationships between predictions of effective beam angle with range from a transducer for every type of deployment. Those equations and passage width data were used to expand the count of each detected fish and to equalize detectability among sample ranges and deployments. The coding solved a deployment-specific polynomial equation for effective beam angle based upon the range of detection of each individual fish (Appendix F), calculated the corresponding beam diameter at the same range (Equation 1), and multiplied the fish's count (i.e., one) by 
the ratio of the passage width to the beam diameter. The polynomials presented in Appendix F can be used to generate the detectability curves. Sampling ranges that were used to solve for effective beam angle truncated the polynomial curves to appropriate ranges.

Table 2.1. Deployment-Specific Variables that Were Input to a Stochastic Detectability Model for Estimating Effective Beam Angle as a Function of Range from a Transducer. Constants were as follows: Blanking range $=1 \mathrm{~m}$; Target Strength threshold $=-56 \mathrm{~dB}$; Maximum ping gap $=2$. A negative tilt is upstream of vertical and a positive tilt is downstream.

\begin{tabular}{|c|c|c|c|c|c|c|c|}
\hline Deployment & $\begin{array}{l}-3 \mathrm{~dB} \\
\text { Beam } \\
\text { Angle }\end{array}$ & $\begin{array}{c}\text { Trans- } \\
\text { ducer Tilt } \\
\text { from } \\
\text { Vertical } \\
\text { (Degrees) }\end{array}$ & $\begin{array}{l}\text { Pings / } \\
\text { Second }\end{array}$ & $\begin{array}{c}\text { Mean } \\
\text { Target } \\
\text { Strength }\end{array}$ & $\begin{array}{c}\text { TS } \\
\text { Standard } \\
\text { Deviation }\end{array}$ & $\begin{array}{c}\text { Minimum } \\
\text { Echo } \\
\text { Count }\end{array}$ & $\begin{array}{l}\text { Maximum } \\
\text { Range }\end{array}$ \\
\hline & & & Spring & & & & \\
\hline $\begin{array}{l}\text { Units } 1-7,9, \& 10 \text { Down- } \\
\text { looking }\end{array}$ & 6 & 9 & 14 & -44.7 & 4.1 & 4 & 21 \\
\hline Units 1-7, 9, \& 10 Up-looking & 6 & 29 & 14 & -44.7 & 4.1 & 4 & 14 \\
\hline Unit 8 Down-looking & 6 & -25 & 14 & -44.7 & 4.1 & 4 & 13 \\
\hline Unit 8 Up-looking & 6 & 28 & 14 & -44.7 & 4.1 & 4 & 13 \\
\hline $\begin{array}{l}\text { Spill Bays } 2,5,6,7,8,10,14 \text {, } \\
\& 15 \text { Down-looking }\end{array}$ & 10 & -8 & 30 & -44.7 & 4.1 & 4 & 10 \\
\hline Spill Bays 4 \& 12 & 10 & -8 & 30 & -44.7 & 4.1 & 7 & 10 \\
\hline Spill Bay 17 Down-looking & 12 & -15 & 30 & -44.7 & 4.1 & 4 & 10 \\
\hline Units 11-18 Down-looking & 6 & 9 & 15 & -44.7 & 4.1 & 4 & 17 \\
\hline Units 11-18 Up-looking & 6 & 36 & 15 & -44.7 & 4.1 & 4 & 10 \\
\hline \multirow[t]{2}{*}{ Upstream of Intake $15 \underline{b}$} & 6 & $17,23,29$ & 14 & -44.7 & 4.1 & 4 & 31 \\
\hline & & & Summer & & & & \\
\hline $\begin{array}{l}\text { Units } 1-7,9, \& 10 \text { Down- } \\
\text { looking }\end{array}$ & 6 & 9 & 14 & -48 & 4.11 & 4 & 21 \\
\hline Units 1-7, 9, \& 10 Up-looking & 6 & 29 & 14 & -48 & 4.11 & 4 & 14 \\
\hline Unit 8 Down-looking & 6 & -25 & 14 & -48 & 4.11 & 4 & 13 \\
\hline Unit 8 Up-looking & 6 & 28 & 14 & -48 & 4.11 & 4 & 13 \\
\hline $\begin{array}{l}\text { Spill Bays 2, 5, 6, 7, 8, 10, 14, } \\
\& 15 \text { Down-looking }\end{array}$ & 10 & -8 & 30 & -48 & 4.11 & 4 & 10 \\
\hline Spill Bays 4 \& 12 & 10 & -8 & 30 & -48 & 4.11 & 7 & 10 \\
\hline Spill Bay 17 Down-looking & 12 & -15 & 30 & -48 & 4.11 & 4 & 10 \\
\hline Units 11-18 Down-looking & 6 & 9 & 15 & -48 & 4.11 & 4 & 17 \\
\hline Units 11-18 Up-looking & 6 & 36 & 15 & -48 & 4.11 & 4 & 10 \\
\hline Upstream of Intake $15 \underline{b}$ & 6 & $17,23,29$ & 14 & -48 & 4.11 & 4 & 31 \\
\hline
\end{tabular}


Table 2.2. Polynomial Inputs or Constants for the Detectability Model for Beam Patterns, Fish Trajectories, and Fish Speeds for Every Deployment

\begin{tabular}{|c|c|c|}
\hline Deployment & Variable & Polynomial or Constants \\
\hline Units 1-7 \& 9 & Beam Shape & $B=-.003330226586 X^{4}+.017471453954 X^{3}-.310142505527 X^{2}+.035753868397 X-.004849602465$ \\
\hline Down-looking & $\begin{array}{l}\text { Trajectory } \\
\text { Speed }\end{array}$ & $\begin{array}{l}\text { plunge }=.002373764589 X^{4}-.112735778158 X^{3}+1.56076075983 X^{2}-6.603395811676 X+36.885504201695 \\
m p s=.000018623951 X^{4}-.001270343248 X^{3}+.025384265243 X^{2}-.103042996658 X+.677731764708\end{array}$ \\
\hline Units $1-7 \& 9$ & Beam Shape & $\mathrm{B}=-.003330226586 \mathrm{X}^{4}+.017471453954 \mathrm{X}^{3}-.310142505527 \mathrm{X}^{2}+.035753868397 \mathrm{X}-.004849602465$ \\
\hline Up-looking & $\begin{array}{l}\text { Trajectory } \\
\text { Speed }\end{array}$ & $\begin{array}{l}\text { plunge }=-.000308771027 X^{4}+.001553540498 X^{3}+.275668020657 X^{2}-5.22697691328 X-4.1964285714 \\
m p s=.000000000001 X^{4}+.000291396396 X^{3}-.003501776837 X^{2}-.051568234978 X+1.362891428571\end{array}$ \\
\hline Unit 10 & Beam Shape & $B=-.00738221648 X^{4}+.040217634582 X^{3}-.404438802016 X^{2}+.036170817387 X-.00152995463$ \\
\hline Down-looking & $\begin{array}{l}\text { Trajectory } \\
\text { Speed }\end{array}$ & $\begin{array}{l}\text { plunge }=.002373764589 X^{4}-.112735778158 X^{3}+1.56076075983 X^{2}-6.603395811676 X+36.885504201695 \\
m p s=.000018623951 X^{4}-.001270343248 X^{3}+.025384265243 X^{2}-.103042996658 X+.677731764708\end{array}$ \\
\hline Unit 10 & Beam Shape & $B=-.00738221648 X^{4}+.040217634582 X^{3}-.404438802016 X^{2}+.036170817387 X-.00152995463$ \\
\hline Up-looking & \begin{tabular}{|l} 
Trajectory \\
Speed
\end{tabular} & $\begin{array}{l}\text { plunge }=-.000308771027 X^{4}+.001553540498 X^{3}+.275668020657 X^{2}-5.22697691328 X-4.1964285714 \\
\text { mps }=.000000000001 X^{4}+.000291396396 X^{3}-.003501776837 X^{2}-.051568234978 X+1.362891428571\end{array}$ \\
\hline Unit 8 Down-looking & $\begin{array}{l}\text { Beam Shape } \\
\text { Trajectory } \\
\text { Speed }\end{array}$ & $\begin{array}{l}B=-.003330226586 X^{4}+.017471453954 X^{3}-.310142606627 X^{2}+.035753868397 X-.004849601465 \\
\text { plunge }=-.000086076347 X^{4}+.016096619208 X^{3}-.667377525502 X^{2}+10.273234879192 X-56.813249624336 \\
m p s=-.000607 X^{3}+.0388228 X^{2}-.201837 X+.8758629\end{array}$ \\
\hline Unit 8 Up-looking & $\begin{array}{l}\text { Beam Shape } \\
\text { Trajectory } \\
\text { Speed }\end{array}$ & $\begin{array}{l}B=-.003330226586 X^{4}+.017471453954 X^{3}-.310142606627 X^{2}+.035753868397 X-.004849601465 \\
\text { plunge }=-28 \\
m p s=.000018340049 X^{4}-.001702427407 X^{3}+.04529765004 X^{2}-.435040205779 X+2.2606\end{array}$ \\
\hline Spill Bays 4 \& 12 & Beam Shape & $B=-.000479254381 X^{4}+.005816071612 X^{3}-.17653166225 X^{2}+.108057677967 X-.001573760223$ \\
\hline Down-looking & \begin{tabular}{|l} 
Trajectory \\
Speed
\end{tabular} & $\begin{array}{l}\text { plunge }=-.08224067599 X^{4}+2.06132672882 X^{3}-17.20578942702 X^{2}+60.665036907455 X-110.10999999990 \\
\text { mps }=-.000528205128 X^{4}+.010511771562 X^{3}-.06068467366 X^{2}+.517001107226 X+.5129833333279999\end{array}$ \\
\hline $\begin{array}{l}\text { Spill Bays } 2,5,6,7,8,10 \\
14, \& 15 \\
\text { Down-looking }\end{array}$ & \begin{tabular}{|l} 
Beam Shape \\
Trajectory \\
Speed
\end{tabular} & $\begin{array}{l}\mathrm{B}=-.000479254381 X^{4}+.005816071612 X^{3}-.17653166225 X^{2}+.108057677967 X-.001573760223 \\
\text { plunge }=-.08224067599 X^{4}+2.06132672882 X^{3}-17.20578942702 X^{2}+60.665036907455 X-110.10999999990 \\
m p s=-.000528205128 X^{4}+.010511771562 X^{3}-.06068467366 X^{2}+.517001107226 X+.5129833333279999\end{array}$ \\
\hline Spill Bay 17 Down-looking & $\begin{array}{l}\text { Beam Shape } \\
\text { Trajectory } \\
\text { Speed }\end{array}$ & $\begin{array}{l}\mathrm{B}=.0003634 \mathrm{X}^{4}-.006977 \mathrm{X}^{3}-.031845 \mathrm{X}^{2}-.012959 \mathrm{X}-.005818 \\
\text { plunge }=-.08224067599 \mathrm{X}^{4}+2.06132672882 \mathrm{X}^{3}-17.20578942702 \mathrm{X}^{2}+60.665036907455 \mathrm{X}-110.10999999990 \\
\mathrm{mps}=-.000528205128 \mathrm{X}^{4}+.010511771562 \mathrm{X}^{3}-.06068467366 \mathrm{X}^{2}+.517001107226 \mathrm{X}+.5129833333279999\end{array}$ \\
\hline Units 11-18 Down-looking & $\begin{array}{l}\text { Beam Shape } \\
\text { Trajectory } \\
\text { Speed } \\
\end{array}$ & $\begin{array}{l}\mathrm{B}=-.003330226586 \mathrm{X}^{4}+.017471453954 \mathrm{X}^{3}-.310142505527 \mathrm{X}^{2}+.035753868397 \mathrm{X}-.004849601465 \\
\text { plunge }=-.003360361183 \mathrm{X}^{4}+.145723292012 \mathrm{X}^{3}-2.010411084854 \mathrm{X}^{2}+7.381654309909 \mathrm{X}+26.672858617129 \\
\mathrm{mps}=.000049630032 \mathrm{X}^{4}-.001581448873 \mathrm{X}^{3}+.012092068792 X^{2}+.071453243301 X+.81122724458\end{array}$ \\
\hline Units 11-18 Up-looking & \begin{tabular}{|l} 
Beam Shape \\
Trajectory \\
Speed
\end{tabular} & $\begin{array}{l}B=-.003330226586 X^{4}+.017471453954 X^{3}-.310142505527 X^{2}+.035753868397 X-.004849601465 \\
\text { plunge }=-26 \\
m p s=-.000499129625 X^{4}+.010107508945 X^{3}-.072403499059 X^{2}+.194463002585 X+1.254298181816\end{array}$ \\
\hline Upstream of Intake 15b & \begin{tabular}{|l} 
Beam Shape \\
Trajectory \\
Speed
\end{tabular} & $\begin{array}{l}\mathrm{B}=.011170692053 \mathrm{X}^{4}-.158786483125 \mathrm{X}^{3}+.231914384635 \mathrm{X}^{2}-.5101118323179999 \mathrm{X}+.056466461582 \\
\text { plunge }=-.0004 \mathrm{X}^{4}+.0183 \mathrm{X}^{3}-.2178 \mathrm{X}^{2}+.2152 \mathrm{X}+20.969 \\
\mathrm{mps}=1.5\end{array}$ \\
\hline
\end{tabular}


Hydroacoustic Evaluation of FPE at Bonneville Dam in 2001 


\subsection{Estimating Fish Passage}

This section describes in detail the estimation of fish passage at Powerhouses 1 and 2 and the spillway at Bonneville Dam in 2001. These estimates of passage will be used in subsequent measures of fish passage performance. Within every hour, we sampled 12 to 30 minutes systematically depending upon location, and we assumed that these systematic samples would behave as if they were simple random samples. This approach should overestimate the variance. We also estimated and added the variation among two or more turbine units to the temporal variation of each unit to make a conservative estimate of spatial variation resulting from sampling one of three intakes per turbine unit.

Confidence intervals for individual intakes or spill bays were calculated as 1.96 times the square root of temporal variance estimate for the time frame of interest (day, week, or season). The following subsections describe procedures for estimating temporal variances in fish passage through individual intakes and spill bays as first steps for estimating the variance for strata of intakes or bays or for each powerhouse and the spillway.

\subsubsection{Powerhouse 1 Unguided Passage}

The sampling at Powerhouse 1 can be viewed as a two-stage sampling scheme. The first stage is the sampling of intake slots within a stratum composed of neighboring turbine units that were operating simultaneously. Typically, two consecutive turbine units would be grouped together to form a stratum, and it would be assumed that two of six intake slots were randomly selected for monitoring. However, the low-flow conditions of 2001 resulted in an unexpected and irregular pattern of turbine use. In many instances, the closure of a turbine unit would result in some strata no longer having the within-strata replication needed for variance estimation.

The proposed solution to the dilemma imposed by the dam operations in 2001 is to post-stratify the operational turbine units into strata according to their proximity to one another. The re-stratification at times is somewhat arbitrary, because there is no single unique way to group the locales. Priority would be given to grouping locations into the most proximal sets of locations while retaining the ability to calculate the spatial sampling variances. The resulting variance estimates can generally be considered conservative, for they often include more between-intake variance than expected under the original sampling design.

Based on load demands and equipment use, the number and location of operational turbine units varied over time. Table 2.3 below illustrates some of the turbine unit configurations observed in 2001 and the subsequent post-stratification used in the data analyses for Powerhouse 1. 
Table 2.3. Stratification Scheme for Estimating among Intake Variance Components at Powerhouse 1

\begin{tabular}{|c|c|c|c|c|c|c|c|c|c|c|c|c|}
\hline \multicolumn{10}{|c|}{ Possible Loading/Units Operations } & \multicolumn{3}{|c|}{ Stratification } \\
\hline 1 & 2 & 3 & 4 & 5 & 6 & 7 & 8 & 9 & 10 & Stratum \#1 & Stratum \#2 & Stratum \#3 \\
\hline 1 & 2 & 3 & & & & 7 & & & 10 & $1,2,3$ & 7,10 & \\
\hline 1 & & & & & & & & & 10 & 1,10 & & \\
\hline 1 & 2 & & & & & & & & 10 & $1,2,10$ & & \\
\hline 1 & 2 & 3 & & & & & & & 10 & 1,2 & 3,10 & \\
\hline 1 & 2 & 3 & & 5 & & 7 & & & 10 & 1,2 & 3,5 & 7,10 \\
\hline 1 & 2 & 3 & & 5 & 6 & 7 & & & 10 & $1,2,3$ & 5,6 & 7,10 \\
\hline & & & & & & & & & 10 & 10 & & \\
\hline
\end{tabular}

Hence, the number of strata and sampling effort within strata varied over time.

The unguided fish passage at Powerhouse 1(TU) will be estimated by the quantity

$$
\widehat{T U}=\sum_{i=1}^{D} \sum_{j=1}^{23} \sum_{k=1}^{K_{i j}}\left[\frac{A_{i j k}}{a_{i j k}}\left[\sum_{l=1}^{a_{i j k}} \widehat{T U}_{i j k l}\right]\right]
$$

where

$\widehat{T U}_{i j k l}=$ estimated fish passage in the lth intake slot $\left(l=1, \ldots, a_{i j k}\right)$ within the kth turbine stratum $\left(k=1, \ldots K_{i j}\right)$ during the $\mathrm{jth}$ hour $(j=1, \ldots, 24)$ on the ith day $(i=1, \ldots, D)$;

$a_{i j k}=$ number of intake slots actually sampled in the kth turbine stratum $\left(k=1, \ldots K_{i j}\right)$ during the jth hour $(j=1, \ldots, 24)$ on the ith day $(i=1, \ldots, D)$;

$A_{i j k}=$ total number of intake slots within the kth turbine stratum $\left(k=1, \ldots K_{i j}\right)$ during the $\mathrm{jth}$ hour $(j=1, \ldots, 24)$ on the ith day $(i=1, \ldots, D)$;

$K_{i j}=$ number of turbine strata created during the $j$ th hour $(j=1, \ldots, 24)$ on the ith day $(i=1, \ldots, D)$.

Because of the varying power loads over time, the number of spatial strata (i.e., $K_{i j}$ ) formed by poststratification of adjacent turbine units may vary between hours $(j=1, \ldots, 24)$ and days $(i=1, \ldots, D)$.

The estimate of $\widehat{T U}_{i j k l}$ is based on the assumption of simple random sampling within a slot-hour, in which case

$$
\widehat{T U}_{i j k l}=\frac{B_{i j k l}}{b_{i j k l}} \sum_{g=1}^{b_{i j k l}} z_{i j k l g} .
$$

Combining Equations (1) and (2), the overall estimate of unguided fish passage at Powerhouse 1 during D days can be expressed as

$$
\widehat{T U}=\sum_{i=1}^{D} \sum_{j=1}^{23} \sum_{k=1}^{K_{i j}}\left[\frac{A_{i j k}}{a_{i j k}}\left[\frac{B_{i j k l}}{b_{i j k l}} \sum_{g=1}^{b_{i j k l}} z_{i j k l g}\right]\right]
$$

where 
$z_{i j k l g}=$ expanded fish count in the gth sampling unit $\left(g=1, \ldots, b_{i j k l}\right)$ in the lth intake slot $\left(l=1, \ldots, a_{i j k}\right)$ within the kth turbine stratum $\left(k=1, \ldots K_{i j}\right)$ during the $\mathrm{jth}$ hour $(j=1, \ldots, 23)$ on the ith day $(i=1, \ldots, D)$;

$b_{i j k l}=$ number of sampling units actually observed in the lth intake slot $\left(l=1, \ldots, a_{i j k}\right)$ within the kth turbine stratum $\left(k=1, \ldots K_{i j}\right)$ during the $j$ th hour $(j=1, \ldots, 23)$ on the ith day $(i=1, \ldots, D)$;

$B_{i j k l}=$ total number of sampling units within the lth intake slot $\left(l=1, \ldots, a_{i j k}\right)$ within the kth turbine stratum $\left(k=1, \ldots K_{i j}\right)$ during the $j$ th hour $(j=1, \ldots, 23)$ on the ith day $(i=1, \ldots, D)$.

Nominally, $B_{i j k l}=60 \forall i j k l$ and $b_{i j k l}=15$ or 20, depending on location. Based on the assumption of simple random sampling

$\widehat{\operatorname{Var}}\left(\widehat{T U}_{i j k l}\right)=\frac{B_{i j k l}^{2}\left(1-\frac{b_{i j k l}}{B_{i j k l}}\right) s_{z_{i j k l}^{2}}^{2}}{b_{i j k l}}$

where

$$
\begin{aligned}
& s_{z_{i j k l}^{2}}^{2}=\frac{\sum_{g=1}^{b_{i j k l}}\left(z_{i j k l g}-\overline{z_{i j k l}}\right)^{2}}{\left(b_{i j k l}-1\right)} \quad \text { and where } \\
& \overline{z_{i j k l}}=\frac{1}{b_{i j k l}} \sum_{g=1}^{b_{i j k l}} z_{i j k l g} .
\end{aligned}
$$

The variance of $\widehat{T U}$ can then be extended by the formula

$$
\widehat{\operatorname{Var}}(\widehat{T U})=\sum_{i=1}^{D} \sum_{j=1}^{24} \sum_{k=1}^{K_{i j}}\left[\frac{A_{i j k}^{2}\left(1-\frac{a_{i j k}}{A_{i j k}}\right) s_{\widehat{T U}_{i j k}}^{2}}{a_{i j k}}+\frac{A_{i j k l} \sum_{l=1}^{a_{i j k}} \widehat{\operatorname{Var}}\left(\widehat{T U}_{i j k l}\right)}{a_{i j k}}\right]
$$

where

$$
\begin{aligned}
& s_{\widehat{T U}_{i j k}}^{2}=\frac{\sum_{l=1}^{a_{i j k}}\left(\widehat{T U}_{i j k l}-\widehat{T U}_{i j k}\right)^{2}}{\left(a_{i j k}-1\right)}, \\
& \widehat{T U}_{i j k}=\frac{1}{a_{i j k}} \sum_{l=1}^{a_{i j k}} \widehat{T U}_{i j k l} .
\end{aligned}
$$

\subsubsection{Powerhouse 1 Guided Passage}


The post-stratification used in estimating unguided passage at Powerhouse 1 is the same as used to estimate guided passage at Powerhouse 1. Hence, the estimator for guided fish passage at Powerhouse 1 can be written as

$$
\widehat{T G}=\sum_{i=1}^{D} \sum_{j=1}^{23} \sum_{k=1}^{K_{i j}}\left[\frac{A_{i j k}}{a_{i j k}}\left[\frac{B_{i j k l}}{b_{i j k l}} \sum_{g=1}^{b_{i j k l}} y_{i j k l g}\right]\right]
$$

where

$y_{i j k l g}=$ expanded fish passage in the gth sampling unit $\left(g=1, \ldots, b_{i j k l}\right)$ in the lth intake slot $\left(l=1, \ldots, a_{i j k}\right)$ within the kth turbine stratum $\left(k=1, \ldots K_{i j}\right)$ during the $\mathrm{jth}$ hour $(j=1, \ldots, 23)$ on the ith day $(i=1, \ldots, D)$.

The estimated variance of $\widehat{T G}$ can then be expressed as

$$
\widehat{\operatorname{Var}}(\widehat{T G})=\sum_{i=1}^{D} \sum_{j=1}^{24} \sum_{k=1}^{K_{i j}}\left[\frac{A_{i j k}^{2}\left(1-\frac{a_{i j k}}{A_{i j k}}\right) s_{\widehat{T G}_{i j k}}^{2}}{a_{i j k}}+\frac{A_{i j k l} \sum_{l=1}^{a_{i j k}} \widehat{\operatorname{Var}}\left(\widehat{T G}_{i j k l}\right)}{a_{i j k}}\right]
$$

where

$$
\begin{aligned}
\widehat{\operatorname{Var}}\left(\widehat{T G}_{i j k l}\right) & =\frac{B_{i j k l}^{2}\left(1-\frac{b_{i j k l}}{B_{i j k l}}\right) s_{y_{i j k l}^{2}}^{2}}{b_{i j k l}}, \\
s_{y_{i j k l}}^{2} & =\frac{\sum_{g=1}^{b_{i j k l}}\left(y_{i j k l g}-\bar{y}_{i j k l}\right)^{2}}{\left(b_{i j k l}-1\right)}, \\
\bar{y}_{i j k l} & =\frac{1}{b_{i j k l}} \sum_{g=1}^{b_{i j k l}} y_{i j k l g},
\end{aligned}
$$

and where

$$
\begin{aligned}
& s_{\widehat{T G}_{i j k}^{2}}=\frac{\sum_{l=1}^{a_{i j k}}\left(\widehat{T G}_{i j k l}-\widehat{T G}_{i j k}\right)^{2}}{\left(a_{i j k}-1\right)}, \\
& \widehat{T G}_{i j k}=\frac{1}{a_{i j k}} \sum_{l=1}^{a_{i j k}} \widehat{T G}_{i j k l} .
\end{aligned}
$$

Because the $z_{i j k l g}$ and the $y_{i j k l g}$ within a turbine intake are measured simultaneously, they are correlated as will be the estimators $\widehat{T U}$ and $\widehat{T G}$. The covariances between $\widehat{T G}$ and $\widehat{T U}$ can then be estimated by the quantity 


$$
\widehat{\operatorname{Cov}}(\widehat{T U}, \widehat{T G})=\sum_{i=1}^{D} \sum_{j=1}^{23} \sum_{k=1}^{K_{i j}}\left[\frac{A_{i j k}^{2}\left(1-\frac{a_{i j k}}{A_{i j k}}\right) \widehat{\operatorname{Cov}}\left(\widehat{T U}_{i j k}, \widehat{T G}_{i j k}\right)}{a_{i j k}}+\frac{A_{i j k l} \sum_{l=1}^{a_{i j k}} \widehat{\operatorname{Cov}}\left(\widehat{T U}_{i j k l}, \widehat{T G}_{i j k l}\right)}{a_{i j k}}\right]
$$

where

$$
\widehat{\operatorname{Cov}}\left(\widehat{T U}_{i j k}, \widehat{T G}_{i j k}\right)=\frac{\sum_{l=1}^{a_{i j k}}\left(\widehat{T U}_{i j k l}-\widehat{T U}_{i j k l}\right)\left(\widehat{T G}_{i j k l}-\widehat{T G}_{i j k l}\right)}{\left(a_{i j k}-1\right)}
$$

and where

$$
\widehat{\operatorname{Cov}}\left(\widehat{T U}_{i j k l}, \widehat{T G}_{i j k l}\right)=\frac{B_{i j k l}^{2}\left(1-\frac{b_{i j k l}}{B_{i j k l}}\right) \operatorname{Cov}\left(z_{i j k l g}, y_{i j k l g}\right)}{b_{i j k l}}
$$

and where

$$
\operatorname{Cov}\left(z_{i j k l g}, y_{i j k l g}\right)=\frac{\sum_{g=1}^{b_{i j k}}\left(z_{i j k l g}-\bar{z}_{i j k l}\right)\left(y_{i j k l g}-\bar{y}_{i j k l}\right)}{\left(b_{i j k l}-1\right)} .
$$

\subsubsection{Spillway Passage}

During spring 2001, hydroacoustic transducers were placed in spill bays $2,4,5,6,7,8,10,12,14,15$, and 17. In practice, only spill bays $2,3,4,6,10,12,16$, and 17 were operated for spill at various times during the study because of drought conditions. We classified spillway sampling into four spill-bay strata (Table 2.4).

Table 2.4. Groups of Spill bays Selected to Form Strata for Calculating Spill Passage and Variances

\begin{tabular}{|c|c|c|c|c||}
\hline Stratum & Spill bays & No. of Bays & No. Monitored & Sampling Fraction \\
\hline 1 & $2,3,4$ & 3 & 2 & $2 / 3$ \\
\hline 2 & 6 & 1 & 1 & 1.0 \\
\hline 3 & 10 & 1 & 1 & 1.0 \\
\hline 4 & $12,16,17$ & 3 & 3 & $2 / 3$ \\
\hline
\end{tabular}

Hence, the sampling at the Bonneville spillway was designed as a stratified two-stage sampling regime. The first stage of sampling was the selection of spill bays within the spatial strata. In two of the four strata (i.e., 2 and 3), the first-stage sampling of spill bays was 100\%. The second stage of sampling was a random sample of time intervals within a spill-bay hour.

Total spillway passage was estimated by the formula 


$$
\hat{S}=\sum_{g=1}^{4}\left[\frac{H_{g}}{h_{g}} \sum_{i=1}^{h_{g}} \sum_{j=1}^{D} \sum_{k=1}^{23} \frac{T_{g i j k}}{t_{g i j k}} \sum_{l=1}^{t_{g i k}} p_{g i j k l}\right]
$$

where

$$
p_{g i j k l}=\text { expanded fish passage in the lth sampling interval }\left(l=1, \ldots, t_{g i k}\right) \text { during the kth hour }
$$

$(k=1, \ldots, 23)$ in the $\mathrm{jth}$ day $(j=1, \ldots, D)$ at the ith spill bay $\left(i=1, \ldots, h_{g}\right)$ in the gth stratum

$(g=1, \ldots, 4)$;

$T_{g i j k}=$ possible number of sampling units within an hour (i.e., nominally $T_{g i j k}=60$ );

$t_{g i j k}=$ actual number of samples drawn within the kth hour $(k=1, \ldots, 23)$ in the jth day $(j=1, \ldots, D)$ at the ith spill bay $\left(i=1, \ldots, h_{g}\right)$ in the gth stratum $(g=1, \ldots, 4)$ (i.e., nominally $t_{g i j k}=10$ or 12$)$;

$H_{g}=$ number of operating (open) spill bays within the gth spillway stratum;

$h_{g}=$ number of operating (open) spill bays actually sampled within the gth spillway stratum.

The variance of $\hat{S}$ was estimated by the quantity

$$
\widehat{\operatorname{Var}}(\hat{S})=\sum_{g=1}^{4} \frac{H_{g}^{2}\left(1-\frac{h_{g}}{H_{g}}\right) S_{\hat{S}_{g}}^{2}}{h_{g}}+\sum_{g=1}^{4}\left[\frac{H_{g} \sum_{j=1}^{h_{g}} \widehat{\operatorname{Var}}\left(\hat{S}_{g i}\right)}{h_{g}}\right]
$$

where

$$
\begin{gathered}
s_{\hat{S}_{g}}^{2}=\frac{\sum_{j=1}^{h_{g}}\left(\hat{S}_{g_{i}}-\hat{\bar{S}}_{g}\right)^{2}}{\left(h_{g}-1\right)}, \\
\hat{\bar{S}}_{g}=\frac{\sum_{i=1}^{h_{g}} \hat{S}_{g_{i}}}{h_{g}}, \\
\hat{S}_{g_{i}}=\sum_{j=1}^{D} \sum_{k=1}^{23} \frac{T_{g i j k}}{t_{g i j k}} \sum_{l=1}^{t_{g i j k}} p_{g i j k l},
\end{gathered}
$$

and where 


$$
\begin{aligned}
\operatorname{Var}\left(\hat{S}_{g_{i}}\right) & =\sum_{j=1}^{D} \sum_{k=1}^{23}\left[T_{g i j k}^{2}\left(1-\frac{t_{g i j k}}{T_{g i j k}}\right) \frac{s_{p_{g i j k}}^{2}}{t_{g i j k}}\right], \\
s_{p_{g j k}}^{2} & =\frac{\sum_{l=1}^{t_{g i j k}}\left(p_{g i j k l}-\overline{p_{g i j k}}\right)^{2}}{\left(t_{g i j k}-1\right)}, \\
\bar{p}_{g i j k} & =\frac{\sum_{l=1}^{t_{g i j k}} p_{g i j k l}}{t_{g i j k}} .
\end{aligned}
$$

Note for strata 2 and 3, $H_{g}=h_{g}$ and the first term in Equation (10) goes to zero.

\subsubsection{Powerhouse 2 Unguided Passage}

The same two-stage sampling scheme used to estimate fish passage at Powerhouse 1 was used to estimate fish passage at Powerhouse 2, units 11 through 18. Nominally, two consecutive turbine units (e.g., 11-12, 13-14, ...) were combined to form a stratum with 2 or 6 intake slots selected for monitoring. In reality, a single intake slot among the three within a turbine intake were randomly selected. Very occasionally, unit shutdowns because of load demands required further post-stratification to ensure within-stratum replication of turbine slots. Under these circumstances, the turbine units at Powerhouse 2 were grouped into three or fewer strata. To accommodate all circumstances, the estimators and variances will be expressed generically.

Using the fish counts from the down-looking transducers, total unguided fish passage at Powerhouse 2 was estimated by the quantity

$$
\widehat{H U}=\sum_{i=1}^{D} \sum_{j=1}^{23} \sum_{k=1}^{K_{i j}}\left[\frac{C_{i j k}}{c_{i j k}}\left[\frac{D_{i j k l}}{d_{i j k l}} \sum_{g=1}^{d_{i j k l}} x_{i j k l g}\right]\right]
$$

where

$x_{i j k l g}=$ expanded fish passage in the gth sampling unit $\left(g=1, \ldots, b_{i j k l}\right)$ in the lth intake slot $\left(l=1, \ldots, a_{i j k}\right)$ within the kth turbine stratum $\left(k=1, \ldots K_{i j}\right)$ during the $\mathrm{jth}$ hour $(j=1, \ldots, 23)$ on the ith day $(i=1, \ldots, D)$;

$d_{i j k l}=$ number of sampling units actually observed in the lth intake slot $\left(l=1, \ldots, a_{i j k}\right)$ within the kth turbine stratum $\left(k=1, \ldots K_{i j}\right)$ during the $j$ th hour $(j=1, \ldots, 23)$ on the ith day $(i=1, \ldots, D)$;

$D_{i j k l}=$ total number of sampling units within the lth intake slot $\left(l=1, \ldots, a_{i j k}\right)$ within the kth turbine stratum $\left(k=1, \ldots K_{i j}\right)$ during the $j$ th hour $(j=1, \ldots, 23)$ on the ith day $(i=1, \ldots, D)$;

$c_{i j k}=$ number of intake slots actually sampled in the kth turbine stratum $\left(k=1, \ldots K_{i j}\right)$ during the jth hour $(j=1, \ldots, 23)$ on the ith day $(i=1, \ldots, D)$; 
$C_{i j k}=$ total number of intake slots within the kth turbine stratum $\left(k=1, \ldots K_{i j}\right)$ during the $\mathrm{jth}$ hour $(j=1, \ldots, 23)$ on the ith day $(i=1, \ldots, D)$;

$K_{i j}=$ number of turbine strata created during the $\mathrm{jth}$ hour $(j=1, \ldots, 23)$ on the ith day $(i=1, \ldots, D)$.

Nominally, $K_{i j}=4 \forall i j, C_{i j k}=6 \forall i j k, c_{i j k}=2 \forall_{i j k}$, and $D_{i j k l}=60 \forall i j k l$. Depending on location, $d_{i j k l}=15$ or 20 .

The variance of $\widehat{H U}$ can then be estimated by the formula

$$
\widehat{\operatorname{Var}}(\widehat{H U})=\sum_{i=1}^{D} \sum_{j=1}^{23} \sum_{k=1}^{K_{i j}}\left[\frac{C_{i j k}^{2}\left(1-\frac{c_{i j k}}{C_{i j k}}\right) s_{\widehat{H U}_{i j k}^{2}}^{2}}{c_{i j k}}+\frac{C_{i j k l} \sum_{l=1}^{c_{i j k}} \widehat{\operatorname{Var}}\left(\widehat{H U}_{i j k l}\right)}{c_{i j k}}\right]
$$

where

$$
\begin{aligned}
\widehat{\operatorname{Var}}\left(\widehat{H U}_{i j k l}\right) & =\frac{D_{i j k l}^{2}\left(1-\frac{d_{i j k l}}{D_{i j k l}}\right) s_{i j k l}^{2}}{d_{i j k l}}, \\
s_{x_{j k l}}^{2} & =\frac{\sum_{g=1}^{d_{i j k l}}\left(x_{i j k l g}-\bar{x}_{i j k l}\right)^{2}}{\left(d_{i j k l}-1\right)}, \\
\bar{x}_{i j k l} & =\frac{1}{d_{i j k l}} \sum_{g=1}^{d_{i j k l}} x_{i j k l g},
\end{aligned}
$$

and where

$$
\begin{aligned}
& s_{\widehat{H U}_{i j k}^{2}}=\frac{\sum_{l=1}^{a_{i j k}}\left(\widehat{H U}_{i j k l}-\widehat{H U}_{i j k}\right)^{2}}{\left(a_{i j k}-1\right)}, \\
& \widehat{H U}_{i j k}=\frac{1}{a_{i j k}} \sum_{l=1}^{a_{i j k}} \widehat{H U}_{i j k l} .
\end{aligned}
$$

\subsubsection{Powerhouse 2 Guided Passage}

The same two-stage sampling scheme used to estimate unguided passage (HU) at Powerhouse 2 is used to simultaneously sample guided passage (HG) at Powerhouse 2. Hence, the estimator for guided fish passage at Powerhouse 2 can be written as

$$
\widehat{H G}=\sum_{i=1}^{D} \sum_{j=1}^{23} \sum_{k=1}^{K_{i j}}\left[\frac{C_{i j k}}{c_{i j k}}\left[\frac{D_{i j k l}}{d_{i j k l}} \sum_{g=1}^{d_{i j k l}} w_{i j k l g}\right]\right]
$$

where 
$w_{i j k l g}=$ expanded fish passage in the gth sampling unit $\left(g=1, \ldots, b_{i j k l}\right)$ in the lth intake slot $\left(l=1, \ldots, a_{i j k}\right)$ within the kth turbine stratum $\left(k=1, \ldots K_{i j}\right)$ during the $\mathrm{jth}$ hour $(j=1, \ldots, 23)$ on the ith day $(i=1, \ldots, D)$.

The estimated variance of $\widehat{H G}$ can then be expressed as

$$
\widehat{\operatorname{Var}}(\widehat{H G})=\sum_{i=1}^{D} \sum_{j=1}^{23} \sum_{k=1}^{K_{i j}}\left[\frac{C_{i j k}^{2}\left(1-\frac{c_{i j k}}{C_{i j k}}\right) s_{\widehat{H G}_{i j k}}^{2}}{c_{i j k}}+\frac{C_{i j k l} \sum_{l=1}^{c_{i j k}} \widehat{\operatorname{Var}}\left(\widehat{H G}_{i j k l}\right)}{c_{i j k}}\right]
$$

where

$$
\begin{aligned}
\widehat{\operatorname{Var}}\left(\widehat{H G}_{i j k l}\right) & =\frac{D_{i j k l}^{2}\left(1-\frac{d_{i j k l}}{D_{i j k l}}\right) s_{w_{i j k l}^{2}}^{2}}{d_{i j k l}}, \\
s_{w_{i j k l}}^{2} & =\frac{\sum_{g=1}^{d_{i j k l}}\left(w_{i j k l g}-\bar{w}_{i j k l}\right)^{2}}{\left(d_{i j k l}-1\right)}, \\
\bar{w}_{i j k l} & =\frac{1}{d_{i j k l}} \sum_{g=1}^{d_{i j k l}} w_{i j k l g},
\end{aligned}
$$

and where

$$
\begin{aligned}
& s_{\widehat{H G}_{i j k}^{2}}=\frac{\sum_{l=1}^{c_{i j k}}\left(\widehat{H G}_{i j k l}-\widehat{H G}_{i j k}\right)^{2}}{\left(c_{i j k}-1\right)}, \\
& \widehat{H G}_{i j k}=\frac{1}{c_{i j k}} \sum_{l=1}^{c_{i j k}} \widehat{H G}_{i j k l} .
\end{aligned}
$$

The response variables $x_{i j k l g}$ and $w_{i j k l g}$ are measured simultaneously in the same water volume by the fast multiplex transducers and, as such, are correlated. Hence, the estimates of fish passage $\widehat{H U}$ and $\widehat{H G}$ for Powerhouse 2 are correlated. Their covariance can be estimated by the quantity

$$
\widehat{\operatorname{Cov}}(\widehat{H U}, \widehat{H G})=\sum_{i=1}^{D} \sum_{j=1}^{23} \sum_{k=1}^{K_{i j}}\left[\frac{C_{i j k}^{2}\left(1-\frac{c_{i j k}}{C_{i j k}}\right) \widehat{\operatorname{Cov}}\left(\widehat{H U}_{i j k}, \widehat{H G}_{i j k}\right)}{c_{i j k}}+\frac{C_{i j k l} \sum_{l=1}^{c_{i j k}} \widehat{\operatorname{Cov}}\left(\widehat{H U}_{i j k l}, \widehat{H G}_{i j k l}\right)}{c_{i j k}}\right]
$$

where 


$$
\widehat{\operatorname{Cov}}\left(\widehat{H U}_{i j k}, \widehat{H G}_{i j k}\right)=\frac{\sum_{l=1}^{c_{i j k}}\left(\widehat{H U}_{i j k l}-\widehat{H U}_{i j k}\right)\left(\widehat{H G}_{i j k l}-\widehat{H G}_{i j k}\right)}{\left(c_{i j k}-1\right)}
$$

and where

$$
\begin{gathered}
\widehat{\operatorname{Cov}}\left(\widehat{H U}_{i j k l}, \widehat{H G}_{i j k l}\right)=\frac{D_{i j k l}^{2}\left(1-\frac{d_{i j k l}}{D_{i j k l}}\right) \widehat{\operatorname{Cov}}\left(x_{i j k l g}, w_{i j k l g}\right)}{d_{i j k l}}, \\
\widehat{\operatorname{Cov}}\left(x_{i j k l g}, w_{i j k l g}\right)=\frac{\sum_{g=1}^{d_{i j k l}}\left(x_{i j k l g}-\bar{x}_{i j k l}\right)\left(w_{i j k l g}-\bar{w}_{i j k l}\right)}{\left(d_{i j k l}-1\right)} .
\end{gathered}
$$

It should be noted that formulas (5), (7), and (8) for Powerhouse 1 are analogous to formulas (12), (13), and (14) for Powerhouse 2. The estimators $\widehat{T U}$ and $\widehat{T G}$ are also analogous to the estimators $\widehat{H U}$ and $\widehat{H G}$, respectively.

\subsection{Estimating Passage Performance}

Estimates of fish passage through the powerhouses and the spillway will be used to estimate measures of project-wide passage performance. This section presents the estimators and associated variance estimators.

\subsubsection{Spill Efficiency (SY)}

The spill efficiency at the Bonneville Project was estimated by the quotient

$$
\widehat{S Y}=\frac{\hat{S}}{[\widehat{T U}+\widehat{T G}+\widehat{H U}+\widehat{H G}+\hat{S}]}=\frac{\hat{S}}{\widehat{N S}+\hat{S}}
$$

where the numerator is the estimated spill-bay passage and the denominator is total project passage. The variance of $\widehat{S E}$ was estimated by

$$
\widehat{\operatorname{Var}}(\widehat{S Y})=\widehat{S Y}^{2}(1-\widehat{S Y})^{2}\left[\frac{\widehat{\operatorname{Var}}(\hat{S})}{\hat{S}^{2}}+\frac{\widehat{\operatorname{Var}}(\widehat{N S})}{\widehat{N S}^{2}}\right]
$$

where

$$
\widehat{N S}=\widehat{T U}+\widehat{T G}+\widehat{H U}+\widehat{H G}
$$

and where

$$
\begin{aligned}
\widehat{\operatorname{Var}}(\widehat{N S})= & \widehat{\operatorname{Var}}(\widehat{T U})+\widehat{\operatorname{Var}}(\widehat{T G})+\widehat{\operatorname{Var}}(\widehat{H U})+\widehat{\operatorname{Var}}(\widehat{H G})+2 \widehat{\operatorname{Cov}}(\widehat{T U}, \widehat{T G}) \\
& +2 \widehat{\operatorname{Cov}}(\widehat{H U}, \widehat{H G}) .
\end{aligned}
$$




\subsubsection{Spill Effectiveness (SE)}

The spill effectiveness at the Bonneville Project was estimated by the quantity

$$
\widehat{S E}=\frac{\left(\frac{\hat{S}}{V_{S}}\right)}{\frac{(\widehat{N S}+\hat{S})}{V_{T}}}=\widehat{S Y} \cdot \frac{V_{T}}{V_{S}}
$$

Where

$$
V_{S}=\text { volume of water spilled, }
$$

$V_{T}=$ total volume of water passing the dam during the period of inference.

The variance of $\widehat{S E}$ can be estimated by

$$
\widehat{\operatorname{Var}}(\widehat{S E})=\left(\frac{V_{T}}{V_{S}}\right)^{2} \cdot \widehat{\operatorname{Var}}(\widehat{S Y})
$$

\subsubsection{Project-Wide Fish Passage Efficiency}

The project-wide FPE was estimated by the quotient

$$
\widehat{F P E}=\frac{[\widehat{S}+\widehat{T G}+\widehat{H G}]}{[\widehat{T U}+\widehat{T G}+\widehat{H U}+\widehat{H G}+\hat{S}]}
$$

where the numerator is the estimated spillway and bypass guided passage and the denominator is total project passage; it is alternatively expressed as

$$
\widehat{F P E}=\frac{\hat{G}}{\hat{G}+\hat{U}}
$$

where

$$
\begin{aligned}
& \widehat{G}=\widehat{S}+\widehat{T G}+\widehat{H G}, \\
& \widehat{U}=\widehat{T U}+\widehat{H U} .
\end{aligned}
$$

The variance of $\widehat{F P E}$ can then be estimated by

$$
\widehat{\operatorname{Var}}(\widehat{F P E})=\widehat{F P E}^{2}(1-\widehat{F P E})^{2}\left[\frac{\widehat{\operatorname{Var}}(\hat{G})}{\hat{G}^{2}}+\frac{\widehat{\operatorname{Var}}(\hat{U})}{\hat{U}^{2}}-\frac{2 \widehat{\operatorname{Cov}}(\hat{G}, \hat{U})}{\hat{G} \cdot \hat{U}}\right]
$$

and where

$$
\begin{aligned}
\widehat{\operatorname{Var}}(\hat{G}) & =\widehat{\operatorname{Var}}(\hat{S})+\widehat{\operatorname{Var}}(\widehat{\operatorname{TG}})+\widehat{\operatorname{Var}}(\widehat{H G}), \\
\widehat{\operatorname{Var}}(\hat{U}) & =\widehat{\operatorname{Var}}(\widehat{T U})+\widehat{\operatorname{Var}}(\widehat{H U}), \\
\widehat{\operatorname{Cov}}(\hat{G}, \hat{U}) & =\widehat{\operatorname{Cov}}(\widehat{T U}, \widehat{T G})+\widehat{\operatorname{Cov}}(\widehat{H U}, \widehat{H G}) .
\end{aligned}
$$




\subsubsection{Powerhouse 1 Fish Passage Efficiency (FPE)}

For Powerhouse 1, FPE was estimated by the quantity

$$
\widehat{F P E}_{1}=\frac{\widehat{T G}}{\widehat{T G}+\widehat{T U}}
$$

with associated variance estimator

$$
\widehat{\operatorname{Var}}\left(\widehat{F P E}_{1}\right)=\widehat{F P E}_{1}^{2}\left(1-\widehat{F P E}_{1}\right)^{2}\left[\frac{\widehat{\operatorname{Var}}(\widehat{T G})}{\widehat{T G}^{2}}+\frac{\widehat{\operatorname{Var}}(\widehat{T U})}{\widehat{T U}^{2}}-\frac{2 \widehat{\operatorname{Cov}}(\widehat{T U}, \widehat{T G})}{\widehat{T U} \cdot \widehat{T G}}\right] \text {. }
$$

\subsubsection{Powerhouse 2 Fish Passage Efficiency (FPE)}

For Powerhouse 2, FPE was estimated by the quantity

$$
\widehat{F P E}_{2}=\frac{\widehat{H G}}{\widehat{H G}+\widehat{H U}}
$$

with associated variance estimator

$$
\widehat{\operatorname{Var}}\left(\widehat{F P E}_{2}\right)=\widehat{F P E}_{2}^{2}\left(1-\widehat{F P E}_{2}\right)^{2}\left[\frac{\widehat{\operatorname{Var}}(\widehat{H G})}{\widehat{H G}^{2}}+\frac{\widehat{\operatorname{Var}}(\widehat{H U})}{\widehat{H U}^{2}}-\frac{2 \widehat{\operatorname{Cov}}(\widehat{H U}, \widehat{H G})}{\widehat{H U} \cdot \widehat{H G}}\right] \text {. }
$$




\subsection{Results}

\subsection{Hydroacoustic Detectability}

In spring, most effective beam angles were within one degree of or above the nominal ( $-3 \mathrm{~dB})$ beam angles (see Appendix B for nominal angles) for each transducer at minimum sampling ranges (Figure 3.1). Exceptions included the transducer sampling guided fish at Unit 8 and spillway transducers at bays 4 and 12. Smaller effective beam angles translate into bigger spatial expansion factors. In summer, curves for effective-beam angle by range had similar shapes to those modeled for spring, although angles at all ranges were narrower in summer than they were in spring (compare Figure 3.1 with Figure 3.2) because mean target strength estimates were lower in summer.
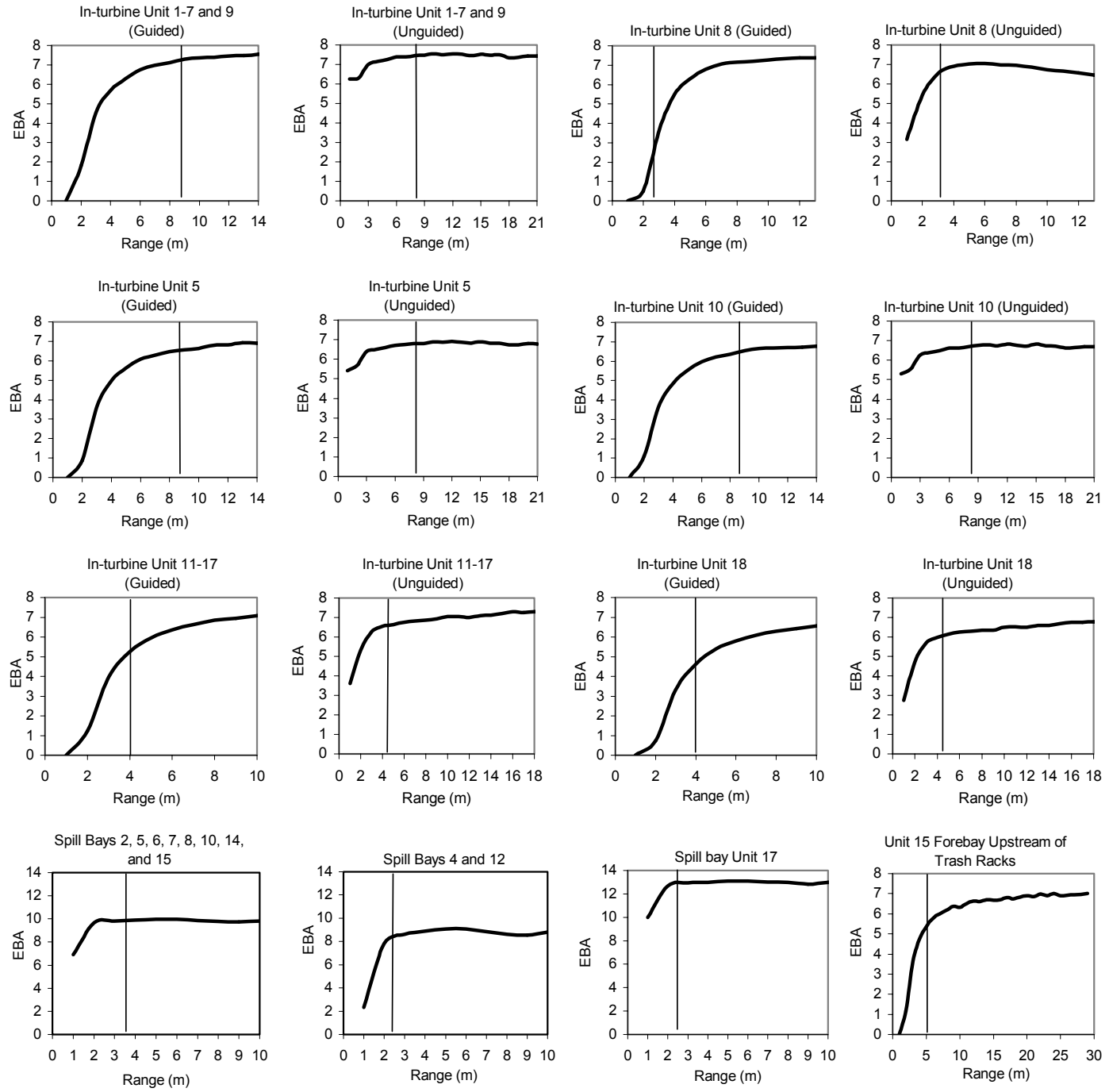

Figure 3.1. Plots of Effective Beam Angle (EBA) as a Function of Range from Transducers Deployed at Bonneville Dam in Spring 2001. Minimum sampling ranges are indicated by vertical bars. Note that both $\mathrm{x}$ and $\mathrm{y}$ scales vary among plots. 

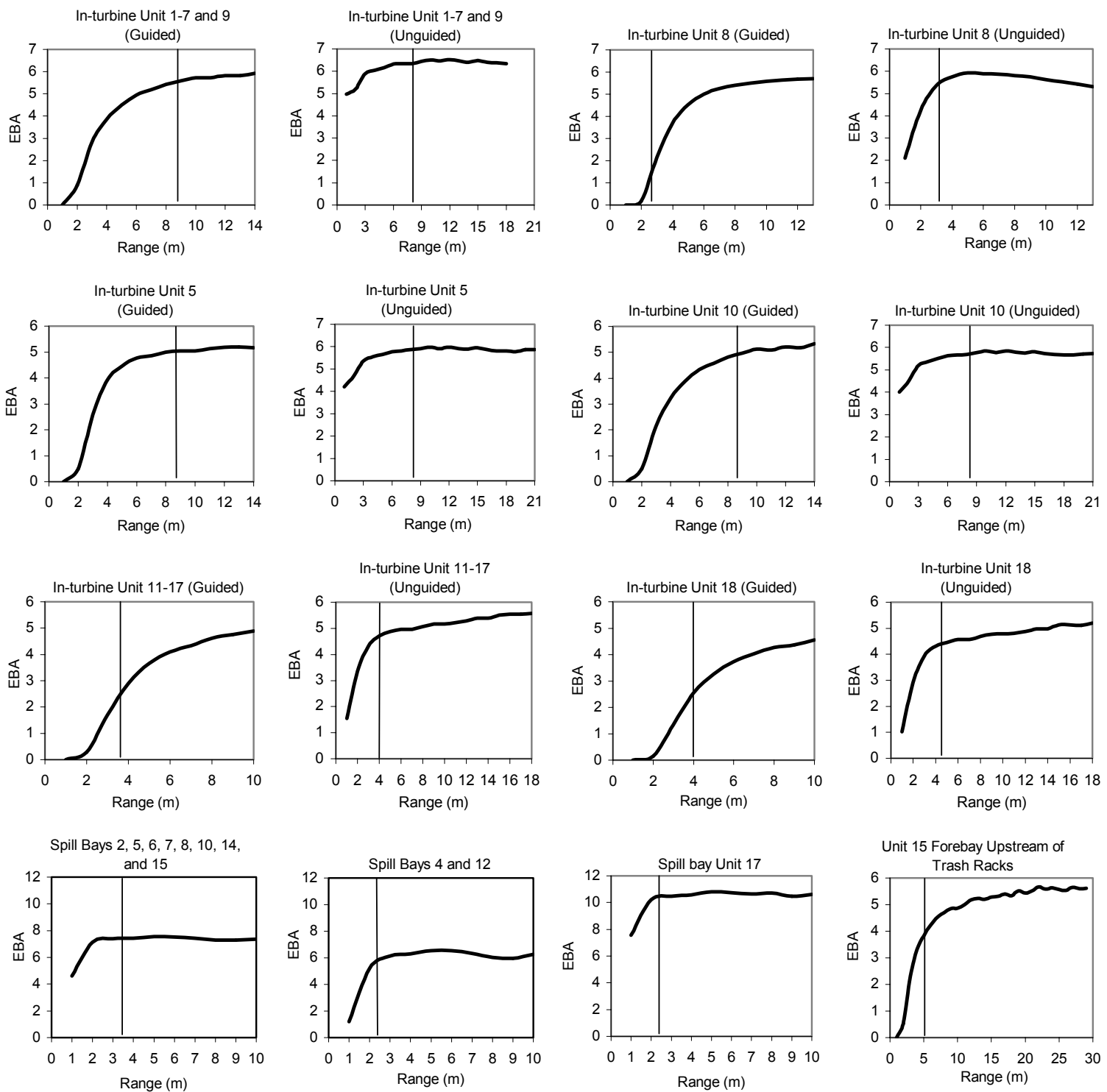

Figure 3.2. Plots of Effective Beam Angle (EBA) as a Function of Range from Transducers Deployed at Bonneville Dam in Summer 2001. Minimum sampling ranges are indicated by vertical bars. Note that both $\mathrm{x}$ and $\mathrm{y}$ scales vary among plots.

\subsection{Validation of Autotracking Hydroacoustic Data}

\subsubsection{Inter-Tracker Error and Human versus Autotracker Comparisons}

In our comparisons among six different human trackers, we found levels of inter-tracker error that could have led to biased results if the same human trackers had processed different passage routes consistently. Figure 3.3 demonstrates the possible cumulative effects of differences among human trackers, and the general tendency of the autotracker to produce estimates that are slightly higher than are those produced by an average human tracker. 

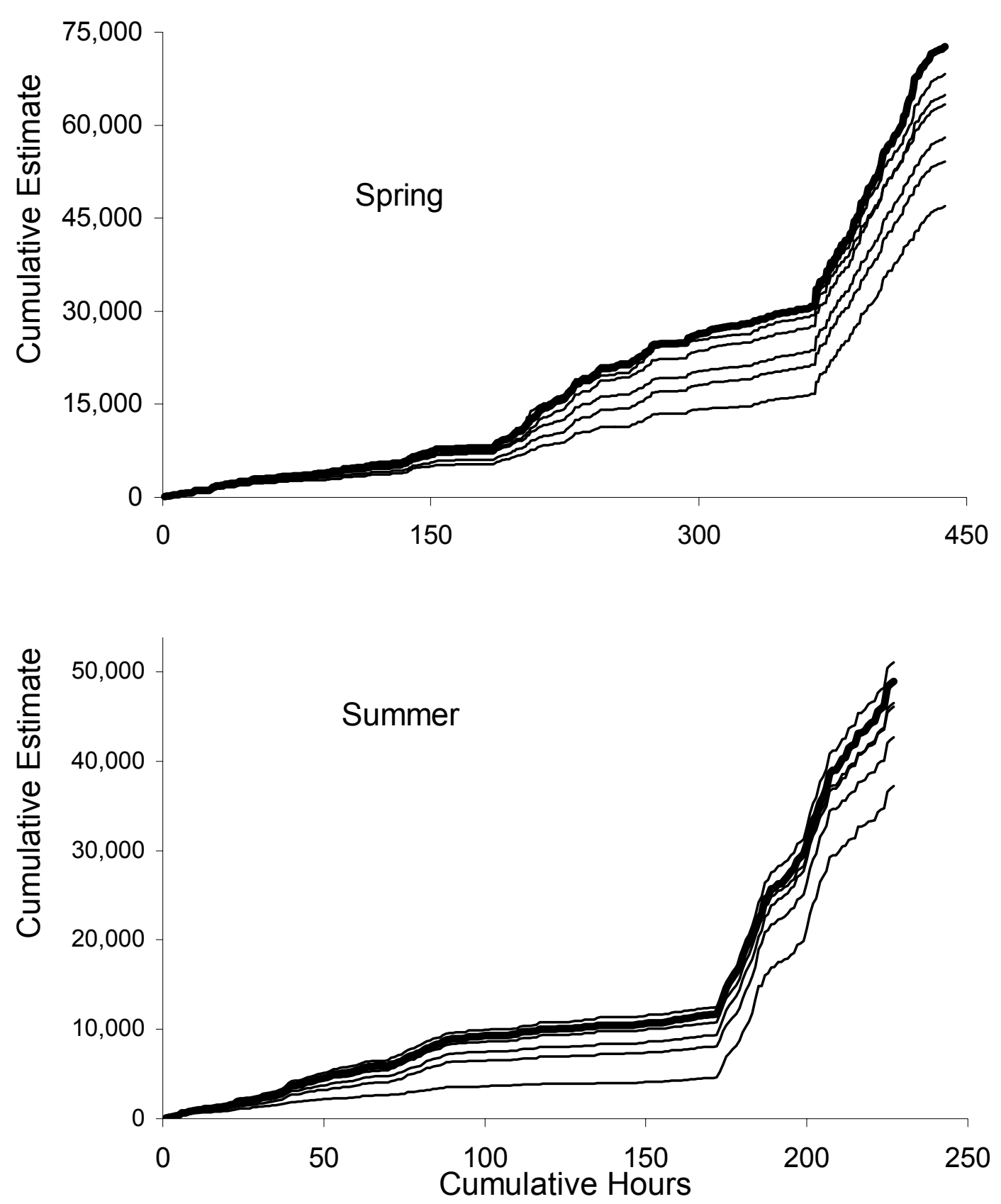

Figure 3.3. Cumulative Differences among Human Trackers in Spring and Summer. Estimates are spatially and temporally expanded fish counts. The heavy line represents the autotrackerbased estimates, and the light lines, some of which may be obscured, are cumulative estimates based on fish counts made by individual human trackers.

Figures 3.3 and 3.5 present scatter plots of regression of mean fish counts by technicians on autotracker counts of the same data in spring and summer, respectively. Regression coefficients are high, indicating a generally good agreement between the autotracker results and the mean human results, although the $95 \%$ confidence bounds on the human estimates can be large, especially on those for guided passage. 

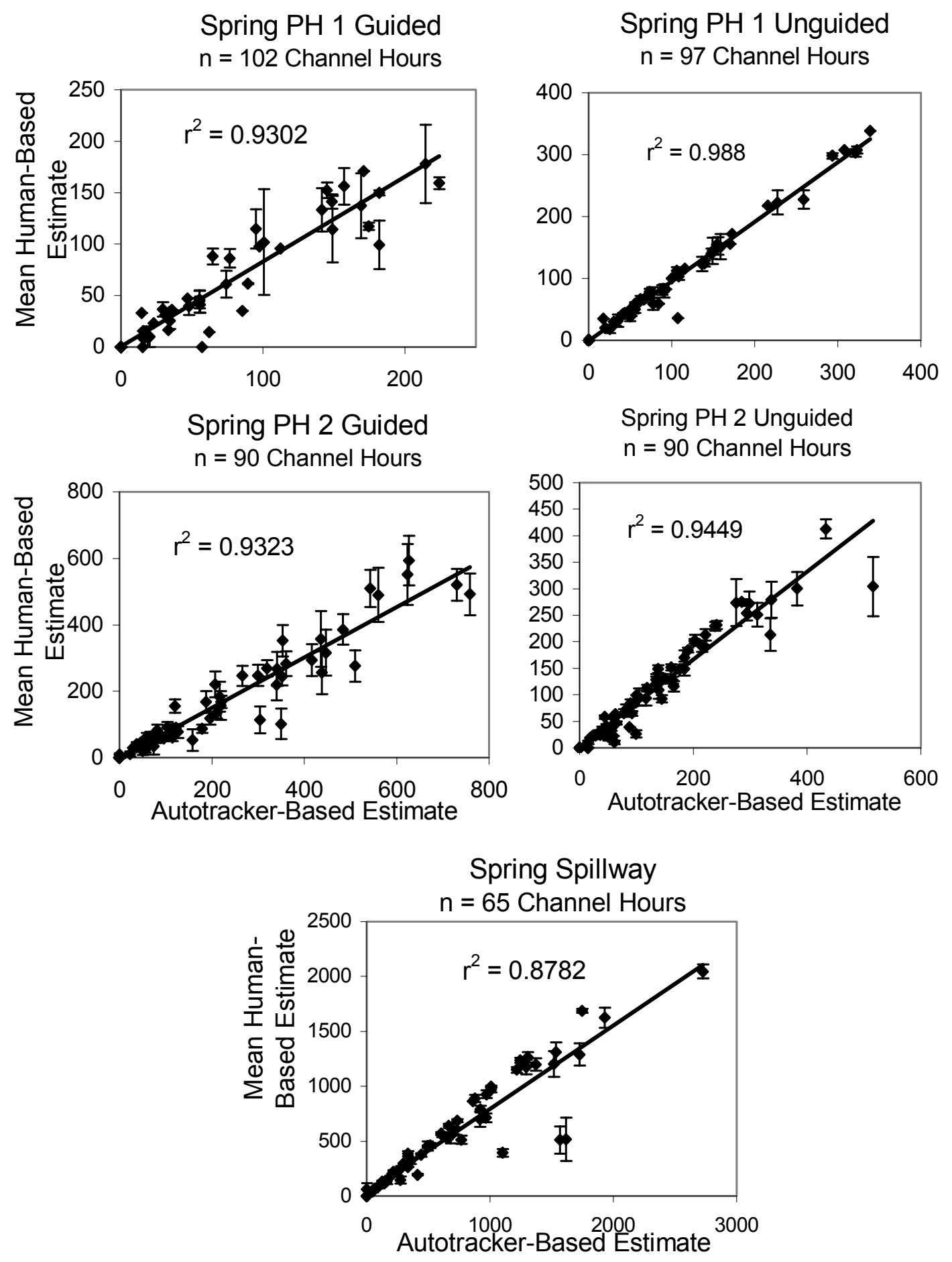

Figure 3.4. Regressions of Mean Human-Tracker Derived Hourly Passage Estimates and AutotrackerDerived Hourly Passage Estimates by Location (structure) and Deployment (passage route) in Spring. Bars indicate $95 \%$ confidence limits. 

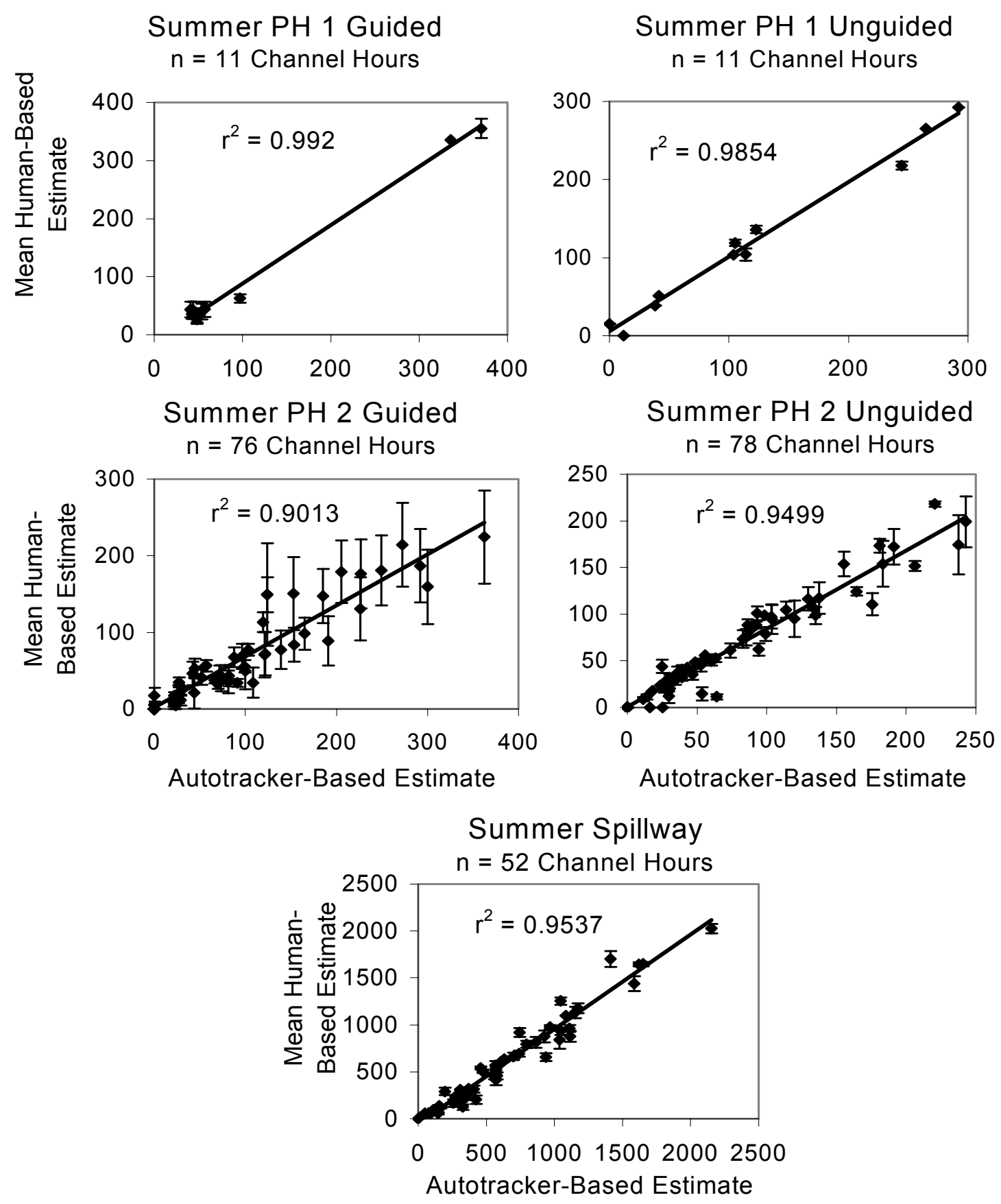

Figure 3.5. Regressions of Mean Human Tracker-Derived Hourly Passage Estimates and AutotrackerDerived Hourly Passage Estimates by Location (structure) and Deployment (passage route) in Summer. Bars indicate $95 \%$ confidence limits.

\subsubsection{Regression Line Slopes for Autotracker Correction}

Since the autotracker counts tend to be somewhat higher than are the mean human-derived counts, we forced the regressions in Figures 3.4 and 3.5 (above) through the origin in order to get estimates for the 
magnitudes of those biases (Figure 3.6). The slopes in those figures are the values that we used to adjust our passage estimates.

\section{Spring PH1 \\ - GUIDED O UNGUIDED}

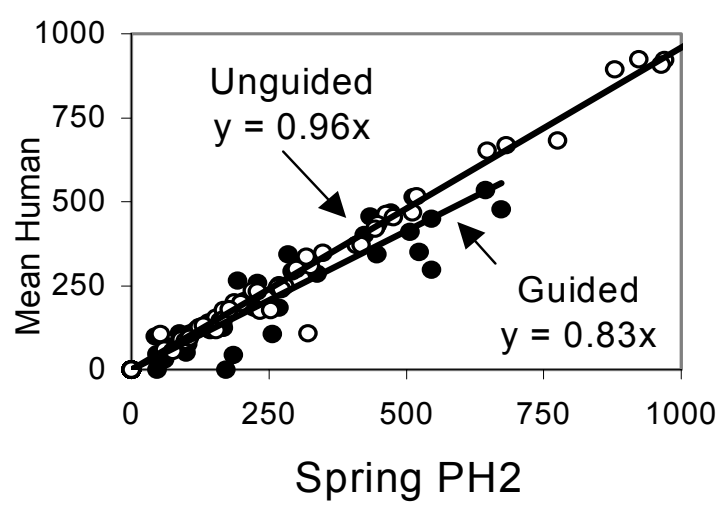

- GUIDED ○ UNGUIDED
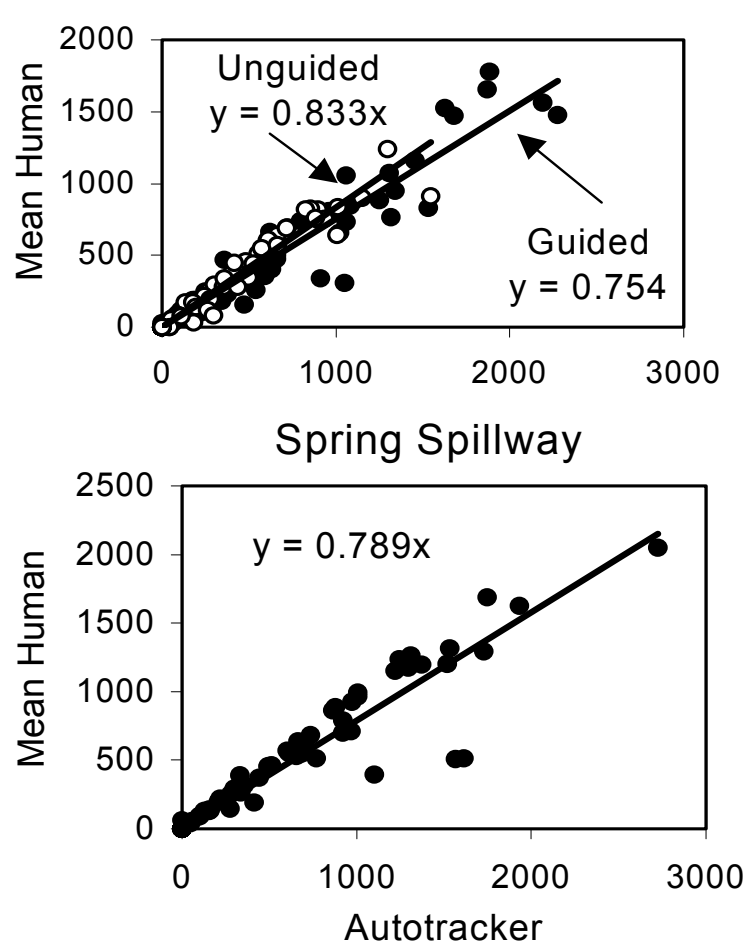

\section{Summer PH1}

- GUIDED o UNGUIDED

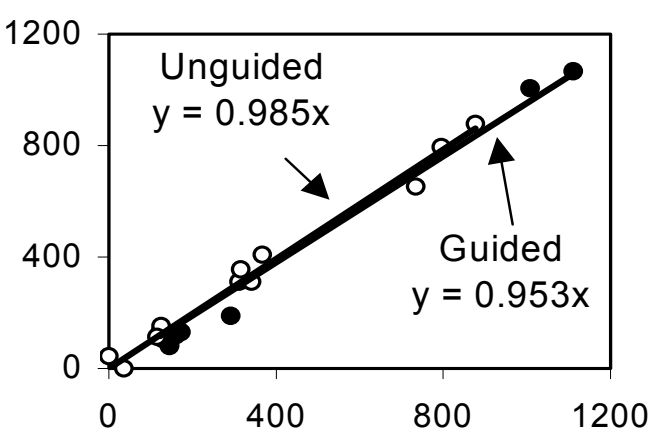

Summer PH2

- GUIDED O UNGUIDED
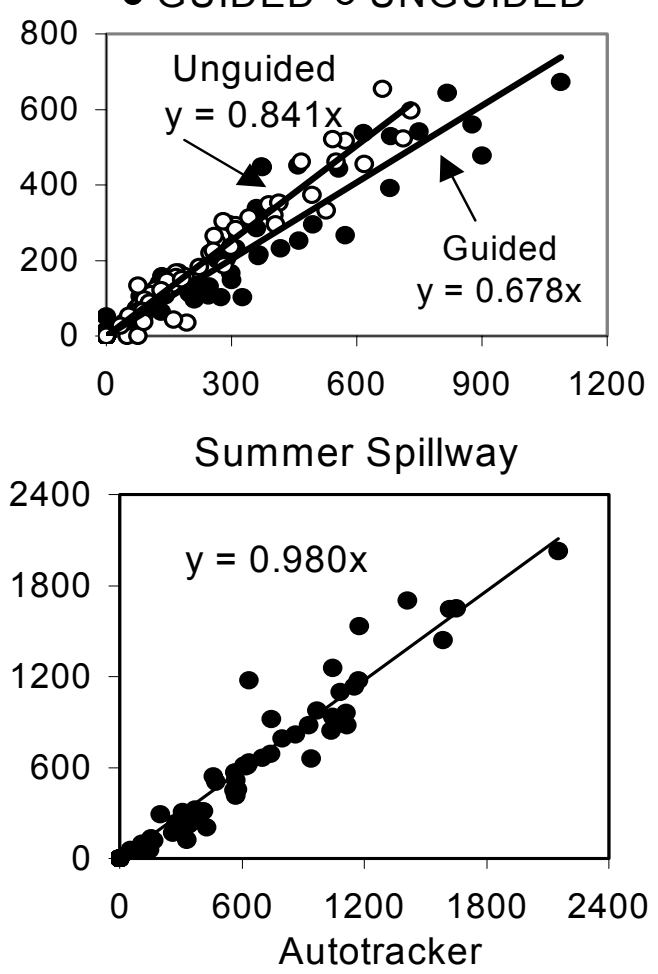

Figure 3.6. Regressions of Autotracker-Based Expanded Hourly Estimates and Mean Human-Based Expanded Hourly Estimates. These same data appear in Figure 3.5 and 3.6 except that the regression lines have been forced through the origins of the graphs. The slopes of these regression lines are the values with which passage estimates were adjusted. 


\subsection{Major Passage Metrics}

\subsubsection{Project and Powerhouse FPE}

Project-wide FPE estimates are presented in Figure 3.7. Project-wide FPE was 63\% in spring and 53\% in summer. During spill periods, the summertime FPE estimate was slightly higher than the estimate for spring. The opposite was true during non-spill periods, when the FPE estimate was higher in spring than in summer. The FPE estimate for Powerhouse 1 declined from $49 \%$ with a $95 \%$ confidence interval $(\mathrm{CI})$ of $4.3 \%$ in spring to $40 \%(\mathrm{CI}=3.6 \%)$ in summer, a drop of $9 \%$. The FPE for Powerhouse 2 declined even more across seasons $(>15 \%)$, with estimates of $57 \%(\mathrm{CI}=1 \%)$ and $42 \%(\mathrm{CI}=1 \%)$ in the spring and summer, respectively. The FPE for powerhouse 2 and the spillway (excluding Powerhouse 1) was 64\% in spring and 54\% in summer. These estimates were both $1 \%$ lower than for the entire project.

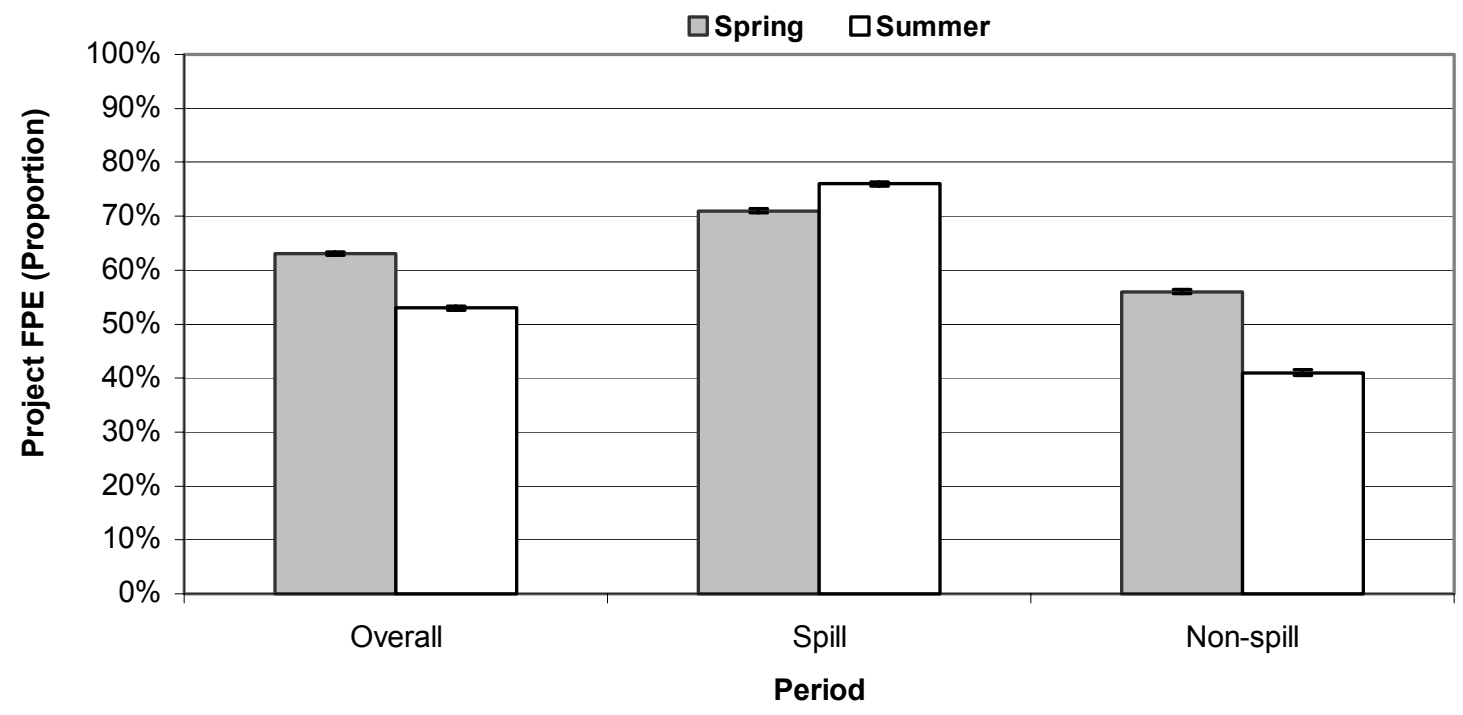

Figure 3.7. Project-Wide Fish Passage Efficiency Estimates for Spring and Summer Seasons at Bonneville Dam in 2001. Estimates are presented by spill and no-spill periods, and overall. Error bars represent $95 \%$ confidence intervals.

\subsubsection{Spill Efficiency and Effectiveness}

Spill efficiency was $14 \%(\mathrm{CI}=0.4 \%)$ in spring and $20 \%(\mathrm{CI}=0.6)$ in summer. For periods of spill, spill efficiency was $33 \%(\mathrm{CI}=1 \%)$ in spring and $58 \%(\mathrm{CI}=1.2 \%)$ in summer. Spill effectiveness was $0.84(\mathrm{CI}=0.01)$ in spring and $1.83(\mathrm{CI}=0.02)$ in summer. For periods of spill, spill effectiveness was $0.93(\mathrm{CI}=0.02)$ in spring and $1.6(\mathrm{CI}=0.02)$ in summer.

\subsubsection{Effects of Spill Level}

We plotted estimates of FPE and spill efficiency on the number of hours of spill per day in spring 2001 (Figure 3.8). Spill discharge was nearly constant at about 50,000 cfs during hours or 
days when water was spilled in spring and summer 2001, and therefore we could not examine the effect of spill discharge or fraction on major passage metrics. In summer, there was only 10 days of 50,000 cfs spill and only one of those days had less than 24 hours of spill.
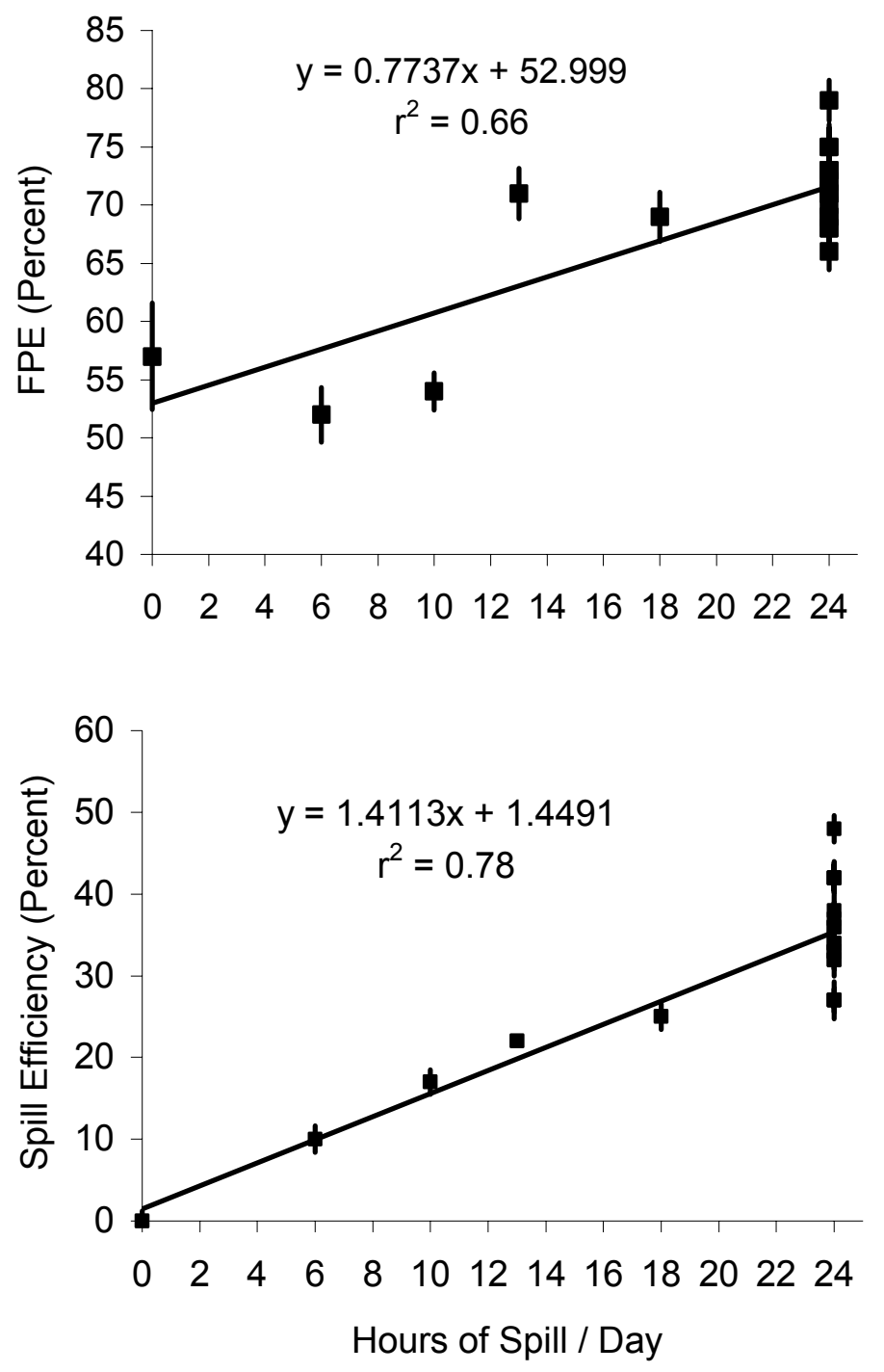

Figure 3.8. Plot of Project FPE and Spill Efficiency on Hours of Spill per Day at Bonneville Dam in 2001

\subsubsection{Comparison with Radio Telemetry Estimates}

We recalculated hydroacoustic estimates based on the USGS's data collection schedule during their radio telemetry study so that we would be comparing the same days in spring and summer. In general, the hydroacoustic estimates are higher than are the radio telemetry estimates (Table 3.8). Powerhouse 1 FGE in summer is the only exception. The largest difference is that 
for Powerhouse 2 FPE and FGE, which differs by 14\%. Spring Project FPE is $11 \%$ higher by hydroacoustics than by radio telemetry. Otherwise, the estimates are within $10 \%$ or less.

Even during "no spill" conditions spill bays 1 and 18 each discharged attraction flow for adult salmonids (about $2 \%$ of project discharge in spring and about $3 \%$ in summer) and a few radio tagged fish could and did pass there when no other bays were open. There was no hydroacoustic sampling of those end spill bays.

Table 3.1. Comparison of Fish-Passage Metrics Estimated by Hydroacoustics (HA) and Radio Telemetry (RT) at Bonneville Dam in 2001. Data from non-overlapping parts of seasons have been deleted and adjusted so that time periods reported here are the same for both methods. Those dates are May 1-June 9 for spring and July 1-July 15 for summer. Some hydroacoustic FGEs are slightly different than those reported elsewhere because the times have been adjusted to match those for radio telemetry.

\begin{tabular}{|c|c|c|c|c|}
\hline Metric & Season and Spill Conditions & HA & RT & Difference \\
\hline \multirow[t]{3}{*}{ Project FPE $^{(\mathrm{a})}$} & Spring overall & $67 \%$ & $56 \%$ & $11 \%(H A>R T)$ \\
\hline & Spring (about 37\% spill) & $71 \%$ & $64 \%$ & $7 \%(\mathrm{HA}>\mathrm{RT})$ \\
\hline & Spring (about $2 \%$ spill) & $56 \%$ & $47 \%$ & $9 \%(\mathrm{HA}>\mathrm{RT})$ \\
\hline \multirow[t]{3}{*}{ PH1 FGE } & Spring overall & $47 \%$ & $45 \%$ & $2 \%(\mathrm{HA}>\mathrm{RT})$ \\
\hline & Spring (about $37 \%$ spill) & $39 \%$ & $\mathrm{~N} / \mathrm{A}^{2}$ & \\
\hline & Spring (about 2\% spill) & $50 \%$ & $45 \%$ & $5 \%(\mathrm{HA}>\mathrm{RT})$ \\
\hline \multirow[t]{3}{*}{ PH1 FPE } & Spring overall & $N / A^{(a)}$ & $87 \%$ & \\
\hline & Spring (about $37 \%$ spill) & $N / A^{(a)}$ & $100 \%$ & \\
\hline & Spring (about $2 \%$ spill) & $N / A^{(a)}$ & $86 \%$ & \\
\hline \multirow[t]{3}{*}{ PH2 FGE \& FPE } & Spring overall & $56 \%$ & $46 \%$ & $10 \%(\mathrm{HA}>\mathrm{RT})$ \\
\hline & Spring (about 37\% spill) & $55 \%$ & $49 \%$ & $6 \%(H A>R T)$ \\
\hline & Spring (about 2\% spill) & $57 \%$ & $43 \%$ & $14 \%(\mathrm{HA}>\mathrm{RT})$ \\
\hline \multirow[t]{2}{*}{ Spill Efficiency } & Spring overall & $26 \%$ & $16 \%$ & $10 \%(\mathrm{HA}>\mathrm{RT})$ \\
\hline & Spring during spill & $38 \%$ & $30 \%$ & $8 \%(H A>R T)$ \\
\hline \multirow[t]{2}{*}{ Spill Effectiveness } & Spring overall & 1.21 & 0.70 & $0.51(\mathrm{HA}>\mathrm{RT})$ \\
\hline & Spring during spill & 1.13 & 0.86 & $0.27(\mathrm{HA}>\mathrm{RT})$ \\
\hline Project FPE & Summer overall (about 3\% spill) & $44 \%$ & $40 \%$ & $4 \%(H A>R T)$ \\
\hline PH1 FPE & Summer overall (about 3\% spill) & $\mathrm{N} / \mathrm{A}^{(\mathrm{b})}$ & $89 \%$ & \\
\hline PH1 FGE & Summer overall (about 3\% spill) & $47 \%$ & $57 \%$ & $10 \%(\mathrm{RT}>\mathrm{HA})$ \\
\hline PH2 FGE \& FPE & Summer overall (about 3\% spill) & $44 \%$ & $35 \%$ & 9\% (HA>RT) \\
\hline \multicolumn{5}{|c|}{$\begin{array}{l}\text { (a) The radio telemetry FPE estimates include fish that pass by the sluiceway at Powerhouse } 1 \text {. There } \\
\text { was no hydroacoustic sampling of Powerhouse } 1 \text { sluiceway passage and so there can be no hydro- } \\
\text { acoustic estimate made to compare directly with the radio telemetry Project or Powerhouse } 1 \text { FPE } \\
\text { estimates. Since the Powerhouse } 2 \text { sluiceway was closed in both seasons FPE = FGE for both hydro- } \\
\text { acoustic and radio telemetry data at Powerhouse } 2 \text {. Since the Powerhouse } 1 \text { sluiceway handled a very } \\
\text { small proportion of the total project passage we neglected this distinction at the project level. } \\
\text { (b) During spring } 37 \% \text { spill, only four radio-tagged fish were tracked through Powerhouse } 1 \text { and they } \\
\text { all passed by the sluiceway, which was not sampled by hydroacoustics. Powerhouse FGE is the } \\
\text { proportion of all fish guided divided by the sum of guided and unguided (turbine) fish. In this case } \\
\text { Powerhouse } 1 \text { FGE would equal } 0 / 0 \text {, which is undefined. }\end{array}$} \\
\hline
\end{tabular}




\subsection{Spatial Trends in Fish Passage}

\subsubsection{Horizontal Distributions}

We estimate that just over $6.15 \mathrm{M}$ fish passed the project during the 46 spring days that we sampled, with nearly $80 \%$ (4.9 $\mathrm{M}$ fish) passing at Powerhouse 2, about $14 \%$ ( $0.84 \mathrm{M}$ fish) passing by spill, and about 7\% (0.42 M fish) passing Powerhouse 1 (Figure 3.9). Project flow was similar to fish passage, with $76 \%$ of discharge occurring at Powerhouse 2 , about $16 \%$ at the spillway, and about $7 \%$ at Powerhouse 1 (Figure 3.10). The density of fish passage, in the number of fish per million cubic meters of water (fish/ $\left.\mathrm{M} \mathrm{m}^{3}\right)$, was highest at Powerhouse $2\left(474 \mathrm{fish} / \mathrm{M} \mathrm{m}^{3}\right)$, followed by Powerhouse 1 (428 fish/ $\mathrm{M} \mathrm{m}^{3}$ ) and the spillway (384 fish/ $\mathrm{M} \mathrm{m}^{3}$ ).

About $70 \%$ of the $0.42 \mathrm{M}$ fish that passed at Powerhouse 1 passed through Units 9 and 10 (Figure 3.9), as did 73\% of the Powerhouse 1 discharge (Figure 3.10). Fish passage and flow were low throughout the rest of Powerhouse 1, with the exception of Units 1 and 2, which passed $8 \%$ of the fish with $14 \%$ of the flow, and $9 \%$ of the fish with $7 \%$ of the flow, respectively.

Fish passage at Powerhouse 2 was noticeably skewed towards the south half of the powerhouse (Figure 3.9). About $70 \%$ of the fish passing through Powerhouse 2 passed through Units 11 through 14 , although these units only discharged slightly more than half of the water (52.6\%; Figure 3.10).

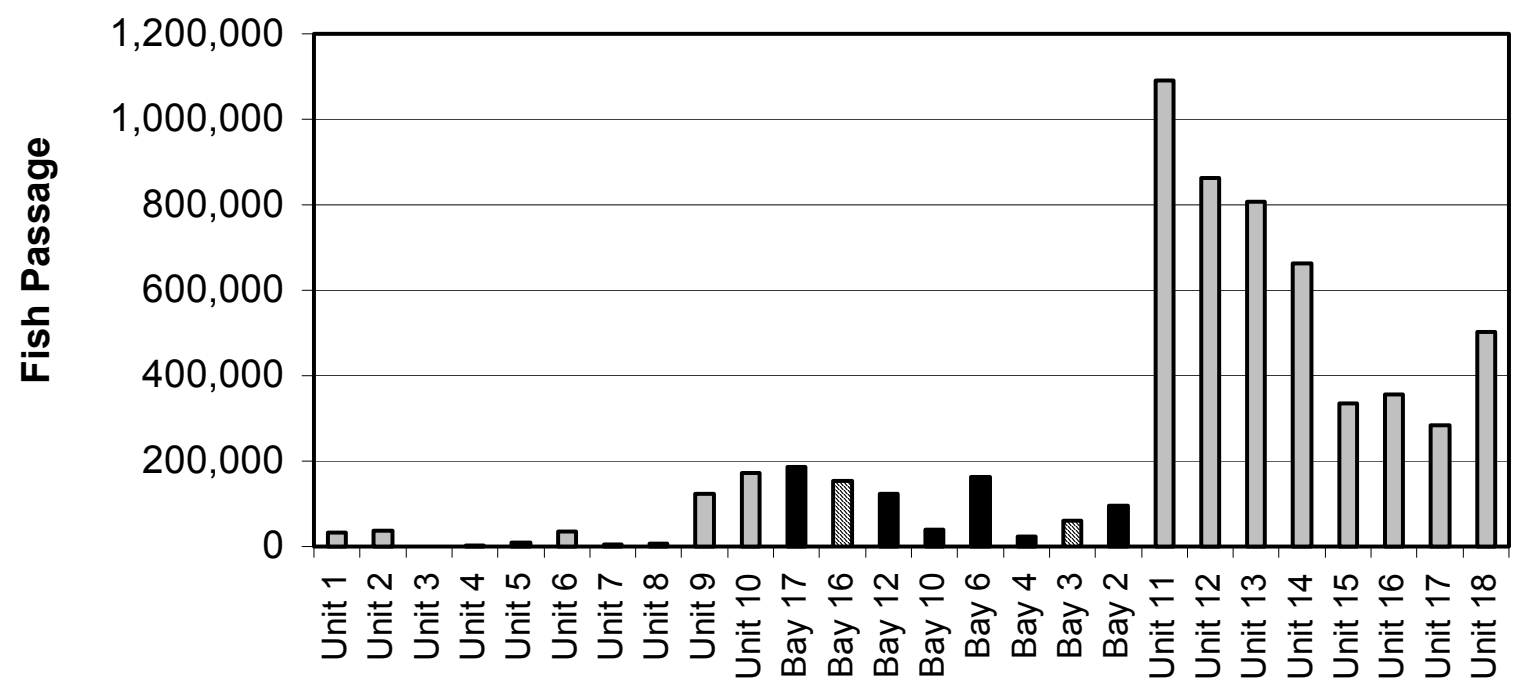

Turbine Unit or Spill Bay

Figure 3.9. Horizontal Distribution of Fish Passage through Turbines (gray bars) and Spill Bays (black or striped bars) in Spring. Spill bays 1 and 18 that were opened only 4 inches and other bays that were closed all season (bays 5, 7-9, 11, and 13-15) are not displayed. Estimates for spill bays 3 and 16 were interpolated from those of the nearest operating spill bays. 
The highest proportions of the fish that passed the project at the spillway passed through Bay 6 (where $19 \%$ of all spillway passage occurred), Bay 16 (18\% of spillway passage), and Bay 17 (22\% of spillway passage; Figure 3.9 ). Passage was distributed unevenly across the spillway but was somewhat skewed towards the south side. Spill discharge was relatively constant in spring and summer at about 50,000 cfs, and the spill pattern (bays and gate openings) varied little (Figure3.10).

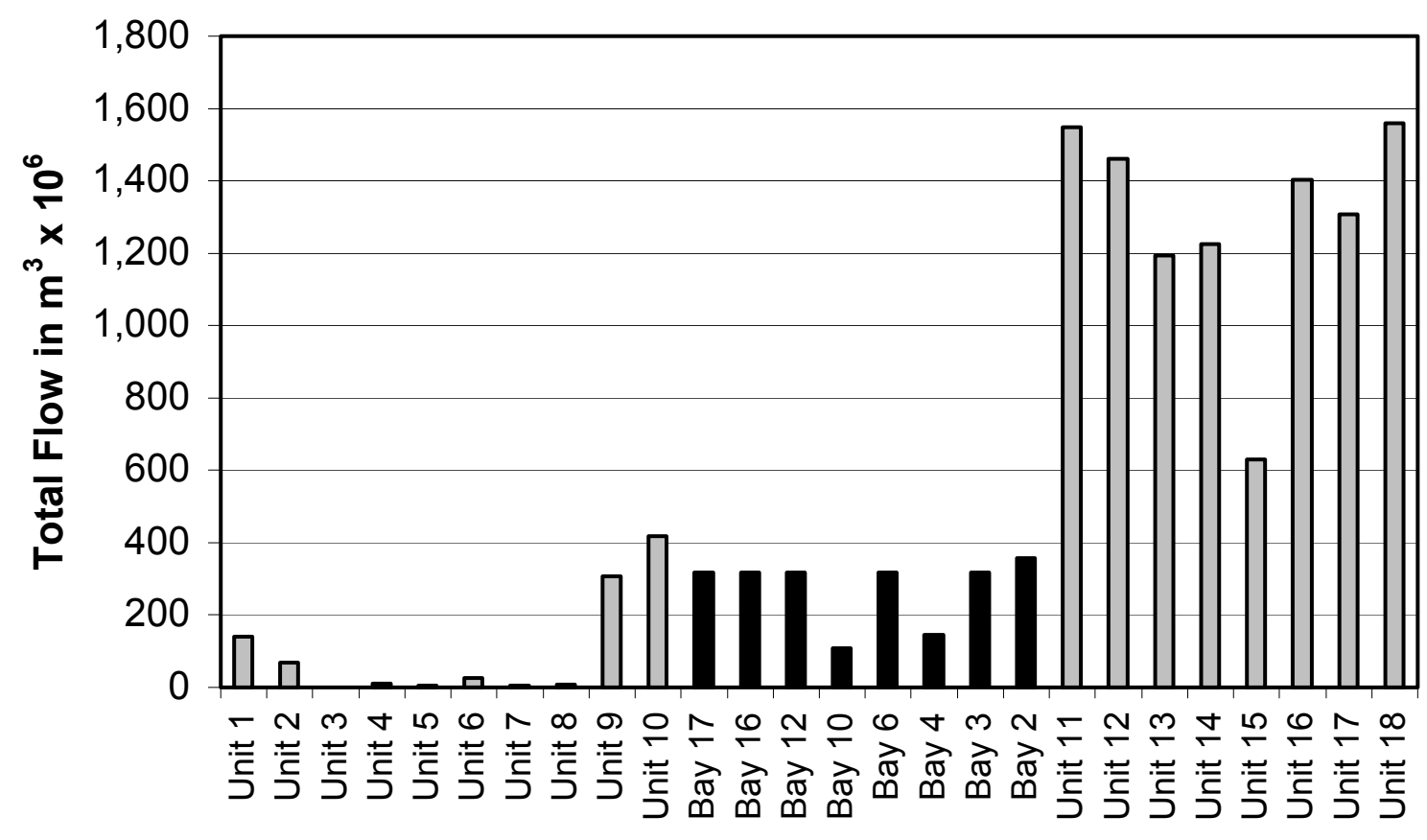

\section{Turbine Unit or Spill Bay}

Figure 3.10. Horizontal Distribution of Discharge through Turbines (gray bars) and Spill Bays (black bars) in Spring. Spill bays 1 and 18 that were opened only 4 inches and other bays that were closed all season (bays 5, 7-9, 11, and 13-15) are not displayed.

In summer, we estimate that $5.1 \mathrm{M}$ fish passed Bonneville Dam during the 40 days we sampled. Of these, $3.7 \mathrm{M}$ or about $72 \%$ of total project passage passed at Powerhouse 2, along with $80 \%$ of project discharge (Figures 3.11 and3.12). The Spillway passed $1 \mathrm{M}$ fish or about $20 \%$ of the project total in about $11 \%$ of project discharge. Powerhouse 1 passed about $4 \%$ of all fish in summer $(0.4 \mathrm{M}$ fish) in about $7.5 \%$ of the total discharge.

Nearly $75 \%$ of the fish that passed Powerhouse 1 in the summer passed at Unit 9 and Unit 10, along with $81 \%$ of the water (Figure 3.11 and 3.12). Discharge at Powerhouse 1 was very low during the summer and was mostly allocated to Units 1, 9, and 10 (Figure 3.12), and Unit 1 passed about $5 \%$ of the fish in about $10.6 \%$ of the flow. Of the remaining units, significant passage occurred only at Unit 6 , which passed $12.6 \%$ of the fish in less than $3 \%$ of the flow. 


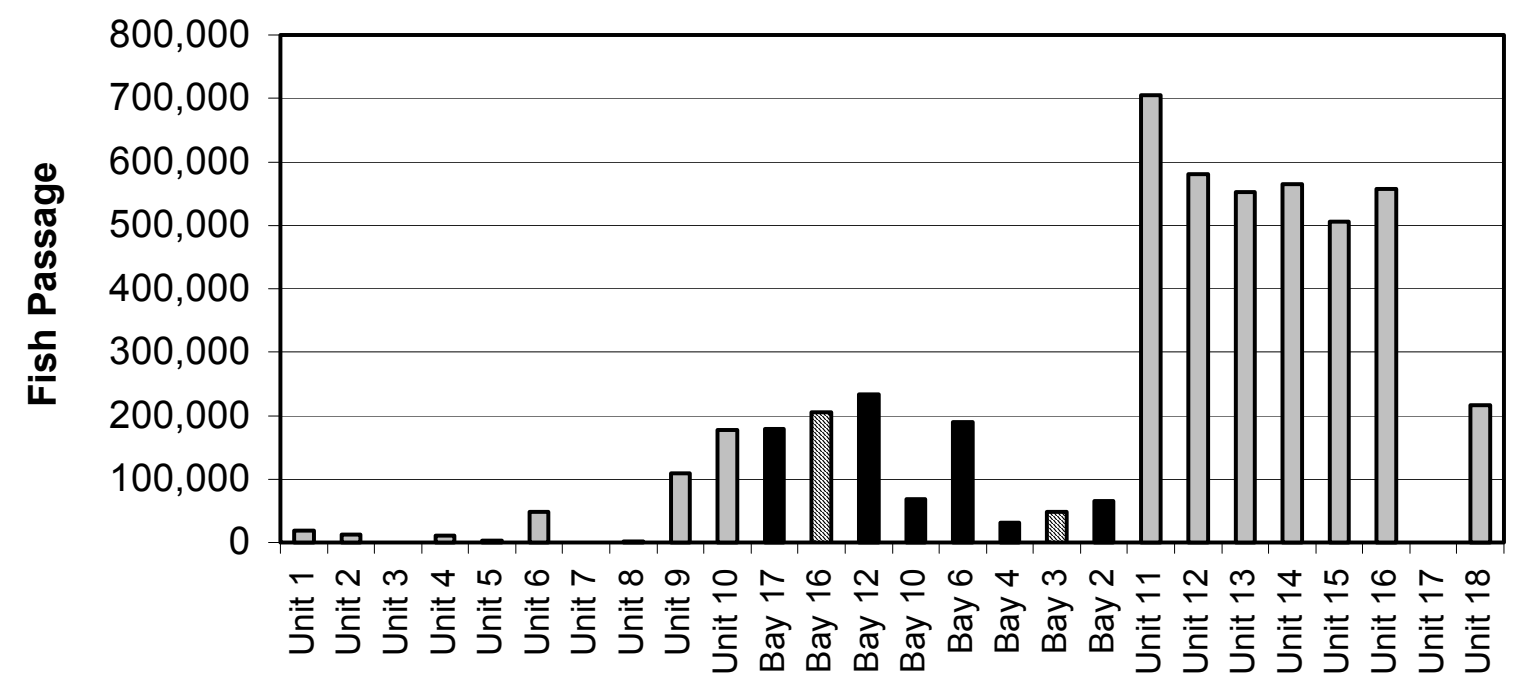

Turbine Unit or Spill Bay

Figure 3.11. Horizontal Dstribution of Fish Passage through Turbines (gray bars) and Spill Bays (black or striped bar) in Summer. Spill bays 1 and 18 that were opened only 4 inches and other bays that were closed all season (bays 5, 7-9, 11, and 13-15) are not displayed. Estimates for spill bays 3 and 16 were interpolated from those of the nearest operating spill bays. Turbine unit 17 did not operate in summer.

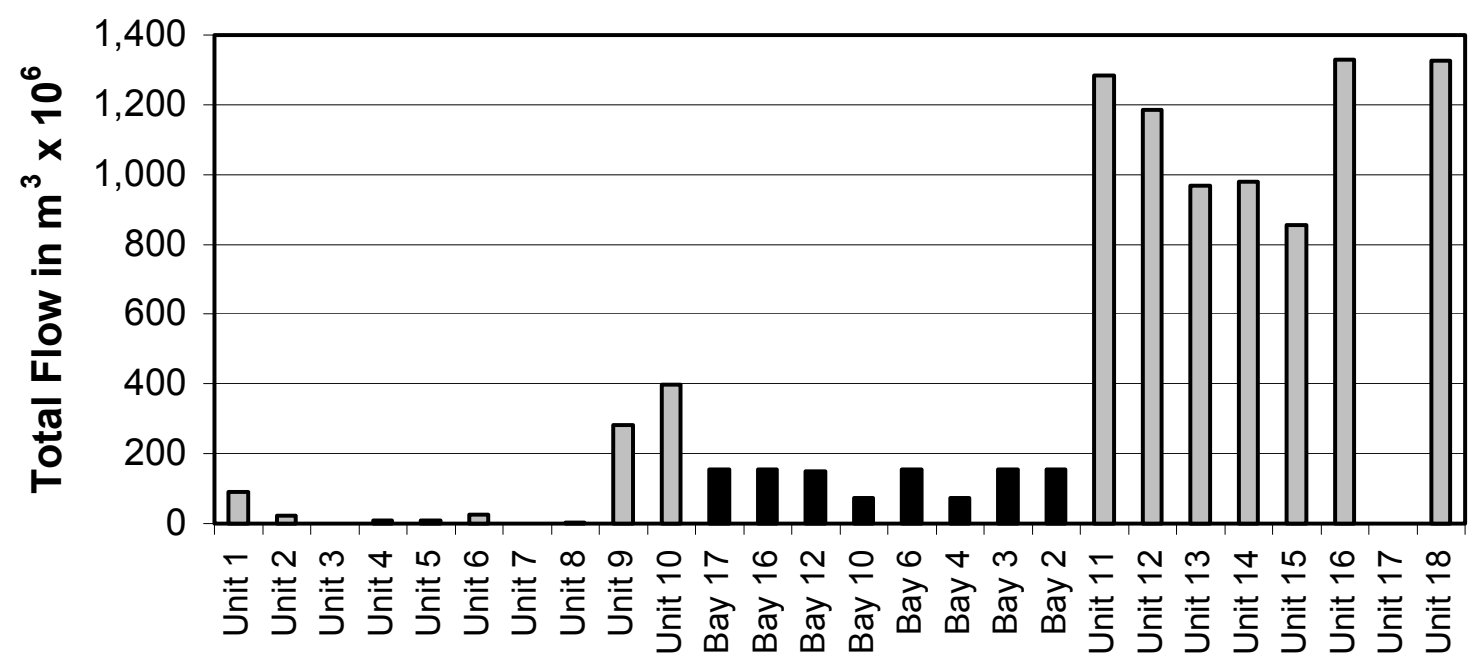

\section{Turbine or Spill Bay}

Figure 3.12. Horizontal Distribution of Discharge through Turbines (gray bars) and Spill Bays (black bars) in Summer. Spill bays 1 and 18 that were opened only 4 inches and other bays that were closed all season (bays 5, 7-9, 11, and 13-15) are not displayed. Turbine unit 17 did not operate in summer. 
To better compare fish passage among the individual units of Powerhouse 2, we standardized passage by reporting the density of fish passage in fish per volume of water in both spring (Figure 3.13) and summer (Figure3.14). Density was highest at the southern and central units (Units 11 through 15), ranging from 531 to 703 fish passed per $\mathrm{M} \mathrm{m}^{3}$ water discharged. Fish passage density was lowest at the three northern units (Units 16, 17, and 18), ranging from 217 to 321 fish passed per $\mathrm{M} \mathrm{m}^{3}$ water discharged.

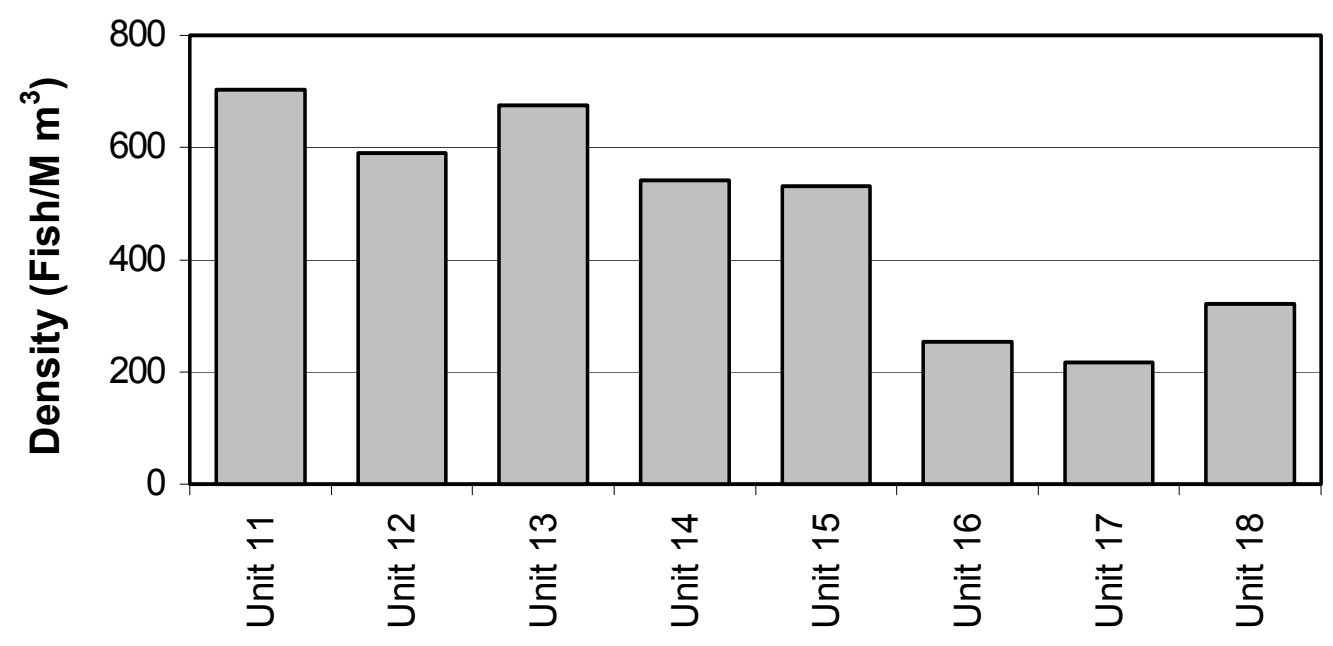

Turbine Unit

Figure 3.13. Horizontal Distribution of Fish Passage Density, in Fish per Millions of Cubic Meters of Water by Turbine Unit at Powerhouse 2 in Spring

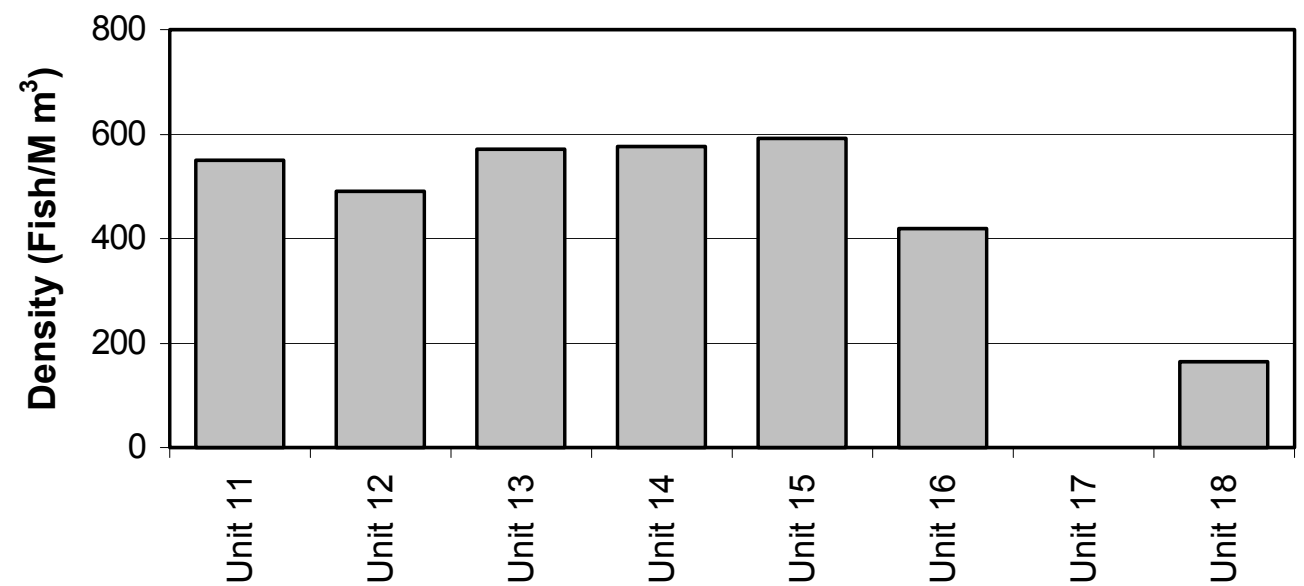

Turbine Unit

Figure 3.14. Horizontal Distribution of Fish Passage Density, in Fish per Million Cubic Meters of Water, at Powerhouse 2 in Summer 
Spillway discharge was terminated on Julian date 166, 10 days into the summer sampling season. For the entire summer sampling season, $11 \%$ of all fish passage occurred at the spillway along with $20 \%$ of all discharge. During the ten days that the spillway was operating, however, the spillway passed $58 \%$ of the fish in $40 \%$ of the water (Figure 3.15 and Figure 3.16 ).

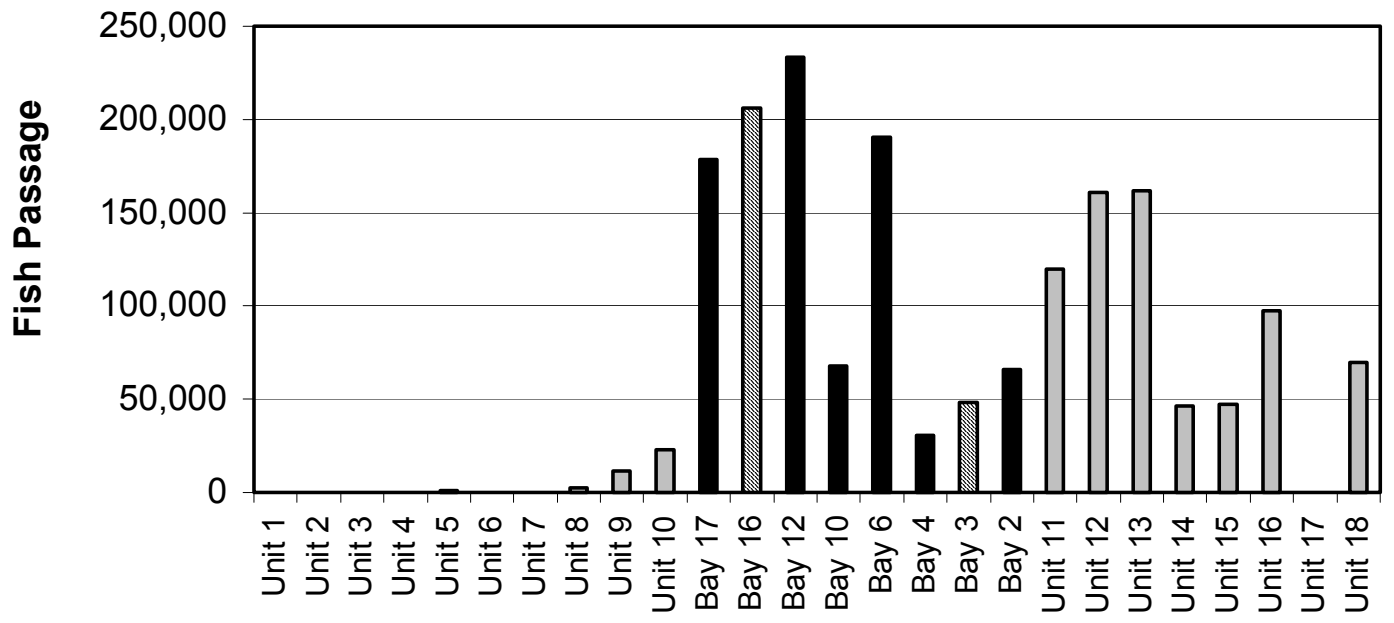

Turbine Unit or Spill Bay

Figure 3.15. Horizontal Distribution of Fish Passage at Turbines (gray bars) and Spill Bays (black or striped bars) during the Ten Days that Spill Occurred in Summer. Spill bays 1 and 18 that were opened only 4 inches and other bays (bays 5, 7-9, 11, and 13-15) that were closed all season are not displayed. Estimates for spill bays 3 and 16 were interpolated from those of the nearest operating spill bays. Turbine Unit 17 did not operate in summer.

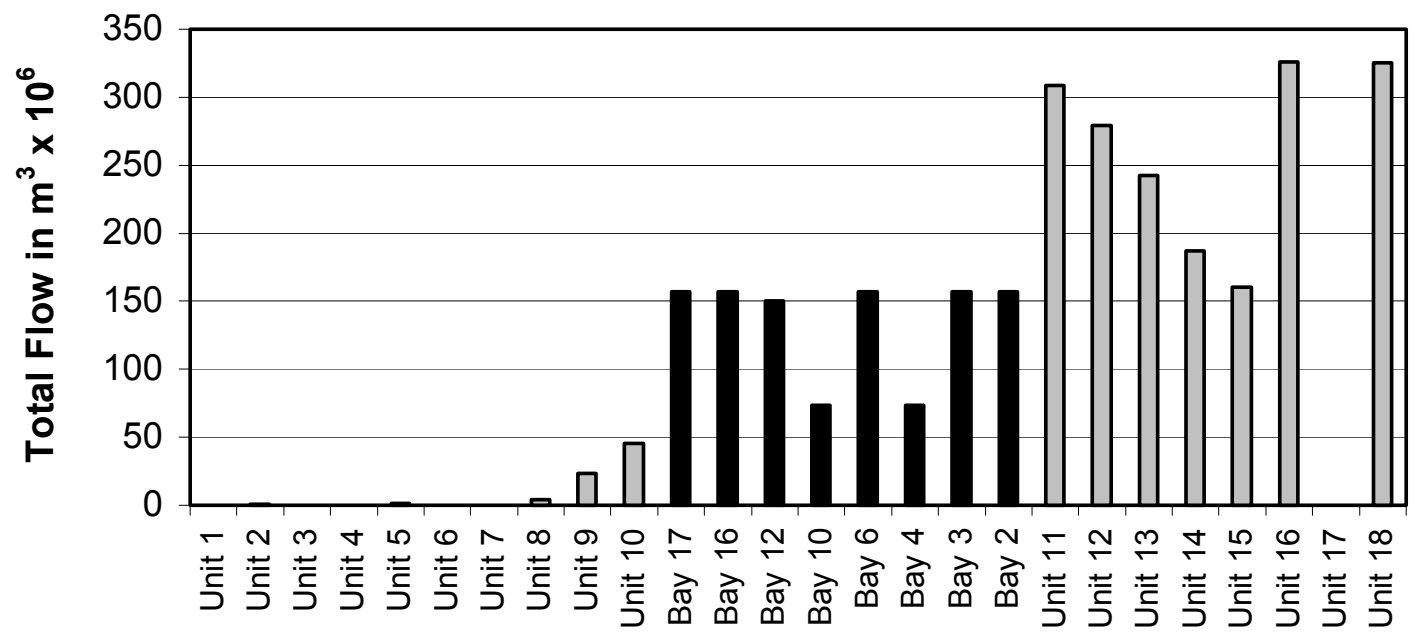

\section{Turbine Unit or Spill Bay}

Figure 3.16. Horizontal Distribution of Discharge at Turbines (gray bars) and Spill Bays (black bars) during the Ten Days that Spill Occurred in Summer. Spill bays 1 and 18 that were opened only 4 inches and other bays that were closed all season (bays 5, 7-9, 11, and 13-15) are not displayed. Turbine Unit 17 did not operate in summer. 


\subsubsection{Vertical Distributions}

\subsubsection{Powerhouse 1 - Inside Intake 10 $\underline{b}$}

At powerhouse 1, we examined the vertical distribution of fish detected by split-beam transducers sampling inside Intake 10B. In spring, we classified about $47 \%$ of all fish as guided by the STS (Figure 3.17), but in summer, that percentage fell to about 36\% (Figure 3.18).

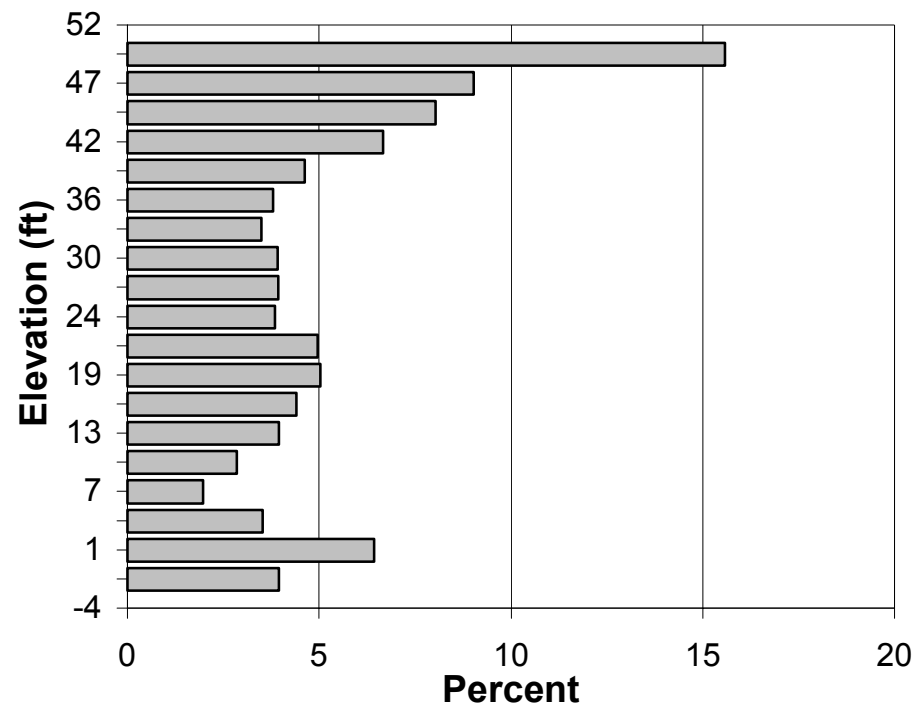

Figure 3.17. Vertical Distribution of Smolt-Sized Fish Detected inside Intake 10 $\underline{\mathrm{b}}$ at Powerhouse 1 in Spring 2001

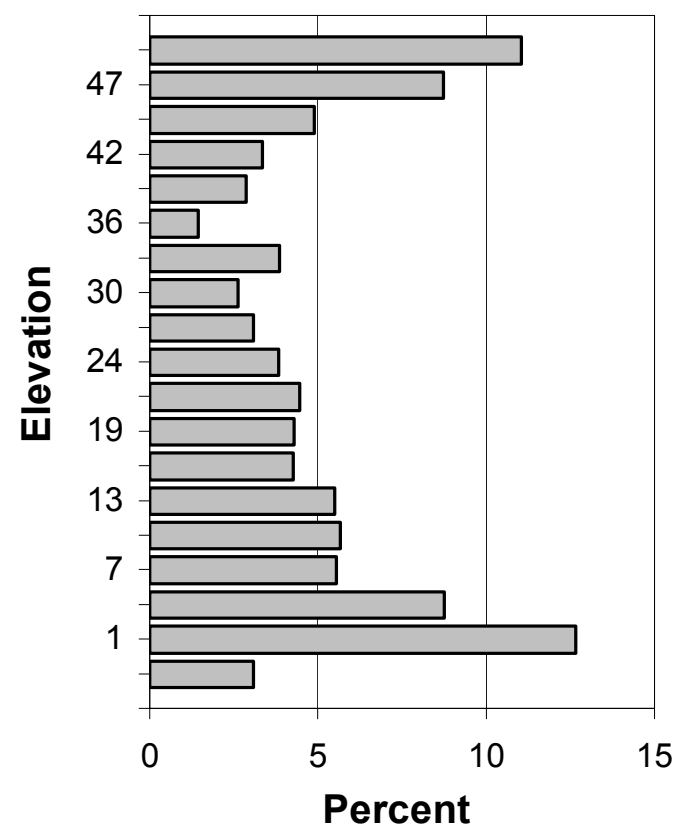

Figure 3.18. Vertical Distribution of Smolt-Sized Fish Detected inside Intake 10ㅁ in Summer 2001 


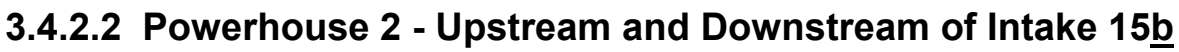

At Powerhouse 2, we examined the vertical distribution of fish detected upstream and downstream of the trash racks at Intake $15 \underline{b}$, where the gatewell and vertical barrier screen had been modified to increase flow up into the gatewell. We also examined the direction of travel of detected fish through three split-beams to better characterize the behavior of fish approaching trash racks and the effect on FGE in spring and summer.

Theoretical (expected) FGE based upon the vertical distribution upstream and downstream of

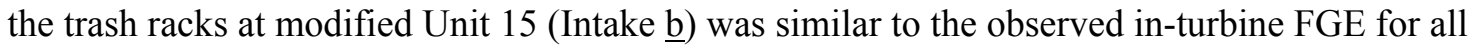
hours sampled in spring but not in summer (Figure 3.19). Theoretical FGE is defined as expected FGE based upon the upstream vertical distribution relative to an elevation for classifying guided and unguided fish projected upstream parallel to the intake roofline from the elevation used inside the turbine. The FGE of 50\% in summer was $29 \%$ less than the theoretical FGE. In spring, fish detected 16 to $21 \mathrm{ft}$ upstream of trash racks were higher in the water column than fish detected 4 to $9 \mathrm{ft}$ from the racks (Figure 3.20). A similar pattern was observed in summer (Figure 3.21), but the peak in the distribution of fish 4 to $9 \mathrm{ft}$ from trash racks was several feet lower in the water column than the peak for fish 4 to $9 \mathrm{ft}$ from racks in spring (compare Figures 3.20 and 3.21). The downward shift in the distribution of fish approaching the trash racks was observed during the day and at night (Figure 3.21).
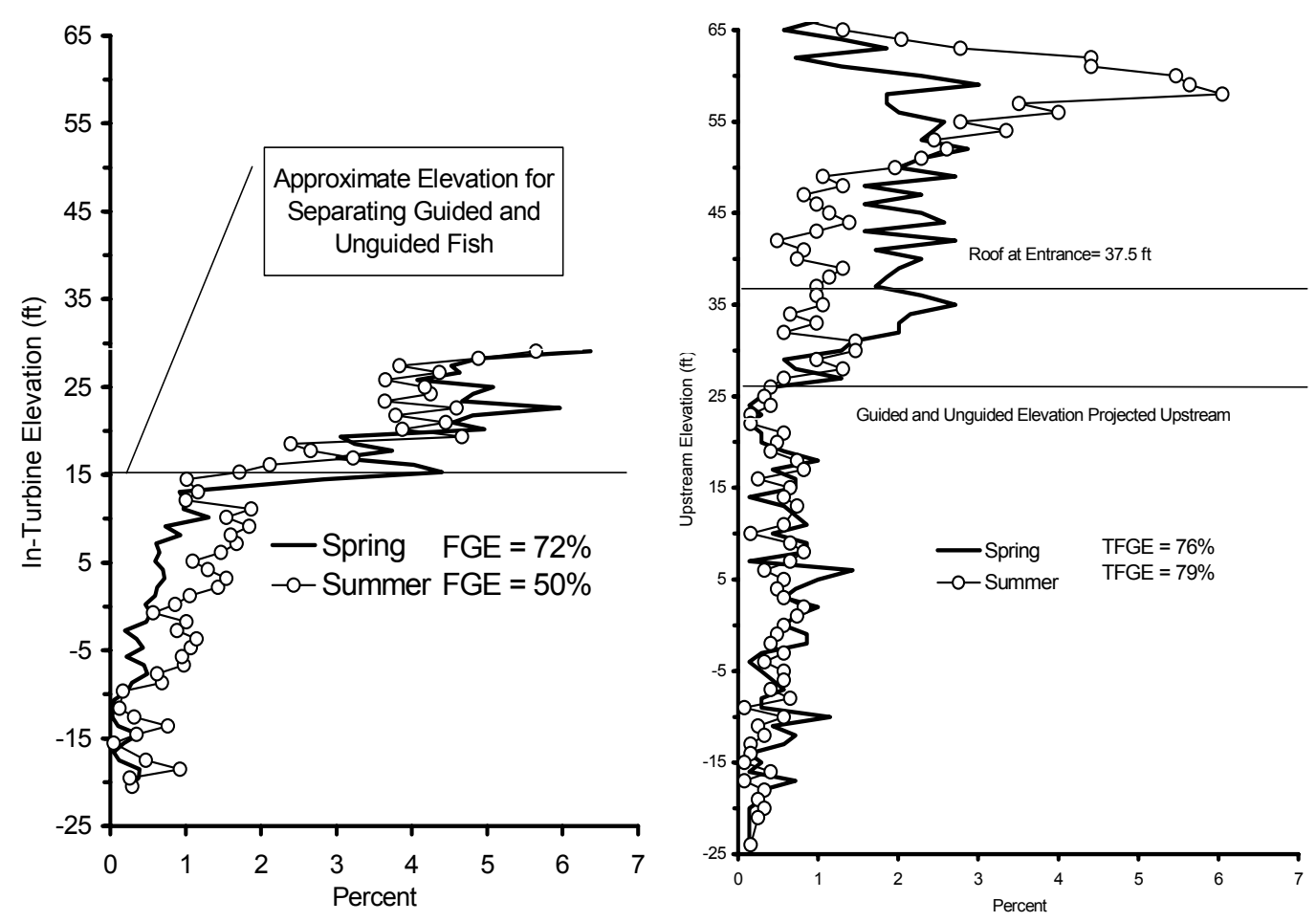

Figure 3.19. Vertical Distributions Upstream (right) and Downstream of the Trash Racks at Modified Unit 15 (Intake b). Theoretical FGE is defined as expected FGE based upon the upstream vertical distribution in spring and summer relative to an elevation for classifying guided and unguided fish projected upstream parallel to the intake roof line from the elevation used inside the turbine. 


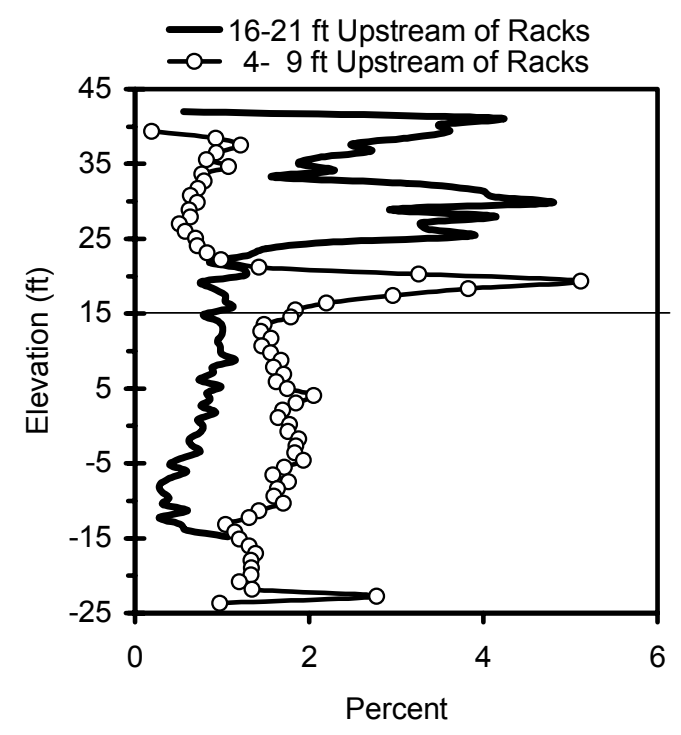

Figure 3.20. Vertical Distributions of Fish 4 to 9 and 16 to $21 \mathrm{ft}$ Upstream of Intake $15 \underline{b}$ Trash Racks in Spring
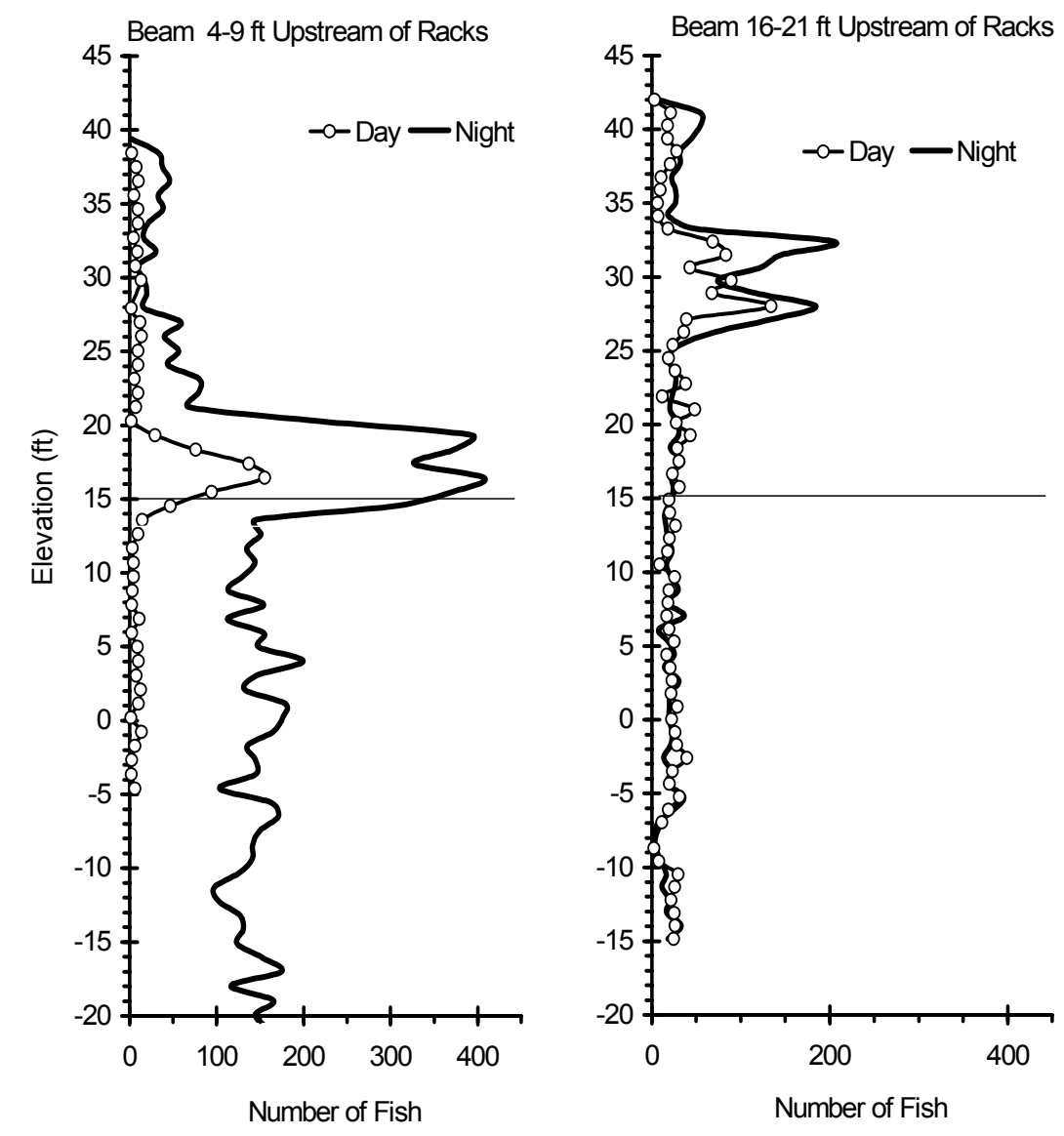

Figure 3.21. Vertical Distributions of Fish 4 to 9 and 16 to $21 \mathrm{ft}$ Upstream of Trash Racks at Intake 15 $\underline{b}$ in Summer 
The azimuth direction of travel of fish and the number of detections in each of the three successive split beams differed considerably. In spring and summer, $16 \%$ and $17 \%$ more fish were moving downstream when passing through the beam sampling 10 to $15 \mathrm{ft}$ upstream of trash racks, than when passing through the beam 4 to $9 \mathrm{ft}$ from trash racks (Figures 3.22 and 3.23). In addition, the number of fish detections was much higher in the downstream and upstream beams, particularly the beam nearest the trash racks, than the number detected in the center beam. Near the trash racks, only $54 \%$ to $55 \%$ of the fish were moving downstream.
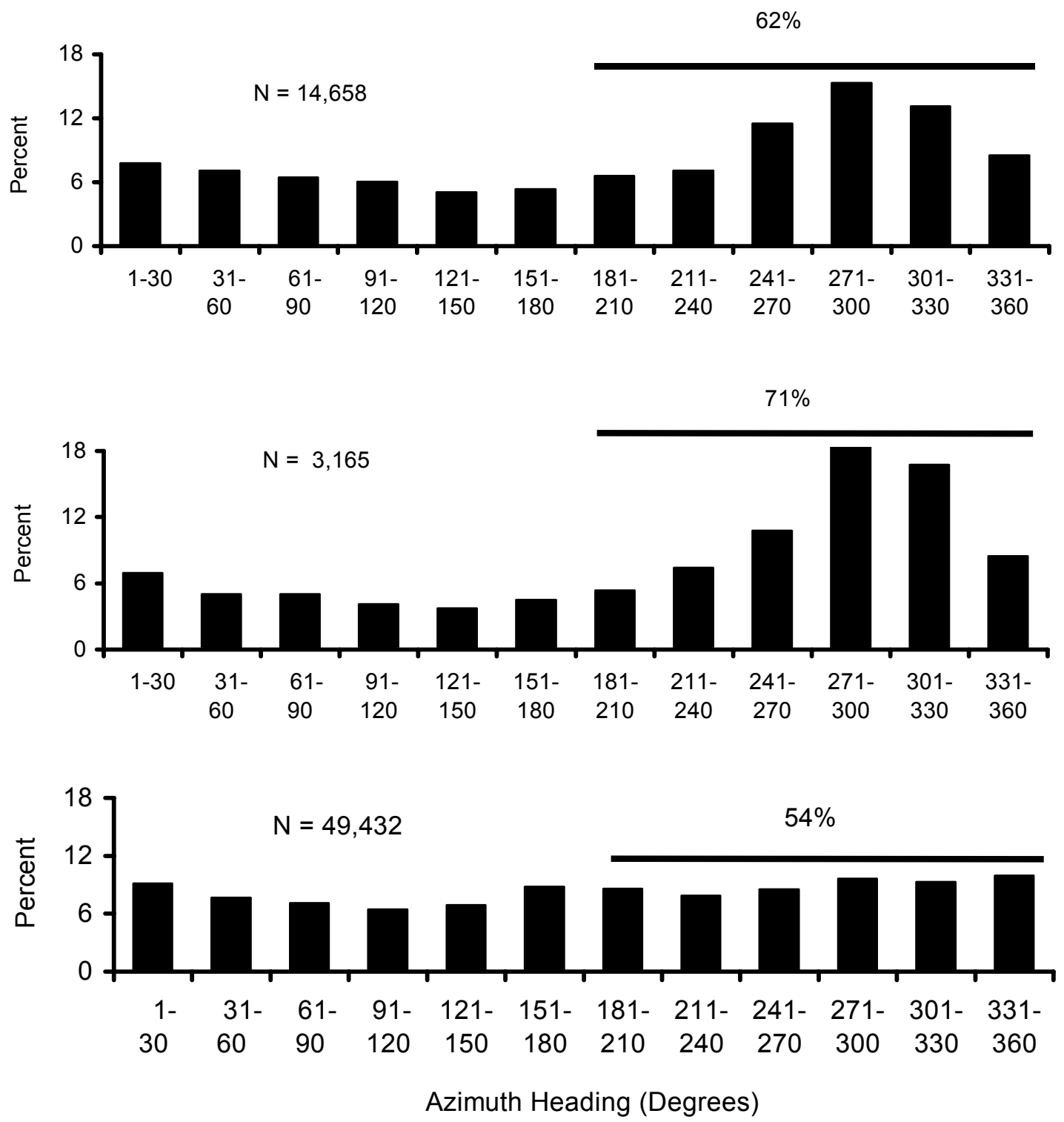

Figure 3.22. Distribution of Azimuth Headings of Fish Approaching Trash Racks at Intake $15 \underline{b}$ in Spring. Data were from down-looking, $6^{\circ}$ split beams sampling about 4 to $9 \mathrm{ft}$ (bottom plot), 10 to $15 \mathrm{ft}$ (middle plot), or 16 to $21 \mathrm{ft}$ (top plot) upstream of trash racks. 

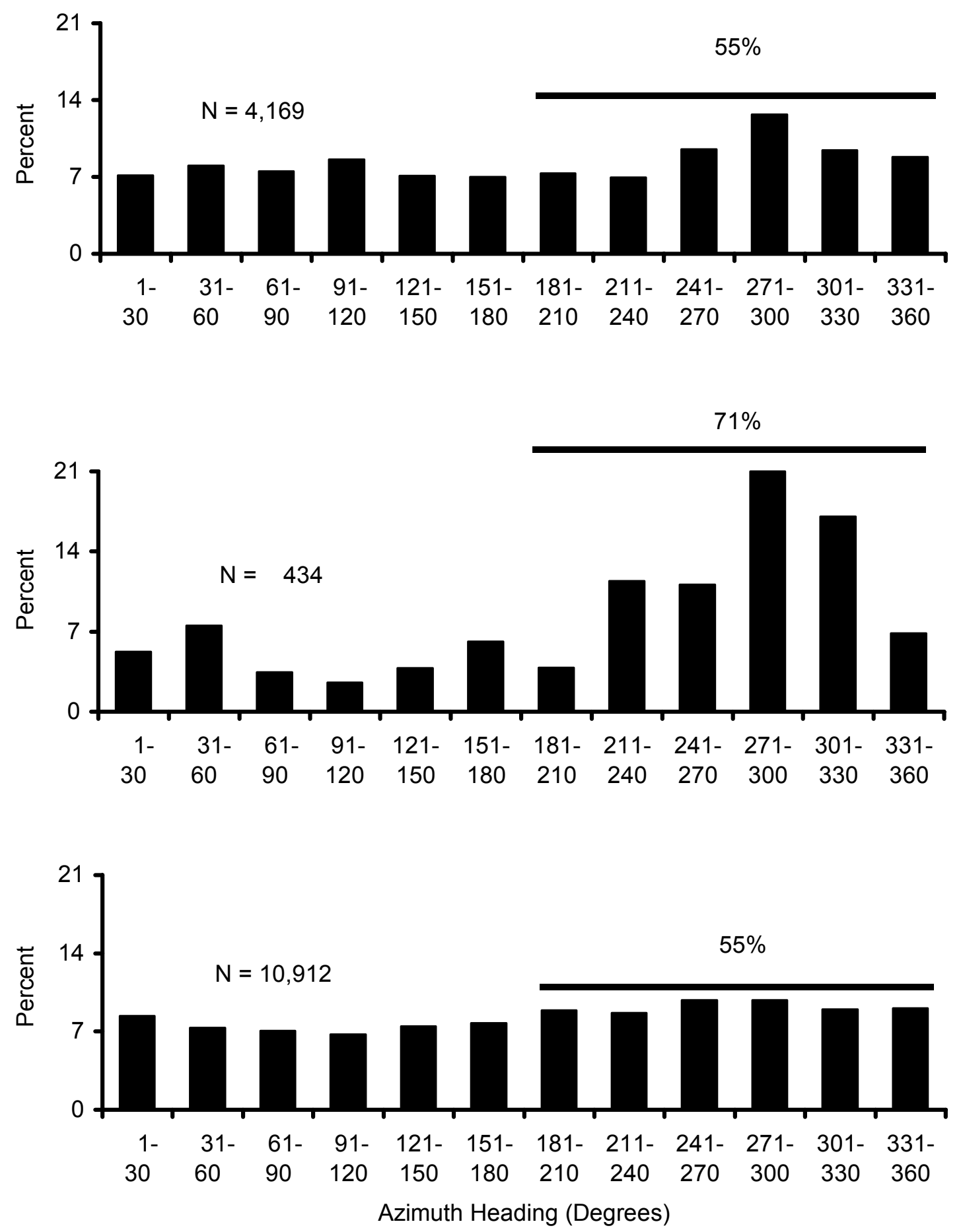

Figure 3.23. Distribution of Azimuth Headings of Fish Approaching Trash Racks at Intake $15 \underline{b}$ in Summer. Data were from down-looking, $6^{\circ}$ split beams sampling about 4-9 ft (bottom plot), $10-15 \mathrm{ft}$ (middle plot), or $16-21 \mathrm{ft}$ (top plot) upstream of trash racks. 


\subsection{Temporal Trends in Fish Passage}

\subsubsection{Seasonal Trends}

\subsubsection{Run Timing}

The run timing curve in 2001 based on hydroacoustic estimates shows that the spring peak occurred on 21 April and the summer peaks occurred on 8 and 27 June (Figure 3.24). During spring, the Juvenile Bypass System (JBS) smolt index data at the Bonneville Project indicated temporal trends similar to those observed with hydroacoustic sampling, with peaks and troughs in general agreement. Although there is some agreement between the two sampling methods in the summer, the peaks detected with hydroacoustics on 8 and 27 June were not reflected in the JBS sampling. The ratio of percentages there was good agreement between the two estimates except for a few dates where larger deviations were apparent.
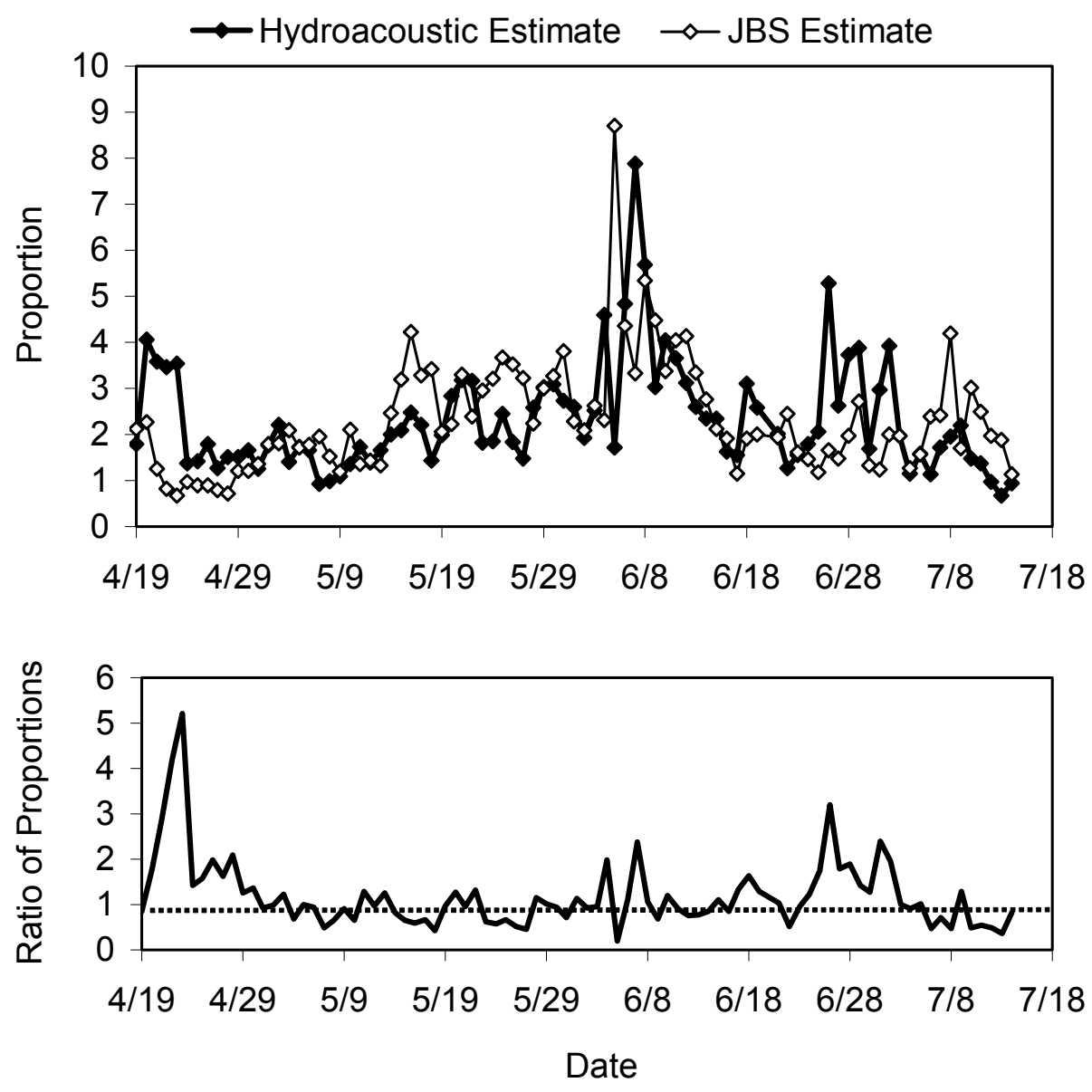

Figure 3.24. Patterns of Run Timing through the Spring and Summer Seasons at Bonneville Dam in 2001 Estimated with Hydroacoustics and by Sampling a Smolt Trap in the Juvenile Bypass System (upper plot) and the Ratio of the Two Estimated Proportions (lower plot) 


\subsubsection{Major Fish-Passage Metrics}

Project FPE was about 57\% in spring with no visually obvious trend until spill began on about 15 May when FPE began a gradual increase into early summer (Figure 3.25). The average FPE during spring spill was about $71 \%$ and $76 \%$ during the 9 days of spill in early summer. Fish passage efficiency dropped down to $34 \%$ on 16 June when spill ended, and it averaged about $40 \%$ with $\pm 10 \%$ fluctuations for the rest of summer.

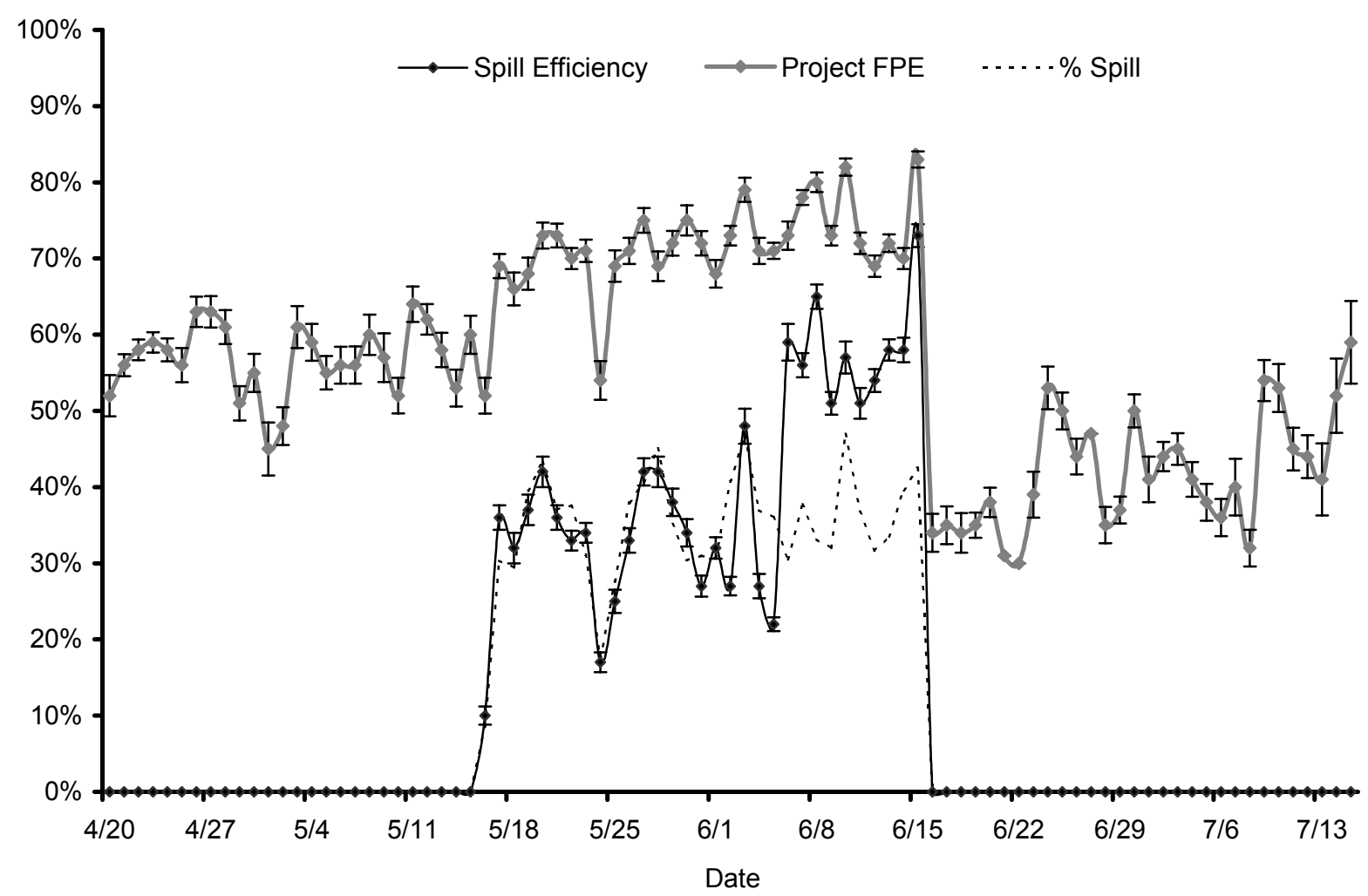

Figure 3.25. Estimated Project FPE and Spill Efficiency, and Proportion of Water Spilled at Bonneville in 2001. Error bars represent $95 \%$ confidence limits.

Powerhouse $1 \mathrm{FPE}$ estimates averaged $49 \%$ in spring and $40 \%$ in summer, but all daily estimates for Powerhouse 1 were much more variable than estimates for Powerhouse 2 (Figure3.26). Powerhouse 2 estimates averaged $57 \%$ in spring and $42 \%$ in summer, ranging from a high of $65 \%$ on 30 May to a low of $0.29 \%$ on 14 June.

Spill efficiency varied considerably from day to day but exhibited a general upward trend from 16 May, when spill began, through 15 June, the last day of spill in 2001 (Figure3.25). Spill efficiency tracked the spill proportion during the first half of the spill season but not the second half. Daily spill effectiveness estimates varied from an initial high of 1.3 on 6 May to a low of 0.6 on 26 May before increasing to the spill period high of 1.96 on 29 May (Figure3.27). As daily discharge over the spillway increased, spill effectiveness decreased. Conversely, as spill discharge decreased, spill effectiveness increased. However, the peak in spill effectiveness on 29 May was not the result of a substantial drop in spill discharge, as discharge volume remained relatively constant to the previous day's discharge. 


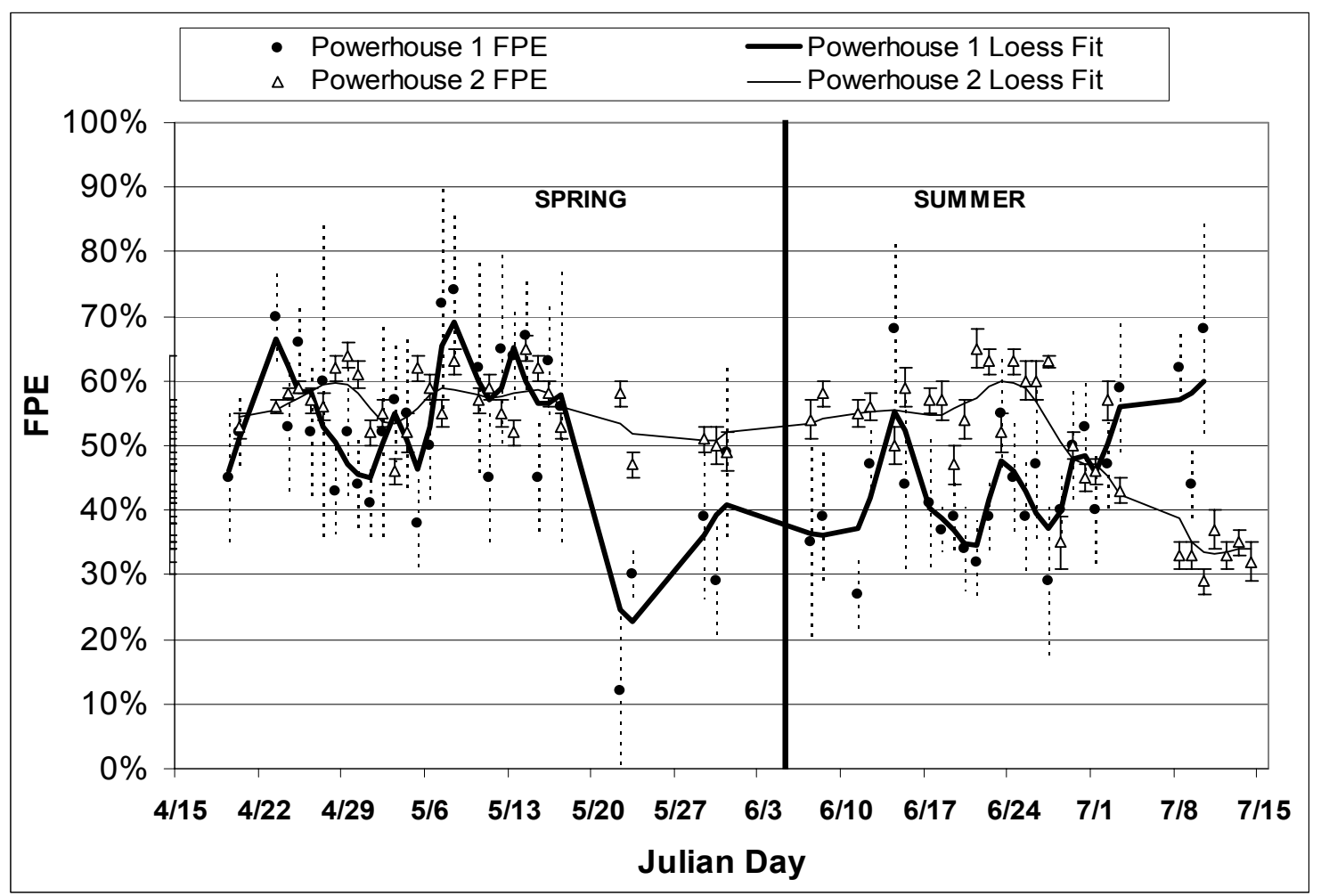

Figure 3.26. Daily Fish Passage Efficiency Estimates for both Powerhouses at Bonneville Dam in 2001. Error bars represent $95 \%$ confidence limits.

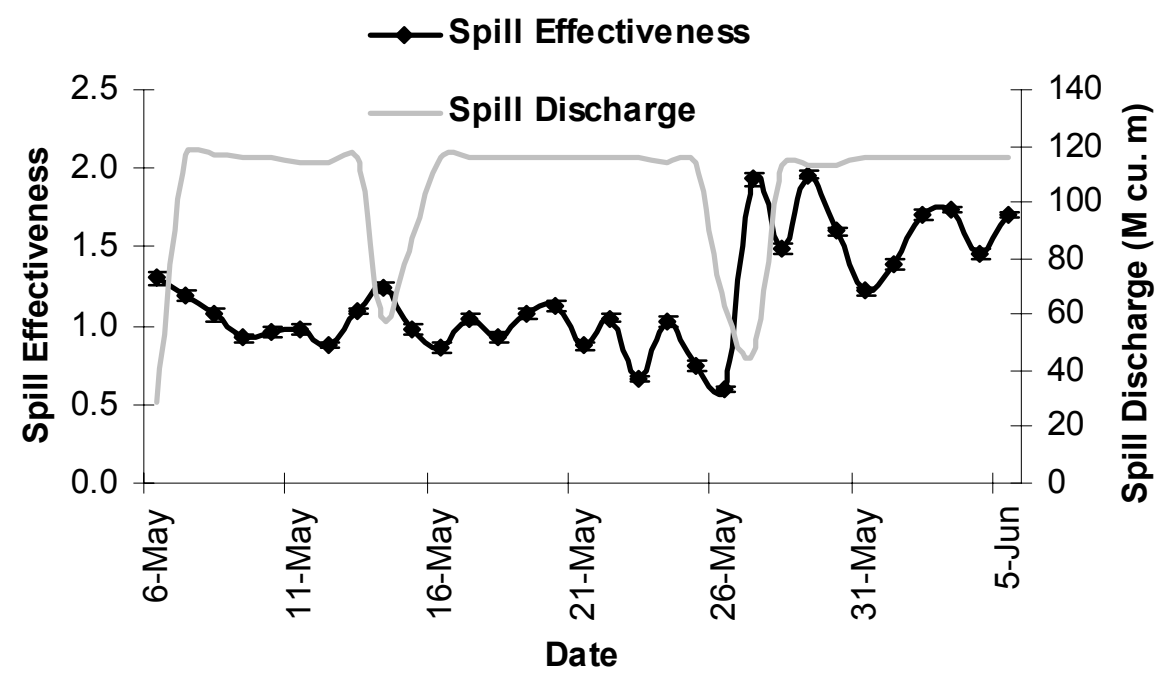

Figure 3.27. Daily Spill Effectiveness Estimates and Spill Discharge during the Limited Spill Period at Bonneville Dam in 2001. Error bars represent 95\% confidence intervals. 


\subsubsection{Guidance Efficiency at Modified Unit 15}

Daily estimates of FGE for modified intake $15 \underline{b}$ and $15 \underline{c}$ based upon all hours sampled each day decreased significantly from spring to summer but were highly variable in both seasons (Figure3.28). Generally FGE estimates for each intake trended downward through the spring and into the second week in June, then trended upward through the remaining sampling period before dipping again at the very end of the summer.

Mean FGE for Intake $15 \underline{\mathrm{b}}$ was significantly higher than for Intake $15 \underline{\mathrm{c}}$ in spring $(72.0 \%$ vs. $59.0 \%)$ and in summer ( $50 \%$ vs. $44 \%$ ). In spring, there were 32 days for which we had FGE estimates for both intakes $15 \mathrm{~b}$ and $15 \mathrm{c}$, and a paired t-test comparing the mean FGEs for each found the difference significant $(p=0.00078)$. In summer, there were 31 days with estimates for both intakes and again the difference was significant ( $\mathrm{p}=0.00166)$. Intake $15 \underline{\mathrm{b}}$ was between two turbine intake extensions (TIEs) and Intake $15 \underline{\mathrm{c}}$ was behind an extension. Although there was agreement between intake FGE estimates for some days (e.g., on 1 and 2 June the estimates were within $1 \%$ of one another), there were also days with large disparity between the intake FGE estimates (on 24 April the FGE for Intake 15 $\underline{b}$ was 35\% greater than for Intake 15ㄷ). In spring, there were 32 days for which we had FGE estimates for both intakes $15 \mathrm{~b}$ and $15 \mathrm{c}$ and paired t-tests comparing the mean FGEs for each found the difference significant $(\mathrm{p}=0.00078$. In summer there were 31 days with estimates for both intakes and again the difference was significant $(\mathrm{p}=0.00166)$. In both cases, the FGE of Intake $15 \mathrm{~b}$ was higher than that of $15 \mathrm{c}$.

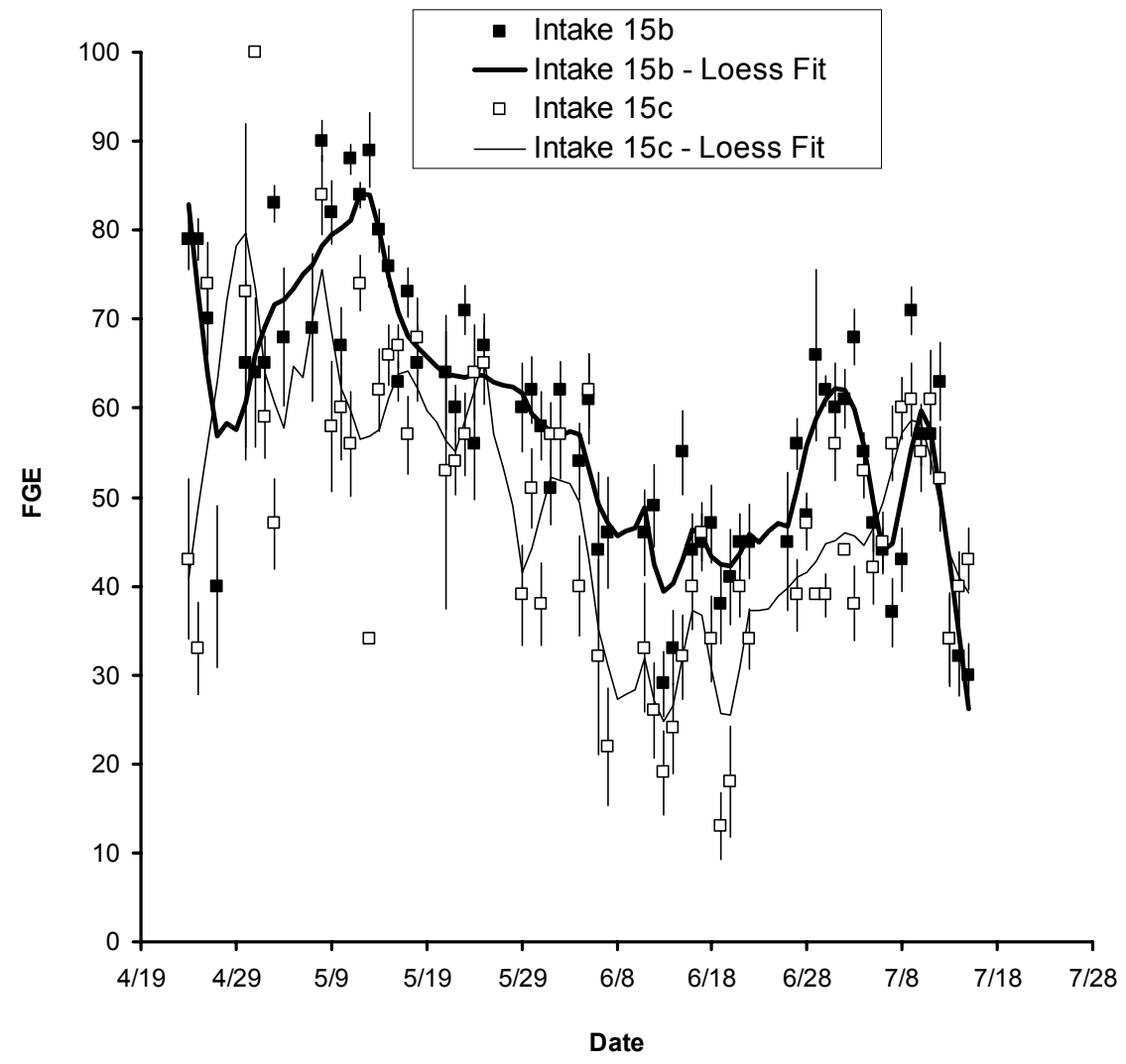

Figure 3.28. Estimates of Fish Guidance Efficiency (FGE) throughout Spring and Summer at Intake 15므 and $15 \underline{c}$ at Bonneville Dam in 2001. Error bars represent $95 \%$ confidence intervals. 


\subsubsection{American Shad Run Timing}

American shad present a problem for hydroacoustic sampling in summer. Almost 2.3 million American shad migrated up through Bonneville Dam in 2001. Shad began arriving at the dam in mid May and showed up in large numbers during the third week in May ( $>50,000 /$ day) before peaking on 1 June when 144,000 individuals were observed (Figure 3.29). By 6 June, 50\% of all the migrating shad had already passed the dam. By 30 June, the shad migration was essentially complete with over $98 \%$ of all fish having passed by that day. Nearly twice as many shad passed through Bonneville Dam in 2001 as passed in 2000 .

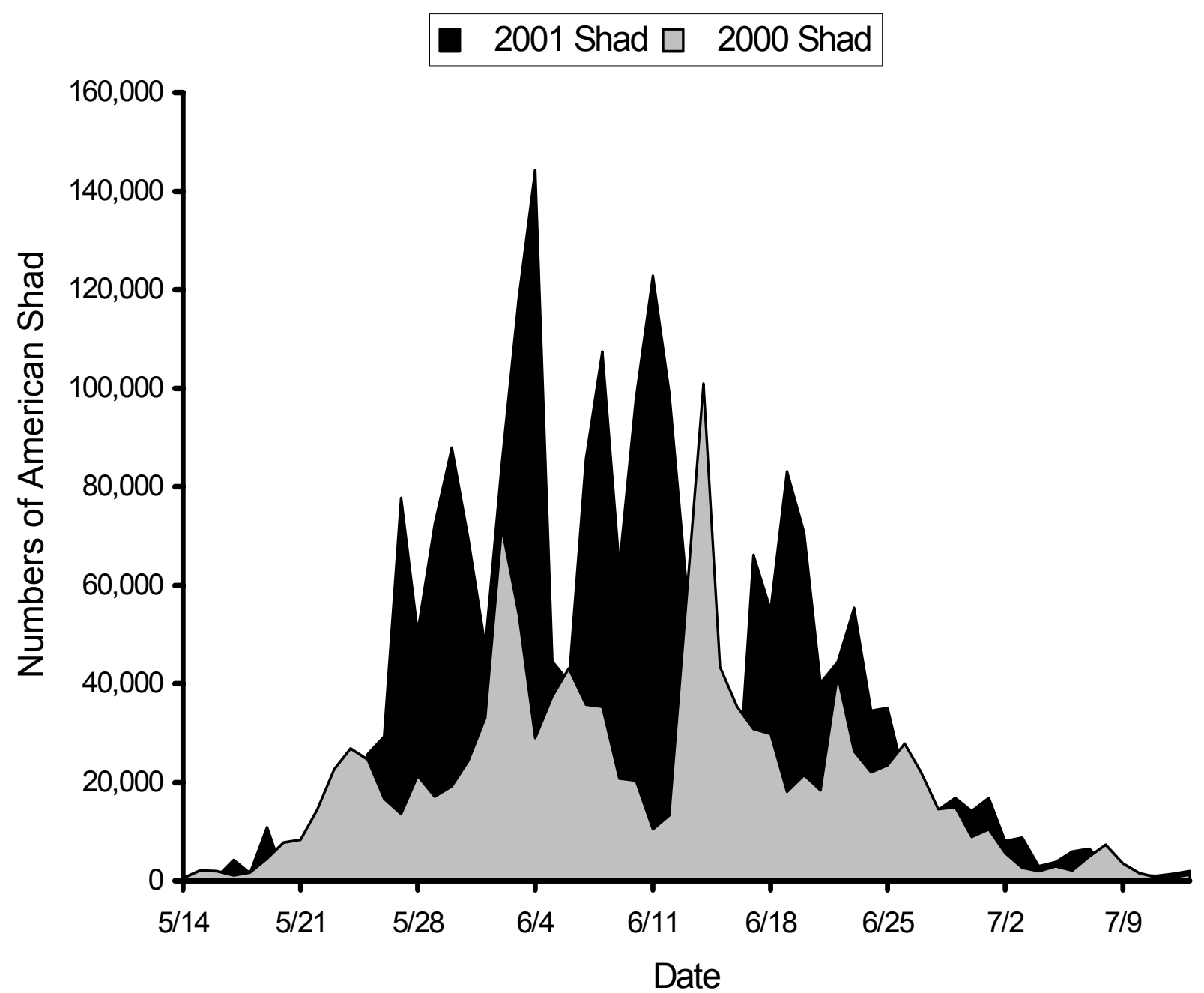

Figure 3.29. Run Timing of Up-Migrating American Shad through the Bonneville Project in 2000 and 2001 


\subsubsection{Diel Trends}

\subsubsection{Project-Wide Estimates and Spill}

On an hourly basis, project-wide estimates of FPE in the springtime were higher at night than during the day, and extreme values only differed by $12 \%$ (Figure 3.30). Summertime estimates of FPE were higher at night than they were during 6 or 7 of the daytime hours, although a diel trend was not as obvious in summer as it was in spring.

Estimates of spill efficiency during the spring were low from mid-morning to early evening and were higher at night than they were during the day (Figure 3.30). Spill efficiency in the summer was highest from early morning to early afternoon and bottomed out in the early evening. Estimates of spill effectiveness in the spring were slightly higher in the late evening and early morning hours but changed very little throughout the day (Figure 3.30). Summertime spill effectiveness followed a pattern similar to that of summer spill efficiency with peaks in the early morning to early afternoon and lows in the early evening.
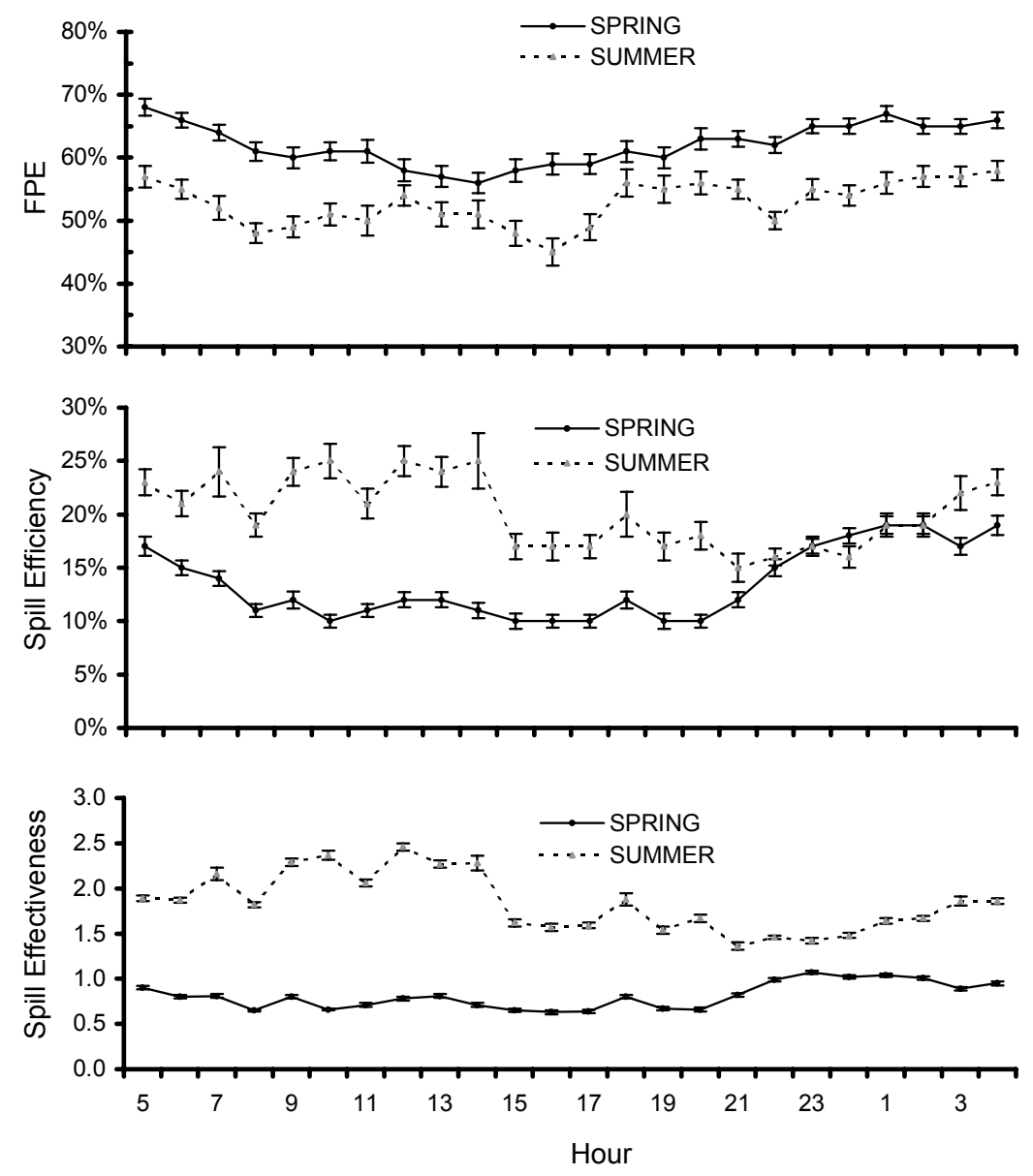

Figure 3.30. Diel Patterns of Fish Passage Efficiency, Spill Efficiency, and Spill Effectiveness during the Spring and Summer at Bonneville Dam in 2001 
Project-wide fish passage through all routes in the spring gradually declined through the day, began to slightly increase in the early evening, and peaked at 2100 then declined again through the early morning hours (Figure 3.31). During daylight hours, total project passage and total flow through the Project exhibited an inverse relationship in the spring. During nighttime hours, total project passage followed total project flow (i.e., as flow decreased, passage decreased). In the summer, total project passage through the day followed a pattern similar to spring except there was a slight increase in passage at 0800, the gradual decline lasted longer into the day, and the peak occurred an hour later (at 2200). As in spring, the relationship between total project passage and flow through the Project in the summer was inverse during daylight hours and direct during nighttime hours.
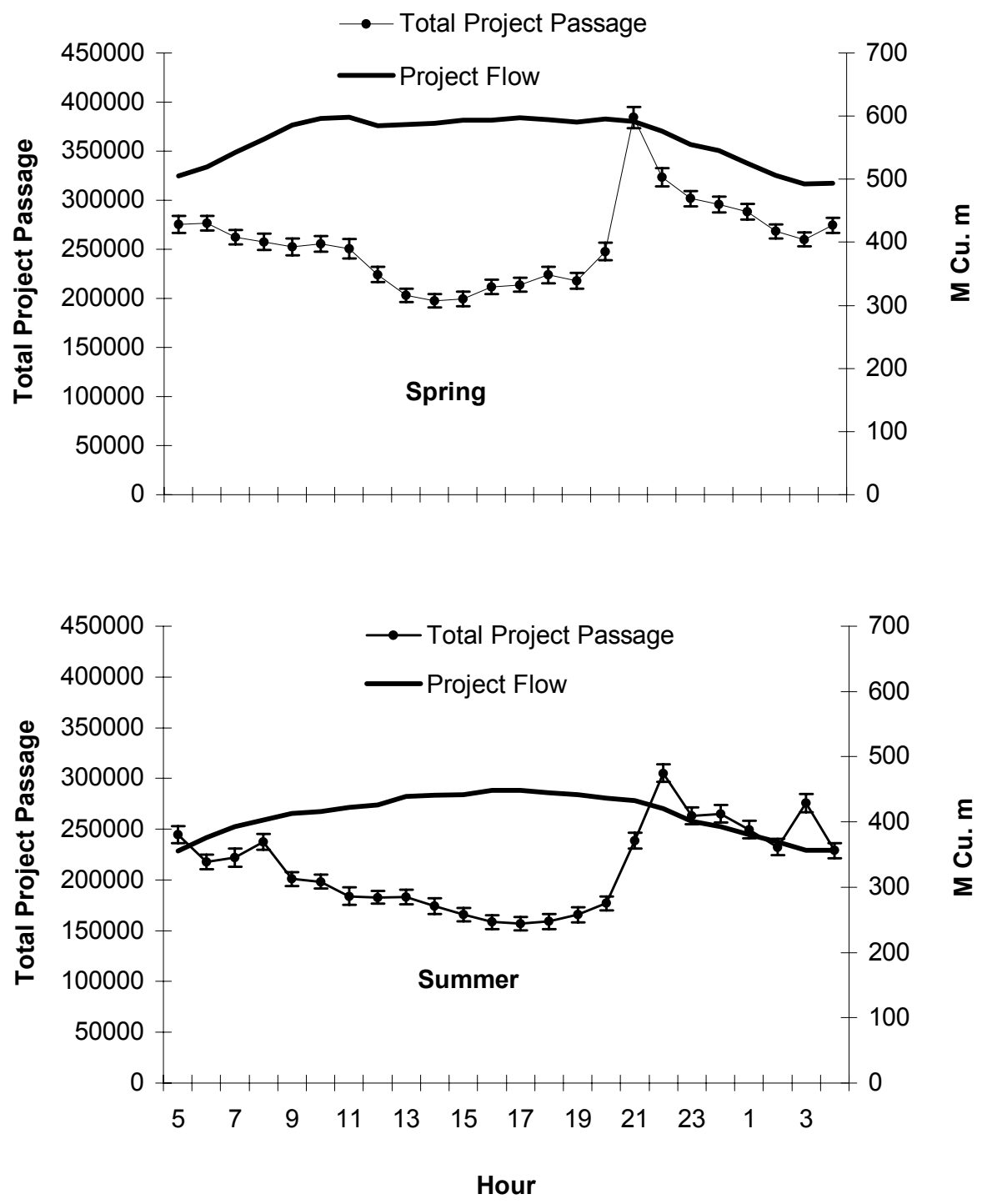

Figure 3.31. Estimates of Diel Trend in Total Fish Passage and Discharge in Spring (top) and Summer through Bonneville Dam in 2001. Error bars represent 95\% confidence intervals. 
Numbers of fish spilled in the spring declined through the day then increased sharply at 2100 and peaked at 0100 (Figure 3.32). The volume of water spilled differed little among hours in the spring, but a slight increase occurred at 2300, coinciding with an increase in the number of fish spilled. In the summer, the pattern of fish spilled through the day was less defined than in spring, but the decreasing trend during the day and an increase in nighttime hours was still evident. Spill passage during the summer peaked at 0300. There was very little variation in hourly spillway flow in the summer.
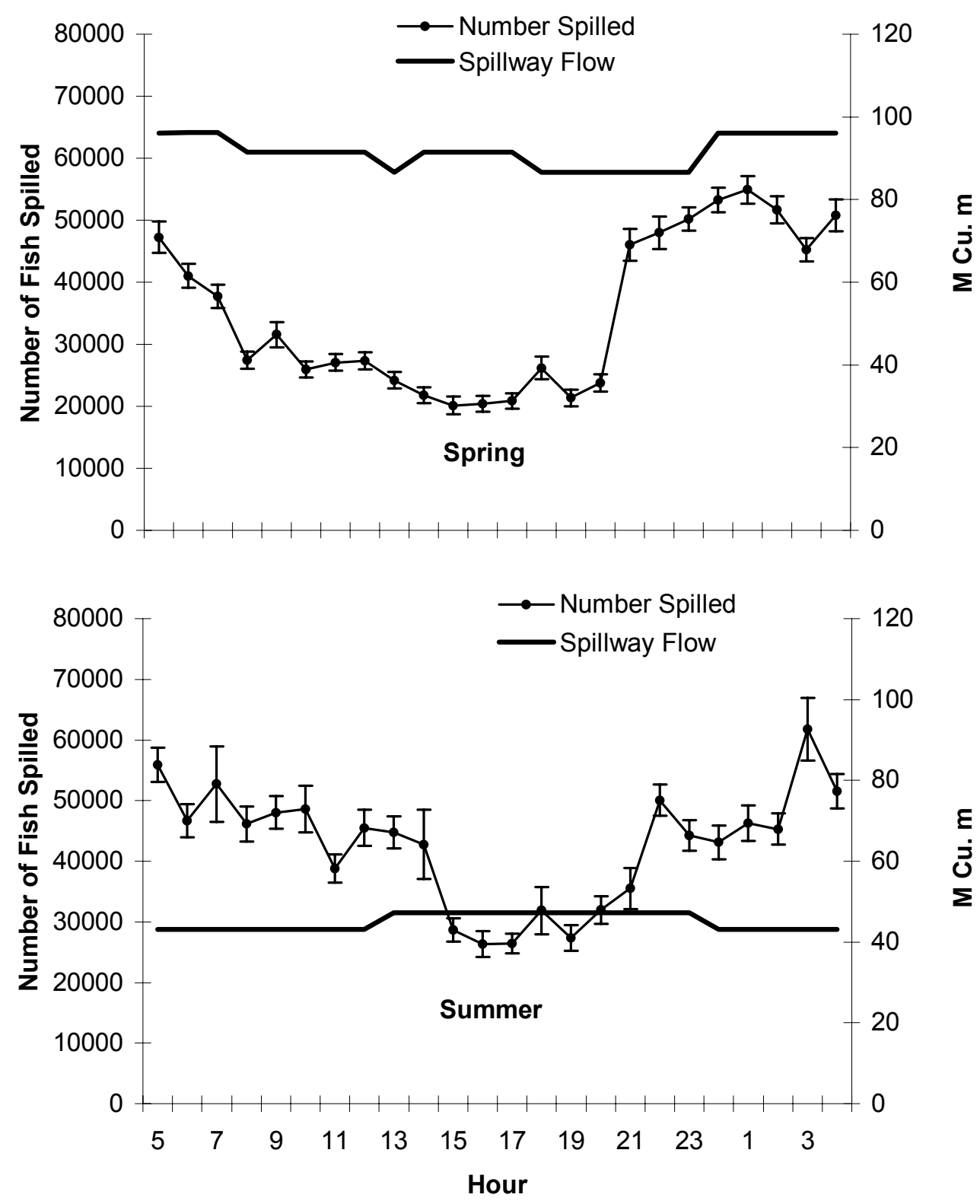

Figure 3.32. Estimates of Diel Trend in Spilled Fish and Discharge over the Spillway in Spring (top) and Summer through Bonneville Dam in 2001. Error bars represent $95 \%$ confidence intervals. 


\subsubsection{Fish Guidance Efficiency and Passage at Turbines}

We found no significant diel trends in FGE at Powerhouse 1 in spring or summer because variances of estimates were too high (Figure 3.33). Total fish passage (guided + unguided) through Powerhouse 1 in the spring was bimodal, with peaks during late morning and early evening hours. Powerhouse 1 FGE estimates in the summer were highest from 0100 to 0600 hours and generally were lowest during late afternoon and early evening hours although these estimates did not differ significantly, as indicated by overlapping 95\% confidence intervals. Total passage through Powerhouse 1 in the summer was higher from about 1600 through 2200 hours than it was during the rest of the day.
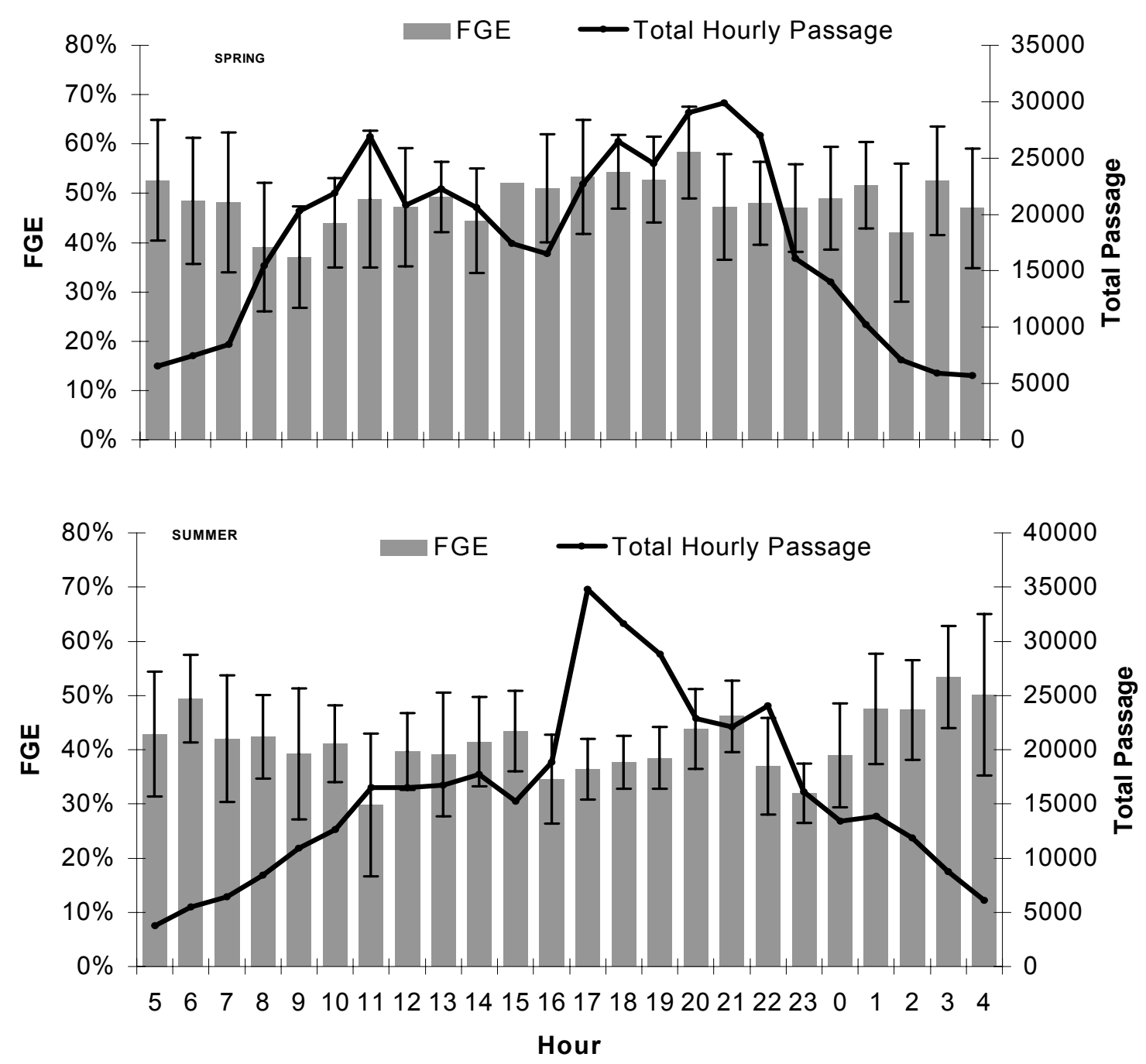

Figure 3.33. Diel Estimates of Fish Guidance Efficiency and Total Fish Passage for Powerhouse 1 during Spring (top) and Summer at Bonneville Dam in 2001. Error bars represent 95\% confidence limits.

Powerhouse 2 FGE estimates were generally higher in late afternoon and at night than they were during the day (Figure 3.34). In spring, the estimates declined slightly from highs at 0100 to 0500 to lows from 1200 to 1500 . Total fish passage in the spring declined through the morning and into the early 
afternoon then slightly increased through the remaining afternoon hours then rose sharply and peaked at 2100. During the summer, FGE estimates at Powerhouse 2 dipped to lows in the midmorning and early afternoon hours and peaked staying relatively constant from 1800 to 0400 . Total passage through Powerhouse 2 in the summer was similar to the pattern observed during spring except the initial increase started later in the afternoon and the peak occurred at 2200 (instead of 2100 as in spring).
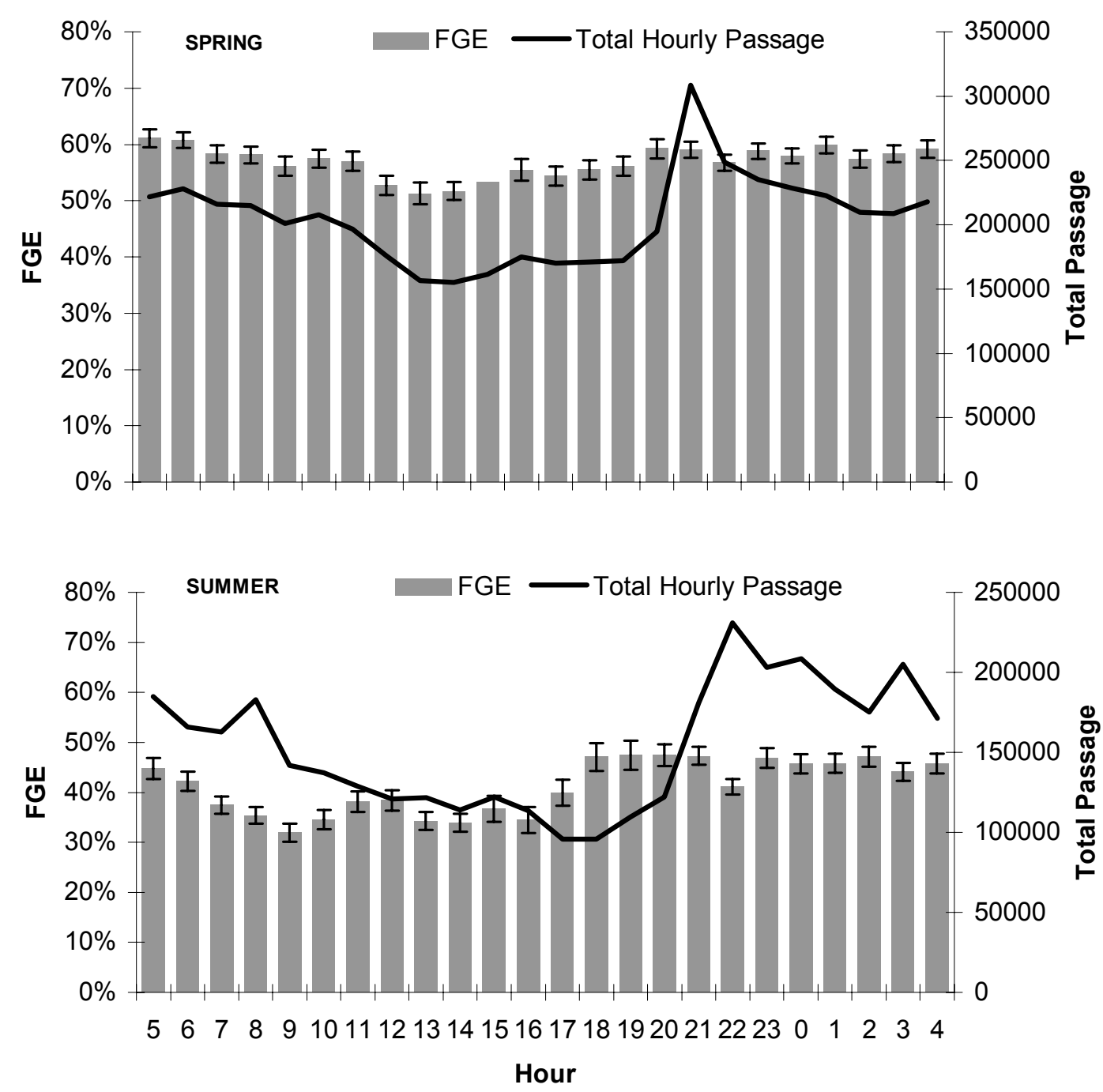

Figure 3.34. Diel Estimates of Fish Guidance Efficiency and Total Fish Passage for Powerhouse 2 during Spring (top) and Summer at Bonneville Dam in 2001. Error bars represent 95\% confidence limits.

\subsubsection{Compared to Radio Telemetry Estimates}

Hydroacoustic and radio telemetry estimates of hourly trends in fish passage for the project were generally similar in both seasons (Figures 3.35and3.36), except for a peak in radio telemetry data in the middle of the afternoon (1400 to 1600 hours) in both seasons that was not evident in the hydroacoustic 
data. The hydroacoustic season was modified to match the radio telemetry spring season. In both spring and summer, both hydroacoustics and radio telemetry methods documented a peak in fish passage after sunset. Scott Evans of USGS provided radio telemetry data for Figures 3.35 and3.36.

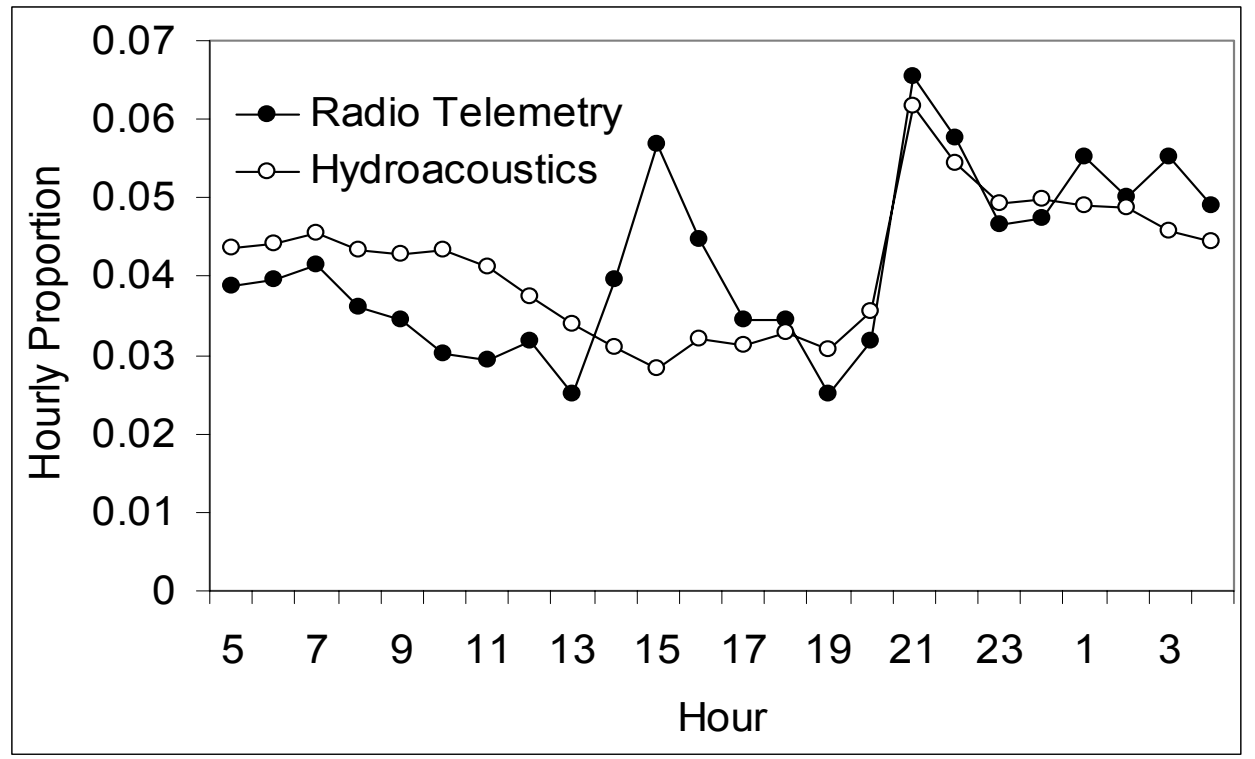

Figure 3.35. Diel Passage Based on Hydroacoustic and Radio Telemetry Sampling at Bonneville Dam in 2001 during the Spring (5/1-6/9) when both Radio Telemetry and Hydroacoustic Studies Were Ongoing

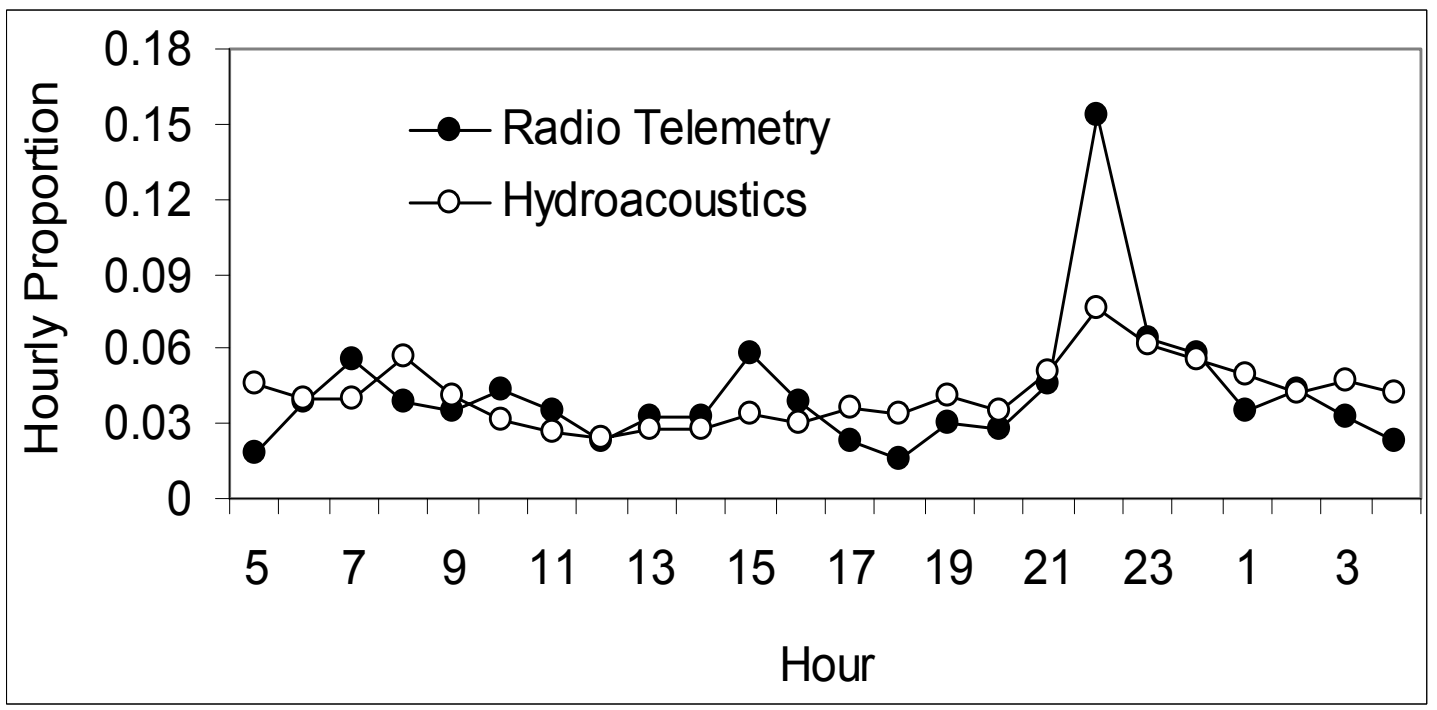

Figure 3.36. Diel Passage Based on Hydroacoustic and Radio Telemetry Data at Bonneville Dam in 2001 during the summer, when both Radio Telemetry and Hydroacoustic Studies Were Ongoing 
The average hourly percentage of fish passage estimated by hydroacoustics to have passed entire structures (powerhouses or the spillway) or combinations of structures in daytime (0500 to 2059 hours) were within one percent of radio telemetry results for the same hours in both spring and summer (Table 3.2).

Table 3.2. Percentage of Fish Estmated by Hydroacoustics (HA) and Radio Telemetry (RT) to Have Passed Bonneville Dam Structures during an Average Daytime Hour (0500 to 2059 hours) in Spring and Summer of 2001. Data from non-overlapping parts of seasons have been deleted and adjusted appropriately so that the times reported here are the same for both methods. Those dates are May 1-June 9 for spring and July 1-July 15 for summer.

\begin{tabular}{|l|c|c|c|}
\hline \multicolumn{1}{|c|}{ Season and Location } & HA Percent & RT Percent & Difference \\
\hline Spring PH1 Only & $4.68 \%$ & $3.86 \%$ & $0.82 \%$ (HA>RT) \\
\hline Spring PH2 Only & $3.77 \%$ & $3.46 \%$ & $0.31 \%(\mathrm{HA}>\mathrm{RT})$ \\
\hline Spring Spillway Only & $3.49 \%$ & $4.04 \%$ & $0.55 \%$ (RT>HA) \\
\hline Spring PH2 + Spillway & $3.67 \%$ & $3.55 \%$ & $0.12 \%(\mathrm{HA}>\mathrm{RT})$ \\
\hline Spring Full Project & $3.73 \%$ & $3.56 \%$ & $0.17 \%(\mathrm{HA}>\mathrm{RT})$ \\
\hline Summer PH1 Only & $4.72 \%$ & $4.17 \%$ & $0.55 \%(\mathrm{HA}>\mathrm{RT})$ \\
\hline Summer PH2 Only & $3.51 \%$ & $3.18 \%$ & $0.33 \%(\mathrm{RT}>\mathrm{HA})$ \\
\hline Summer Spillway Only & $\mathrm{N} / \mathrm{A}$ & $5.73 \%$ & $\mathrm{~N} / \mathrm{A}$ \\
\hline Summer Full Project & $3.58 \%$ & $3.30 \%$ & $0.28 \%(\mathrm{HA}>\mathrm{RT})$ \\
\hline
\end{tabular}




\subsection{Fish Guidance Efficiencies}

\subsubsection{Background}

Fish guidance efficiency is the ratio of the estimated number of fish passing a turbine by a nonturbine route ("guided" fish) to the estimated number of all of the fish passing that turbine ("guided" + "unguided" fish). Fish passage efficiency is the same calculation done on the scale of a powerhouse or the entire project. Based upon historical information, FPE and FGE are expected to be lower in summer than in spring. Results of the efficiency evaluations of fish-guidance structures are presented in the following order: 1) the STS versus the ESBS at Powerhouse 1; 2) Powerhouse 1 versus Powerhouse 2 STS; 3) Modified Unit 15 STS versus other Powerhouse 2 STS.

\subsubsection{Comparing Performance of Fish-Guidance Structures}

In spring, the FGE of the ESBS at Unit 8 was higher than that of all STS-equipped units, except for modified Unit 15 at Powerhouse 2, but in summer, the FGE of Unit 15 was higher than that of the ESBS and the combined FGE of all other unmodified STS units (Figure3.37). Despite an impressive FGE in spring, Unit 8 only ran for about $8 \mathrm{~h}$, so its contribution to FPE was minimal. It only ran $5 \mathrm{~h}$ in summer. The FGE of the modified Unit 15 was higher than that of STS-equipped units at Powerhouse 1 and Powerhouse 2, which had similar ranges in FPE, in most of spring and all but the end of summer (Figure 3.38). Spring FGE was significantly higher than summer FGE, particularly for Unit 15 and other Powerhouse 2 units (Figure 3.37 and 3.38).

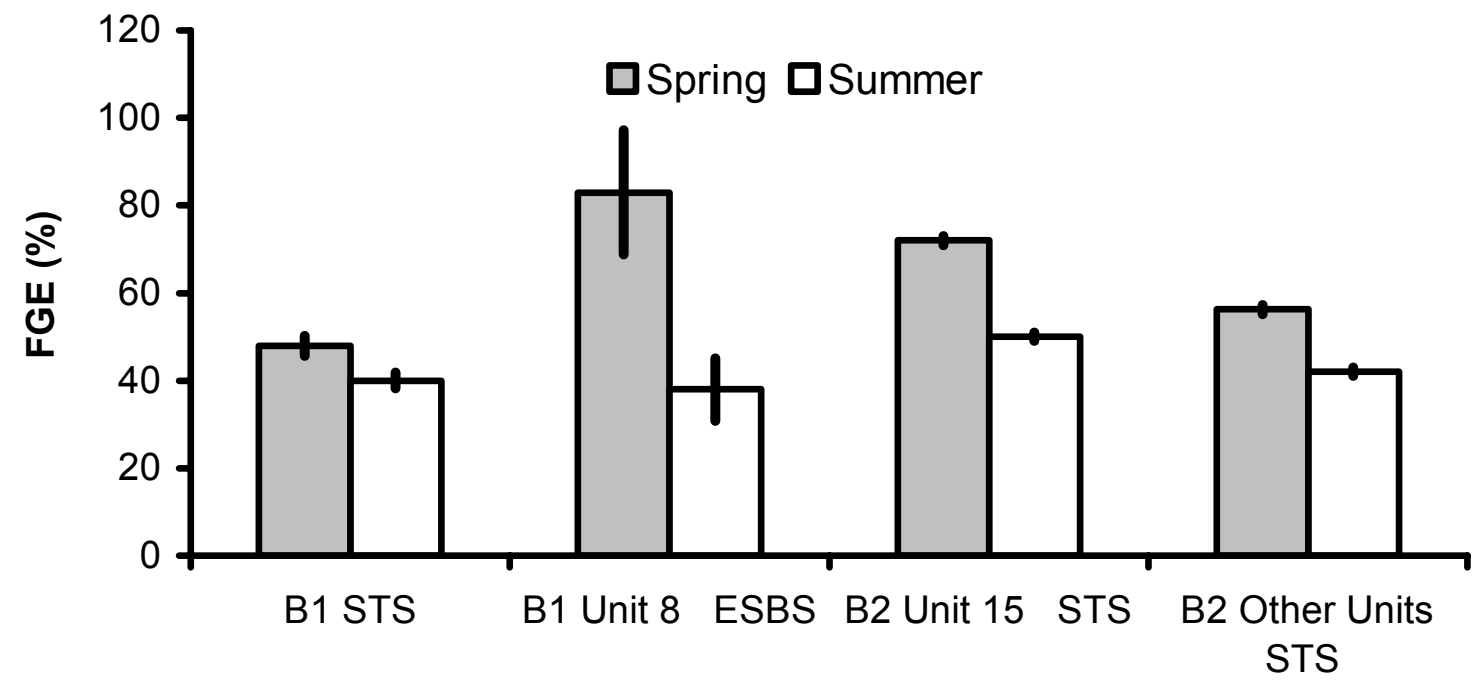

\section{Guidance Location and Type}

Figure 3.37. Comparison of FGE among Combinations of Location and Fish-Guidance Devices or Conditions. Unit 15 had extensive structural modifications to a gatewell and vertical barrier screen to increase flow up the gatewell slot. Error bars are 95\% confidence limits and estimates with overlapping bars are not considered different. 


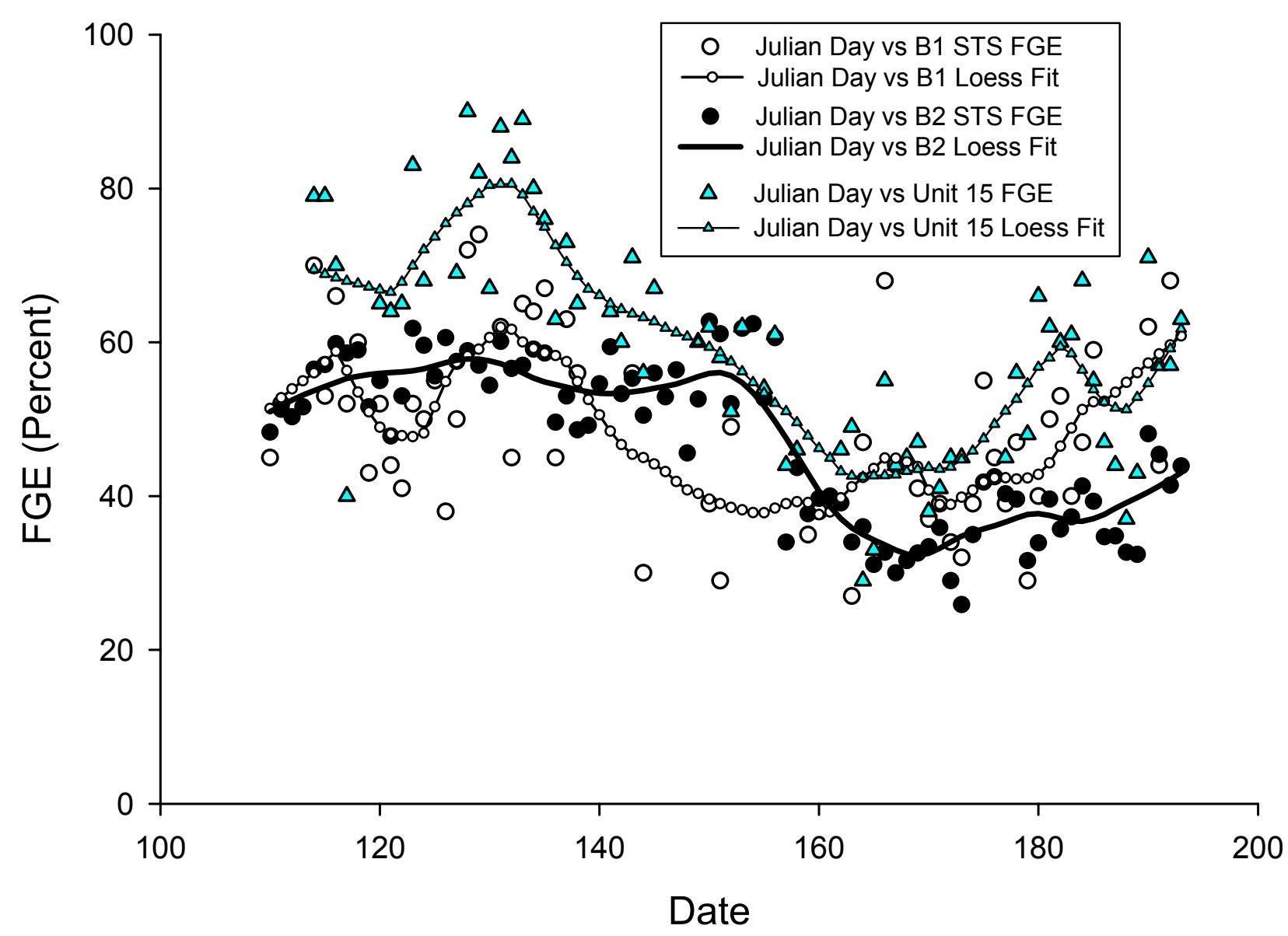

Figure 3.38. Comparison of FGE among Types of Units with STS's at Powerhouse 1, Powerhouse 2, and at Modified Unit 15 by Date

The FGE of individual units (Figure3.39) was more variable than that estimated for units with similar guidance devices or passage conditions (Figure 3.37). For example, the FGE of Unit 15 in summer actually was $4 \%$ less than that observed at Unit 14 and statistically the same as that estimated for Unit 13, although it exceeded the FGE of all other Powerhouse 2 units (Figure 3.39). In summer, units 2 and 6 also had high FGE estimates, but they only ran $2 \%$ of the time (20 and 23 hours, respectively). The $95 \%$ confidence limits associated with estimates at Powerhouse 1 units were wider than those at Powerhouse 2.

There was a tendency for FGE to be higher at intakes between turbine intake extensions (TIEs) than at intakes behind TIEs. For example, randomly sampled intakes that happened to be between TIEs at units 12,13,14, and 15 had higher FGEs than estimated for Unit 11 and 18 in spring and summer and at Unit 16 in summer. Intakes at units 11, 16, and 17 were behind TIEs. We also observed higher FGE at Intake $15 \underline{b}$, which was between two TIEs than we did at Intake 15ㅁ, which was behind a TIE, although the difference was much greater in spring than in summer (Figure 3.40). Intake 15 $\underline{b}$ also passed significantly more fish than did Intake 15 $\underline{\mathrm{c}}$ in both seasons, and FGE was higher in spring than in summer at both 
intakes. Exceptions to the trend of higher FGEs at intakes between TIEs included the intake sampled at Unit 16 in spring, which had a high FGE despite being behind a TIE and the intake at Unit 17, which produced a below-average FGE in spring despite being between two TIEs. The lowest FGEs were recorded at an intake behind a TIE at Unit 18 in spring and summer, and an intake behind a TIE at Unit 11 had the next-to-the-lowest FGE in summer. There was a trend for FGE to be higher at units near the center than at the ends of Powerhouse 2. Unit 1, which is located at one end of Powerhouse 1 had the lowest FGE of all units at that Powerhouse in both spring and summer.

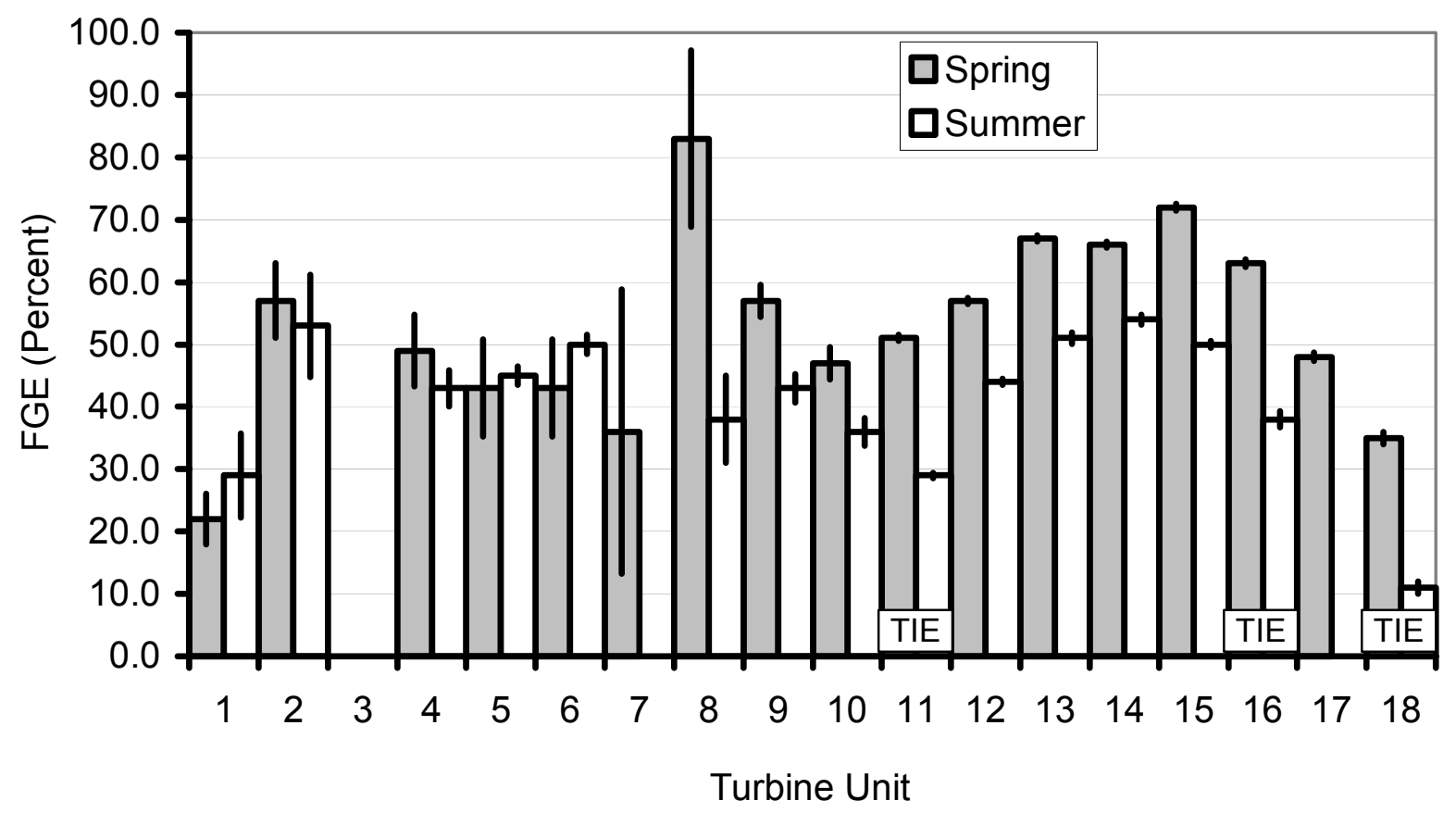

Figure 3.39. Estimates of FGE and 95\% Confidence Limits for Turbine Units at Bonneville Dam in Spring and Summer 


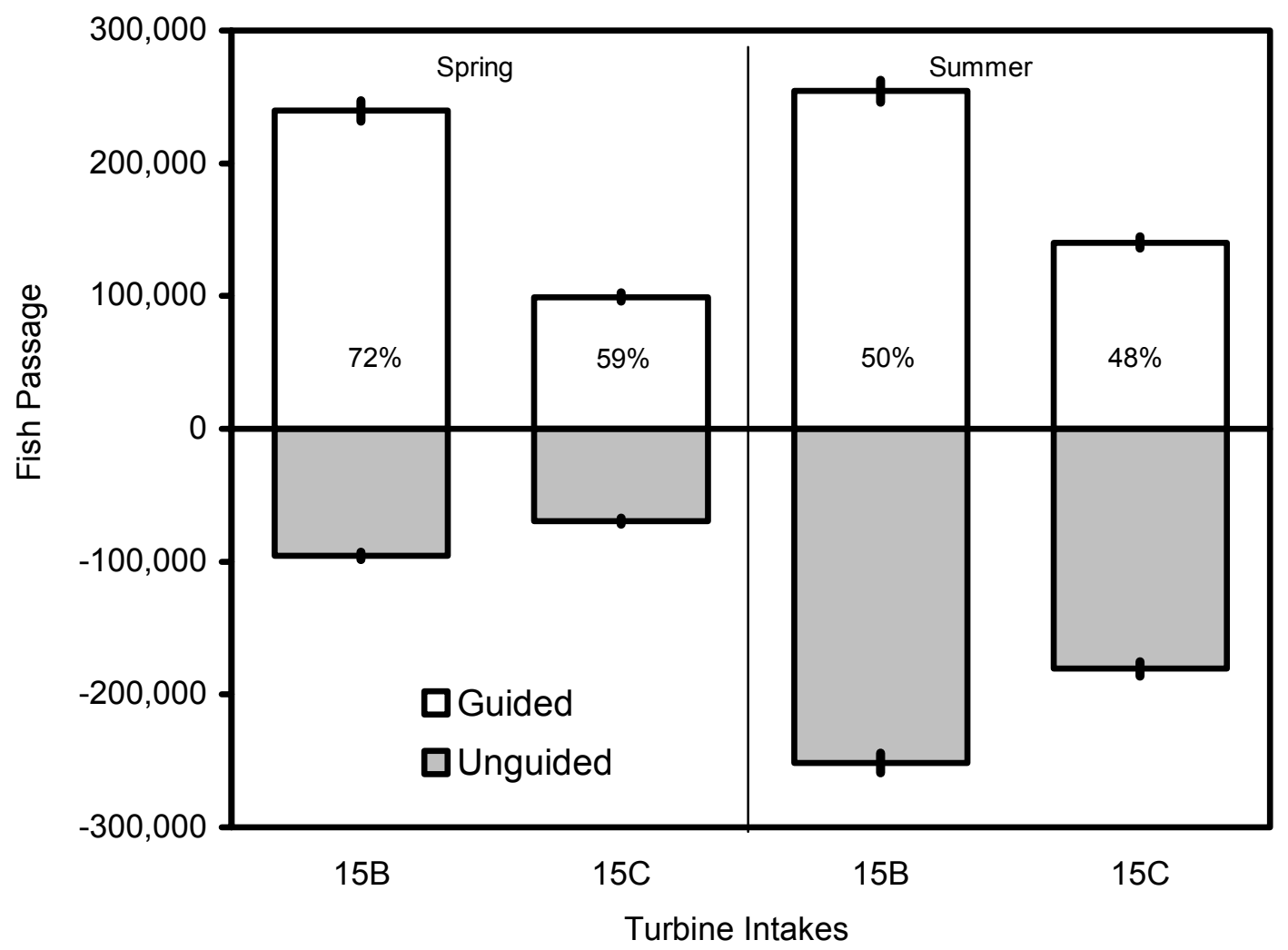

Figure 3.40. Estimates of the Number of Guided and Unguided Fish and FGE at Intakes $15 \underline{b}$ (between TIEs) and 15 (behind a TIE) during all Hours the Turbine Was Operated in Spring. The $95 \%$ confidence limits on FGE estimates were about 1\%. Vertical bars show $95 \%$ confidence limits on passage estimates.

\subsubsection{Comparing FGE Estimates by Different Sampling Methods}

We had the opportunity to compare our estimates of the FGE of turbine units at Powerhouse 2 with estimates by two other methods. The USGS estimated FGE for every unit at Powerhouse 2 based upon the distribution of passage of radio-tagged fish, and the NMFS estimated FGE for modified Unit 15 by gatewell dipping and fyke netting. Comparison with radio tagging estimates of FGE could be examined for more units, but sampling with the hydroacoustics and radio telemetry was not simultaneous as it was for the hours netted at Unit 15 by the NMFS. Scott Evans (USGS) provided radio telemetry estimates and Bruce Monk (NMFS) provided gatewell and fyke-net estimates presented in this section.

\subsubsection{Comparison with Gatewell Dipping and Fyke Netting Estimates}

We sampled continuously at Unit 15, while the NMFS sampled with nets from about 2000 until 2100 or 2200 depending upon the number of fish they collected in the dip basket sampling the gatewell. Sampling duration was only as long as needed to obtain a reliable FGE estimate based upon catches of guided fish and knowledge of FGE ranges that were likely. 
By season, our concurrent estimates of FGE were similar to those made by netting, as were estimates of number of guided and unguided fish (Figure 3.41). Hydroacoustics underestimated the number of guided fish in spring and underestimated the number of unguided fish in summer, according to the lack of overlap in $95 \%$ confidence limits. In spring, the FGE estimates were very similar, but in summer, hydroacoustic estimates were about $5 \%$ lower than netting estimates.

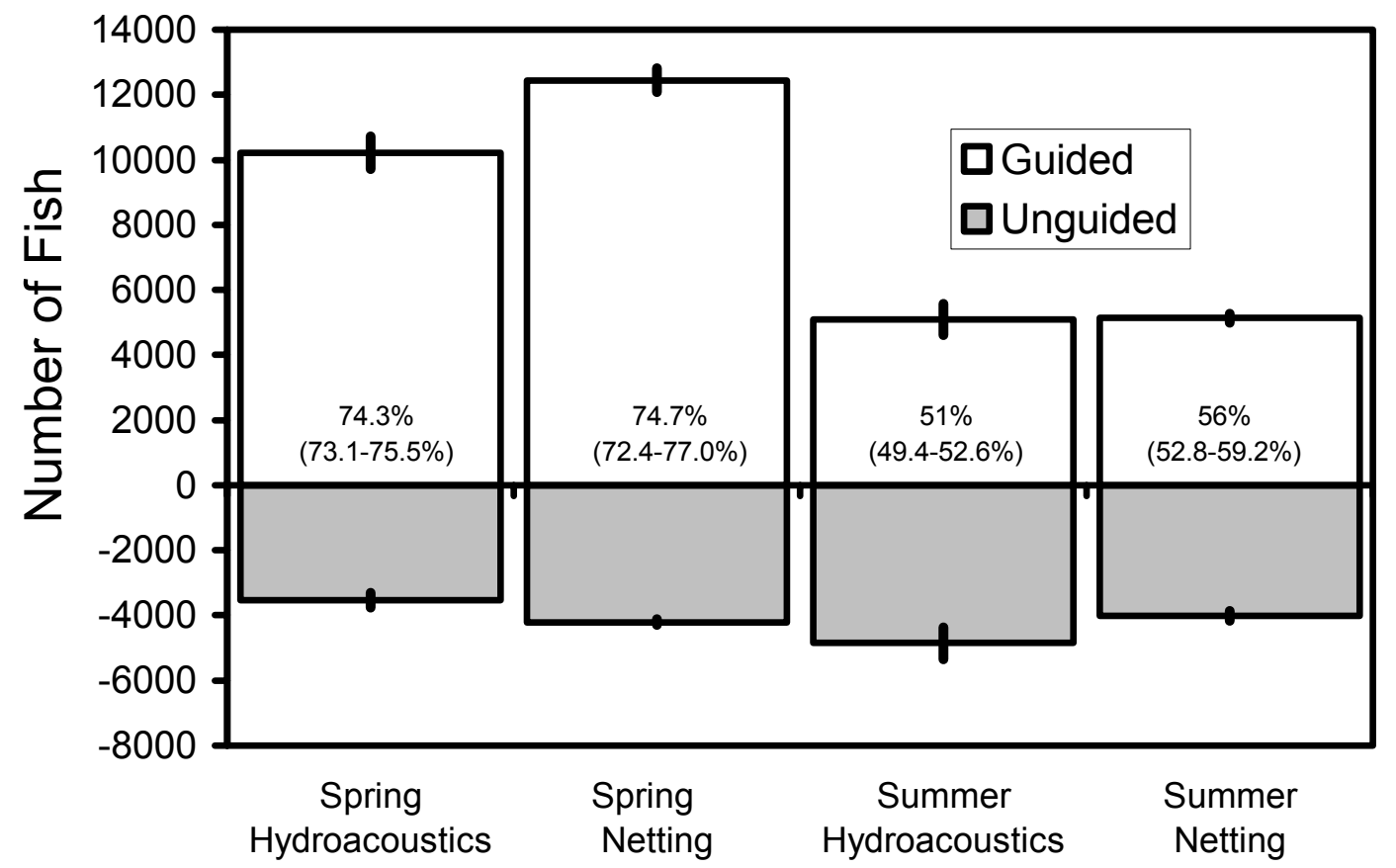

\section{Season and Sampling Method}

Figure 3.41. Plot of the Number of Guided and Unguided Fish Estimated by Concurrent Hydroacoustic and Net Sampling at Unit 15 in Spring and Summer. The percentages inside bars for guided fish are estimates of FGE and numbers in parentheses are $95 \%$ confidence limits.

We also were able to make estimates based upon all hours that we sampled and during which the turbines operated (day and night) and we compared them to netting estimates (Figure 3.42). In both cases, hydroacoustic estimates were lower than the respective netting estimates. This result surprised us because we expected that detecting more fish would improve our estimates.

Investigating further, we compared estimates based upon all nighttime hours (2000 through 0500 hours) sampled by hydroacoustics with netting estimates made from 2000 to 2100 or 2200 hours and the agreement between the two improved considerably (Figure 3.43). The 95\% confidence intervals overlapped in both spring and summer. 


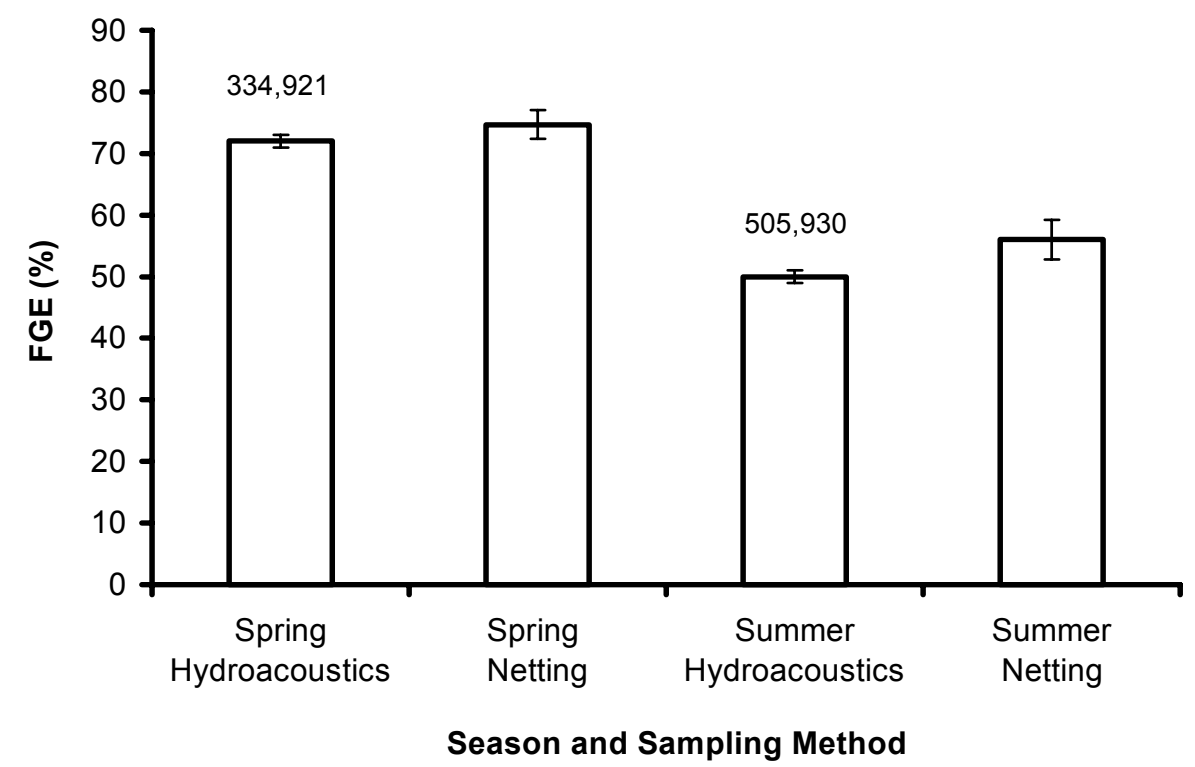

Figure 3.42. Plot of FGE Estimates Made from all Hours of Hydroacoustic Sampling Compared to Estimates Based upon Netting from about 2000 to 2100 or $2200 \mathrm{~h}$. Vertical bars are $95 \%$ confidence limits. The expanded numbers of fish upon which FGE estimates were based are shown above the bars for hydroacoustic sampling each season.

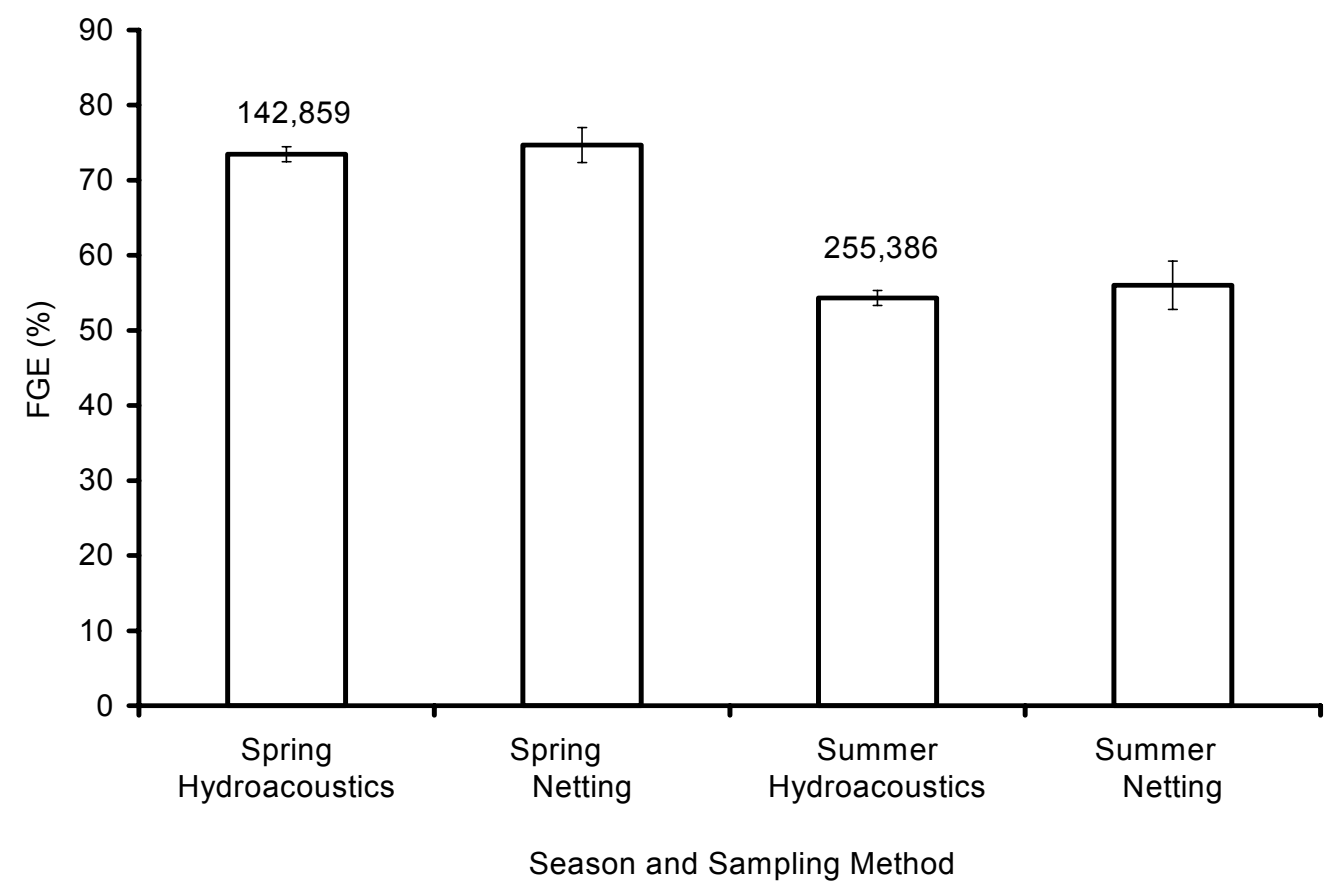

Figure 3.43. Plot of FGE Estimates Made from all Nighttime Hours of Hydroacoustic Sampling (20000500) Compared to Estimates Based upon Netting from about 2000 to 2100 or $2200 \mathrm{~h}$. Vertical bars are $95 \%$ confidence limits. The expanded numbers of fish upon which FGE estimates were based are shown above the bars for hydroacoustic sampling each season. 


\subsubsection{Comparison with Radio Telemetry Estimates}

The radio telemetry study also produced unit-specific estimates of FGE for Powerhouse 2, and those estimates and hydroacoustic estimates are presented in Table 3.3. On the unit level, estimates by hydroacoustics were higher than estimates by radio telemetry in five of eight units $(12,13,14,15$, and 16) in spring and in three of four units for which there were radio telemetry estimates in summer (units 12, 13, and 14). Hydroacoustic estimates were lower than radio telemetry estimates at units 17 and 18 in spring and at Unit 11 in summer. Estimates were only similar at Unit 11 in spring.

Radio telemetry estimates pooled for four adjacent units were within $10 \%$ of similarly pooled hydroacoustic estimates (Table 3.3). In spring, the hydroacoustic estimates exceeded radio telemetry estimates by $9 \%$ for units 11 through 14 and by only $2 \%$ for units 15 through 18 . In summer, the hydroacoustic estimates exceeded radio telemetry estimates by $8 \%$ for units 11 through 14 , and no radio telemetry estimates were available for units 15 through 18 .

The comparison of estimates at Unit 15 is of particular interest because NMFS' netting study estimate is available. The hydroacoustic estimate of $72 \%$ for all hours of the day in spring was within $3 \%$ of NMFS estimate for sampling at 2000 to 2100 or 2200 hour, but it was $34 \%$ higher than the radio telemetry estimate. Similarly, NMFS' netting estimate was $37 \%$ higher than the radio telemetry estimate.

Table 3.3. Hydroacoustic (HA) and Radio Telemetry (RT) Estimates of FGE for Turbines at Bonneville Dam Powerhouse 2 in 2001. For this comparison, only data from 1 May to 9 June for spring and 1 July to 15 July for summer were used, so these hydroacoustic FGEs differ slightly from those reported elsewhere.

\begin{tabular}{|c|c|c|c|}
\hline Location & HA Estimate & "RT Estimate & Difference \\
\hline \multicolumn{4}{|c|}{ Spring } \\
\hline Unit 11 & $50 \%$ & 51\% & $1 \%(\mathrm{RT}>\mathrm{HA})$ \\
\hline Unit 12 & $59 \%$ & $40 \%$ & $19 \%(\mathrm{HA}>\mathrm{RT})$ \\
\hline Unit 13 & $67 \%$ & $58 \%$ & $9 \%(\mathrm{HA}>\mathrm{RT})$ \\
\hline Unit 14 & $62 \%$ & $43 \%$ & $19 \%(\mathrm{HA}>\mathrm{RT})$ \\
\hline Units $11-14$ & $58 \%$ & $49 \%$ & $9 \%(\mathrm{HA}>\mathrm{RT})$ \\
\hline Unit 15 & $70 \%$ & $38 \%$ & $32 \%(\mathrm{HA}>\mathrm{RT})$ \\
\hline Unit 16 & $60 \%$ & $48 \%$ & $12 \%(\mathrm{HA}>\mathrm{RT})$ \\
\hline Unit 17 & $48 \%$ & $64 \%$ & $16 \%(\mathrm{RT}>\mathrm{HA})$ \\
\hline Unit 18 & $32 \%$ & $42 \%$ & $10 \%(\mathrm{RT}>\mathrm{HA})$ \\
\hline Units $15-18$ & $51 \%$ & $49 \%$ & $2 \%(\mathrm{HA}>\mathrm{RT})$ \\
\hline All PH2 & $56 \%$ & $46 \%$ & $10 \%(\mathrm{HA}>\mathrm{RT})$ \\
\hline \multicolumn{4}{|c|}{ Summer } \\
\hline Unit 11 & $26 \%$ & $33 \%$ & $7 \%(\mathrm{RT}>\mathrm{HA})$ \\
\hline Unit 12 & $40 \%$ & $19 \%$ & $21 \%(\mathrm{HA}>\mathrm{RT})$ \\
\hline Unit 13 & $48 \%$ & $38 \%$ & $10 \%(\mathrm{HA}>\mathrm{RT})$ \\
\hline Unit 14 & $53 \%$ & $32 \%$ & $21 \%(\mathrm{HA}>\mathrm{RT})$ \\
\hline Units11-14 & $39 \%$ & $31 \%$ & $8 \%(\mathrm{HA}>\mathrm{RT})$ \\
\hline Unit 15 & $52 \%$ & $34 \%$ & $18 \%(\mathrm{HA}>\mathrm{RT})$ \\
\hline Unit 16 & $53 \%$ & $46 \%$ & $7 \%(\mathrm{HA}>\mathrm{RT})$ \\
\hline Unit 17 & $\mathrm{~N} / \mathrm{A}$ & $\mathrm{N} / \mathrm{A}$ & \\
\hline Unit 18 & $19 \%$ & $7 \%$ & $12 \%(\mathrm{HA}>\mathrm{RT})$ \\
\hline Unit 15-18 & $50 \%$ & $39 \%$ & $11 \%(\mathrm{HA}>\mathrm{RT})$ \\
\hline All PH2 & $44 \%$ & $35 \%$ & 9\% (HA>RT) \\
\hline
\end{tabular}




\subsection{Discussion}

\subsection{Hydroacoustic Detectability}

The motivating force behind efforts to improve detectability modeling is the desire to provide hydroacoustic estimates that are quantitative as well as relative indices to fish passage. Ratio estimators such as fish guidance efficiency only require that the hydroacoustic beams sampling guided and unguided fish have equal detectability so that the ratios of counts, not necessarily the counts themselves, are accurate. Combining counts from different locations such as powerhouses and a spillway also requires equal detectability so that counts from different locations are comparable, although the counts themselves may not be accurate. Nevertheless, accurate counts estimated by proper expansion of detected fish have the potential to provide estimates with inherent quantitative value as well as providing acceptable relative estimates.

One of the ways to check the adequacy of detectability is to regress numbers of fish per transducer hour on discharge volume and to look for negative slopes that might indicate lower detectability. Lower detectability may result if fish speed through the beam faster at high than at low discharge and return fewer than the minimum number of echoes. This is one of the quality control checks that we perform every year, and as expected, we found no significant regressions between fish counts and discharge. We know from work in 2000 that our ping rate of 30 pings per second at the spillway was adequate for detecting fish at the highest possible spill levels, and the drought and limited spill rates of 50,000 cfs in 2001 assured that spillway detectability was adequate.

We had some concern that detectability at Powerhouse 2 might be a problem because of the Powerhouse 2 priority and drought-limited discharge through Powerhouse 1 and the spillway. We compared expanded hydroacoustic counts of guided and unguided fish at Intake 15 $\underline{b}$ with estimates from netting by the NMFS to evaluate the reasonableness of our detectability modeling and the resulting spatial expansion factors. The closeness of concurrent hydroacoustic and netting estimates of fish passage for all of the spring and summer seasons (Figure 3.41) provided independent verification that our detectability modeling and corrections to expansion factors were reasonable for Powerhouse 2. In spring, the sum of all hydroacoustic and netting estimates of guided fish numbers differed by only $22 \%$, and in summer, the estimates did not differ $(<1 \%)$. The sum of all unguided fish by the two methods also were reasonably close and differed by less than $1 \%$ in spring and by about $21 \%$ in summer. The bias in hydroacoustic estimates of guided and unguided fish passage relative to netting estimates can be much worse. For example, Ploskey and Carlson (1999) reported ratios of differences for netting to hydroacoustic counts ranging from 2 to 11 for guided fish and from 10 to 13 for unguided fish, although FGE estimates were closer because of error compensation in the ratio estimator (Ploskey and Carlson 1999).

\subsection{Validation of Autotracking Hydroacoustic Data}

For the past four years we have been evaluating and dealing with inter-individual differences in human hydroacoustic analysis. Over that time, it has become clear that individuals are substantially and consistently different in their results when given the same large data set to analyze. Out of a pool of trackers, even when trained together over several weeks, some individuals consistently produce 
substantially lower-than-average fish counts and some produce substantially higher-than-average fish counts. Failure to recognize individual bias and assign different passage routes to different trackers has the potential to produce biased and perhaps very biased estimates. That potential is especially clear for ratio estimates. Although this year the agreement among our trackers was better than it has sometimes been, the cumulative difference in passage estimate for the lowest tracker was only about $72.8 \%$ that of the highest tracker for the 438 channel hours we compared in spring and $68.8 \%$ for the 227 channel hours we compared in summer (Figure 3.3). The degree by which individuals disagree is at least partly related to noise. Up-looking deployments that sample guided fish and shallow water routes (sluiceways, surface collector entrances) are more problematic than are down-looking deployments sampling the spillway or unguided fish in turbines (Ploskey et al. 2001a; Ploskey et al. 2002).

The high coefficients of determination for regressions of human-based counts on autotracker counts for each deployment (Figures 3.4 and 3.5) indicate that the estimates comport very well. This year we used human trackers only to verify and adjust the results of the autotracker. The slopes of regression lines in Figure 3.6 were used to correct our autotracked results downward to offset the tendency of the autotracker to overestimate passage. We consider this method of evaluation and correction, when based on large samples of data analyzed and compared at the level of channel hour, to be an adequate method of quality control and assurance for our autotracked estimates. This approach is not only more economical but qualitatively superior to manual tracking by individual humans.

\subsection{Major Passage Metrics}

\subsubsection{Project and Powerhouse FPE}

The drought of 2001 provided a unique opportunity to evaluate Project FPE during spill and non-spill periods in the same year. Project FPE was $15 \%$ and 35\% higher during 50,000 cfs spill periods in spring and summer, respectively, than it was during non-spill periods. In 2000, continuous spill at 75,000 or $120,000 \mathrm{cfs}$ throughout spring and summer and the operation of a prototype surface collector at Powerhouse 1 produced Project FPE estimates of $79 \%$ in both seasons. These estimates were 16\% (spring) and 26\% (summer) higher than estimates for spring and summer seasons in 2001, which included spill and non-spill periods rather than continuous spill.

Project FPE was only about 1\% lower in spring and in summer than FPE calculated for Powerhouse 2 and the spillway, without Powerhouse 1. This was not surprising given that Powerhouse 1 passed only about $7.3 \%$ of the water and $6.9 \%$ of the fish in spring and $8.6 \%$ of the water and $7.5 \%$ of the fish in summer.

\subsubsection{Spill Efficiency and Effectiveness}

Spill efficiency estimates in spring (14\%) and summer (20\%) 2001 were significantly lower than estimates made in spring (44\%) and summer (49\%) 2000, undoubtedly because of reduced volume and duration of spill during the drought in 2001. Spill effectiveness also was about 38\% lower in spring 2001 than it was the previous spring. In 2000, spill was continuous at about 75,000 cfs during the day and $120,000 \mathrm{cfs}$ at night, but lack of water in 2001 limited spill to about 50,000 cfs for about 21 of 45 days in spring and 10 of 40 days in summer. About 5\% of the reduction in spill efficiency between 2000 and 2001 could be the result of our conservative choice of a flux factor to correct spill passage estimates for 
fish direction of travel in spring and summer, but that still leaves a spring and summer decrease of $33 \%$ and $24 \%$, respectively from 2000 to 2001 .

The fish-flux factor that we used was more conservative than multiplying by the fraction moving downstream because it subtracted the upstream fraction from the downstream fraction. For example, if $90 \%$ of detected fish are moving downstream and $10 \%$ are moving upstream, the flux factor applied was 0.8 instead of 0.9 . In reality, all we know is that some fish moving upstream could have been counted more than once and that the flux factor should be somewhere between 0.8 and 0.9 . We could have split the difference and used 0.85 , but we wanted to be certain not to overestimate spillway passage in a drought year.

Effectiveness seems to be a meaningful metric when differences in flow proportions do not exceed about $30 \%$, which was not the case in comparisons between summer 2000 and 2001. In summer 2001, spill effectiveness was about $55 \%$ higher than the previous year's estimate, likely because the proportion of water spilled in summer 2001 was much lower than it was in 2000. The denominator in the spillefficiency calculation (the proportion of water spilled) in summer 2000 was 0.48 whereas it was only 0.11 in summer 2001. The inverse of these proportions represents how much spill efficiency is expanded (i.e., by 2.1 in 2000 and by 9.1 in 2001 . The inflation of the effectiveness statistic can be observed in estimates of effectiveness at sluiceways and surface collectors, which are always higher than estimates for a spillway because these small routes pass orders of magnitude less water than a spillway passes. For this reason, we believe that efficiency is a more meaningful metric than effectiveness, which can be inflated by very low spill proportions.

Another possible explanation for the high spill effectiveness in 2001 is the early and large run of American shad (Figure 3.29) that could have contaminated spillway samples, but we did not observe a lot of evidence of shad schools in the summer echograms that we processed for quality control. In echograms, shad usually can be recognized because they occur in dense schools, often high in the water column. In contrast, juvenile salmon usually pass through hydroacoustic beams as single traces. With reduced spill, it is possible that shad could visit spill bays and wallow through the upper one half of hydroacoustic beams without threat of fallback in spill. Although we apply target and echo strength filters to reduce detection of fish larger than smolts, it would be impossible to eliminate false detections with single beams because even a large fish detected far off the axis of a single beam can return smoltsized echoes. We usually do not have evidence of shad contamination of spillway or in-turbine samples until late June or July when weak, spent shad begin to fall back downstream.

\subsubsection{Effects of Spill Level}

We found several significant relationships that suggest an optimum spill strategy for future drought years that includes night spill lasting at least 11 hours. There were positive relations between the number of hours of spill per day and FPE and spill-efficiency metrics (Figure3.8), and we observed significantly higher fish passage through the spillway at night than during the day (Figure 3.32), even though the amount of spill was the same during each period. We observed a similar trend in 2000, but nighttime spill discharge was much higher than it was during the daytime, and we could not determine whether the pattern was driven by spill level or day versus night. With constant spill in 2001, we can confidently describe the effect as a diel pattern unrelated to spillway discharge. Spill efficiency increased linearly with the number of spill hours per day in spring. Although we plotted a linear relation for FPE 
(Figure 3.8), there really were only two obvious levels of effect that could be classified at low-spill durations of 0-10 h/day that produced an average FPE of about 54\% and high-spill durations of 11 to 24 $\mathrm{h} /$ day that produced an average FPE of about $71 \%$ (Figure 4.1 ). We were only able to examine the effect of hours of spill per day because spill was constant at about 50,000 cfs on days when spill occurred. Spilling at night also has the advantage of eliminating fallback of adult salmonids through the spillway during the day and may reduce fish losses due to visual predators such as birds and fishes in the spillway tailrace.

\subsubsection{Comparison with Radio Telemetry and Netting Estimates}

The level of agreement between our hydroacoustic and the radio telemetry-based estimates by our USGS colleagues was better for major fish-passage metrics and entire powerhouses than it was for individual units. At the level of the individual turbine unit (Table 3.3), the agreement was sometimes very poor. The worst case was a $34 \%$ difference at Unit 15 in spring, and the best case was a $1 \%$ difference at Unit 11 in spring. Unit 15 was unusual in that it was very intermittent in its operation during high passage hours due to the NMFS studies there. The next largest differences were at units 12 and 14 in both spring (19\% both seasons) and summer (21\% both seasons). Unit-specific differences between the two methods averaged $14.7 \%$ for eight units in spring and $13.7 \%$ for 7 units (Unit 17 did not operate) in summer.

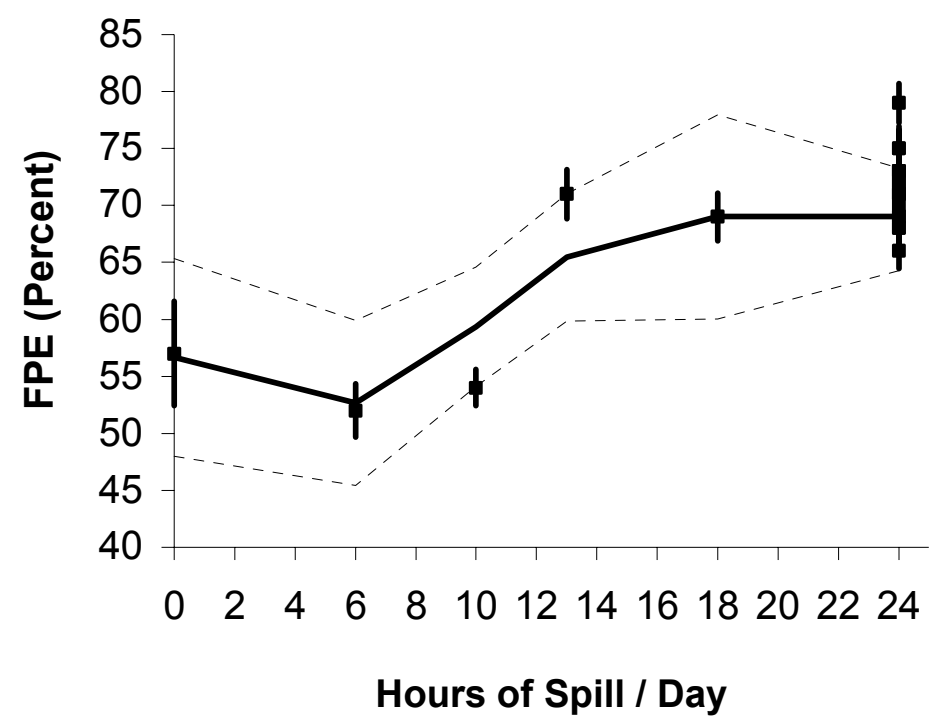

Figure 4.1. Relation between Fish Passage Efficiency (FPE) and Hours of Spill per Day in Spring 2001. The solid line was Loess fitted to points and the dashed lines represent $95 \%$ confidence intervals on the fitted line. Vertical bars represent $95 \%$ confidence intervals on individual estimates of FPE.

Across the entire project or a powerhouse or spillway structure differences were somewhat smaller (Table 3.1). The worst case was a 14\% difference for Powerhouse 2 FPE during low spill in spring. The next greatest difference is for Project FPE in spring, and all other differences are $10 \%$ or less. Diel passage estimates for the two methods (Figure 3.35 with Figure 3.36) are very similar, with the notable exception of mid afternoons (1400-1600 hrs), especially in spring. Further pooling samples into daytime versus total passage further reduces differences in some cases (Table 3.2). Hydroacoustic and radio- 
telemetry estimates at Powerhouse 1 still differed by $21.4 \%$ in spring and $13.2 \%$ in summer, but Powerhouse 1 had an unusually limited generation schedule. The only other differences that were greater than $10 \%$ were the spillway in spring (15.6\%) and Powerhouse $2(10.4 \%)$.

We believe that our hydroacoustic estimates are reasonably close to those of the USGS radio telemetry workers and that a good part of the differences that exist can be attributed to the small sample sizes that are inherent in highly partitioned radio telemetry estimates. Powerhouse unit-specific FGE estimates from radio telemetry were based on from 14 (Unit 18) to 136 (Unit 14) fish in spring and from 15 (Unit 18) to 136 (Unit 14) fish in summer. When you consider that those numbers are composed of varying number of different species, it is not surprising that radio telemetry estimates sometimes differ. In contrast, unit-specific hydroacoustic estimates are based upon thousands of fish each season.

All sampling methods are imperfect and each has unique advantages and disadvantages. Radio telemetry can provide data on movements of known fish and is not limited to the dam itself. Information on travel time, large-scale trajectories, forebay residency, survivorship, species or origin and even rearing (wild versus hatchery) differences is potentially available. However, the power of radio telemetry is diminished when the number of tagged fish is divided among too many treatments or passage routes, and it provides no data on untagged animals. In contrast, the NMFS continues gatewell dipping and fyke netting single units until the number of fish sampled is believed to be sufficient to provide a reliable species-specific FGE estimate. The number of fish captured during 1 to 2 hours of net sampling by the NMFS effort usually is an order of magnitude larger than the number available for radio telemetry estimates for an entire season. However, netting is labor intensive and may injure or kill fish, including individuals from endangered populations; therefore, it cannot be used for more than a few hours per day at one or two intakes. The restriction of physical capture to one and at the most two or three samples per day prevents biologists from obtaining daily estimates of sample variance or increased resolution of the temporal and spatial variation in FGE.

While hydroacoustic methods provide FGE estimates that are very comparable to physical capturebased estimates, they can only provide a relative index to fish passage unless calibrated by net sampling and cannot directly provide species-specific estimates. However, hydroacoustic methods can be economically applied to all intakes $24 \mathrm{~h}$ per day, and provide information about variations among intakes and hours of the day. While hydroacoustic sampling requires more than the 1 to 2 hours needed by netting to obtain reliable FGE estimates, it can provide seasonal estimates for single routes that are not limited by the number of fish sampled. Fixed-aspect hydroacoustics provides estimates for unidentified and untagged fish and can provide estimates for individual passage routes that usually comport with estimates from more intensive netting methods.

\subsection{Spatial Trends in Fish Passage}

\subsubsection{Horizontal Distributions}

The proportion of discharge through major passage routes was a good indicator of the relative percentage of fish passage among those routes in spring but was less so in the summer. In spring, about $7 \%$ of both fish passage and discharge occurred at Powerhouse $1,14 \%$ of the fish and $16 \%$ of the flow passed through the spillway, and Powerhouse 2 passed $79 \%$ of the fish with $76 \%$ of the flow. Fish and flow percentages also matched up well at Powerhouse 1 in summer (about $8 \%$ of the fish with about $9 \%$ 
of the flow), but the relative proportions at the other passage routes (the spillway and Powerhouse 2) differed. For the entire summer period, the spillway passed $20 \%$ of the fish in summer with $11 \%$ of the flow and Powerhouse 2 passed about $72 \%$ of the fish with $80 \%$ of the flow. During spill days in summer, the spillway passed $58 \%$ of the fish in just $36 \%$ of the flow, while Powerhouse 2 passed $40 \%$ of the fish in $61 \%$ of the flow.

The exceptional effectiveness of the spillway during the 10 days of spill in early summer may be explained by a peak in the summer migration, spill at the expense of generation at some Powerhouse 2 units, and the fact that forebay elevations were falling (Figure 4.2). According to salmonid run-timing estimates by the hydroacoustics and JBS counts (Figure 3.24), the largest peak in the summer run passed the dam during these early days of summer sampling. When forebay elevations drop (as in Figure 4.2), the depth of a bottom ridge upstream of Cascades Island and into the Powerhouse 2 forebay is shallower than it is when pool levels are high. Subyearling fish migrating along the shore upstream of the Powerhouse 2 forebay may guide along the channel edge that separates the Powerhouse 2 forebay from the main channel leading to the spillway, particularly when water levels decrease. In 2001, Powerhouse 2 was the priority powerhouse and usually was fully loaded. However, during the 10 days of spill in early summer, the percent of off-hours for Powerhouse 2 turbines was higher than usual (Unit $17=100 \%$; Unit $15=46 \%$; Unit $14=41 \%$; Unit $13=25 \%$; Unit $12=14 \%$; and Unit $11=5 \%$ ).

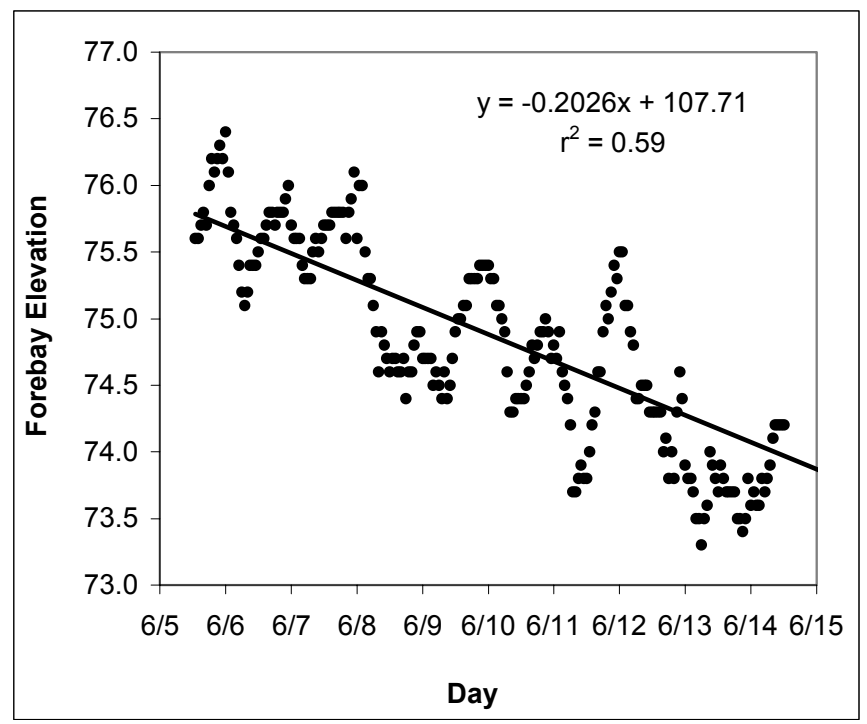

Figure 4.2. Plot of Bonneville Dam Forebay Elevation during the First 9 Days of Summer when Spill was Occurring in 2001.

Lateral fish passage patterns that may normally occur during times of full loading of Powerhouse 1 could not occur in 2001 given the drought and a Powerhouse 2 priority for generation. Flow was so low in both spring and summer at Powerhouse 1 that many of the units seldom ran, particularly during periods of spill. Horizontal passage patterns at Powerhouse 1 were consistent between seasons, the majority of both fish passage and discharge occurring through Unit 9 and Unit 10.

Fish passage at the spillway was slightly skewed to the south during both seasons, despite a relatively even distribution of discharge across the spillway. This was mainly due to low passage rates at Bays 2, 
which passed far fewer fish than bays at the southern end of the spillway, although they discharged about the same amount of water as the bays to the south.

The southern skew in the distribution of fish passage at Powerhouse 2 in both seasons was much more noticeable in 2001 than it was in 2000, and it certainly supports the management decision to build a corner collector adjacent to Unit 11. Fish passage through the south half of the second powerhouse was consistently high during both sampling seasons. About $70 \%$ of the fish passing through Powerhouse 2 passed through units 11 to 14, although these units discharged only slightly more than half of the water $(52.6 \%)$. Not only was the total number of fish passing higher at units 11 to 15 than anits 16 through 18 , but fish density or concentration of fish also was higher. Units 11 to 15 passed roughly similar numbers of fish per volume of water during spring and summer. Unit 17 was off-line all summer. We also observed a southern skew in the passage distribution in summer 1996 (Ploskey et al. 1998).

Individual turbine FGE at Powerhouse 2 was lowest at the two units operating nearest each end of the powerhouse during spring and summer. The low turbine FGE values estimated at Units 17 and 18 in spring and Units 16 and 18 in summer did not affect powerhouse FGE as much as the low turbine FGE values at Units 11 and 12 because fish passage densities at the north units were low. The two units at the south end of the powerhouse, on the other hand, passed many fish at relatively high densities with poor guidance and so had a larger negative contribution to total powerhouse FGE.

\subsubsection{Vertical Distributions}

\subsubsection{Powerhouse 1 -- Unit 10}

The vertical distributions of fish at Unit 10 in spring and summer strongly suggest that installing an ESBS similar to the one installed at Unit 8 would improve FGE in spring, but the benefit would be less in summer. The elevation for classifying detected fish as guided or unguided was about $21 \mathrm{ft}$ MSL. According to Figure 3.19 an ESBS and this cutoff criterion, an ESBS would guide about $68 \%$ of the fish in spring but only about $50 \%$ in summer. In spring 2001 , we classified about $47 \%$ of all fish as guided by the STS, but in summer, that percentage fell to about $36 \%$. In the 2000 passage season we found an estimated FGE of $72 \%$ in spring that fell to $50 \%$ in summer (Ploskey et al. 2002a).

\subsubsection{Upstream and Downstream of Modified Unit 15}

Two pieces of evidence indicate that fish approaching trash racks increased in depth and changed behavior, and these factors may make them more or less susceptible to being guided by a STS inside the turbine. First, peaks in vertical distributions of fish located below the elevation of the top of the intake and 4 to $9 \mathrm{ft}$ from trash racks were 9 to $12 \mathrm{ft}$ deeper than peaks in distributions sampled 16 to $21 \mathrm{ft}$ upstream (Figures 3.21 and 3.22). Second, direction-of-movement and fish-detection statistics show that $70 \%$ of the relatively few detections 10 to $15 \mathrm{ft}$ upstream of trash racks were moving downstream, whereas only about $54 \%$ to $55 \%$ of many detections within 4 to $9 \mathrm{ft}$ of trash racks were moving downstream.

In short, we found lower numbers and deeper distributions of fish detected 4 to $9 \mathrm{ft}$ from the racks than of fish detected 16 to $21 \mathrm{ft}$ from the racks. These differences were consistent for both spring and summer. Higher numbers of fish close to the trash racks may indicate that fish paused in their 
downstream movement as they encounter physical cues relating to the presence of the racks. If fish paused just upstream of the racks, they could easily have been counted multiple times as they passed in and out of the sampling volume, resulting in higher cumulative counts. Horizontal fish movement was oriented fairly randomly close to the trash racks, while movement was oriented more downstream farther upstream of the racks.

Smaller individuals that make up the summer smolt population likely are less able to maintain their vertical position in the water column when they pause upstream of the trash racks. Fish that pause in their downstream movement just upstream of the trash racks are not only exposed to the downstream component of flow, they also encounter strong downward water velocities. The agreement of theoretical FGE with observed in-turbine FGE during spring may indicate that the spring-migrating smolts were able to maintain both their horizontal and their vertical position in the water column as they paused before going through the trash racks. In summer, the lower vertical distribution of fish detected 4-9 $\mathrm{ft}$ upstream of the trash racks, as compared to those detected 16-21 ft upstream of the racks, was more exaggerated than during spring. In addition, theoretical FGE was significantly higher than observed in-turbine FGE in summer (Figure 3.19). Our analysis of theoretical FGE is based on the hypothesis that fish detected in front of the trash racks at Intake 15 $\underline{b}$ will follow the flow lines that parallel the roof of the intake ceiling into the intake.

\subsection{Temporal Trends in Fish Passage}

\subsubsection{Seasonal Trends}

\subsubsection{Run Timing}

Run timing estimated by hydroacoustics compared favorably with the estimate based upon sampling the juvenile bypass facility at Powerhouse 2 by the NMFS. Most major peaks in the run-timing distributions occur at similar times, although size and duration of those peaks were not identical.

American shad present a problem for hydroacoustic sampling in summer. Almost 2.3 million American shad migrated up through Bonneville Dam in 2001. Shad began arriving at the dam in mid May and were present in large numbers during the third week in May before peaking on 1 June when 144,000 individuals were observed. By 6 June, $50 \%$ of all the migrating shad had already passed the dam. By 30 June, the shad migration was essentially complete with over $98 \%$ of all fish having passed by that day. The Bonneville Dam 2001 shad up migration was nearly twice as large as the 2000 run and it peaked 10 days earlier.

\subsubsection{Major Fish Passage Metrics}

The 9\% decline in FPE from spring to summer at Powerhouse 1 and the $26 \%$ decline at Powerhouse 2 were similar to but slightly larger than seasonal declines observed in 2000 for Powerhouse $1(6 \%)$ and for Powerhouse $2(19 \%)$. Powerhouse $1 \mathrm{FPE}$ in 2000 was $67 \%$ in spring and $61 \%$ in summer, and these estimates were $18 \%$ and $21 \%$ higher than respective estimates in spring and summer 2001 . The difference most likely resulted from the nearly continuous operation of the PSC and Unit 8 with an ESBS in 2001. In 2001, the PSC units functioned as standard STS units and Unit 8 ran less than 1 day each season, because of drought prioritization of operations. 


\subsubsection{Guidance Efficiency at Modified Unit 15}

The spring to summer decline in FGE that we observed at Unit 15 was typical of what we have observed at most units at Bonneville Dam, but the summer FGE estimate was not as low as those from other STSequipped units at Powerhouse 1 or 2 in the summer of 2000. It was comparable to adjacent Units 14 and 16 in 2001. The nighttime FGE of Unit 15 decreased about 20\% from 74 to 54 from spring through summer in 2001. In 2000, the summer FGE estimate for Powerhouse 1 units running STS and the summer FPE of Powerhouse 2, which had no modified units was about $30 \%$.

\subsubsection{Diel Trends}

Providing a Powerhouse 2 priority and nighttime spill could significantly improve fish-passage efficiency in spring by as much as $6 \%$ to $12 \%$ during a drought year, while minimizing fallback of adult salmonids through the spillway. Factors contributing to a $6 \%$ to $12 \%$ higher project FPE at night than during the day included significantly higher nighttime fish passage through the project (Figure 3.31), including the spillway (Figure 3.32) and Powerhouse 2 (Figure 3.34), and higher FGE of Powerhouse-2 turbines at night (Figure 3.34) than during the day.

We have no definitive explanation for the higher spill efficiency and spill effectiveness observed from morning through early afternoon in summer, except to note that those observations were based on only 10 days of spill in summer. If American shad contaminated samples at the spillway in early summer, they might be expected to do so at night and in early morning, when most are not actively migrating upstream, as they do in the afternoon and evening (Figure 4.3). However, we observed few incidences of shad contamination of samples at the spillway in the echograms that we processed manually for quality control and assurance.

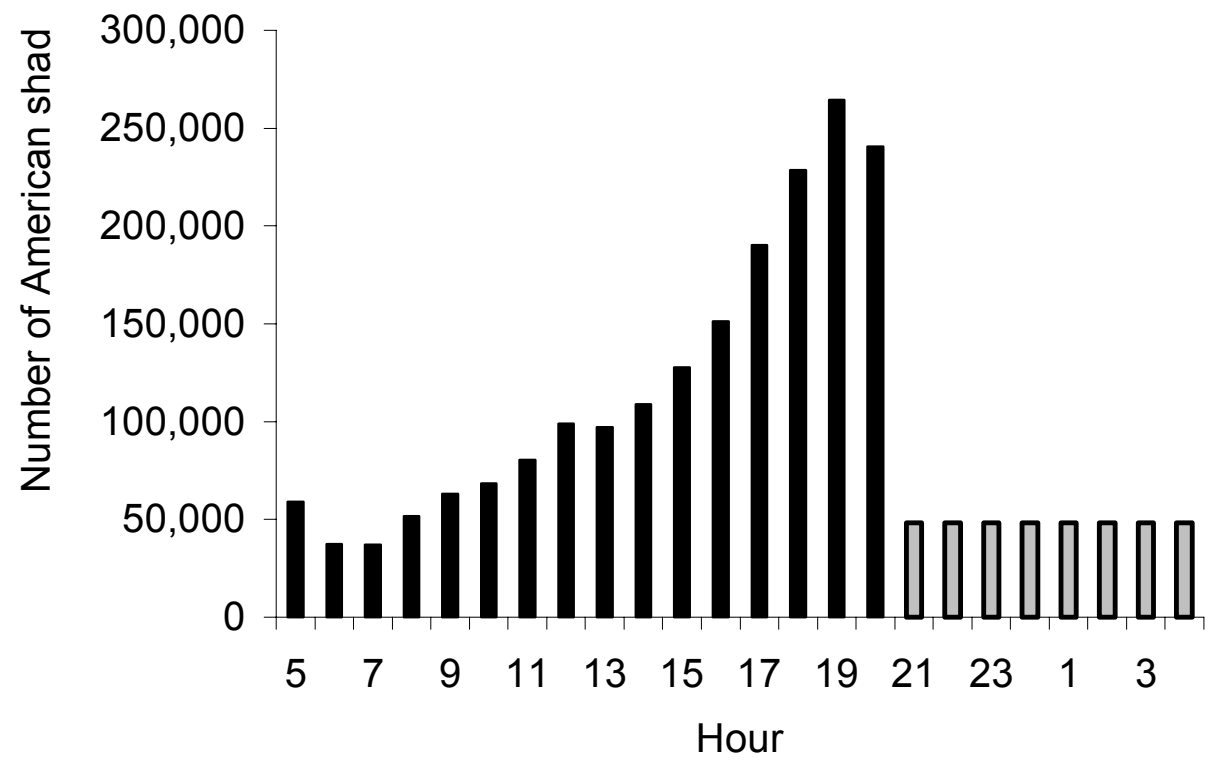

Figure 4.3. Diel Pattern of Shad Passage through Bonneville Dam in Summer 2001. Gray bars are hourly estimates produced by dividing the difference between the total season count and the sum of the hourly counts from 0500 to 2000 hours by eight. 


\subsection{Fish Guidance Efficiencies}

\subsubsection{Comparing Performance of Fish-Guidance Structures}

Modification of Unit 15 increased the FGE of this unit relative to all other unmodified units (Unit 8 with an ESBS excluded) in spring and summer (Figure 3.39), and its FGE was among the highest for individual Powerhouse 2 units summer (Figure 3.40). It is important to note that FGE estimates for different units were not computed for exactly the same days and hours because units ran at different times. Therefore, time of day and day-to-day variation in FGE are a part of these estimates and comparisons. Unit 8 had a 40-ft-long ESBS while the gatewell and vertical barrier screen at Unit 15 were modified to improve flow up the gatewell and improve FGE. As in 2000, the FGE of the ESBS in summer was no better than that of STS during the same season. We considered FGE estimates for Intake $15 \underline{b}$ to be more reliable than those did for $15 \underline{c}$ (which were lower) because we sampled more minutes per hour and confidence intervals were tighter. Intake $15 \underline{b}$ passed 2.42 times more fish than did Intake $15 \underline{c}$ in both seasons so the Intake $15 \underline{b}$ estimate provided a closer approximation to FGE for the entire unit than did the estimate for Intake $15 \underline{\mathrm{c}}$.

Provision of a Powerhouse 2 priority in spring was a good management tactic because Powerhouse 2 units tended to provide higher FGE than do those at Powerhouse 1 units in spring. The FGE was similar and low for both powerhouses in summer. The higher FGE of Powerhouse 2 units may have resulted from the presence of TIES at every other intake, and the fact that five of nine intakes that we sampled were between TIES where passage and FGE tended to be higher. We also observed higher FGE in spring at Intake $15 \underline{b}$, which was between two TIES, than we did at Intake 15ㅁ, which was behind a TIE (Figure 3.41). There also was a tendency for FGE to be lower at the ends of Powerhouse 2 than in the middle, but since the intakes we sampled at end units of Powerhouse 2 were behind instead of between TIES, the effect of unit location could have been masked. Unit 1 had the lowest FGE at Powerhouse 1 in both spring and summer.

\subsubsection{Comparing FGE Estimates by Different Sampling Methods}

Our estimates of FGE compared very well with netting estimates by the NMFS in both seasons, particularly when we estimated FGE from all nighttime hours sampled instead of just hours of concurrent sampling (Figure 4.1). Hydroacoustic estimates of FGE require longer sampling durations than the 1 to 2 hours that are commonly used to estimate FGE by netting, because hydroacoustic beams sample only about $5 \%$ of the cross-sectional area of an intake compared to near $100 \%$ coverage by netting. For example, Ploskey and Carlson (1999) observed that the precision of hydroacoustic estimates of FGE at John Day Dam increased by $50 \%$, and the $\mathrm{r}^{2}$ of a correlation line between hydroacoustic and netting estimates increased by $19 \%$, when the hydroacoustic sampling duration was extended from the typical netting duration of 1-2 $\mathrm{h}$ to $4 \mathrm{~h}$. In 2001, we were able to sample throughout the night only when the NMFS was conducting orifice passage efficiency testing, and the unit was operated all night. On most nights of netting to estimate FGE, Unit 15 was shut down after netting and was not restarted until the next FGE test the following night. This type of on and off operation, as depicted in Figure 4.4, severely limited the number of fish that could be detected by hydroacoustics and the precision and accuracy of hydroacoustic estimates. We made up for this shortcoming by using all available hours of nighttime sampling to make seasonal estimates, but it would have been preferable for hydroacoustic sampling to run the unit throughout the night after FGE netting ends. 

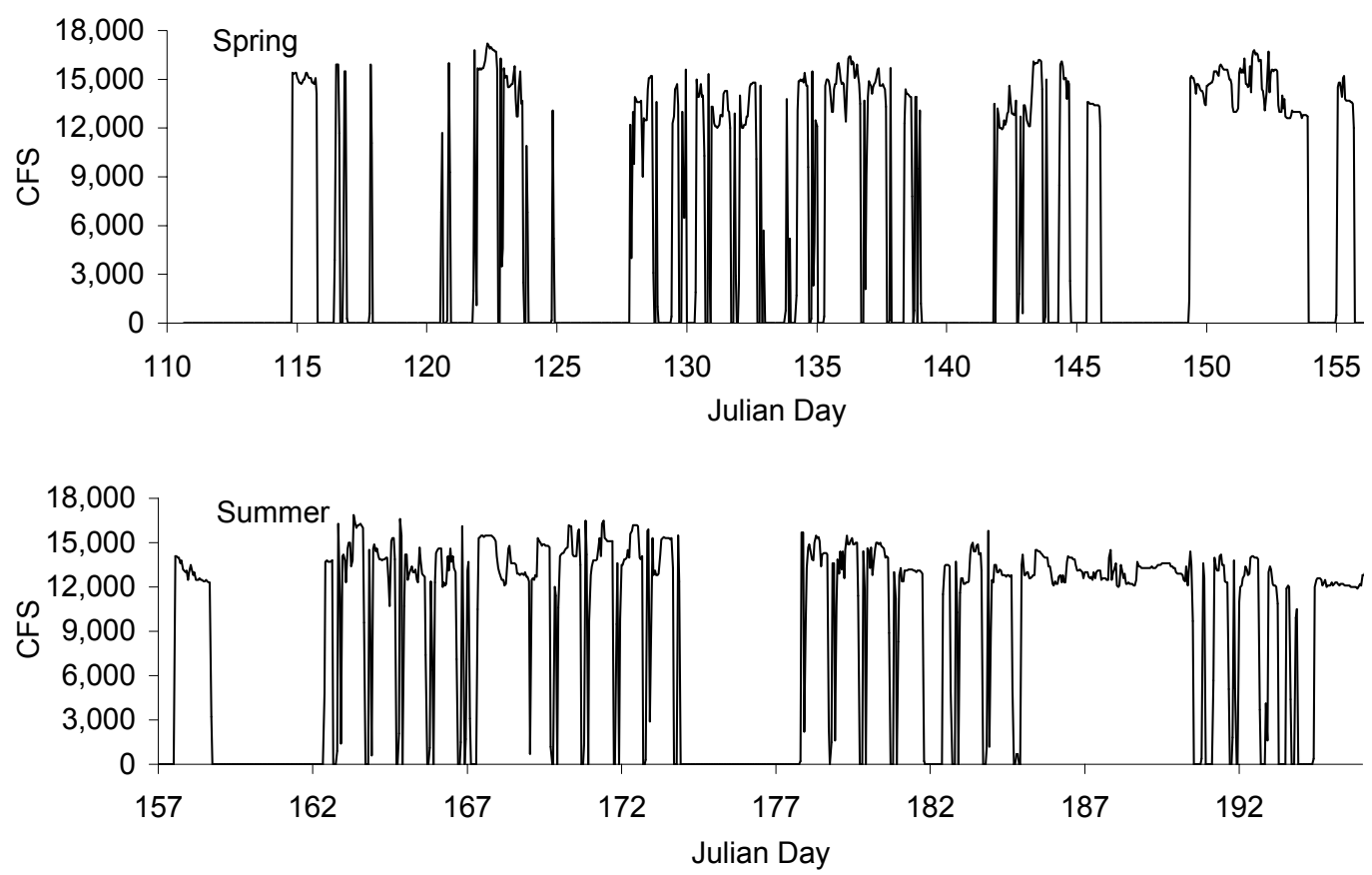

Figure 4.4. Patterns of Discharge of Modified Unit 15 in Spring and Summer 2001 showing the Frequency of On and Off Periods

Another problem introduced by excessive on and off operation of a turbine unit is that hydroacoustic beams continue to sample and fish that are swimming around in the unit when it is off are detected, often many times. At Unit 15, we carefully threw out all fish detected before or after FGE netting based upon start and end times provided by Bruce Monk (NMFS). In addition, we threw out all fish detected during hours in which the Unit 15 discharged $<65 \%$ of its maximum discharge because the operations data available in 2001 was only for whole hours. Operations data reported at 5-minute intervals, like those available in 2000 and earlier years, were much better for accurately assigning zero fish counts to samples collected when units are off.

We have two recommendations for FGE testing in 2002 to provide better hydroacoustic FGE estimates. First, we recommend that the test unit be run as much as possible instead of having it run solely for FGE and orifice passage netting. Second, we recommend that on and off times be recorded with the dam operations data or at least that discharge be recorded at 5-minute intervals instead of hourly.

Similar hydroacoustic and netting estimates of FGE for Unit 15 were 32.0 and 36.7\% higher, respectively, than were radio telemetry estimates for the same unit in spring, and this may be a function of limited sample sizes in radio tagged data for individual units. The $38 \%$ FGE estimate by radio telemetry in spring was based upon only 19 guided fish of 50 (total) for the entire season, whereas netting estimates usually were based upon $>10$ times that number in 1 to 2 hours of sampling. The number of fish counted by concurrent hydroacoustic sampling $(14,687)$ and netting $(16,651)$ also were similar. Dispersion expected for 19 of 50 fish based upon the binomial distribution (i.e., 25\% to 53\%; Cliff Pereira - Personal Communication) does not account for the magnitude of observed differences between the low radiotelemetry estimate and the higher and concordant netting and hydroacoustic estimates. 
Hydroacoustic Evaluation of FPE at Bonneville Dam in 2001 


\subsection{References}

BioSonics, Incorporated. 1998. Hydroacoustic Evaluation and Studies at Bonneville Dam, Spring/Summer 1997. Contract Report to the U.S. Army Corps of Engineers Portland District, Portland, Oregon.

Gessel, M. H., B. H. Monk, and J. G. Williams. 1988. Evaluation of the Juvenile Fish Collection and Bypass Systems at Bonneville Dam 1987. Annual Report by the U.S. Department. Commerce, National Oceanic and Atmospheric Administration, National Marine Fisheries Service, Coastal Zone and Estuarine Studies Division to the U.S. Army Engineers Portland District, Portland, Oregon.

Gessel, M. H., J. G. Williams, D. A. Brege, and R. F. Krcma. 1991. "Juvenile Salmonid Guidance at the Bonneville Dam Second Powerhouse, Columbia River, 1983-1989." North American Journal of Fisheries Management 11:400-412.

Giorgi, A. E. and J. R. Stevenson. 1995. A Review of Biological Investigations Describing Smolt Passage Behavior at Portland District Corps of Engineer Projects: Implications in Surface Collection Systems. Contract Report prepared by Don Chapman Consultants, Inc. for the U.S. Army Engineer District, Portland, Oregon.

Hawkes, L. A., R. D. Martinson, R. F. Absolon, and S. Killins. 1991. Monitoring of Downstream Salmon and Steelhead at Federal Hydroelectric Facilities. Annual Report 1990 by the U.S. Department. Commerce, National Oceanic and Atmospheric Administration, National Marine Fisheries Service, ETSD, to the U.S. Department of Energy, Bonneville Power Administration, Portland, Oregon.

Johnson, G. E. and T. J. Carlson. 2000. Monitoring and Evaluation of the Prototype Surface Collector at Bonneville First Powerhouse in 2000: Synthesis of Information on PSC Performance. U. S. Army Corps of Engineers Draft Report prepared by BioAnalysts, Inc and Battelle.

Johnson, G. E. and A. E. Giorgi. 1999. Development of Surface Flow Bypasses at Bonneville Dam: A Synthesis of Data from 1995 to 1998 and a Draft M\&E Plan for 2000. Draft final report submitted October 8, 1999 to Portland District, U.S. Army Corps of Engineers, Portland, Oregon.

Krcma, R. F., D. DeHart, M. Gessel, C. Long, and C. W. Sims. 1982. Evaluation of Submersible Traveling Screens, Passage of Juvenile Salmonids through the Ice-Trash Sluiceway, and Cycling of Gatewell-Orifice Operations at the Bonneville First Powerhouse, 1981. Final Report by the U.S. Department Commerce, National Oceanic and Atmospheric Administration, National Marine Fisheries Service, Coastal Zone and Estuarine Studies Div. to the U.S. Army Engineer District, Portland, Oregon.

Love, R. H. 1977. "Target Strength of an Individual Fish at any Aspect." Journal of the Acoustical Society of America 62(6):1397-1403.

Magne, R. A., D. J. Rawding, and W. T. Nagy. 1986. Hydroacoustic Monitoring at the Bonneville Dam Second Powerhouse during 1986 Fish Guiding Efficiency Tests. Fishery Field Unit, U.S. Army Engineer District, Portland, Oregon. 
Magne, R. A. 1987. Hydroacoustic Monitoring at the Bonneville Dam Project in 1987. Fishery Field Unit, U.S. Army Engineer District, Portland, Oregon.

Magne, R. A., R. J. Stansell, and W. T. Nagy. 1989. A Summary of Hydroacoustic Monitoring at the Bonneville Dam Second Powerhouse in 1988. Fishery Field Unit, U.S. Army Engineer District, Portland, Oregon.

Muir, W. D., A. E. Giorgi, W. S. Zaugg, and B. R. Beckman. 1989. An Assessment of the Relationship between Smolt Development and Fish Guidance Efficiency at Bonneville Dam. Annual Report by the National Marine Fisheries Service, Coastal Zone and Estuarine Studies Division, Northwest Fisheries Center, Seattle, Washington.

Ploskey, G. R. and T. J. Carlson. 1999. "Comparison of Hydroacoustic and Net Estimates of Fish Guidance Efficiency of an Extended Submersible Bar Screen at John Day Dam." North American Journal of Fisheries Management 19:1066-1079.

Ploskey, G. R., P. N. Johnson, W. T. Nagy, M. G. Burczinski, and L. R. Lawrence. 1998. Hydroacoustic Evaluations of Smolt Passage at Bonneville Dam Including Surface Collection Simulations. USAE Waterway Experiment Station Technical Report EL-98-4 prepared for the U.S. Army Engineer District, Portland, Oregon.

Ploskey, G. R., W. T. Nagy, L. R. Lawrence, D. S. Patterson, C. R. Schilt, P. N. Johnson, and J. R. Skalski. 2001a. Hydroacoustic Evaluation of Juvenile Salmonid Passage through Experimental Routes at Bonneville Dam in 1998. Technical Report ERDC/EL TR-01-2, U.S. Army Engineer Research and Development Center, Vicksburg, MS.

Ploskey, G. R., W.T. Nagy, L.R. Lawrence, M.E. Hanks, C.R. Schilt, P. N. Johnson, G. E. Johnson, D. S. Patterson, and J. R. Skalski. 2001b. Hydroacoustic Evaluation of Juvenile Salmon Passage at The Dalles Dam: 1999. Technical Report ERDC/EL TR-01-11, U.S. Army Engineer Research and Development Center, Vicksburg, MS.

Ploskey, G.R., C.R. Schilt, M.E. Hanks, J.R. Skalski, W.T. Nagy, P.N. Johnson, D.S. Patterson, J. Kim, and L. Lawrence. 2002b. Hydroacoustic Evaluation of Fish Passage through Bonneville Dam in 2000. Technical Report ERDC/ELTR-02-8 of the U.S. Army Engineer Research and Development Center, Waterways Experiment Station, Vicksburg, Mississippi.

Ploskey, G.R., C.R. Schilt, M.E. Hanks, J.R. Skalski, W.T. Nagy, P.N. Johnson, D.S. Patterson, J. Kim, and L. Lawrence. 2002a Hydroacoustic Evaluation of a Prototype Surface Collector and In-Turbine Screens at Bonneville Dam First Powerhouse in 2000. Technical Report ERDC/ELTR-02-15 of the U.S. Army Research and Development Center, Waterways Experiment Station, Vicksburg, Mississippi.

Skalski, J. R., and D. S. Robson. 1992. Techniques for Wildlife Investigations: Design and Analysis of Capture Data. Academic Press. San Diego, California.

Stansell R. J., R. A. Magne, W. T. Nagy, and L. M. Beck. 1990. Hydroacoustic Monitoring of Downstream Migrant Juvenile Salmonids at Bonneville Dam, 1989. Fishery Field Unit, U.S. Army Engineer District, Portland, Oregon. 
Steig, T. W. and B. H. Ransom. 1993. "Long-Term Hydroacoustic Evaluations of a Fixed In-Turbine Fish Diversion Screen at Rocky Reach Dam on the Columbia River, Washington." In Waterpower '93, Proceedings of the International Conference on Hydropower, Editor D.W. Hall (pp. 219-228). American Society of Civil Engineers, New York.

Thorne, R. E. and E. S. Kuehl. 1989. Evaluation of Hydroacoustics Techniques for Assessment of Juvenile Fish Passage at Bonneville Powerhouse I. Final Report by BioSonics Inc., Seattle, WA for the U.S. Army Engineer District, Portland, Oregon.

Uremovich, B. L., S. P. Cramer, C. F. Willis, and C. O. Junge. 1980. Passage of Juvenile Salmonids through the Ice-Trash Sluiceway and Sqawfish Predation at Bonneville Dam, 1980. Oregon Department of Fish and Wildlife Annual progress report prepared for the U.S. Army Engineer District, Portland, Oregon.

Willis, C. F. and B. L. Uremovich. 1981. Evaluation of the Ice and Trash Sluiceway at Bonneville Dam as a Bypass System for Juvenile Salmonids, 1981. Oregon Department of Fish and Wildlife Annual progress report prepared for the U.S. Army Engineer District, Portland, Oregon.

Wood, L. A., R. D. Martinson, R. J. Graves, D. R. Carroll, S. D. Killins. 1994. Monitoring of Downstream Salmon and Steelhead at Federal Hydroelectric Facilities. Annual Report 1993 by the U.S. Department. Commerce, National Oceanic and Atmospheric Administration, National Marine Fisheries Service, ETSD to the U.S. Dep. Energy, Bonneville Power Administration, Portland, Oregon. 
Hydroacoustic Evaluation of FPE at Bonneville Dam in 2001

5.4 
Appendix A

Transducer Calibrations and Receiver Gains 



\section{Appendix A}

\section{Transducer Calibrations and Receiver Gains}

Appendix A-1. Calibration Data and Calculated Receiver Gains for Single-Beam and Split-Beam Transducers Deployed at Powerhouse 1 to Provide Equal Detectability for On-Axis Targets Ranging in Acoustic Size from -56 to $-36 \mathrm{~dB}$. Results for split-beam transducers are presented for the $x$ phase, $y$ phase, and the mean of $x$ and $y$ phases.

\begin{tabular}{|c|c|c|c|c|c|c|c|c|c|}
\hline $\begin{array}{c}\text { Echo- } \\
\text { sounder } \\
\text { Letter and } \\
\text { Channel } \\
\text { Number }\end{array}$ & $\begin{array}{l}\text { Trans- } \\
\text { ducer } \\
\text { Number } \\
\text { and Phase } \\
\text { (if split } \\
\text { beams) }\end{array}$ & \begin{tabular}{|} 
Difference in \\
Cable \\
Length \\
Between \\
Calibrated \\
Cable and \\
Installed \\
Cable (ft)
\end{tabular} & $\begin{array}{c}\text { Receiver } \\
\quad \text { Gain } \\
\text { Adjusted for } \\
\text { Difference in } \\
\text { Cable } \\
\text { Length (dB) }\end{array}$ & $\begin{array}{c}\text { Source } \\
\text { Level } \\
\text { Adjusted for } \\
\text { Difference in } \\
\text { Cable } \\
\text { Length (dB) }\end{array}$ & $\begin{array}{c}\text { Receiver } \\
\text { Sensitivity } \\
\text { Adjusted for } \\
\text { Difference in } \\
\text { Cable } \\
\text { Length (dB) }\end{array}$ & $\begin{array}{c}\text { Target } \\
\text { Strengthof } \\
\text { Smallest } \\
\text { On-axis } \\
\text { Target (dB) }\end{array}$ & $\begin{array}{c}\text { Voltage of } \\
\text { Smallest } \\
\text { On-axis } \\
\text { Target (dB) }\end{array}$ & $\begin{array}{c}\text { Voltage of } \\
\text { Smallest } \\
\text { On-axis } \\
\text { Target at } \\
20 \mathrm{~dB} \text { per } \\
\text { Volt (V) }\end{array}$ & $\begin{array}{c}\text { Turbine } \\
\text { Intake }\end{array}$ \\
\hline C-8 & 8 & -2 & 3.14 & 215.04 & -112.18 & -56 & 50 & 2.5 & $4 \mathrm{~A}$ \\
\hline $\mathrm{C}-7$ & 7 & -2 & 2.42 & 215.42 & -111.84 & -56 & 50 & 2.5 & $4 \mathrm{~A}$ \\
\hline C-6 & 6 & -2 & 3.76 & 214.86 & -112.62 & -56 & 50 & 2.5 & $3 C$ \\
\hline C-5 & 5 & -2 & 2.23 & 215.45 & -111.68 & -56 & 50 & 2.5 & $3 C$ \\
\hline C-4 & 4 & -2 & 3.12 & 215.08 & -112.20 & -56 & 50 & 2.5 & $2 \mathrm{~A}$ \\
\hline C-3 & 3 & -2 & 4.55 & 214.37 & -112.92 & -56 & 50 & 2.5 & $2 A$ \\
\hline C-2 & 2 & -2 & 3.01 & 215.09 & -112.10 & -56 & 50 & 2.5 & $1 \mathrm{~B}$ \\
\hline $\mathrm{C}-1$ & 1 & -1 & 2.79 & 215.15 & -111.94 & -56 & 50 & 2.5 & $1 \mathrm{~B}$ \\
\hline D-8 & 19 & -2 & 2.23 & 215.63 & -111.86 & -56 & 50 & 2.5 & $9 \mathrm{C}$ \\
\hline D-7 & 18 & -2 & 1.91 & 215.65 & -111.56 & -56 & 50 & 2.5 & $9 \mathrm{C}$ \\
\hline D-6 & 17 & -2 & 2.19 & 215.63 & -111.82 & -56 & 50 & 2.5 & $8 B$ \\
\hline D-5 & 13 & -2 & 3.73 & 214.91 & -112.64 & -56 & 50 & 2.5 & $8 B$ \\
\hline D-4 & 12 & -2 & 3.74 & 214.92 & -112.66 & -56 & 50 & 2.5 & $7 A$ \\
\hline D-3 & 11 & -1 & 3.23 & 215.11 & -112.34 & -56 & 50 & 2.5 & $7 A$ \\
\hline D-2 & 10 & -2 & 2.75 & 215.23 & -111.98 & -56 & 50 & 2.5 & $6 C$ \\
\hline D-1 & 9 & 0 & 3.02 & 215.09 & -112.11 & -56 & 50 & 2.5 & $6 C$ \\
\hline$A-1$ & $105(x)$ & 0 & 10.53 & 214.04 & -108.57 & -56 & 60 & 3.0 & $10 \mathrm{~B}$ \\
\hline$A-1$ & $105(y)$ & 0 & 10.47 & 214.08 & -108.55 & -56 & 60 & 3.0 & $10 \mathrm{~B}$ \\
\hline$A-1$ & 105 & 0 & 10.50 & 214.06 & -108.56 & -56 & 60 & 3.0 & $10 \mathrm{~B}$ \\
\hline$A-0$ & $53(x)$ & 0 & 10.29 & 214.16 & -108.45 & -56 & 60 & 3.0 & $10 \mathrm{~B}$ \\
\hline$A-0$ & $53(y)$ & 0 & 10.29 & 214.20 & -108.49 & -56 & 60 & 3.0 & $10 \mathrm{~B}$ \\
\hline$A-0$ & 53 & 0 & 10.29 & 214.18 & -108.47 & -56 & 60 & 3.0 & $10 \mathrm{~B}$ \\
\hline$X-1$ & $412(x)$ & 0 & 4.14 & 215.17 & -103.31 & -56 & 60 & 3.0 & $5 B$ \\
\hline$X-1$ & $412(y)$ & 0 & 4.14 & 215.17 & -103.31 & -56 & 60 & 3.0 & $5 B$ \\
\hline$X-1$ & 412 & 0 & 4.14 & 215.17 & -103.31 & -56 & 60 & 3.0 & $5 B$ \\
\hline$X-0$ & $413(x)$ & 0 & 4.17 & 215.14 & -103.31 & -56 & 60 & 3.0 & $5 B$ \\
\hline$X-0$ & $413(y)$ & 0 & 4.14 & 215.15 & -103.29 & -56 & 60 & 3.0 & $5 B$ \\
\hline$X-0$ & 413 & 0 & 4.16 & 215.15 & -103.30 & -56 & 60 & 3.0 & $5 B$ \\
\hline
\end{tabular}


Appendix A-2. Calibration Data and Calculated Receiver Gains for Single-Beam and Split-Beam Transducers Deployed at the Spillway to Provide Equal Detectability for On-Axis Targets Ranging in Acoustic Size from -56 to $-36 \mathrm{~dB}$. Results for split-beam transducers are presented for the $x$ phase, $y$ phase, and the mean of $x$ and $y$ phases.

\begin{tabular}{|c|c|c|c|c|c|c|c|c|c|}
\hline \begin{tabular}{|c|} 
Echo- \\
sounder \\
Letter and \\
Channel \\
Number
\end{tabular} & \begin{tabular}{|} 
Trans- \\
ducer \\
Number \\
and Phase \\
(if split \\
beams)
\end{tabular} & $\begin{array}{c}\text { Difference in } \\
\text { Cable } \\
\text { Length } \\
\text { Between } \\
\text { Calibrated } \\
\text { Cable and } \\
\text { Installed } \\
\text { Cable (ft) }\end{array}$ & $\begin{array}{c}\text { Receiver } \\
\text { Gain } \\
\text { Adjusted for } \\
\text { Difference } \\
\text { in Cable } \\
\text { Length (dB) }\end{array}$ & \begin{tabular}{|c|} 
Source \\
Level \\
Adjusted for \\
Difference in \\
Cable \\
Length (dB)
\end{tabular} & \begin{tabular}{|c|} 
Receiver \\
Sensitivity \\
Adjusted for \\
Difference in \\
Cable \\
Length (dB)
\end{tabular} & $\begin{array}{c}\text { Target } \\
\text { Strength of } \\
\text { Smallest } \\
\text { On-axis } \\
\text { Target (dB) }\end{array}$ & $\begin{array}{c}\text { Voltage of } \\
\text { Smallest } \\
\text { On-axis } \\
\text { Target (dB) }\end{array}$ & $\begin{array}{c}\text { Voltage of } \\
\text { Smallest } \\
\text { On-axis } \\
\text { Target at } \\
20 \mathrm{~dB} \text { per } \\
\text { Volt (V) }\end{array}$ & Spill Bay \\
\hline $\mathrm{P}-1$ & 49 & -300 & 9.44 & 210.66 & -104.10 & -56 & 60 & 3.0 & 8.0 \\
\hline P-3 & 50 & 0 & 4.04 & 213.77 & -101.81 & -56 & 60 & 3.0 & 12.0 \\
\hline $\mathrm{P}-2$ & 51 & -200 & 7.13 & 212.60 & -103.73 & -56 & 60 & 3.0 & 10.0 \\
\hline P-5 & 54 & 0 & 3.24 & 214.29 & -101.53 & -56 & 60 & 3.0 & 15.0 \\
\hline P-4 & 56 & 0 & 4.69 & 213.74 & -102.43 & -56 & 60 & 3.0 & 14.0 \\
\hline Q-1 & 42 & 0 & 4.06 & 213.71 & -101.77 & -56 & 60 & 3.0 & 2.0 \\
\hline Q-2 & 43 & 0 & 4.08 & 213.97 & -102.05 & -56 & 60 & 3.0 & 4.0 \\
\hline Q-3 & 44 & 0 & 3.93 & 213.56 & -101.49 & -56 & 60 & 3.0 & 5.0 \\
\hline Q-4 & 45 & 0 & 3.83 & 213.96 & -101.79 & -56 & 60 & 3.0 & 6.0 \\
\hline Q-5 & 48 & 0 & 5.58 & 212.09 & -101.67 & -56 & 60 & 3.0 & 7.0 \\
\hline $\mathrm{O}-0$ & $120(x)$ & 0 & 15.27 & 209.76 & -109.03 & -56 & 60 & 3.0 & 17.0 \\
\hline $\mathrm{O}-0$ & $120(\mathrm{y})$ & 0 & 15.34 & 209.69 & -109.03 & -56 & 60 & 3.0 & 17.0 \\
\hline $\mathrm{O}-0$ & 120 & 0 & 15.31 & 209.73 & -109.03 & -56 & 60 & 3.0 & 17.0 \\
\hline
\end{tabular}


Appendix A-3. Calibration Data and Calculated Receiver Gains for Single and Split-Beam Transducers to Provide Equal Detectability for On-Axis Targets Ranging from -56 to $-36 \mathrm{~dB}$ in Acoustic Size at Powerhouse 2. Results for split-beam transducers are presented for the $x$ phase, $y$ phase, and the mean of $x$ and $y$ phases.

\begin{tabular}{|c|c|c|c|c|c|c|c|c|c|}
\hline $\begin{array}{c}\text { Echo- } \\
\text { sounder } \\
\text { Letter and } \\
\text { Channel } \\
\text { Number }\end{array}$ & \begin{tabular}{|c|} 
Trans- \\
ducer \\
Number \\
and Phase \\
(if split \\
beams)
\end{tabular} & $\begin{array}{l}\text { Difference } \\
\text { in Cable } \\
\text { Length } \\
\text { Between } \\
\text { Calibrated } \\
\text { Cable and } \\
\text { Installed } \\
\text { Cable (ft) }\end{array}$ & $\begin{array}{l}\text { Receiver } \\
\text { Gain } \\
\text { Adjusted } \\
\text { for } \\
\text { Difference } \\
\text { in Cable } \\
\text { Length (dB) }\end{array}$ & $\begin{array}{c}\text { Source } \\
\text { Level } \\
\text { Adjusted } \\
\text { for } \\
\text { Difference } \\
\text { in Cable } \\
\text { Length (dB) }\end{array}$ & $\begin{array}{c}\text { Receiver } \\
\text { Sensitivity } \\
\text { Adjusted for } \\
\text { Difference } \\
\text { in Cable } \\
\text { Length (dB) }\end{array}$ & $\begin{array}{c}\text { Target } \\
\text { Strength } \\
\text { of } \\
\text { Smallest } \\
\text { On-axis } \\
\text { Target } \\
\text { (dB) }\end{array}$ & $\begin{array}{c}\text { Voltage of } \\
\text { Smallest } \\
\text { On-axis } \\
\text { Target } \\
\text { (dB) }\end{array}$ & $\begin{array}{c}\text { Voltage of } \\
\text { Smallest } \\
\text { On-axis } \\
\text { Target at } \\
20 \mathrm{~dB} \text { per } \\
\text { Volt (V) }\end{array}$ & Turbine Intake \\
\hline G-2 & 28 & 0 & 3.60 & 215.03 & -112.63 & -56 & 50 & 2.5 & $11 \mathrm{C}$ \\
\hline G-1 & 40 & -2 & 1.73 & 216.01 & -111.74 & -56 & 50 & 2.5 & $11 \mathrm{C}$ \\
\hline G-3 & 44 & 0 & 2.85 & 215.32 & -112.17 & -56 & 50 & 2.5 & $12 \mathrm{~A}$ \\
\hline G-4 & 35 & 25 & 2.01 & 215.92 & -111.92 & -56 & 50 & 2.5 & $12 \mathrm{~A}$ \\
\hline G-6 & 42 & 0 & 2.17 & 215.70 & -111.87 & -56 & 50 & 2.5 & $13 \mathrm{~B}$ \\
\hline G-5 & 39 & -31 & 1.86 & 215.55 & -111.41 & -56 & 50 & 2.5 & 13B \\
\hline G-8 & 38 & -24 & 2.29 & 215.60 & -111.89 & -56 & 50 & 2.5 & $14 \mathrm{C}$ \\
\hline G-7 & 36 & 5 & 2.94 & 215.39 & -112.32 & -56 & 50 & 2.5 & $14 \mathrm{C}$ \\
\hline $\mathrm{H}-6$ & 57 & 2 & 3.69 & 215.01 & -112.70 & -56 & 50 & 2.5 & 16B \\
\hline $\mathrm{H}-5$ & 58 & 0 & 1.02 & 216.39 & -111.41 & -56 & 50 & 2.5 & 16B \\
\hline $\mathrm{H}-7$ & 59 & 0 & 3.67 & 214.98 & -112.65 & -56 & 50 & 2.5 & 17B \\
\hline $\mathrm{H}-8$ & 60 & 0 & 2.60 & 215.43 & -112.03 & -56 & 50 & 2.5 & 17B \\
\hline $\mathrm{H}-1$ & 61 & -1 & 2.60 & 215.46 & -112.06 & -56 & 50 & 2.5 & 15B \\
\hline $\mathrm{H}-2$ & 63 & 0 & 4.10 & 214.89 & -112.99 & -56 & 50 & 2.5 & 15B \\
\hline $\mathrm{H}-3$ & 56 & 3 & 4.08 & 214.85 & -112.93 & -56 & 50 & 2.5 & $15 \mathrm{C}$ \\
\hline $\mathrm{H}-4$ & 29 & 0 & 1.61 & 215.96 & -111.57 & -56 & 50 & 2.5 & $15 \mathrm{C}$ \\
\hline $1-0$ & $51(x)$ & 0 & 7.03 & 214.66 & -105.69 & -56 & 60 & 3.0 & 18B \\
\hline $\mathrm{I}-0$ & $51(\mathrm{y})$ & 0 & 6.83 & 214.66 & -105.49 & -56 & 60 & 3.0 & $18 \mathrm{~B}$ \\
\hline $\mathrm{I}-0$ & 51 & 0 & 6.93 & 214.66 & -105.59 & -56 & 60 & 3.0 & 18B \\
\hline $\mathrm{I}-10$ & $52(x)$ & 0 & 9.18 & 213.87 & -107.05 & -56 & 60 & 3.0 & 18B \\
\hline $\mathrm{I}-10$ & $52(y)$ & 0 & 9.20 & 213.87 & -107.07 & -56 & 60 & 3.0 & 18B \\
\hline $\mathrm{I}-10$ & 52 & 0 & 9.19 & 213.87 & -107.06 & -56 & 60 & 3.0 & 18B \\
\hline $\mathrm{R}-0$ & $414(x)$ & 0 & 0.00 & 0.00 & 0.00 & -56 & -56 & -2.8 & 15B upstream \\
\hline $\mathrm{R}-0$ & $414(\mathrm{y})$ & 0 & 0.00 & 0.00 & 0.00 & -56 & -56 & -2.8 & 15B upstream \\
\hline $\mathrm{R}-0$ & 414 & 0 & 0.00 & 0.00 & 0.00 & -56 & -56 & -2.8 & 15B upstream \\
\hline $\mathrm{R}-1$ & $415(x)$ & 0 & 0.00 & 0.00 & 0.00 & -56 & -56 & -2.8 & 15B upstream \\
\hline $\mathrm{R}-1$ & $415(\mathrm{y})$ & 0 & 0.00 & 0.00 & 0.00 & -56 & -56 & -2.8 & 15B upstream \\
\hline$R-1$ & 415 & 0 & 0.00 & 0.00 & 0.00 & -56 & -56 & -2.8 & 15B upstream \\
\hline $\mathrm{R}-2$ & $416(x)$ & 0 & 0.00 & 0.00 & 0.00 & -56 & -56 & -2.8 & 15B upstream \\
\hline $\mathrm{R}-2$ & $416(y)$ & 0 & 0.00 & 0.00 & 0.00 & -56 & -56 & -2.8 & 15B upstream \\
\hline $\mathrm{R}-2$ & 416 & 0 & 0.00 & 0.00 & 0.00 & -56 & -56 & -2.8 & 15B upstream \\
\hline
\end{tabular}




$$
\text { A. } 4
$$


Appendix B

Detailed Transducer Locations and Aiming Angles 



\section{Appendix B}

\section{Detailed Transducer Locations and Aiming Angles}

Appendix B-1. Transducer Locations at Powerhouse 1 in 2001. Angle refers to the angle off the trashrack or extended-submerged-bar-screen (ESBS) plane. Abbreviations are as follows: $\mathrm{SB}=$ split-beam; $(\mathrm{D})=$ downstream; Rack = trash rack, where Rack 1 is the uppermost of six trash racks, and its top is at Elevation $69 \mathrm{ft} \mathrm{MSL}$.

\begin{tabular}{|c|c|c|c|c|c|c|c|c|c|}
\hline $\begin{array}{c}\text { System } \\
\text { Letter }\end{array}$ & Channel & $\begin{array}{l}\text { Trans- } \\
\text { ducer }\end{array}$ & $\begin{array}{l}\text { Beam } \\
\text { Angle }\end{array}$ & $\begin{array}{l}\text { Intake } \\
\text { or Bay }\end{array}$ & Structure & $\begin{array}{c}\text { Location on } \\
\text { Placement on Structure }\end{array}$ & $\begin{array}{r}\text { Eleva } \\
\text { (ft) }\end{array}$ & \begin{tabular}{c|c} 
tion \\
Aim
\end{tabular} & $\begin{array}{c}\text { Angle } \\
\text { (Degrees) }\end{array}$ \\
\hline & & & & & & & & & \\
\hline $\mathrm{C}$ & 1 & 1 & 6 & $1 \mathrm{~B}$ & Rack 1 & $4.4 \mathrm{ft}$ below top; $11.0 \mathrm{ft} \mathrm{S}$ of N Side & 64.6 & Down & $20(\mathrm{D})$ \\
\hline $\mathrm{C}$ & 2 & 2 & 6 & $1 \mathrm{~B}$ & Rack 5 & Bottom Shelf; $11.0 \mathrm{ft}$ S of N Side & 11.0 & $\mathrm{Up}$ & $18(\mathrm{D})$ \\
\hline $\mathrm{C}$ & 3 & 3 & 6 & $2 \mathrm{~A}$ & Rack 1 & $4.4 \mathrm{ft}$ below top; $13.2 \mathrm{ft} \mathrm{S}$ of N Side & 64.6 & Down & $20(\mathrm{D})$ \\
\hline $\mathrm{C}$ & 4 & 4 & 6 & $2 \mathrm{~A}$ & Rack 5 & Bottom Shelf; $13.2 \mathrm{ft}$ S of N Side & 11.0 & $\mathrm{Up}$ & $18(\mathrm{D})$ \\
\hline $\mathrm{C}$ & 5 & 5 & 6 & $2 \mathrm{C}$ & Rack 1 & $4.4 \mathrm{ft}$ below top; $8.8 \mathrm{ft} \mathrm{S}$ of N Side & 64.6 & Down & $20(\mathrm{D})$ \\
\hline $\mathrm{C}$ & 6 & 6 & 6 & $2 \mathrm{C}$ & Rack 5 & Bottom Shelf; $8.8 \mathrm{ft} \mathrm{S}$ of N Side & 11.0 & $\mathrm{Up}$ & $18(\mathrm{D})$ \\
\hline $\mathrm{C}$ & 7 & 7 & 6 & $4 \mathrm{~A}$ & Rack 1 & $4.4 \mathrm{ft}$ below top; $11.0 \mathrm{ft} \mathrm{S}$ of N Side & 64.6 & Down & $20(\mathrm{D})$ \\
\hline $\mathrm{C}$ & 8 & 8 & 6 & $4 \mathrm{~A}$ & Rack 5 & Bottom Shelf; $11.0 \mathrm{ft} \mathrm{S}$ of N Side & 11.0 & $\mathrm{Up}$ & $18(\mathrm{D})$ \\
\hline $\mathrm{X}$ & 0 & 413 & SB 6 & $5 \mathrm{~B}$ & Rack 1 & $4.4 \mathrm{ft}$ below top; $13.2 \mathrm{ft} \mathrm{S}$ of N Side & 64.6 & Down & $20(\mathrm{D})$ \\
\hline $\mathrm{X}$ & 1 & 412 & SB 6 & $5 \mathrm{~B}$ & Rack 5 & Bottom Shelf; $13.2 \mathrm{ft}$ S of N Side & 11.0 & $\mathrm{Up}$ & $18(\mathrm{D})$ \\
\hline $\mathrm{D}$ & 1 & 9 & 6 & $6 \mathrm{C}$ & Rack 1 & $4.4 \mathrm{ft}$ below top; $8.8 \mathrm{ft} \mathrm{S}$ of N Side & 64.6 & Down & $20(\mathrm{D})$ \\
\hline $\mathrm{D}$ & 2 & 10 & 6 & $6 \mathrm{C}$ & Rack 5 & Bottom Shelf; $8.8 \mathrm{ft} \mathrm{S}$ of N Side & 11.0 & $\mathrm{Up}$ & $18(\mathrm{D})$ \\
\hline $\mathrm{D}$ & 3 & 11 & 6 & $7 \mathrm{~A}$ & Rack 1 & $4.4 \mathrm{ft}$ below top; $11.0 \mathrm{ft} \mathrm{S}$ of N Side & 64.6 & Down & $20(\mathrm{D})$ \\
\hline $\mathrm{D}$ & 4 & 12 & 6 & $7 \mathrm{~A}$ & Rack 5 & Bottom Shelf; $11.0 \mathrm{ft}$ S of N Side & 11.0 & $\mathrm{Up}$ & $18(\mathrm{D})$ \\
\hline $\mathrm{D}$ & 5 & 13 & 6 & $8 \mathrm{~B}$ & Rack 5 & $7.6 \mathrm{ft}$ below top; $11.0 \mathrm{ft} \mathrm{S}$ of N Side & 14.0 & $\mathrm{Up}$ & $21(\mathrm{D})$ \\
\hline $\mathrm{D}$ & 6 & 17 & 6 & $8 \mathrm{~B}$ & ESBS & $2.0 \mathrm{ft}$ below pivot; $13.0 \mathrm{ft} \mathrm{S}$ of N Side & 39.2 & Down & $30(\mathrm{D})$ \\
\hline $\mathrm{D}$ & 7 & 18 & 6 & $9 \mathrm{C}$ & Rack 1 & $4.4 \mathrm{ft}$ below top; $8.8 \mathrm{ft} \mathrm{S}$ of N Side & 64.6 & Down & $20(\mathrm{D})$ \\
\hline $\mathrm{D}$ & 8 & 19 & 6 & $9 \mathrm{C}$ & Rack 5 & Bottom Shelf; $8.8 \mathrm{ft} \mathrm{S}$ of N Side & 11.0 & $\mathrm{Up}$ & $18(\mathrm{D})$ \\
\hline $\mathrm{A}$ & 0 & 53 & SB 6 & $10 \mathrm{~B}$ & Rack 1 & $4.4 \mathrm{ft}$ below top; $8.8 \mathrm{ft} \mathrm{S}$ of N Side & 64.6 & Down & $20(\mathrm{D})$ \\
\hline $\mathrm{A}$ & 1 & 105 & SB 6 & $10 \mathrm{~B}$ & Rack 5 & Bottom Shelf; $8.8 \mathrm{ft} \mathrm{S}$ of N Side & 11.0 & $\mathrm{Up}$ & $18(\mathrm{D})$ \\
\hline
\end{tabular}


Appendix B-2. Transducer Locations at the Spillway in 2001. Spillway transducer elevations depend upon gate position and are presented for a $3 \mathrm{ft}$ opening, the maximum observed in 2001. Angle is the angle of the center of the transducer beam off the spill-gate. Abbreviations are as follows: $S B=$ split-beam; $(U)=$ upstream.

\begin{tabular}{|c|c|c|c|c|c|c|c|c|c|}
\hline $\begin{array}{l}\text { System } \\
\text { Number }\end{array}$ & Channel & $\begin{array}{l}\text { Trans- } \\
\text { ducer }\end{array}$ & $\begin{array}{l}\text { Beam } \\
\text { Angle }\end{array}$ & $\begin{array}{l}\text { Intake } \\
\text { or Bay }\end{array}$ & Structure & $\begin{array}{c}\text { Location on } \\
\text { Placement on Structure }\end{array}$ & $\begin{array}{r}\text { Elevati } \\
\text { (ft) }\end{array}$ & Aim & $\begin{array}{c}\text { Angle } \\
\text { (Degrees) }\end{array}$ \\
\hline & & & & & & & & & \\
\hline Q & 1 & 42 & 10 & 2 & Spill Gate & $28 \mathrm{ft}$ below the top; $28.5 \mathrm{ft} \mathrm{S}$ of $\mathrm{N}$ side & 59.0 & Down & $8(\mathrm{U})$ \\
\hline $\mathrm{Q}$ & 2 & 43 & 10 & 4 & Spill Gate & $28 \mathrm{ft}$ below the top; $17.1 \mathrm{ft} \mathrm{S}$ of $\mathrm{N}$ side & 59.0 & Down & $8(\mathrm{U})$ \\
\hline $\mathrm{Q}$ & 3 & 44 & 10 & 5 & Spill Gate & $28 \mathrm{ft}$ below the top; $37.0 \mathrm{ft} \mathrm{S}$ of $\mathrm{N}$ side & 59.0 & Down & $8(\mathrm{U})$ \\
\hline $\bar{Q}$ & 4 & 45 & 10 & 6 & Spill Gate & $28 \mathrm{ft}$ below the top; $28.5 \mathrm{ft} \mathrm{S}$ of $\mathrm{N}$ side & 59.0 & Down & $8(\mathrm{U})$ \\
\hline $\mathrm{Q}$ & 5 & 48 & 10 & 7 & Spill Gate & $28 \mathrm{ft}$ below the top; $37.1 \mathrm{ft} \mathrm{S}$ of $\mathrm{N}$ side & 59.0 & Down & $8(\mathrm{U})$ \\
\hline$P$ & 1 & 49 & 10 & 8 & Spill Gate & $28 \mathrm{ft}$ below the top; $17.1 \mathrm{ft} \mathrm{S}$ of $\mathrm{N}$ side & 59.0 & Down & $8(\mathrm{U})$ \\
\hline $\mathrm{P}$ & 2 & 51 & 10 & 10 & Spill Gate & $28 \mathrm{ft}$ below the top; $40.0 \mathrm{ft} \mathrm{S}$ of $\mathrm{N}$ side & 59.0 & Down & $8(\mathrm{U})$ \\
\hline$P$ & 3 & 50 & 10 & 12 & Spill Gate & $28 \mathrm{ft}$ below the top; $25.6 \mathrm{ft} \mathrm{S}$ of $\mathrm{N}$ side & 59.0 & Down & $8(\mathrm{U})$ \\
\hline$P$ & 4 & 56 & 10 & 14 & Spill Gate & $28 \mathrm{ft}$ below the top; $36.8 \mathrm{ft} \mathrm{S}$ of $\mathrm{N}$ side & 59.0 & Down & $8(\mathrm{U})$ \\
\hline $\mathrm{P}$ & 5 & 54 & 10 & 15 & Spill Gate & $28 \mathrm{ft}$ below the top; $28.5 \mathrm{ft} \mathrm{S}$ of $\mathrm{N}$ side & 59.0 & Down & $8(\mathrm{U})$ \\
\hline $\mathrm{O}$ & 0 & 120 & SB 12 & 17 & Spill Gate & $28 \mathrm{ft}$ below the top; $25.5 \mathrm{ft} \mathrm{S}$ of $\mathrm{N}$ side & 59.0 & Down & $15(\mathrm{U})$ \\
\hline
\end{tabular}


Appendix B-3. Transducer Locations at Powerhouse 2 in 2001. Angle refers to the angle off the trashrack plane. Abbreviations are as follows: $S B=$ split-beam; $(D)=$ downstream; $(U)=$ upstream; Beam = a horizontal beam lowered into the trash-rack slot; Rack = trash rack, where Rack 1 is the uppermost of six trash racks, and its top is at Elevation $38 \mathrm{ft} \mathrm{MSL}$.

\begin{tabular}{|c|c|c|c|c|c|c|c|c|c|}
\hline $\begin{array}{l}\text { System } \\
\text { Number }\end{array}$ & Channel & $\begin{array}{l}\text { Trans- } \\
\text { ducer }\end{array}$ & $\begin{array}{l}\text { Beam } \\
\text { Angle }\end{array}$ & $\begin{array}{l}\text { Tntake } \\
\text { or Bay }\end{array}$ & Structure & $\begin{array}{l}\text { Location on } \\
\text { on Structure }\end{array}$ & $\begin{array}{r}\text { Elevatic } \\
\text { (ft) }\end{array}$ & Aim & $\begin{array}{c}\text { Angle } \\
\text { (Degrees) }\end{array}$ \\
\hline & & & & & & & & & \\
\hline $\mathrm{G}$ & 1 & 40 & 6.5 & $11 \mathrm{C}$ & Rack 1 & $18.5^{\prime} \mathrm{S}$ of N Side of rack & 30.7 & Down & $20(\mathrm{D})$ \\
\hline $\mathrm{G}$ & 2 & 28 & 6.5 & $11 \mathrm{C}$ & Rack 4 & $18.5^{\prime} \mathrm{S}$ of N Side of rack & 4.5 & $\mathrm{Up}$ & $25(\mathrm{D})$ \\
\hline $\mathrm{G}$ & 3 & 44 & 6.5 & $12 \mathrm{~A}$ & Rack 1 & $8.17^{\prime} \mathrm{S}$ of $\mathrm{N}$ side of rack & 30.7 & Down & $20(\mathrm{D})$ \\
\hline $\mathrm{G}$ & 4 & 35 & 6.5 & $12 \mathrm{~A}$ & Rack 4 & $8.17^{\prime} \mathrm{S}$ of $\mathrm{N}$ side of rack & 4.5 & $\mathrm{Up}$ & $25(\mathrm{D})$ \\
\hline $\mathrm{G}$ & 5 & 39 & 6.5 & 13B & Rack 1 & $13^{\prime} \mathrm{S}$ of $\mathrm{N}$ side of rack & 30.7 & Down & $20(\mathrm{D})$ \\
\hline $\mathrm{G}$ & 6 & 42 & 6.5 & 13B & Rack 4 & $13^{\prime} \mathrm{S}$ of $\mathrm{N}$ side of rack & 4.5 & $\mathrm{Up}$ & $25(\mathrm{D})$ \\
\hline $\mathrm{G}$ & 7 & 36 & 6.5 & $14 \mathrm{C}$ & Rack 1 & $13^{\prime} \mathrm{S}$ of $\mathrm{N}$ side of rack & \begin{tabular}{l|l|}
30.7 \\
\end{tabular} & Down & $20(\mathrm{D})$ \\
\hline $\mathrm{G}$ & 8 & 38 & 6.5 & $14 \mathrm{C}$ & Rack 4 & 13' S of $\mathrm{N}$ side of rack & 4.5 & $\mathrm{Up}$ & $25(\mathrm{D})$ \\
\hline $\mathrm{H}$ & 1 & 61 & 6.5 & $15 \mathrm{~B}$ & Rack 1 & 18.5' S of N Side of rack & 30.7 & Down & $20(\mathrm{D})$ \\
\hline $\mathrm{H}$ & 2 & 63 & 6.5 & $15 \mathrm{~B}$ & Rack 4 & $18.5^{\prime} \mathrm{S}$ of N Side of rack & 4.5 & $\mathrm{Up}$ & $25(\mathrm{D})$ \\
\hline $\mathrm{H}$ & 3 & 56 & 6.5 & $15 \mathrm{C}$ & Rack 1 & $8.17^{\prime} \mathrm{S}$ of $\mathrm{N}$ side of rack & 30.7 & Down & $20(\mathrm{D})$ \\
\hline $\mathrm{H}$ & 4 & 29 & 6.5 & $15 \mathrm{C}$ & Rack 4 & $8.17^{\prime} \mathrm{S}$ of $\mathrm{N}$ side of rack & 4.5 & $\mathrm{Up}$ & $25(\mathrm{D})$ \\
\hline $\mathrm{H}$ & 5 & 58 & 6.5 & $16 \mathrm{~B}$ & Rack 1 & 13' $\mathrm{S}$ of $\mathrm{N}$ side of rack & 30.7 & Down & $20(\mathrm{D})$ \\
\hline $\mathrm{H}$ & 6 & 57 & 6.5 & $16 \mathrm{~B}$ & Rack 4 & $13^{\prime} \mathrm{S}$ of $\mathrm{N}$ side of rack & 4.5 & $\mathrm{Up}$ & $25(\mathrm{D})$ \\
\hline $\mathrm{H}$ & 7 & 59 & 6.5 & 17B & Rack 1 & $13^{\prime} \mathrm{S}$ of $\mathrm{N}$ side of rack & 30.7 & Down & $20(\mathrm{D})$ \\
\hline $\mathrm{H}$ & 8 & 60 & 6.5 & 17B & Rack 4 & $13^{\prime} \mathrm{S}$ of $\mathrm{N}$ side of rack & 4.5 & $\mathrm{Up}$ & $25(\mathrm{D})$ \\
\hline $\mathrm{I}$ & 0 & 51 & 6 & $18 \mathrm{~B}$ & Rack 1 & $19.75^{\prime} \mathrm{S}$ of N Side of rack & 30.7 & Down & $20(\mathrm{D})$ \\
\hline $\mathrm{I}$ & 10 & 52 & 6 & $18 \mathrm{~B}$ & Rack 4 & $19.75^{\prime} \mathrm{S}$ of N Side of rack & 4.5 & $\mathrm{Up}$ & $25(\mathrm{D})$ \\
\hline $\mathrm{R}$ & 0 & 414 & SB 6 & $15 \mathrm{~B}$ & Beam & Variable laterally & $70 \mathrm{ft}$ & Down & $6(\mathrm{U})$ \\
\hline $\mathrm{R}$ & 1 & 415 & SB 6 & $15 \mathrm{~B}$ & Beam & Variable laterally & $70 \mathrm{ft}$ & Down & $12(\mathrm{U})$ \\
\hline $\mathrm{R}$ & 2 & 416 & SB 6 & $15 \mathrm{~B}$ & Beam & Variable laterally & $70 \mathrm{ft}$ & Down & $18(\mathrm{U})$ \\
\hline
\end{tabular}


B. 4 
Appendix C

Autotracker Definitions and Settings 



\section{Appendix C}

\section{Autotracker Definitions and Settings}

Appendix C-1. Definitions of Autotracking Software Parameters Used for Processing Hydroacoustic Data from Bonneville Dam in 2001. Values of parameters that did not vary among deployments are set in the Parameter column.

\begin{tabular}{|c|c|}
\hline Parameter & Definition \\
\hline Block Size & Maximum number of ping of data to process as a sample \\
\hline Maximum Range & Range $(\mathrm{cm})$ to end autotracking \\
\hline Minimum Range & Range $(\mathrm{cm})$ to begin autotracking \\
\hline Structure Threshold $=0.075$ & $\begin{array}{c}\text { Fraction of possible echoes in a range bin that triggers } \\
\text { assignment as structure }\end{array}$ \\
\hline Range noise $=0.2$ decimeters & $\begin{array}{c}\text { Range (decimeters) uncertainty in the position of an echo } \\
\text { in range for initial binning of echoes }\end{array}$ \\
\hline Vertical Gate Size & $\begin{array}{l}\text { Maximum range about the predicted postion of the next } \\
\text { echo in which an encounter echo will be } \\
\text { added to a fish track }\end{array}$ \\
\hline Maximum Ping Gap $=2$ & $\begin{array}{l}\text { Maximum ping gap before the tracker will quit trying to add } \\
\text { echoes to a track segment. This does not } \\
\text { preclude linking segments. }\end{array}$ \\
\hline Alpha $=0.6$ & $\begin{array}{l}\text { Parameter used in an Alpha-Beta tracking formula; Beta } \\
\quad \text { was calculated from Alpha as follows: } \\
\text { Beta }=2(2-\text { Alpha })-4(1-\text { Alpha }) 0.5\end{array}$ \\
\hline Link Gate & $\begin{array}{l}\text { Range }(\mathrm{cm}) \text { over which two colinear tracked segments will } \\
\text { be linked }\end{array}$ \\
\hline $\begin{array}{l}\text { Maximum Echo or Target Strength }=36 \\
\mathrm{~dB}\end{array}$ & $\begin{array}{l}\text { Largest acoustic size acceptible for autotracking. This may } \\
\text { be based upon echo strength }(\mathrm{dB}) \text { from } \\
\text { single beams or target strength }(\mathrm{dB}) \text { from } \\
\text { split beams }\end{array}$ \\
\hline $\begin{array}{c}\text { Minimum Echo or Target Strength }=56 \\
\mathrm{~dB}\end{array}$ & $\begin{array}{c}\text { Smallest acoustic size acceptible for tracking. Also known } \\
\text { as the on-axis strength of an echo. }\end{array}$ \\
\hline Noise Level $=5$ & $\begin{array}{c}\text { Number of times an echo will be expanded to define noise } \\
\text { regions in a noise-characterization routine }\end{array}$ \\
\hline Range to Start Bottom Detect & $\begin{array}{l}\text { Sets the range at which a bottom detection routine will } \\
\text { begin. If this parameter exceeds Maximum } \\
\text { Range, then no bottom detection routine is } \\
\text { implemented. }\end{array}$ \\
\hline Bottom Count Threshold $=0.3$ & $\begin{array}{l}\text { Threshold for classifying a range bin as bottom based upon } \\
\text { the fraction of pings within a range bin that } \\
\text { exceed some amplitude threshold. This } \\
\text { can be important for up-looking transducers } \\
\text { aimed to the waters surface which can } \\
\text { flucturate. }\end{array}$ \\
\hline Bottom Amplitude Threshold $=-33 \mathrm{~dB}$ & $\begin{array}{c}\text { Acoustic amplitude }(\mathrm{dB}) \text { required for a of an echo to be } \\
\text { considered as a bottom echo. }\end{array}$ \\
\hline Segment Link Gate $=20$ & $\begin{array}{l}\text { Maximum number of pings allowed between colinear track } \\
\text { segments. }\end{array}$ \\
\hline
\end{tabular}


Appendix C-2. Autotracking Software Settings Used for Bonneville Dam Data in 2001

\begin{tabular}{|c|c|c|c|c|c|c|}
\hline $\begin{array}{l}\text { System } \\
\text { (Channe) \& } \\
\text { Aiming } \\
\text { Direction }\end{array}$ & $\begin{array}{l}\text { Data } \\
\text { Block } \\
\text { Size } \\
\text { (pings) }\end{array}$ & $\begin{array}{l}\text { Max. } \\
\text { Range } \\
(\mathrm{cm})\end{array}$ & $\begin{array}{l}\text { Min. } \\
\text { Range } \\
\text { (cm) }\end{array}$ & $\begin{array}{c}\text { Vertical } \\
\text { Gate } \\
\text { Size } \\
\text { (cm) }\end{array}$ & $\begin{array}{l}\text { Link } \\
\text { Gate } \\
\text { (cm) }\end{array}$ & $\begin{array}{l}\text { Range } \\
\text { to Start } \\
\text { Bottom } \\
\text { Detect } \\
\text { (cm) }\end{array}$ \\
\hline$A(0) U p$ & 2000 & 1330 & 810 & 6 & 20 & 3600 \\
\hline A (1) Down & 2000 & 2000 & 830 & 15 & 40 & 3600 \\
\hline C (1) Down & 2000 & 2020 & 810 & & 40 & 3600 \\
\hline C (2) Up & 2000 & 1340 & 830 & 6 & 20 & 3600 \\
\hline C (3) Down & 2000 & 2020 & 810 & 15 & 40 & 3600 \\
\hline C (4) Up & 2000 & 1350 & 830 & 6 & 20 & 3600 \\
\hline C (5) Down & 2000 & 2020 & 810 & 15 & 40 & 3600 \\
\hline $\mathrm{C}(6) \mathrm{Up}$ & 2000 & 1350 & 830 & 6 & 20 & 3600 \\
\hline C (7) Down & 2000 & 2030 & 810 & 15 & 40 & 3600 \\
\hline C (8) Up & 2000 & 1350 & 830 & 6 & 20 & 3600 \\
\hline D (1) Down & 2000 & 2020 & 810 & 15 & 40 & 3600 \\
\hline $\mathrm{D}(2) \mathrm{Up}$ & 2000 & 1350 & 830 & 6 & 20 & 3600 \\
\hline D (3) Down & 2000 & 2010 & 810 & 15 & 40 & 3600 \\
\hline $\mathrm{D}(4) \mathrm{Up}$ & 2000 & 1350 & 830 & 6 & 20 & 3600 \\
\hline $\mathrm{D}(5) \mathrm{Up}$ & 2000 & 1280 & 270 & 6 & 20 & 3600 \\
\hline $\mathrm{D}(6) \mathrm{Up}$ & 2000 & 1240 & 310 & 15 & 40 & 3600 \\
\hline D (7) Down & 2000 & 2020 & 810 & 15 & 40 & 3600 \\
\hline D (8) Up & 2000 & 1390 & 830 & 6 & 20 & 3600 \\
\hline X (1) Down & 2000 & 1330 & 810 & 15 & 40 & 3600 \\
\hline$X(2) U p$ & 2000 & 2020 & 830 & 6 & 20 & 3600 \\
\hline O (0) Down & 2000 & 1300 & 0 & 15 & 40 & 1050 \\
\hline P (1) Down & 2000 & 1300 & 0 & 15 & 40 & 1050 \\
\hline P (2) Down & 2000 & 1300 & 0 & 15 & 40 & 1050 \\
\hline P (3) Down & 2000 & 1300 & 0 & 15 & 40 & 1050 \\
\hline P (4) Down & 2000 & 1300 & 0 & 15 & 40 & 1050 \\
\hline P (5) Down & 2000 & 1300 & 0 & 15 & 40 & 1050 \\
\hline Q (1) Down & 2000 & 1300 & 0 & 15 & 40 & 1050 \\
\hline Q (2) Down & 2000 & 1300 & 0 & 15 & 40 & 1050 \\
\hline Q (3) Down & 2000 & 1300 & 0 & 15 & 40 & 1050 \\
\hline Q (4) Down & 2000 & 1300 & 0 & 15 & 40 & 1050 \\
\hline Q (5) Down & 2000 & 1300 & 0 & 15 & 40 & 1050 \\
\hline G (1) Down & 2000 & 1630 & 520 & 15 & 40 & 3600 \\
\hline G (2) Up & 2000 & 930 & 328 & 6 & 20 & 3600 \\
\hline G (3) Down & 2000 & 1640 & 520 & 15 & 40 & 3600 \\
\hline G (4) Up & 2000 & 930 & 328 & 6 & 20 & 3600 \\
\hline G (5) Down & 2000 & 1640 & 520 & 15 & 40 & 3600 \\
\hline G (6) Up & 2000 & 930 & 328 & 6 & 20 & 3600 \\
\hline G (7) Down & 2000 & 1640 & 520 & 15 & 40 & 3600 \\
\hline G (8) Up & 2000 & 930 & 328 & 6 & 20 & 3600 \\
\hline H (1) Down & 1000 & 1650 & 520 & 15 & 40 & 3600 \\
\hline$H(2) U p$ & 1000 & 930 & 328 & 6 & 20 & 3600 \\
\hline H (3) Down & 2000 & 1650 & 520 & 15 & 40 & 3600 \\
\hline H (4) Up & 2000 & 920 & 328 & 6 & 20 & 3600 \\
\hline H (5) Down & 2000 & 1650 & 520 & 15 & 40 & 3600 \\
\hline H (6) Up & 2000 & 920 & 328 & 6 & 20 & 3600 \\
\hline H (7) Down & 2000 & 1650 & 520 & 15 & 40 & 3600 \\
\hline H (8) Up & 2000 & 930 & 328 & 6 & 20 & 3600 \\
\hline I (0) Down & 2000 & 1610 & 520 & 15 & 40 & 3600 \\
\hline I (10) Up & 2000 & 1040 & 328 & 6 & 20 & 3600 \\
\hline R (0) Down & 2000 & 2990 & 0 & 15 & 40 & 3600 \\
\hline R (1) Down & 2000 & 3030 & 0 & 15 & 40 & 3600 \\
\hline R (2) Down & 2000 & 3130 & 0 & 15 & 40 & 3600 \\
\hline
\end{tabular}




\section{Appendix D}

\section{Statistical Analysis System Code for Filtering Echo Traces Selected by Autotracking Softwar}





\section{Appendix D}

\section{Statistical Analysis System Code for Filtering Echo Traces Selected by Autotracking Software}

Appendix D-1. Definitions of Variables Used for Filtering Echo Traces Selected by Autotracking Software in 2001

\begin{tabular}{|l|l||}
\hline \multicolumn{1}{|c|}{ Parameter } & \multicolumn{1}{c|}{ Definition } \\
\hline System & $\begin{array}{l}\text { Corresponds to an echosounder and associated transducers. Echosounder channels and } \\
\text { transducer locations are described in Appendix B. }\end{array}$ \\
\hline Channel & Corresponds to a single transducer attached to one specific echosounder channel. \\
\hline First Ping & The absolute ping number for the first echo in an a series of echoes forming an echo trace. \\
\hline Last Ping & $\begin{array}{l}\text { The absolute ping number for the last echo in an a series of echoes forming an echo trace. } \\
\text { Last Ping / Group Size is the total number of pings in an echo trace. }\end{array}$ \\
\hline Group Size & $\begin{array}{l}\text { Describes the number transducers sampled simultaneously (1=slow multiplex; 2=fast } \\
\text { multiplex) }\end{array}$ \\
\hline Mean Target Strength & $\begin{array}{l}\text { The average echo amplitude of a fish trace in dB. This would be echo strength for fish } \\
\text { detected by single beam transducers. Maximum echo-strength thresholds were set 2.3 dB } \\
\text { lower than target-strength thresholds based upon empirical data from the two types of } \\
\text { distributions. }\end{array}$ \\
\hline Echo Count & The number of echoes in a series forming an echo trace. \\
\hline Linearity1 & The mean cm deviation of echoes from a line fit through a series of echoes forming a trace. \\
\hline Linearity2 & $\begin{array}{l}\text { The mean cm deviation of echoes from a parabola fit through a series of echoes forming a } \\
\text { trace. }\end{array}$ \\
\hline Noise Count Average & $\begin{array}{l}\text { The number of noise echoes in a window around an echo trace. The window began } 5 \text { pings } \\
\text { before the first echo and ended } 5 \text { pings after the last echo in the trace and was } \pm 0.5 \mathrm{~m} \text { in } \\
\text { range. }\end{array}$ \\
\hline Slope & The change in range of an echo trace through time. Units are cm / ping. \\
\hline Mid Range & The average of the ranges of the first and last echoes in an echo trace. \\
\hline
\end{tabular}


D.2 
Appendix D-2. Statistical Analysis System (SAS) Code for Filtering Out Echo Traces that Did Not Meet Fish Trace Criteria in Spring 2001. Minimum ranges for sampling guided, unguided, and spilled fish, which are presented in legends of Figures 1-4, were implemented elsewhere in the processing program.

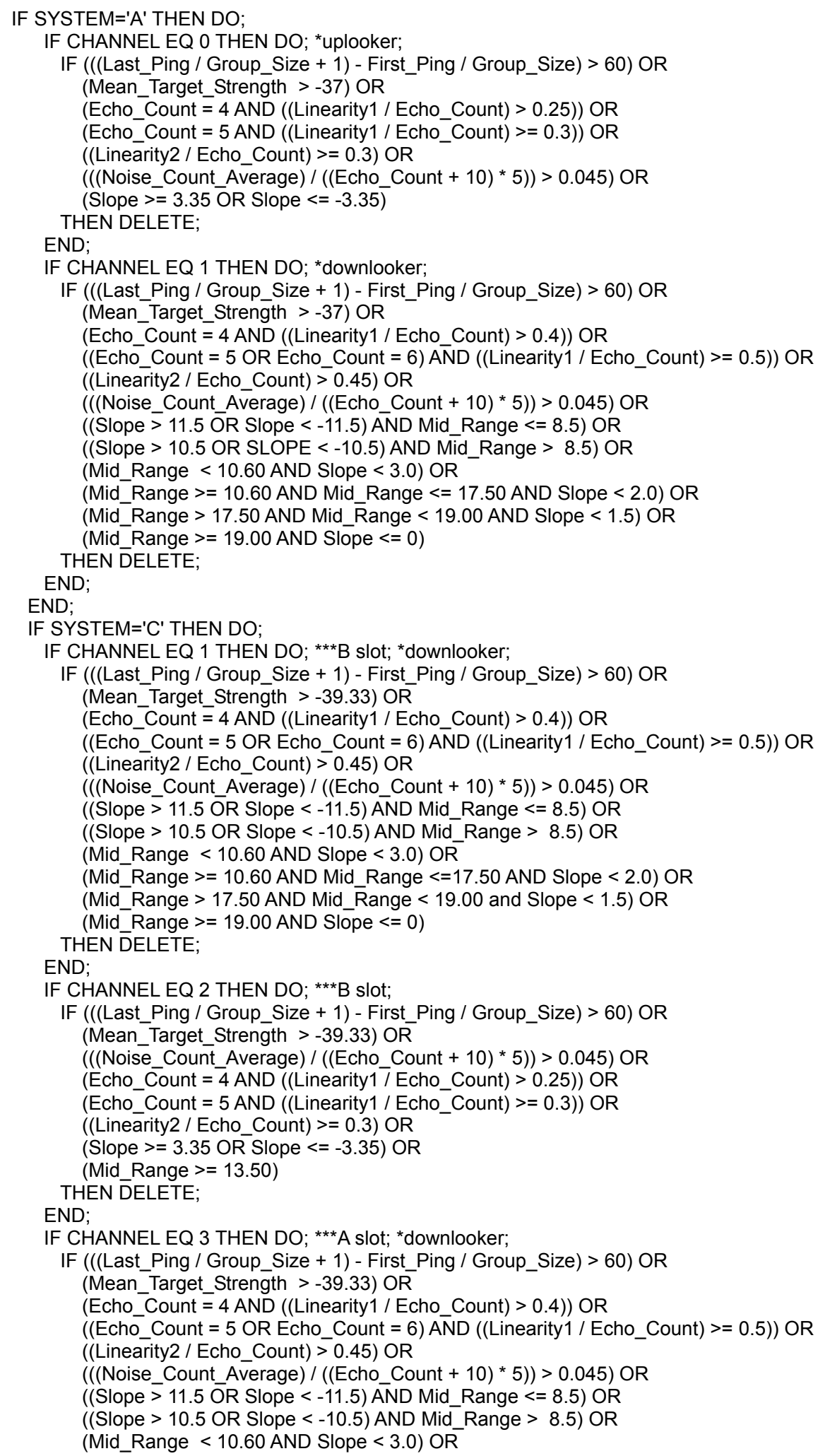




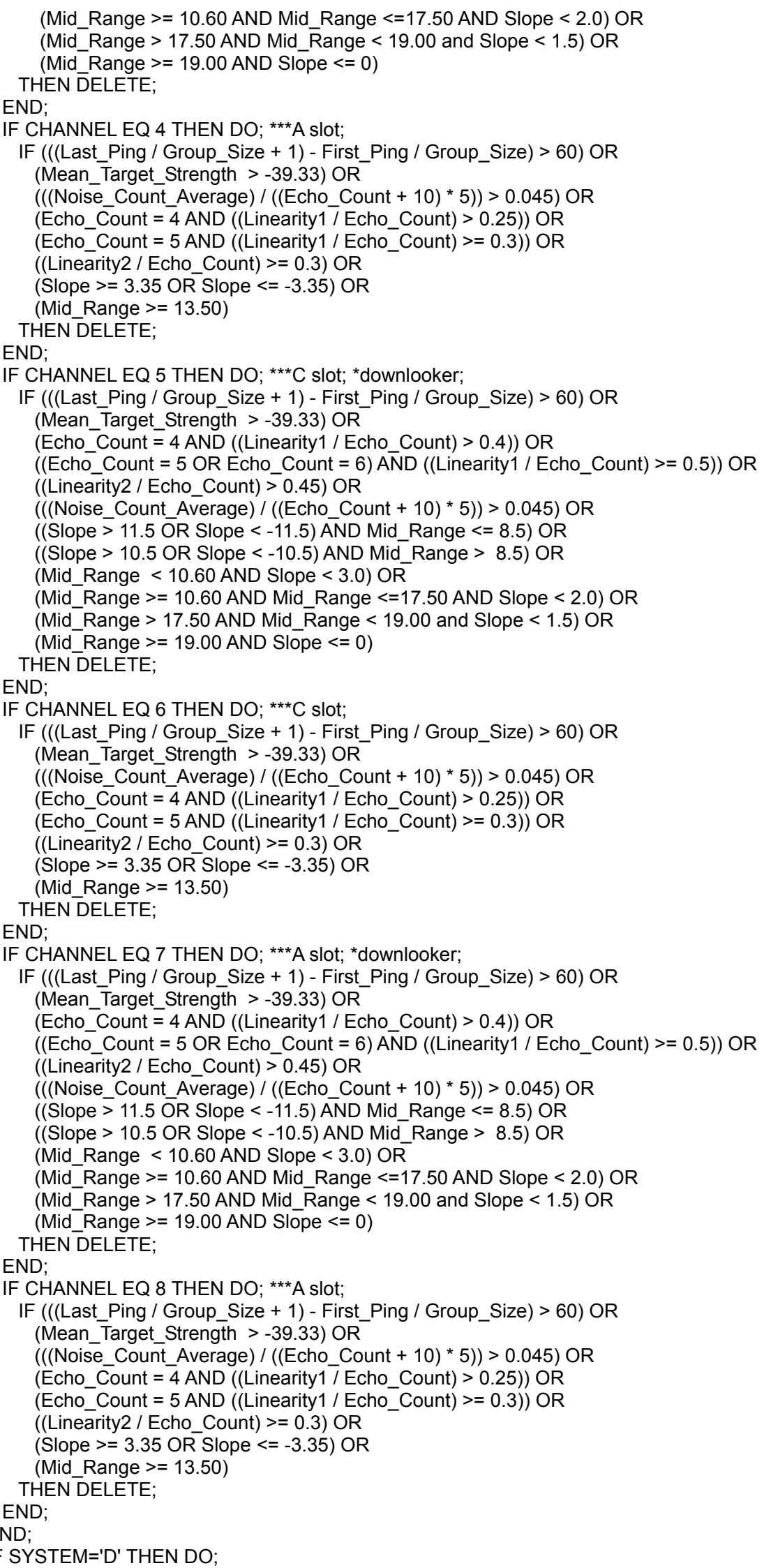


IF CHANNEL EQ 1 THEN DO; *downlooker;

IF ((Last_Ping / Group_Size + 1) - First_Ping / Group_Size $)>60)$ OR

(Mean Target Strength > -39.33) OR

$($ Echo_Count $=4$ AND $(($ Linearity1 $/$ Echo_Count $)>0.4))$ OR

$(($ Echo_Count $=5$ OR Echo_Count $=6)$ AN̄D $(($ Linearity $1 /$ Echo_Count $)>=0.5))$ OR

((Linearity2 / Echo_Count) $>0.45)$ OR

$((($ Noise_Count_Average $) /(($ Echo_Count +10$) * 5))>0.045)$ OR

((Slope > 11.5 OR Slope <-11.5) AND Mid_Range <= 8.5) OR

$(($ Slope $>10.5$ OR Slope < -10.5) AND Mid_Range > 8.5) OR

(Mid_Range $<10.60$ AND Slope $<3.0$ ) OR

(Mid_Range $>=10.60$ AND Mid_Range $<=17.50$ AND Slope $<2.0$ ) OR

(Mid_Range $>17.50$ AND Mid_Range $<19.00$ AND Slope $<1.5$ ) OR

(Mid_Range $>=19.00$ AND Slope $<=0$ ) OR

(First_Range $>=18.60$ AND First_Range $<=18.80$ AND Last_Range $>=18.60$ AND Last_Range $<=18.80$ ) THEN DELETE;

END;

IF CHANNEL EQ 2 THEN DO;

IF (( Last_Ping / Group_Size + 1) - First_Ping / Group_Size $)>60)$ OR

(Mean_Target_Strength > -39.33) OR

$($ Echo_Count $=4$ AND $(($ Linearity $1 /$ Echo_Count $)>0.25))$ OR

$($ Echo_Count $=5$ AND $(($ Linearity $1 /$ Echo_Count $)>=0.3))$ OR

((Linearity2 / Echo Count) $>=0.3$ ) OR

$((($ Noise_Count_Average $) /(($ Echo_Count +10$) * 5))>0.045)$ OR

(Slope $>=3.35$ OR Slope $<=-3.35$ )

THEN DELETE;

END;

IF CHANNEL EQ 3 THEN DO; *downlooker;

IF (( (Last_Ping / Group_Size + 1) - First_Ping / Group_Size $)>60)$ OR

(Mean Target Strength > -39.33) OR

$($ Echo_Count $=4$ AND $(($ Linearity $1 /$ Echo_Count $)>0.4))$ OR

$(($ Echo_Count $=5$ OR Echo Count $=6)$ AND $(($ Linearity $1 /$ Echo Count $)>=0.5))$ OR

((Linearity2 / Echo_Count) $>0.45)$ OR

$((($ Noise Count Average $) /(($ Echo Count +10$) * 5))>0.045)$ OR

$(($ Slope $>11.5$ OR Slope $<-11.5)$ AND Mid_Range $<=8.5)$ OR

((Slope > 10.5 OR Slope <-10.5) AND Mid Range > 8.5) OR

(Mid_Range < 10.60 AND Slope < 3.0) OR

(Mid_Range $>=10.60$ AND Mid_Range $<=17.50$ AND Slope $<2.0$ ) OR

(Mid_Range $>17.50$ AND Mid_Range $<19.00$ AND Slope $<1.5$ ) OR

(Mid Range $>=19.00$ AND Slope $<=0$ ) OR

(Mid_Range > 16.30 AND Echo_Count/((Last_Ping / $2+1)$ - First_Ping / 2) < 1.1) AND (Echo_Count >= 10 AND

$\left((\right.$ Noise_Count_Average $) /\left((\right.$ Echo_Count +10$\left.\left.\left.){ }^{*} 5\right)\right)>0.045\right)$ OR

(First_Range $>=19.50$ )

THEN DELETE;

END;

IF CHANNEL EQ 4 THEN DO;

IF (((Last_Ping / Group_Size + 1) - First_Ping / Group_Size $)>60)$ OR

(Mean_Target_Strength $>-39.33$ ) OR

(Echo_Count $=4$ AND $(($ Linearity $1 /$ Echo Count $)>0.25))$ OR

$($ Echo_Count $=5$ AND $(($ Linearity $1 /$ Echo_Count $)>=0.3))$ OR

((Linearity2 / Echo Count) $>=0.3$ ) OR

$((($ Noise_Count_Average $) /(($ Echo_Count +10$) * 5))>0.045)$ OR

(Slope $>=3.35$ OR Slope $<=-3.35$ )

THEN DELETE;

END;

IF CHANNEL EQ 5 THEN DO; *uplooker;

IF (( (Last_Ping / Group_Size + 1) - First Ping / Group_Size $)>60)$ OR

(Mean_Target_Strength > -39.33) OR

(Echo_Count $=4$ AND $(($ Linearity $1 /$ Echo_Count $)>0.25))$ OR

$($ Echo_Count $=5$ AND $(($ Linearity $1 /$ Echo_Count $)>=0.25))$ OR

((Linearity2 / Echo Count) $>=0.25)$ OR

$((($ Noise_Count_Average $) /(($ Echo_Count +10$) * 5))>0.045)$ OR

(Slope $>=3.35$ OR Slope $<=-3.35)$ OR

(Mid_Range $>12.20$ And Slope $>-0.25$ AND Slope $<0.25$ )

THEN DELETE;

END;

IF CHANNEL EQ 6 THEN DO; *downlooker;

IF (((Last_Ping / Group_Size + 1) - First_Ping / Group_Size) > 60) OR

(Mean_Target_Strength > -39.33) OR

(Echo Count $=4$ AND $(($ Linearity $1 /$ Echo Count $)>0.25))$ OR

$($ Echo_Count $=5$ AND $(($ Linearity $1 /$ Echo_Count $)>=0.25))$ OR 
((Linearity2 / Echo_Count) $>=0.25)$ OR

$((($ Noise_Count_Average $) /(($ Echo_Count +10$) * 5))>0.045)$ OR

(Slope $>=5$ OR Slope $<=-5$ ) OR

$(($ Mid_Range $>=11.35)$ AND (Slope $>-1$ OR Slope $<1)$ ) OR

(First_Range $>=11.30$ And First_Range $<=11.70$ AND Last_Range $>=11.30$ AND Last_Range $<=11.70$ ) OR

(First_Range $>=12.00$ And First_Range $<=12.20$ AND Last_Range $>=12.00$ AND Last_Range $<=12.20$ ) THEN DELETE;

END;

IF CHANNEL EQ 7 THEN DO; *downlooker;

IF (((Last_Ping / Group_Size + 1) - First_Ping / Group_Size $)>60)$ OR

(Mean_Target_Strength > -39.33) OR

$($ Echo_Count $=4$ AND $(($ Linearity $1 /$ Echo_Count $)>0.4))$ OR

$(($ Echo_Count $=5$ OR Echo_Count $=6)$ AÑ $(($ Linearity $1 /$ Echo_Count $)>=0.5))$ OR

((Linearity2 / Echo_Count) $>0.45)$ OR

$((($ Noise_Count_Average $) /(($ Echo_Count +10$) * 5))>0.045)$ OR

((Slope $>11.5$ OR Slope $<-11.5)$ AND Mid_Range $<=8.5)$ OR

((Slope > 10.5 OR Slope <-10.5) AND Mid_Range > 8.5) OR

(Mid_Range $<10.60$ AND Slope $<3.0$ ) OR

(Mid_Range $>=10.60$ AND Mid_Range $<=17.50$ AND Slope $<2.0$ ) OR

(Mid_Range $>17.50$ AND Mid_Range $<19.00$ AND Slope $<1.5$ ) OR

(Mid_Range $>=19.00$ AND Slope $<=0$ ) OR

(First_Range $>=12.75$ AND First_Range $<=12.90$ AND Last_Range $>=12.75$ AND Last_Range $<=12.90$ ) OR

(First_Range $>=14.70$ AND First_Range $<=14.85$ AND Last_Range $>=14.70$ AND Last_Range $<=14.85$ ) OR

(First_Range $>=18.15$ AND First_Range $<=18.35$ AND Last_Range $>=18.15$ AND Last_Range $<=18.35$ )

THEN DELETE;

END;

IF CHANNEL EQ 8 THEN DO;

IF (((Last_Ping / Group_Size + 1) - First_Ping / Group_Size $)>60)$ OR

(Mean_Target_Strength > -39.33) OR

$($ Echo_Count $=4$ AND $(($ Linearity $1 /$ Echo_Count $)>0.25))$ OR

$($ Echo_Count $=5$ AND $(($ Linearity $1 /$ Echo_Count $)>=0.3))$ OR

((Linearity2 / Echo_Count) $>=0.3)$ OR

$((($ Noise_Count_Average $) /(($ Echo_Count +10$) * 5))>0.045)$ OR

(Slope $>=3.35$ OR Slope $<=-3.35)$ OR

(Mid_Range > 13.30 AND ((Noise Count Average $) /(($ Echo Count +10$) * 5))>0.03)$ OR

(First_Range $>=12.60$ And First_Range $<=12.90$ And Last_Range $>=12.60$ AND Last_Range $<=12.90$ ) OR

(First_Range $>=12.08$ And First_Range $<=12.44$ And Last_Range $>=12.08$ AND Last_Range $<=12.44$ )

THEN DELETE; END;

END;

IF SYSTEM='G' THEN DO;

IF CHANNEL EQ 1 THEN DO; *downlooker;

IF (( Last_Ping / Group_Size + 1) - First_Ping / Group_Size $)>60)$ OR

(Mean_Target_Strength > -39.33) OR

$($ Echo_Count $=4$ AND $(($ Linearity1 $/$ Echo_Count $)>0.4))$ OR

$(($ Echo_Count $=5$ OR Echo_Count $=6)$ AÑ $(($ Linearity $1 /$ Echo_Count $)>=0.6))$ OR

((Linearity2 / Echo_Count) $>0.6)$ OR

$((($ Noise_Count_Average $) /(($ Echo_Count +10$) * 5))>0.045)$ OR

$(($ Slope $>11.5$ OR Slope $<-11.5)$ AND Mid_Range $<=8.5)$ OR

((Slope > 10.5 OR Slope <-10.5) AND Mid Range > 8.5) OR

(Mid_Range $<8.50$ AND Slope $<4.0$ ) OR

(Mid_Range $>=8.50$ AND Mid_Range $<=14.00$ AND Slope $<2.7$ ) OR

(Mid_Range $>14.00$ AND Slope $<2.5$ )

THEN DELETE;

END;

IF CHANNEL EQ 2 THEN DO;

IF ((Last_Ping / Group_Size + 1) - First_Ping / Group_Size) > 60) OR

(Mean_Target_Strength $>-39.33)$ OR

$($ Echo_Count $=4$ AND $(($ Linearity $1 /$ Echo_Count $)>0.3))$ OR

$($ Echo_Count $=5$ AND $(($ Linearity $1 /$ Echo_Count $)>=0.34))$ OR

((Linearity2 / Echo_Count) $>=0.34)$ OR

$((($ Noise_Count_Average $) /(($ Echo_Count +10$) * 5))>0.045)$ OR

(Slope $>=3.35$ OR Slope $<=-3.35)$

THEN DELETE;

END;

IF CHANNEL EQ 3 THEN DO; *downlooker;

IF (((Last_Ping / Group_Size + 1) - First_Ping / Group_Size $)>60)$ OR

(Mean_Target_Strength > -39.33) OR

$($ Echo Count $=4$ AND $(($ Linearity $1 /$ Echo Count $)>0.4))$ OR

$(($ Echo_Count $=5$ OR Echo_Count $=6)$ AND $(($ Linearity $1 /$ Echo_Count $)>=0.6))$ OR 


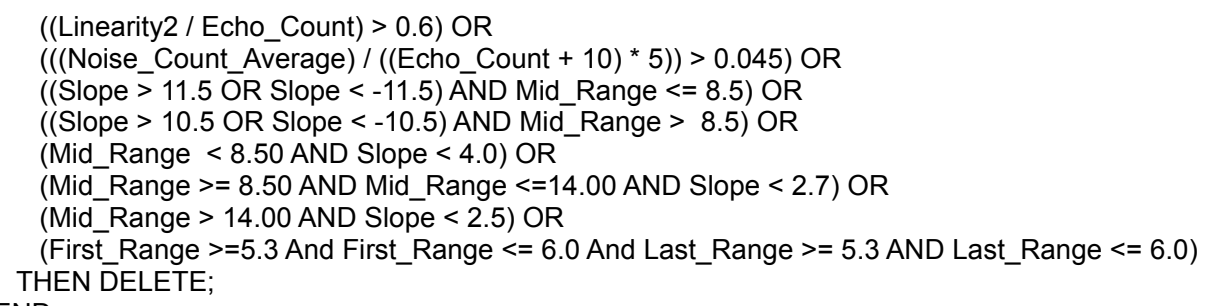


IF CHANNEL EQ 1 THEN DO; *downlooker;

IF (((Last_Ping / Group_Size + 1) - First_Ping / Group_Size) > 60) OR

(Mean Target Strength $>-39.33$ ) OR

$($ Echo_Count $=4$ AND $(($ Linearity1 $/$ Echo_Count $)>0.4))$ OR

$(($ Echo_Count $=5$ OR Echo_Count $=6)$ AÑ $(($ Linearity $1 /$ Echo_Count $)>=0.6))$ OR

((Linearity2 / Echo_Count) $>0.6)$ OR

$((($ Noise_Count_Average $) /(($ Echo_Count +10$) * 5))>0.045)$ OR

$(($ Slope $>11.5$ OR Slope $<-11.5)$ AND Mid_Range $<=8.5)$ OR

$(($ Slope $>10.5$ OR Slope < -10.5) AND Mid_Range > 8.5) OR

(Mid_Range $<8.50$ AND Slope $<4.0$ ) OR

(Mid_Range $>=8.50$ AND Mid_Range $<=14.00$ AND Slope $<2.7$ ) OR

(Mid_Range $>14.00$ AND Slope $<2.5$ ) OR

(First_Range $>=5.56$ AND Last_Range $<=5.85$ ) OR

(First Range $>=13.62$ AND Last Range $<=13.88$ ) OR

(First_Range $>=15.69$ AND Last_Range $<=15.88$ )

END;

IF CHANNEL EQ 2 THEN DO;

IF (((Last_Ping / Group_Size + 1) - First_Ping / Group_Size $)>60)$ OR

(Mean_Target_Strength $>-39.33$ ) OR

$($ Echo_Count $=4$ AND $(($ Linearity $1 /$ Echo_Count $)>0.25))$ OR

$($ Echo_Count $=5$ AND $(($ Linearity $1 /$ Echo_Count $)>=0.34))$ OR

((Linearity2 / Echo_Count) $>=0.34)$ OR

$\left(\left((\right.\right.$ Noise_Count_Average $) /\left((\right.$ Echo_Count +10$\left.\left.\left.){ }^{*} 5\right)\right)>0.045\right)$ OR

(Slope $>=3.35$ OR Slope $<=-3.35$ )

THEN DELETE;

END;

IF CHANNEL EQ 3 THEN DO; *downlooker;

IF (((Last_Ping / Group_Size + 1) - First_Ping / Group_Size) > 60) OR

(Mean_Target_Strength $>-39.33$ ) OR

$($ Echo Count $=4$ AND $(($ Linearity $1 /$ Echo Count $)>0.4))$ OR

$(($ Echo_Count $=5$ OR Echo_Count $=6)$ AND $(($ Linearity $1 /$ Echo_Count $)>=0.6))$ OR

((Linearity2 / Echo_Count) $>=0.6)$ OR

$((($ Noise_Count_Average $) /(($ Echo_Count +10$) * 5))>0.045)$ OR

((Slope > 11.5 OR Slope $<-11.5)$ AND Mid_Range $<=8.5)$ OR

$(($ Slope $>10.5$ OR Slope <-10.5) AND Mid_Range > 8.5) OR

(Mid_Range $<8.50$ AND Slope $<4.0$ ) OR

(Mid_Range $>=8.50$ AND Mid_Range $<=14.00$ AND Slope $<2.7$ ) OR

(Mid_Range $>14.00$ AND Slope $<2.5$ ) OR

(Echo_Count / ((Last_Ping / $2+1)$ - First_Ping / 2) $<0.7$ ) OR

(First_Range $>=13.70$ AND Last_Range $<=13.88$ ) OR

(First_Range $>=14.71$ AND Last_Range $<=14.93$ ) OR

(First_Range $>=15.40$ AND Last_Range $<=15.78$ )

THEN DELETE;

END;

IF CHANNEL EQ 4 THEN DO;

IF (( (Last_Ping / Group_Size + 1) - First_Ping / Group_Size $)>60)$ OR

(Mean_Target_Strength > -39.33) OR

$($ Echo_Count $=4$ AND $(($ Linearity $1 /$ Echo_Count $)>0.25))$ OR

$($ Echo_Count $=5$ AND $(($ Linearity1 $/$ Echo_Count $)>=0.34))$ OR

((Linearity2 / Echo_Count) $>=0.34)$ OR

$((($ Noise_Count_Average $) /(($ Echo_Count +10$) * 5))>0.045)$ OR

(Slope $>=3.35$ OR Slope $<=-3.35$ )

THEN DELETE;

END;

IF CHANNEL EQ 5 THEN DO; *downlooker;

IF (( Last_Ping / Group_Size + 1) - First_Ping / Group_Size $)>60)$ OR

(Mean_Target_Strength $>-39.33$ ) OR

(Echo_Count $=4$ AND $(($ Linearity $1 /$ Echo_Count $)>0.4))$ OR

$(($ Echo_Count $>=5$ AND Echo_Count $<=\overline{6})$ AND ((Linearity $1 /$ Echo_Count $)>=0.6))$ OR

((Linearity2 / Echo_Count) $>0.6)$ OR

$((($ Noise_Count_Average $) /(($ Echo_Count +10$) * 5))>0.045)$ OR

$(($ Slope $>11.5$ OR Slope $<-11.5)$ AND Mid_Range $<=8.5)$ OR

$(($ Slope > 10.5 OR Slope < -10.5) AND Mid_Range > 8.5) OR

(Mid_Range $<8.50$ AND Slope $<4.0$ ) OR

(Mid_Range $>=8.50$ AND Mid_Range $<=13.00$ AND Slope $<2.7$ ) OR

(Mid_Range > 13.00 AND Slope < 2.5) OR

(First Range $>=13.53$ AND Last Range $<=13.78$ ) OR

(First_Range $>=15.03$ AND Last_Range $<=15.15$ ) 
THEN DELETE;

END

IF CHANNEL EQ 6 THEN DO;

IF (( Last_Ping / Group_Size + 1) - First_Ping / Group_Size $)>60)$ OR

(Mean Target Strength $>-39.33)$ OR

$($ Echo_Count $=4$ AND $(($ Linearity $1 /$ Echo_Count $)>0.25))$ OR

$($ Echo_Count $=5$ AND $(($ Linearity $1 /$ Echo_Count $)>=0.34))$ OR

((Linearity2 / Echo_Count) $>=0.34)$ OR

$\left(\left((\right.\right.$ Noise_Count_Average $) /\left((\right.$ Echo_Count +10$\left.\left.\left.){ }^{*} 5\right)\right)>0.045\right)$ OR

(Slope $>=3.35$ OR Slope $<=-3.35$ )

THEN DELETE;

END;

IF CHANNEL EQ 7 THEN DO; *downlooker;

IF (( Last_Ping / Group_Size + 1) - First_Ping / Group_Size $)>60)$ OR

(Mean_Target_Strength > -39.33) OR

$($ Echo Count $=4$ AND $(($ Linearity $1 /$ Echo Count $)>0.4))$ OR

$(($ Echo_Count $>=5$ AND Echo_Count $<=\overline{6})$ AND ((Linearity1 / Echo_Count $)>=0.6))$ OR

((Linearity2 / Echo_Count) $>0.6)$ OR

$((($ Noise_Count_Average $) /(($ Echo_Count +10$) * 5))>0.045)$ OR

((Slope > 11.5 OR Slope <-11.5) AND Mid_Range <= 8.5) OR

((Slope > 10.5 OR Slope <-10.5) AND Mid_Range > 8.5) OR

(Mid_Range $<8.50$ AND Slope $<4.0$ ) OR

(Mid_Range $>=8.50$ AND Mid_Range $<=13.00$ AND Slope $<2.7$ ) OR

(Mid_Range $>13.00$ AND Slope $<2.5$ ) OR

(First_Range $>=13.70$ AND Last_Range $<=13.99$ )

THEN DELETE;

END;

IF CHANNEL EQ 8 THEN DO;

IF (((Last_Ping / Group_Size + 1) - First_Ping / Group_Size $)>60)$ OR

(Mean_Target_Strength > -39.33) OR

(Echo Count $=4$ AND $(($ Linearity $1 /$ Echo Count $)>0.25))$ OR

$($ Echo_Count $=5$ AND $(($ Linearity $1 /$ Echo_Count $)>=0.34))$ OR

((Linearity2 / Echo Count) $>=0.34)$ OR

$((($ Noise_Count_Average $) /(($ Echo_Count +10$) * 5))>0.045)$ OR

(Slope $>=3.35$ OR Slope $<=-3.35$ )

THEN DELETE;

END;

END;

IF SYSTEM='I' THEN DO

IF CHANNEL EQ 0 THEN DO; *downlooker;

IF (( Last_Ping / Group_Size + 1) - First_Ping / Group_Size $)>60)$ OR

(Mean_Target_Strength > -37) OR

$($ Echo_Count $=4$ AND $(($ Linearity $1 /$ Echo_Count $)>0.4))$ OR

$(($ Echo_Count $=5$ OR Echo_Count $=6)$ AND $(($ Linearity $1 /$ Echo_Count $)>=0.6))$ OR

((Linearity2 / Echo_Count) $>=0.6)$ OR

$((($ Noise_Count_Average $) /(($ Echo_Count +10$) * 5))>0.045)$ OR

((Slope $>11.5$ OR Slope $<-11.5)$ AND Mid_Range $<=8.5)$ OR

((Slope > 10.5 OR Slope < -10.5) AND Mid_Range > 8.5) OR

(Mid_Range $<8.50$ AND Slope $<4.0$ ) OR

(Mid Range $>=8.50$ AND Mid Range $<=14.00$ AND Slope $<2.7$ ) OR

(Mid_Range $>14.00$ AND Slope $<2.5$ ) OR

(First Range $>=14.35$ AND First Range $<=14.65$ ) AND (Last Range $>=14.35$ AND Last Range $<=14.65$ ) OR

(First_Range $>=14.90$ AND First_Range $<=15.25$ ) AND (Last_Range $>=14.90$ AND Last_Range $<=15.25$ )

THEN DELETE;

END;

IF CHANNEL EQ 10 THEN DO;

IF (((Last_Ping / Group_Size + 1) - First_Ping / Group_Size $)>60)$ OR

(Mean_Target_Strength > -37) OR

$($ Echo_Count $=4$ AND $(($ Linearity1 $/$ Echo_Count $)>0.25))$ OR

$($ Echo_Count $=5$ AND $(($ Linearity $1 /$ Echo_Count $)>=0.34))$ OR

((Linearity2 / Echo_Count) $>=0.34)$ OR

$\left(\left((\right.\right.$ Noise_Count_Average $) /\left((\right.$ Echo_Count +10$\left.\left.\left.){ }^{*} 5\right)\right)>0.045\right)$ OR

(Slope $>=3.35$ OR Slope $<=-3.35$ ) OR

(First_Range $>5.00$ AND First_Range $<=5.80$ ) AND (Last_Range $>5.00$ AND Last_Range $<=5.80$ ) OR

(First_Range $>8.80$ AND First_Range $<8.90$ ) AND (Last_Range $>8.80$ AND Last_Range $<8.90$ ) OR

(First_Range > 8.85 AND First_Range < 9.25) AND (Last_Range > 8.85 AND Last_Range < 9.25 )

THEN DELETE; END;

END; 


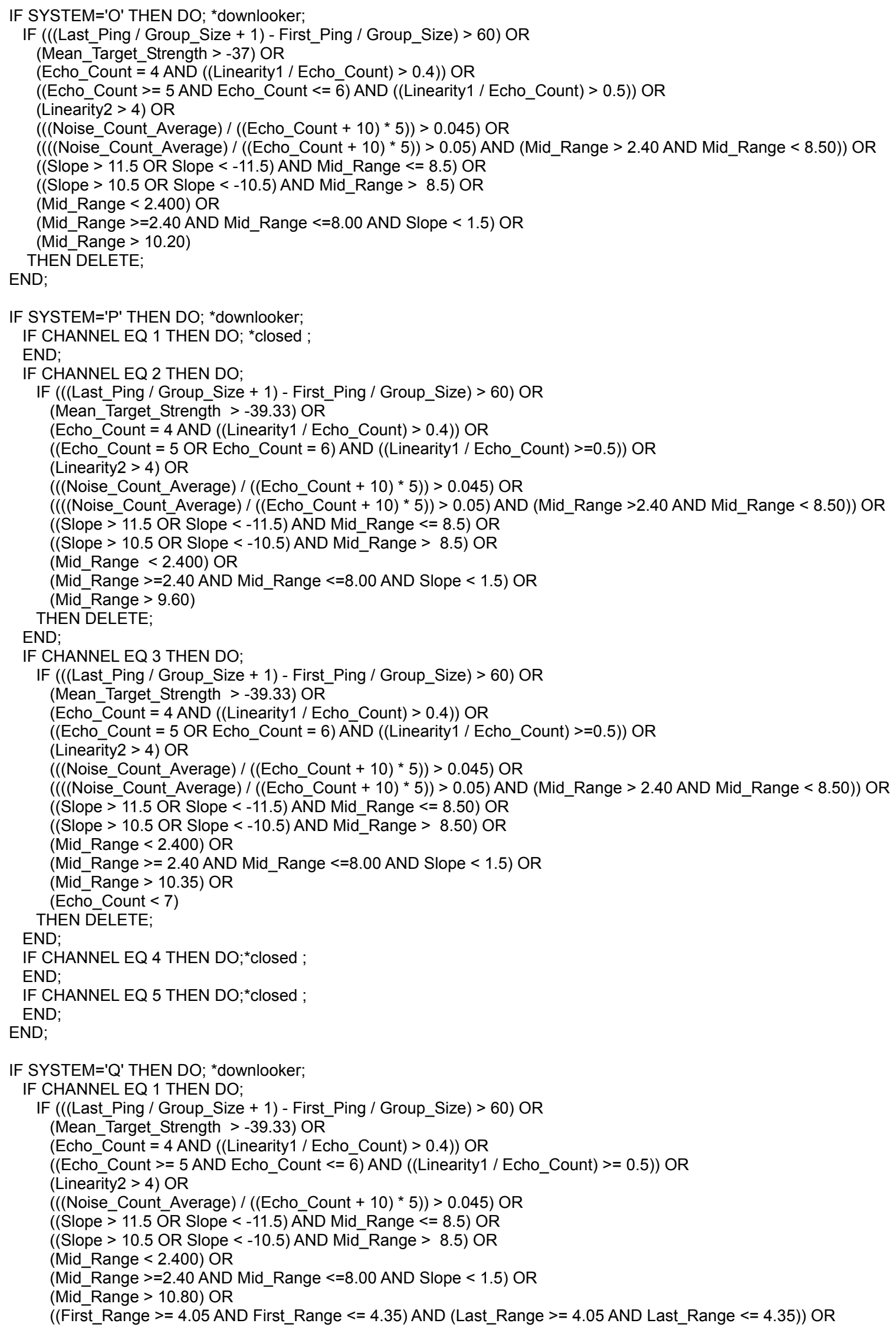


$(($ First_Range $>=4.15$ AND First_Range $<=4.60)$ AND (Last_Range $>=4.15$ AND Last_Range $<=4.60)$ ) OR
$(($ First_Range $>=9.20$ AND First_Range $<=9.45)$ AND (Last_Range $>=9.20$ AND Last_Range $<=9.45)$ ) OR
((First_Range $>=9.40$ AND First_Range $<=9.65)$ AND (Last_Range $>=9.40$ AND Last_Range $<=9.65)$ ) OR
((First_Range $>=9.60$ AND First_Range $<=9.90)$ AND (Last_Range $>=9.60$ AND Last_Range $<=9.90)$ ) OR
((First_Range $>=9.75$ AND First_Range $<=9.95)$ AND (Last_Range $>=9.75$ AND Last_Range $<=9.95)$ ) THEN DELETE;

END;

IF CHANNEL EQ 2 THEN DO;

IF (( Last_Ping / Group_Size + 1) - First_Ping / Group_Size $)>60)$ OR

(Mean_Target_Strength > -39.33) OR

$($ Echo_Count $=4$ AND $(($ Linearity1 $/$ Echo_Count $)>0.4))$ OR

$(($ Echo_Count $=5$ OR Echo_Count $=6)$ AND $(($ Linearity1 $/$ Echo_Count $)>=0.5))$ OR

(Linearity2 > 4) OR

$(($ Noise Count Average / $(($ Echo Count +10$) * 5))>0.04)$ OR

$(($ Slope $>11.5$ OR Slope $<-11.5)$ AND Mid_Range $<=8.50)$ OR

((Slope > 10.5 OR Slope <-10.5) AND Mid Range > 8.50) OR

(Mid_Range $<2.400$ ) OR

(Mid_Range $>=2.40$ AND Mid_Range $<=8.00$ AND Slope $<1.5$ ) OR

(Mid_Range > 9.75) OR

((First Range $>=4.30$ AND First Range $<=5.65$ ) AND (Last Range $>=4.30$ And Last Range $<=5.65)$ ) OR

((First_Range $>=6.00$ AND First_Range $<=6.40$ ) AND (Last_Range $>=6.00$ And Last_Range $<=6.40)$ ) OR

((First_Range $>=8.05$ AND First_Range $<=8.25$ ) AND (Last_Range $>=8.05$ And Last_Range $<=8.25)$ ) OR

((First_Range $>=8.35$ AND First_Range $<=8.55)$ AND (Last_Range $>=8.35$ And Last_Range $<=8.55)$ ) OR

((First_Range $>=9.25$ AND First_Range $<=9.45$ ) AND (Last_Range $>=9.25$ And Last_Range $<=9.45)$ ) OR

(Echo_Count $<7$ )

THEN DELETE;

END;

IF CHANNEL EQ 3 THEN DO; *closed;

END;

IF CHANNEL EQ 4 THEN DO;

IF ((Last Ping / Group Size + 1) - First Ping / Group_Size $)>60)$ OR

(Mean_Target_Strength > -39.33) OR

$($ Echo Count $=4$ AND $(($ Linearity $1 /$ Echo Count $)>0.4))$ OR

$(($ Echo_Count $=5$ OR Echo_Count $=6)$ AND $(($ Linearity $1 /$ Echo_Count $)>=0.5))$ OR

(Linearity2 > 4) OR

$(($ Noise_Count_Average / $(($ Echo_Count +10$) * 5))>0.045)$ OR

$(($ Slope $>11.5$ OR Slope $<-11.5)$ AND Mid_Range $<=8.5)$ OR

((Slope > 10.5 OR Slope <-10.5) AND Mid_Range > 8.5) OR

(Mid_Range $<2.400$ ) OR

(Mid_Range $>=2.40$ AND Mid_Range $<=8.00$ AND Slope $<1.5$ ) OR

(Mid_Range $>10.20$ )

THEN DELETE;

END;

IF CHANNEL EQ 5 THEN DO; *closed ;

END;

END;

IF SYSTEM='R' THEN DO; *downlooker;

IF $(($ Noise_Count_Average / $(($ Echo_Count +10$) * 5))>0.04)$ THEN DELETE;

IF Mean_Target_Strength > -39.33 THEN DELETE;

IF NUM PING GT 60 THEN DELETE;

IF CHANNNEL EQ 0 THEN DO;

IF Slope GT -1 AND Slope LT 1 THEN DELETE;

END;

IF CHANNEL EQ 1 THEN DO;

IF Slope GT -1 AND Slope LT 1 THEN DELETE;

IF Mid_Range GT 24.5 THEN DELETE;

END;

IF CHANNEL EQ 2 THEN DO;

IF Slope GT -0.05 AND Slope LT 0.05 THEN DELETE; END; END;

IF SYSTEM='X' THEN DO;

IF CHANNEL EQ 0 THEN DO; *uplooker;

IF (((Last_Ping / Group_Size + 1) - First_Ping / Group_Size $)>60)$ OR

(Mean_Target_Strength > -37) OR

$($ Echo Count $=4$ AND $(($ Linearity $1 /$ Echo Count $)>0.25))$ OR

$($ Echo_Count $=5$ AND $(($ Linearity $1 /$ Echo_Count $)>=0.3))$ OR

((Linearity2 / Echo_Count) $>=0.3)$ OR

$((($ Noise_Count_Average $) /(($ Echo_Count +10$) * 5))>0.045)$ OR 
(Slope $>=3.35$ OR Slope $<=-3.35$ ) OR

(Mid_Range $>=13.55$ )

THEN DELETE;

END;

IF CHANNEL EQ 1 THEN DO; *downlooker;

IF (((Last_Ping / Group_Size + 1) - First_Ping / Group_Size $)>60)$ OR

(Mean_Target_Strength > -37) OR

$($ Echo_Count $=4$ AND $(($ Linearity $1 /$ Echo_Count $)>0.4))$ OR

$(($ Echo_Count $=5$ OR Echo_Count $=6)$ AND $(($ Linearity1 $/$ Echo_Count $)>=0.5))$ OR

((Linearity2 / Echo_Count) $>0.45)$ OR

$((($ Noise_Count_Average $) /(($ Echo_Count +10$) * 5))>0.045))$ OR

((Slope > 11.5 OR Slope <-11.5) AND Mid_Range <=8.5) OR

$(($ Slope $>10.5$ OR Slope < -10.5) AND Mid_Range > 8.5) OR

(Mid Range $<10.60$ AND Slope $<3.0$ ) OR

(Mid_Range $>=10.60$ AND Mid_Range $<=17.50$ AND Slope $<2.0$ ) OR

(MidRange $>17.50$ AND Mid Range $<19.00$ AND Slope $<1.5$ ) OR

(Mid_Range $>=19.00$ AND Slope $<=0$ ) OR

(First_Range $>=10.57$ And First_Range $<=10.81$ And Last_Range $>=10.57$ AND Last_Range $<=10.81$ ) THEN DELETE; 
Appendix D-3. Statistical Analysis System Code for Filtering Out Echo Traces that Did Not Meet Fish Trace Criteria in Summer 2001. Minimum ranges for sampling guided, unguided, and spilled fish, which are presented in legends of Figures 1-4, were implemented elsewhere in the processing program.

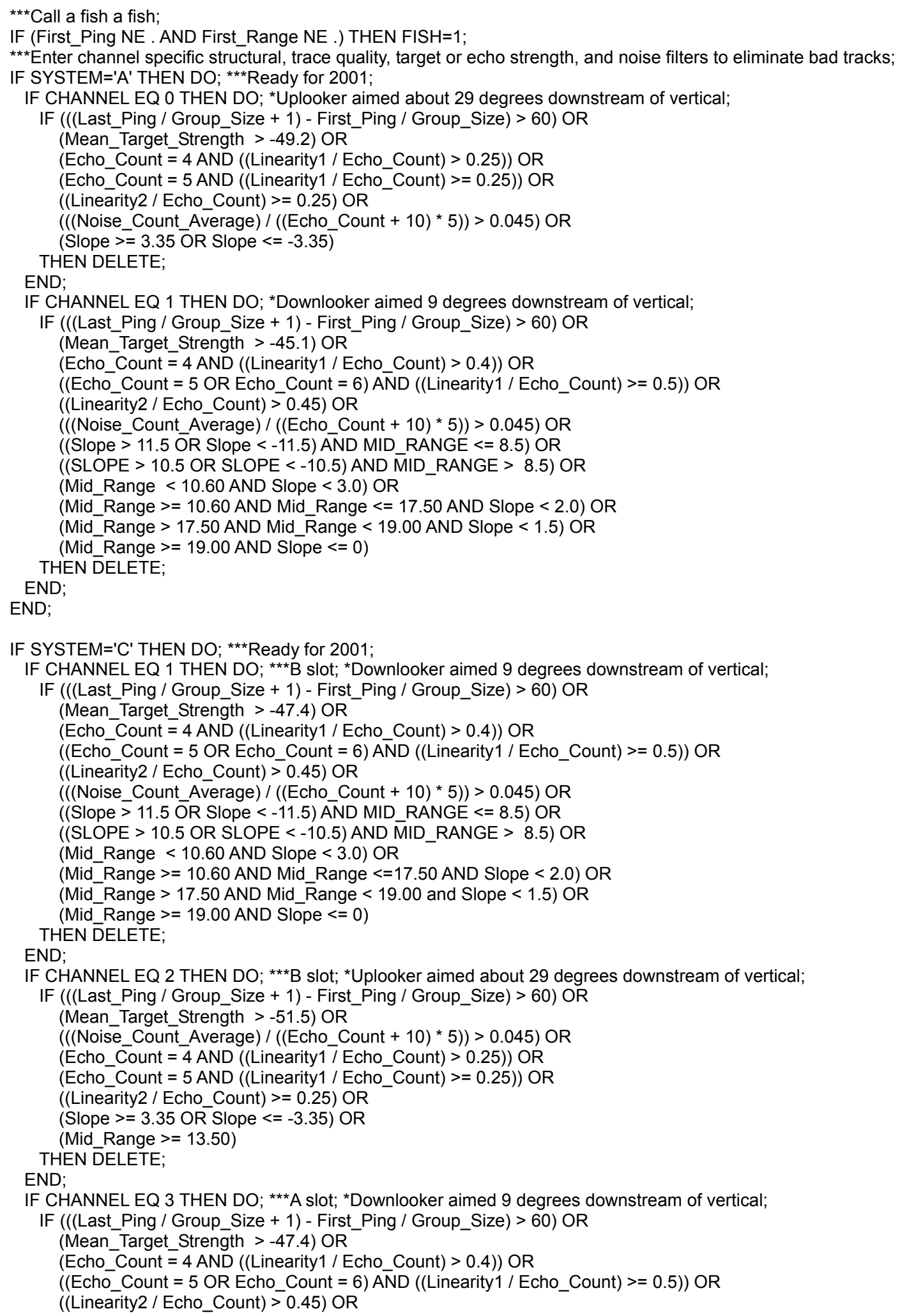


$((($ Noise_Count_Average $) /(($ Echo_Count +10$) * 5))>0.045)$ OR

$(($ Slope $>11.5$ OR Slope < -11.5) AND MID_RANGE <= 8.5) OR

((SLOPE > 10.5 OR SLOPE <-10.5) AND MID_RANGE > 8.5) OR

(Mid_Range $<10.60$ AND Slope $<3.0$ ) OR

(Mid_Range $>=10.60$ AND Mid_Range $<=17.50$ AND Slope $<2.0$ ) OR

(Mid_Range > 17.50 AND Mid_Range $<19.00$ and Slope $<1.5$ ) OR

(Mid_Range $>=19.00$ AND Slope $<=0$ )

THEN DELETE;

END;

IF CHANNEL EQ 4 THEN DO; ${ }^{* * * A}$ slot; *Uplooker aimed about 29 degrees downstream of vertical;

IF (( Last_Ping / Group_Size + 1) - First_Ping / Group_Size $)>60)$ OR

(Mean Target Strength > -51.5) OR

$((($ Noise_Count_Average $) /(($ Echo_Count +10$) * 5))>0.045)$ OR

(Echo Count $=\overline{4}$ AND $(($ Linearity $1 /$ Echo Count $)>0.25))$ OR

(Echo_Count $=5$ AND $(($ Linearity1 $/$ Echo_Count $)>=0.25))$ OR

((Linearity2 / Echo Count) $>=0.25)$ OR

(Slope $>=3.35$ OR Slope $<=-3.35$ ) OR

(Mid Range $>=13.50$ )

THEN DELETE;

END;

IF CHANNEL EQ 5 THEN DO; ${ }^{* *} \mathrm{C}$ slot; ${ }^{*}$ Downlooker aimed 9 degrees downstream of vertical;

IF (((Last_Ping / Group_Size + 1) - First_Ping / Group_Size $)>60)$ OR

(Mean_Target_Strength $>-47.4$ ) OR

$($ Echo_Count $=4$ AND $(($ Linearity1 $/$ Echo_Count $)>0.4))$ OR

$(($ Echo_Count $=5$ OR Echo_Count $=6)$ AND $(($ Linearity $1 /$ Echo_Count $)>=0.5))$ OR

((Linearity2 / Echo_Count) $>0.45)$ OR

$((($ Noise_Count_Average $) /(($ Echo_Count +10$) * 5))>0.045)$ OR

$(($ Slope $>11.5$ OR Slope $<-11.5)$ AND MID_RANGE $<=8.5)$ OR

((SLOPE > 10.5 OR SLOPE <-10.5) AND MID_RANGE > 8.5) OR

(Mid_Range $<10.60$ AND Slope $<3.0$ ) OR

(Mid Range $>=10.60$ AND Mid Range $<=17.50$ AND Slope $<2.0$ ) OR

(Mid_Range > 17.50 AND Mid_Range < 19.00 and Slope < 1.5) OR

(Mid Range $>=19.00$ AND Slope $<=0$ )

THEN DELETE;

END;

IF CHANNEL EQ 6 THEN DO; ${ }^{* * *} \mathrm{C}$ slot; *Uplooker aimed about 29 degrees downstream of vertical;

IF (( Last_Ping / Group_Size + 1) - First Ping / Group_Size ) > 60) OR

(Mean_Target_Strength > -51.5) OR

$((($ Noise Count Average $) /(($ Echo Count +10$) * 5))>0.045)$ OR

$($ Echo_Count $=4$ AND $(($ Linearity $1 /$ Echo_Count $)>0.25))$ OR

$($ Echo_Count $=5$ AND $(($ Linearity $1 /$ Echo_Count $)>=0.25))$ OR

((Linearity2 / Echo_Count) $>=0.25)$ OR

(Slope $>=3.35$ OR Slope $<=-3.35$ ) OR

(Mid_Range $>=13.50$ )

THEN DELETE;

END;

IF CHANNEL EQ 7 THEN DO; ***A slot; *Downlooker aimed 9 degrees downstream of vertical;

IF (((Last_Ping / Group_Size + 1) - First_Ping / Group_Size) $>60)$ OR

(Mean_Target_Strength > -47.4) OR

$($ Echo Count $=4$ AND $(($ Linearity $1 /$ Echo Count $)>0.4))$ OR

$(($ Echo_Count $=5$ OR Echo_Count $=6)$ AND $(($ Linearity $1 /$ Echo_Count $)>=0.5))$ OR

((Linearity2 / Echo Count) >0.45) OR

$((($ Noise_Count_Average $) /(($ Echo_Count +10$) * 5))>0.045)$ OR

((Slope > 11.5 OR Slope <-11.5) AND MID_RANGE <= 8.5) OR

((SLOPE > 10.5 OR SLOPE <-10.5) AND MID_RANGE > 8.5) OR

(Mid Range $<10.60$ AND Slope $<3.0$ ) OR

(Mid_Range $>=10.60$ AND Mid_Range $<=17.50$ AND Slope $<2.0$ ) OR

(Mid_Range $>17.50$ AND Mid_Range $<19.00$ and Slope $<1.5$ ) OR

(Mid_Range $>=19.00$ AND Slope $<=0$ )

THEN DELETE;

END;

IF CHANNEL EQ 8 THEN DO; ***A slot; *Uplooker aimed about 29 degrees downstream of vertical;

IF (((Last_Ping / Group_Size + 1) - First_Ping / Group_Size $)>60)$ OR

(Mean_Target_Strength > -51.5) OR

$((($ Noise Count Average $) /(($ Echo Count +10$) * 5))>0.045)$ OR

$($ Echo_Count $=\overline{4}$ AND $(($ Linearity $1 /$ Echo_Count $)>0.25))$ OR

(Echo_Count $=5$ AND $(($ Linearity $1 /$ Echo_Count $)>=0.25))$ OR

((Linearity2 / Echo_Count) $>=0.25)$ OR

(Slope $>=3.35$ OR Slope $<=-3.35$ ) OR

(Mid_Range $>=13.50$ ) 
THEN DELETE;

END;
END;

IF SYSTEM='D' THEN DO; ${ }^{* * *}$ Ready for 2001;

IF CHANNEL EQ 1 THEN DO; *Downlooker aimed 9 degrees downstream of vertical;

IF (((Last_Ping / Group_Size + 1) - First_Ping / Group_Size $)>60)$ OR

(Mean_Target_Strength > -47.4) OR

$($ Echo_Count $=4$ AND $(($ Linearity1 $/$ Echo_Count $)>0.4))$ OR

$(($ Echo_Count $=5$ OR Echo_Count $=6)$ AÑ $(($ Linearity1 $/$ Echo_Count $)>=0.5))$ OR

((Linearity2 / Echo_Count) $>0.45)$ OR

$((($ Noise_Count_Average $) /(($ Echo_Count +10$) * 5))>0.045)$ OR

$(($ Slope $>11.5$ OR Slope < -11.5) AND MID_RANGE <= 8.5) OR

((SLOPE > 10.5 OR SLOPE <-10.5) AND MID_RANGE > 8.5) OR

(Mid_Range $<10.60$ AND Slope $<3.0$ ) OR

(Mid Range $>=10.60$ AND Mid Range $<=17.50$ AND Slope $<2.0$ ) OR

(Mid_Range $>17.50$ AND Mid_Range $<19.00$ AND Slope $<1.5$ ) OR

(Mid_Range $>=19.00$ AND Slope $<=0$ ) OR

(First_Range $>=18.60$ AND First_Range $<=18.80$ AND Last_Range $>=18.60$ AND Last_Range $<=18.80$ ) THEN DELETE;

END;

IF CHANNEL EQ 2 THEN DO; *Uplooker aimed about 29 degrees downstream of vertical;

IF (((Last_Ping / Group_Size + 1) - First_Ping / Group_Size $)>60)$ OR

(Mean_Target_Strength $>-51.5)$ OR

$($ Echo_Count $=4$ AND $(($ Linearity $1 /$ Echo_Count $)>0.25))$ OR

$($ Echo_Count $=5$ AND $(($ Linearity $1 /$ Echo_Count $)>=0.25))$ OR

((Linearity2 / Echo_Count) $>=0.25)$ OR

$((($ Noise_Count_Average $) /(($ Echo_Count +10$) * 5))>0.045)$ OR

(Slope $>=3.35$ OR Slope $<=-3.35$ )

THEN DELETE;

END;

IF CHANNEL EQ 3 THEN DO; *Downlooker aimed 9 degrees downstream of vertical;

IF (( Last_Ping / Group_Size + 1) - First_Ping / Group_Size $)>60)$ OR

(Mean_Target_Strength $>-47.4$ ) OR

(Echo Count $=4$ AND $(($ Linearity $1 /$ Echo Count $)>0.4))$ OR

$(($ Echo_Count $=5$ OR Echo_Count $=6)$ AND $(($ Linearity $1 /$ Echo_Count $)>=0.5))$ OR

((Linearity2 / Echo Count $)>0.45)$ OR

$((($ Noise_Count_Average $) /(($ Echo_Count +10$) * 5))>0.045)$ OR

((Slope $>11.5$ OR Slope <-11.5) AND MID_RANGE <= 8.5) OR

((SLOPE > 10.5 OR SLOPE <-10.5) AND MID_RANGE > 8.5) OR

(Mid_Range $<10.60$ AND Slope $<3.0$ ) OR

(Mid_Range $>=10.60$ AND Mid_Range $<=17.50$ AND Slope $<2.0$ ) OR

(Mid_Range $>17.50$ AND Mid_Range $<19.00$ AND Slope $<1.5$ ) OR

(Mid_Range $>=19.00$ AND Slope $<=0$ ) OR

(Mid_Range > 16.30 AND Echo_Count/((Last_Ping / 2 + 1) - First_Ping / 2) < 1.1) AND (Echo_Count $>=10$ AND

$(($ Noise_Count_Average $) /(($ Echo_Count +10$) * 5))>0.045)$ OR

(First_Range $>=$ 19.50)

THEN DELETE;

END;

IF CHANNEL EQ 4 THEN DO; *Uplooker aimed about 29 degrees downstream of vertical;

IF (( Last_Ping / Group_Size + 1) - First_Ping / Group_Size $)>60)$ OR

(Mean_Target_Strength $>-51.5$ ) OR

$($ Echo_Count $=4$ AND $(($ Linearity $1 /$ Echo_Count $)>0.25))$ OR

$($ Echo_Count $=5$ AND $(($ Linearity $1 /$ Echo_Count $)>=0.25))$ OR

((Linearity2 / Echo_Count) $>=0.25)$ OR

$((($ Noise_Count_Average $) /(($ Echo_Count +10$) * 5))>0.045)$ OR

(Slope $>=3.35$ OR Slope $<=-3.35)$

THEN DELETE;

END;

IF CHANNEL EQ 5 THEN DO; *Uplooker aimed about 32 degrees downstream of vertical;

IF (( Last_Ping / Group_Size + 1) - First_Ping / Group_Size $)>60)$ OR

(Mean_Target_Strength $>-51.5)$ OR

$($ Echo_Count $=4$ AND $(($ Linearity $1 /$ Echo_Count $)>0.25))$ OR

$($ Echo_Count $=5$ AND $(($ Linearity $1 /$ Echo_Count $)>=0.25))$ OR

((Linearity2 / Echo_Count) $>=0.25)$ OR

$((($ Noise_Count_Average $) /(($ Echo_Count +10$) * 5))>0.045)$ OR

(Slope $>=3.35$ OR Slope $<=-3.35$ ) OR

(Mid_Range $>12.20$ And Slope $>-0.25$ AND Slope $<0.25$ )

THEN DELETE;

END; 
IF CHANNEL EQ 6 THEN DO; *Downlooker aimed about 25 degrees upstream of vertical;

IF ((Last_Ping / Group_Size + 1) - First_Ping / Group_Size $)>60)$ OR

(Mean Target Strength > -47.4) OR

$($ Echo_Count $=4$ AND $(($ Linearity $1 /$ Echo_Count $)>0.25))$ OR

$($ Echo_Count $=5$ AND $(($ Linearity $1 /$ Echo_Count $)>=0.25))$ OR

((Linearity2 / Echo_Count) $>=0.25)$ OR

$((($ Noise_Count_Average $) /(($ Echo_Count +10$) * 5))>0.045)$ OR

(Slope $>=5$ OR Slope $<=-5$ ) OR

((Mid_Range $>=11.35)$ AND (SLOPE $>-1$ OR SLOPE $<1)$ ) OR

(First_Range $>=11.30$ And First_Range $<=11.70$ AND Last_Range $>=11.30$ AND Last_Range $<=11.70$ ) OR

(First_Range $>=12.00$ And First_Range $<=12.20$ AND Last_Range $>=12.00$ AND Last_Range $<=12.20$ ) THEN DELETE;

END;

IF CHANNEL EQ 7 THEN DO; *Downlooker aimed 9 degrees downstream of vertical;

IF (((Last_Ping / Group_Size + 1) - First_Ping / Group_Size ) > 60) OR

(Mean Target Strength $>-47.4$ ) OR

$($ Echo_Count $=4$ AND $(($ Linearity $1 /$ Echo_Count $)>0.4))$ OR

$(($ Echo_Count $=5$ OR Echo_Count $=6)$ AND $(($ Linearity $1 /$ Echo_Count $)>=0.5))$ OR

((Linearity2 / Echo_Count) $>0.45)$ OR

$((($ Noise_Count_Average $) /(($ Echo_Count +10$) * 5))>0.045)$ OR

((Slope > 11.5 OR Slope < -11.5) AND MID_RANGE < < 8.5) OR

((SLOPE > 10.5 OR SLOPE <-10.5) AND MID_RANGE > 8.5) OR

(Mid_Range < 10.60 AND Slope < 3.0) OR

(Mid_Range $>=10.60$ AND Mid_Range $<=17.50$ AND Slope $<2.0$ ) OR

(Mid_Range > 17.50 AND Mid_Range $<19.00$ AND Slope $<1.5$ ) OR

(Mid_Range $>=19.00$ AND Slope $<=0$ ) OR

(First_Range $>=12.75$ AND First_Range $<=12.90$ AND Last_Range $>=12.75$ AND Last_Range $<=12.90$ ) OR

(First_Range $>=14.70$ AND First_Range $<=14.85$ AND Last_Range $>=14.70$ AND Last_Range $<=14.85$ ) OR

(First_Range $>=18.15$ AND First_Range $<=18.35$ AND Last_Range $>=18.15$ AND Last_Range $<=18.35$ ) THEN DELETE;

END;

IF CHANNEL EQ 8 THEN DO; *Uplooker aimed about 29 degrees downstream of vertical;

IF ((Last Ping / Group_Size + 1) - First Ping / Group_Size $)>60)$ OR

(Mean_Target_Strength > -51.5) OR

(Echo_Count $=4$ AND $(($ Linearity $1 /$ Echo_Count $)>0.25))$ OR

$($ Echo_Count $=5$ AND $(($ Linearity $1 /$ Echo_Count $)>=0.25))$ OR

((Linearity2 / Echo_Count) $>=0.25)$ OR

$((($ Noise_Count_Average $) /(($ Echo_Count +10$) * 5))>0.045)$ OR

(Slope $>=3.35$ OR Slope $<=-3.35$ ) OR

(Mid_Range > 13.30 AND ((Noise_Count_Average) / $\left((\right.$ Echo_Count +10$\left.\left.\left.){ }^{*} 5\right)\right)>0.03\right)$ OR

(First_Range $>=12.60$ And First_Range $<=12.90$ And Last_Range $>=12.60$ AND Last_Range $<=12.90$ ) OR

(First_Range $>=12.08$ And First_Range $<=12.44$ And Last_Range $>=12.08$ AND Last_Range $<=12.44$ ) END;

THEN DELETE;

END;

IF SYSTEM='G' THEN DO; ***Ready for 2001;

IF CHANNEL EQ 1 THEN DO; *Downlooker aimed 9 degrees downstream of vertical;

IF (((Last_Ping / Group_Size + 1) - First_Ping / Group_Size $)>60)$ OR

(Mean_Target Strength > -47.4) OR

$($ Echo_Count $=4$ AND $(($ Linearity1 $/$ Echo_Count $)>0.4))$ OR

$(($ Echo_Count $=5$ OR Echo_Count $=6)$ AND $(($ Linearity1 $/$ Echo Count $)>=0.6))$ OR

((Linearity2 / Echo_Count) $>0.6)$ OR

$((($ Noise_Count Average $) /(($ Echo_Count +10$) * 5))>0.045)$ OR

((Slope $>11.5$ OR Slope $<-11.5)$ AND MID_RANGE $<=8.5)$ OR

((SLOPE > 10.5 OR SLOPE < -10.5) AND MID_RANGE > 8.5) OR

(Mid_Range $<8.50$ AND Slope $<4.0$ ) OR

(Mid_Range $>=8.50$ AND Mid_Range $<=14.00$ AND Slope $<2.7$ ) OR

(Mid_Range $>14.00$ AND Slope $<2.5$ )

THEN DELETE;

END;

IF CHANNEL EQ 2 THEN DO; *Uplooker aimed about 36 degrees downstream of vertical;

IF (((Last_Ping / Group_Size + 1) - First_Ping / Group_Size $)>60)$ OR

(Mean_Target_Strength > -51.5) OR

$($ Echo_Count $=4$ AND $(($ Linearity $1 /$ Echo_Count $)>0.25))$ OR

$($ Echo_Count $=5$ AND $(($ Linearity $1 /$ Echo_Count $)>=0.3))$ OR

((Linearity2 / Echo_Count) $>=0.3)$ OR

$((($ Noise_Count_Average $) /(($ Echo_Count +10$) * 5))>0.045)$ OR

(Slope $>=3.35$ OR Slope $<=-3.35$ )

THEN DELETE; 
END;

IF CHANNEL EQ 3 THEN DO; *Downlooker aimed about 9 degrees downstream of vertical;

IF (((Last_Ping / Group_Size + 1) - First_Ping / Group_Size) > 60) OR

(Mean_Target_Strength > -47.4) OR

$($ Echo_Count $=4$ AND $(($ Linearity $1 /$ Echo_Count $)>0.4))$ OR

$(($ Echo_Count $=5$ OR Echo_Count $=6)$ AND $(($ Linearity1 $/$ Echo_Count $)>=0.6))$ OR

((Linearity2 / Echo_Count) $>0.6)$ OR

$((($ Noise_Count_Average $) /(($ Echo_Count +10$) * 5))>0.045)$ OR

((Slope $>11.5$ OR Slope $<-11.5)$ AND MID_RANGE $<=8.5)$ OR

((SLOPE > 10.5 OR SLOPE <-10.5) AND MID_RANGE > 8.5) OR

(Mid_Range $<8.50$ AND Slope $<4.0$ ) OR

(Mid_Range $>=8.50$ AND Mid_Range $<=14.00$ AND Slope $<2.7$ ) OR

(Mid_Range $>14.00$ AND Slope $<2.5$ ) OR

(First_Range $>=5.3$ And First_Range $<=6.0$ And Last_Range $>=5.3$ AND Last_Range $<=6.0$ ) THEN DELETE;

END;

IF CHANNEL EQ 4 THEN DO; *Uplooker aimed about 36 degrees downstream of vertical;

IF (((Last_Ping / Group_Size + 1) - First_Ping / Group_Size) $>60)$ OR

(Mean_Target_Strength > -51.5) OR

$($ Echo_Count $=4$ AND $(($ Linearity $1 /$ Echo_Count $)>0.25))$ OR

$($ Echo_Count $=5$ AND $(($ Linearity $1 /$ Echo_Count $)>=0.3))$ OR

((Linearity2 / Echo_Count) $>=0.3)$ OR

$((($ Noise_Count_Average $) /(($ Echo_Count +10$) * 5))>0.045)$ OR

(Slope $>=3.35$ OR Slope $<=-3.35$ )

THEN DELETE;

END;

IF CHANNEL EQ 5 THEN DO; *Downlooker aimed about 9 degrees downstream of vertical;

IF (( Last_Ping / Group_Size + 1) - First_Ping / Group_Size $)>60)$ OR

(Mean_Target_Strength > -47.4) OR

$($ Echo_Count $=4$ AND $(($ Linearity $1 /$ Echo_Count $)>0.4))$ OR

$(($ Echo_Count $=5$ OR Echo_Count $=6)$ AND $(($ Linearity1 $/$ Echo_Count $)>=0.6))$ OR

((Linearity2 / Echo_Count) $>0.6)$ OR

$((($ Noise Count Average $) /(($ Echo Count +10$) * 5))>0.045)$ OR

((Slope > 11.5 OR Slope < -11.5) AND MID_RANGE < < 8.5) OR

((SLOPE > 10.5 OR SLOPE <-10.5) AND MID_RANGE > 8.5) OR

(Mid_Range $<8.50$ AND Slope $<4.0$ ) OR

(Mid_Range $>=8.50$ AND Mid_Range $<=14.00$ AND Slope $<2.7$ ) OR

(Mid_Range $>14.00$ AND Slope $<2.5$ )

THEN DELETE;

END;

IF CHANNEL EQ 6 THEN DO; *Uplooker aimed about 36 degrees downstream of vertical;

IF (( Last_Ping / Group_Size + 1) - First_Ping / Group_Size $)>60)$ OR

(Mean_Target_Strength $>-51.5)$ OR

$($ Echo_Count $=4$ AND $(($ Linearity1 $/$ Echo_Count $)>0.25))$ OR

$($ Echo_Count $=5$ AND $(($ Linearity $1 /$ Echo_Count $)>=0.3))$ OR

((Linearity2 / Echo_Count) $>=0.3)$ OR

$((($ Noise_Count_Average $) /(($ Echo_Count +10$) * 5))>0.045)$ OR

(Slope $>=3.35$ OR Slope $<=-3.35$ )

THEN DELETE;

END;

IF CHANNEL EQ 7 THEN DO; *Downlooker aimed about 9 degrees downstream of vertical;

IF (((Last Ping / Group Size + 1) - First Ping / Group Size ) > 60) OR

(Mean_Target_Strength > -47.4) OR

$($ Echo_Count $=4$ AND $(($ Linearity $1 /$ Echo_Count $)>0.4))$ OR

$(($ Echo_Count $=5$ OR Echo_Count $=6)$ AND $(($ Linearity $1 /$ Echo_Count $)>=0.6))$ OR

((Linearity2 / Echo_Count) > 0.6) OR

$((($ Noise_Count_Average $) /(($ Echo_Count +10$) * 5))>0.045)$ OR

((Slope $>11.5$ OR Slope $<-11.5)$ AND MID_RANGE <= 8.5) OR

((SLOPE > 10.5 OR SLOPE <-10.5) AND MID_RANGE > 8.5) OR

(Mid Range $<8.50$ AND Slope $<4.0$ ) OR

(Mid_Range $>=8.50$ AND Mid_Range $<=14.00$ AND Slope $<2.7$ ) OR

(Mid_Range $>14.00$ AND Slope $<2.5$ )

THEN DELETE;

END;

IF CHANNEL EQ 8 THEN DO; *Uplooker aimed about 36 degrees downstream of vertical;

IF (( Last_Ping / Group_Size + 1) - First_Ping / Group_Size $)>60)$ OR

(Mean_Target_Strength > -51.5) OR

$($ Echo_Count $=4$ AND $(($ Linearity1 $/$ Echo_Count $)>0.25))$ OR

$($ Echo_Count $=5$ AND $(($ Linearity $1 /$ Echo_Count $)>=0.3))$ OR

((Linearity2 / Echo_Count) $>=0.3)$ OR 
$((($ Noise_Count_Average $) /(($ Echo_Count +10$) * 5))>0.045)$ OR

(Slope $>=3.35$ OR Slope $<=-3.35)$

THEN DELETE;

END;

END;

IF SYSTEM='H' THEN DO; *Ready for 2001;

IF CHANNEL EQ 1 THEN DO; *Downlooker aimed about 9 degrees downstream of vertical;

IF (((Last_Ping / Group_Size + 1) - First_Ping / Group_Size) > 60) OR

(Mean_Target_Strength > -47.4) OR

$($ Echo_Count $=4$ AND $(($ Linearity $1 /$ Echo_Count $)>0.4))$ OR

$(($ Echo_Count $=5$ OR Echo_Count = 6) AÑ $(($ Linearity $1 /$ Echo_Count $)>=0.6))$ OR

((Linearity2 / Echo_Count) $>0.6)$ OR

$((($ Noise_Count_Average $) /(($ Echo_Count +10$) * 5))>0.045)$ OR

((Slope > 11.5 OR Slope < -11.5) AND MID_RANGE <= 8.5) OR

((SLOPE > 10.5 OR SLOPE <-10.5) AND MID_RANGE > 8.5) OR

(Mid_Range $<8.50$ AND Slope $<4.0$ ) OR

(Mid_Range $>=8.50$ AND Mid_Range $<=14.00$ AND Slope $<2.7$ ) OR

(Mid Range $>14.00$ AND Slope $<2.5$ ) OR

(First_Range $>=5.56$ AND Last_Range $<=5.85$ ) OR

(First_Range $>=13.62$ AND Last_Range $<=13.88$ ) OR

(First_Range $>=15.69$ AND Last_Range $<=15.88$ )

THEN DELETE;

END;

IF CHANNEL EQ 2 THEN DO; *Uplooker aimed about 36 degrees downstream of vertical;

IF (((Last_Ping / Group_Size + 1) - First_Ping / Group_Size) > 60) OR

(Mean_Target_Strength > -51.5) OR

$($ Echo_Count $=4$ AND $(($ Linearity $1 /$ Echo_Count $)>0.25))$ OR

$($ Echo_Count $=5$ AND $(($ Linearity $1 /$ Echo_Count $)>=0.3))$ OR

((Linearity2 / Echo_Count) $>=0.3)$ OR

$((($ Noise_Count_Average $) /(($ Echo_Count +10$) * 5))>0.045)$ OR

(Slope $>=3.35$ OR Slope $<=-3.35)$

THEN DELETE;

END;

IF CHANNEL EQ 3 THEN DO; *Downlooker aimed about 9 degrees downstream of vertical;

IF (( Last_Ping / Group_Size + 1) - First_Ping / Group_Size) > 60) OR

(Mean_Target_Strength $>-47.4)$ OR

$($ Echo_Count $=4$ AND $(($ Linearity1 $/$ Echo_Count $)>0.4))$ OR

$(($ Echo_Count $=5$ OR Echo_Count $=6)$ AÑ $(($ Linearity $1 /$ Echo_Count $)>=0.6))$ OR

((Linearity2 / Echo_Count) $>=0.6)$ OR

$((($ Noise_Count_Average $) /(($ Echo_Count + 10) * 5) $)>0.045)$ OR

((Slope > 11.5 OR Slope <-11.5) AND MID_RANGE <= 8.5) OR

((SLOPE > 10.5 OR SLOPE <-10.5) AND MID_RANGE > 8.5) OR

(Mid_Range $<8.50$ AND Slope $<4.0$ ) OR

(Mid_Range $>=8.50$ AND Mid_Range $<=14.00$ AND Slope $<2.7$ ) OR

(Mid_Range $>14.00$ AND Slope $<2.5$ ) OR

(Echo_Count / ( (Last_Ping / $2+1)$ - First_Ping / 2) $<0.7)$ OR

(First_Range $>=13.70$ AND Last_Range $<=13.88$ ) OR

(First_Range $>=14.71$ AND Last_Range $<=14.93$ ) OR

(First_Range $>=15.40$ AND Last_Range $<=15.78$ )

THEN DELETE;

END;

IF CHANNEL EQ 4 THEN DO; *Uplooker aimed about 36 degrees downstream of vertical;

IF (((Last_Ping / Group_Size + 1) - First_Ping / Group_Size $)>60)$ OR

(Mean_Target_Strength $>-51.5$ ) OR

(Echo_Count $=4$ AND $(($ Linearity1 $/$ Echo_Count $)>0.25))$ OR

$($ Echo_Count $=5$ AND $(($ Linearity $1 /$ Echo_Count $)>=0.3))$ OR

((Linearity2 / Echo_Count) $>=0.3)$ OR

$((($ Noise_Count_Average $) /(($ Echo_Count +10$) * 5))>0.045)$ OR

(Slope $>=3.35$ OR Slope $<=-3.35)$

THEN DELETE;

END;

IF CHANNEL EQ 5 THEN DO; *Downlooker aimed about 9 degrees downstream of vertical;

IF (((Last_Ping / Group_Size + 1) - First_Ping / Group_Size $)>60)$ OR

(Mean_Target_Strength > -47.4) OR

$($ Echo_Count $=4$ AND $(($ Linearity1 $/$ Echo_Count $)>0.4))$ OR

$(($ Echo_Count $>=5$ AND Echo_Count $<=\overline{6})$ AND $(($ Linearity $1 /$ Echo_Count $)>=0.6))$ OR ((Linearity2 / Echo_Count) $>0.6)$ OR

$((($ Noise_Count_Average $) /(($ Echo_Count +10$) * 5))>0.045)$ OR

((Slope > 11.5 OR Slope < -11.5) AND MID RANGE < = 8.5) OR

$(($ SLOPE > 10.5 OR SLOPE <-10.5) AND MID_RANGE > 8.5) OR 


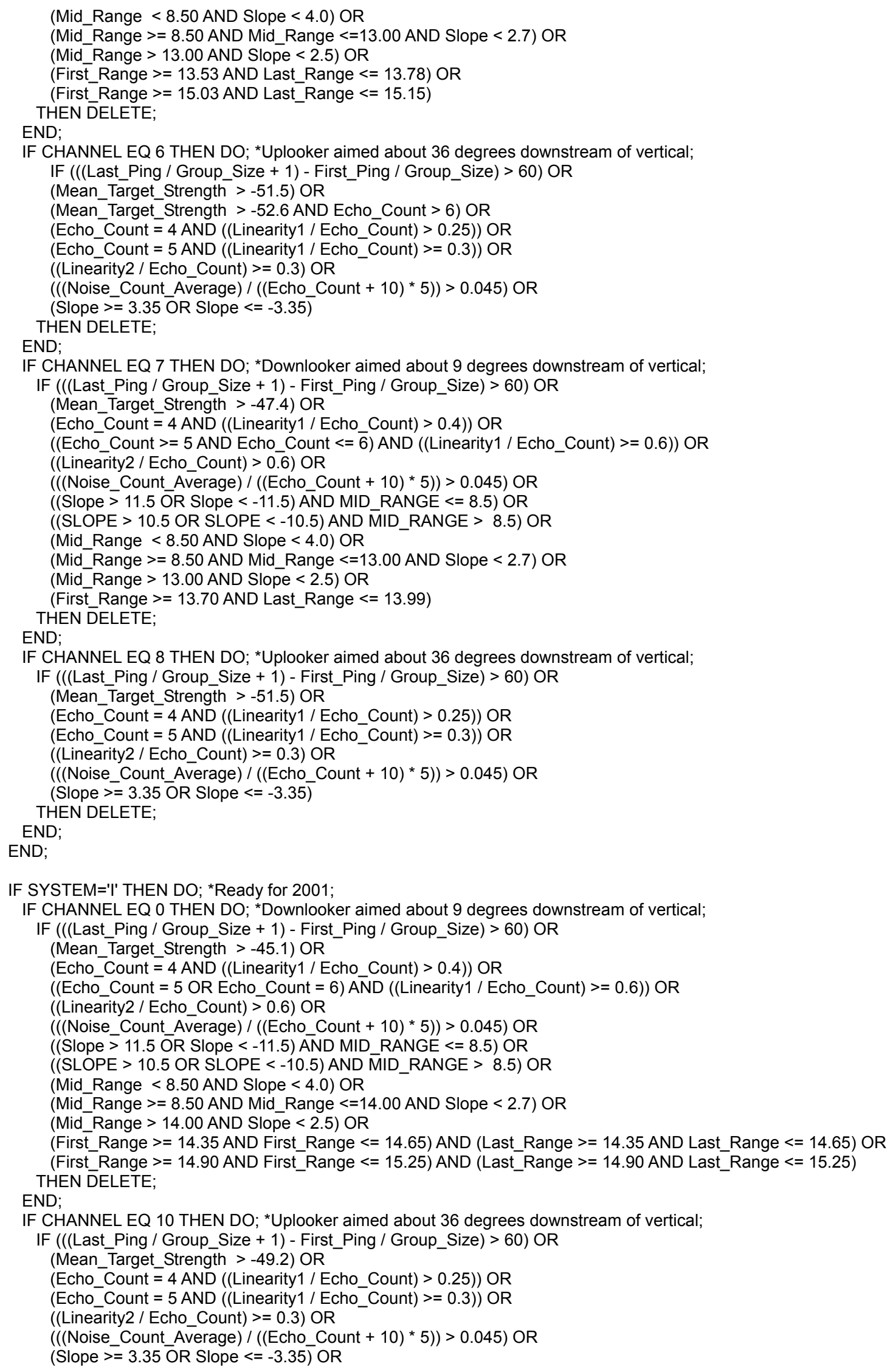


(First_Range $>5.00$ AND First_Range $<=5.80$ ) AND (Last_Range $>5.00$ AND Last_Range $<=5.80$ ) OR

(First_Range $>8.80$ AND First_Range $<8.90$ ) AND (Last_Range $>8.80$ AND Last_Range $<8.90$ ) OR

(First_Range > 8.85 AND First_Range $<9.25$ ) AND (Last_Range $>8.85$ AND Last_Range $<9.25$ )

THEN DELETE; END;

END;

*Ready for 2001;

IF SYSTEM='O' THEN DO; *Downlooker aimed about 15 degrees upstream of vertical;

IF (((Last_Ping / Group_Size + 1) - First_Ping / Group_Size $)>60)$ OR

(Mean_Target_Strength > -45.1) OR

$($ Echo_Count $=4$ AND $(($ Linearity1 $/$ Echo_Count $)>0.4))$ OR

$(($ Echo_Count $>=5$ AND Echo_Count $<=\overline{6})$ AND $(($ Linearity $1 /$ Echo_Count $)>0.5))$ OR

(Linearity2 > 4) OR

$((($ Noise_Count_Average $) /(($ Echo_Count +10$) * 5))>0.045)$ OR

$(((($ Noise Count Average $) /(($ Echo Count +10$) * 5))>0.05)$ AND (Mid Range $>2.40$ AND Mid Range $<8.50))$ OR

((Slope > 11.5 OR Slope < -11.5) AÑD MID_RANGE <= 8.5) OR

((SLOPE > 10.5 OR SLOPE <-10.5) AND MID_RANGE > 8.5) OR

(Mid_Range $<2.400$ ) OR

(Mid_Range $>=2.40$ AND Mid_Range $<=8.00$ AND Slope $<1.5$ ) OR

(Mid_Range > 10.20)

THEN DELETE;

END;

${ }^{*}$ Ready for 2001;

IF SYSTEM='P' THEN DO; *Downlookers aimed about 8 degrees upstream of vertical;

IF CHANNEL EQ 1 THEN DO; *closed ;

END;

IF CHANNEL EQ 2 THEN DO;

IF (((Last_Ping / Group_Size + 1) - First_Ping / Group_Size $)>60)$ OR

(Mean Target Strength > -47.4) OR

$($ Echo_Count $=4$ AND $(($ Linearity $1 /$ Echo_Count $)>0.4))$ OR

$(($ Echo Count $=5$ OR Echo Count $=6)$ AND $(($ Linearity $1 /$ Echo Count $)>=0.5))$ OR

(Linearity2 > 4) OR

$((($ Noise_Count_Average $) /(($ Echo_Count +10$) * 5))>0.045)$ OR

$(((($ Noise_Count_Average $) /(($ Echo_Count +10$) * 5))>0.05)$ AND (Mid_Range $>2.40$ AND Mid_Range $<8.50))$ OR

$(($ Slope $>11.5$ OR Slope $<-11.5)$ AÑN MID_RANGE $<=8.5)$ OR

((SLOPE > 10.5 OR SLOPE <-10.5) AND MID_RANGE > 8.5) OR

(Mid_Range $<2.400$ ) OR

(Mid_Range $>=2.40$ AND Mid_Range $<=8.00$ AND Slope $<1.5$ ) OR

(Mid Range > 9.60)

THEN DELETE;

END;

IF CHANNEL EQ 3 THEN DO;

IF (( Last_Ping / Group_Size + 1) - First_Ping / Group_Size $)>60)$ OR

(Mean_Target_Strength > -47.4) OR

$($ Echo_Count $=4$ AND $(($ Linearity $1 /$ Echo_Count $)>0.4))$ OR

$(($ Echo_Count $=5$ OR Echo_Count $=6)$ AND $(($ Linearity1 $/$ Echo_Count $)>=0.5))$ OR

(Linearity2 > 4) OR

$((($ Noise Count Average $) /(($ Echo Count +10$) * 5))>0.045)$ OR

$((($ Noise_Count_Average $) /(($ Echo_Count +10$) * 5))>0.05)$ AND $($ Mid_Range $>2.40$ AND Mid_Range $<8.50))$ OR

((Slope > 11.5 OR Slope < -11.5) AÑD MID RANGE <= 8.50) OR

((SLOPE > 10.5 OR SLOPE < -10.5) AND MID_RANGE > 8.50) OR

(Mid_Range $<2.400$ ) OR

(Mid_Range $>=2.40$ AND Mid_Range $<=8.00$ AND Slope $<1.5$ ) OR

(Mid Range $>10.35$ ) OR

(Echo_Count $<7$ )

THEN DELETE;

END;

IF CHANNEL EQ 4 THEN DO;*closed ;

END;

IF CHANNEL EQ 5 THEN DO; ${ }^{*}$ losed ;

END;

END;

${ }^{*}$ Ready for 2001;

IF SYSTEM='Q' THEN DO; *Downlookers aimed about 8 degrees upstream of vertical;

IF CHANNEL EQ 1 THEN DO;

IF (( Last_Ping / Group_Size + 1) - First_Ping / Group_Size) $>60)$ OR

(Mean_Target_Strength > -47.4) OR 
$($ Echo_Count $=4$ AND $(($ Linearity $1 /$ Echo_Count $)>0.4))$ OR

$(($ Echo_Count $>=5$ AND Echo_Count $<=\overline{6})$ AND $(($ Linearity $1 /$ Echo_Count $)>=0.5))$ OR

(Linearity2 > 4) OR

$((($ Noise_Count_Average $) /(($ Echo_Count +10$) * 5))>0.045)$ OR

((Slope $>11.5$ OR Slope $<-11.5)$ AND MID_RANGE $<=8.5)$ OR

((SLOPE > 10.5 OR SLOPE <-10.5) AND MID_RANGE > 8.5) OR

(Mid_Range $<2.400$ ) OR

(Mid_Range $>=2.40$ AND Mid_Range $<=8.00$ AND Slope $<1.5$ ) OR

(Mid_Range $>10.80$ ) OR

((First_Range $>=4.05$ AND First_Range $<=4.35)$ AND (Last_Range $>=4.05$ AND Last_Range $<=4.35)$ ) OR

((First_Range $>=4.15$ AND First_Range $<=4.60)$ AND (Last_Range $>=4.15$ AND Last_Range $<=4.60)$ ) OR

((First_Range $>=9.00$ AND First_Range $<=9.35)$ AND (Last_Range $>=9.00$ AND Last_Range $<=9.35)$ ) OR

((First_Range $>=9.40$ AND First_Range $<=9.65)$ AND (Last_Range $>=9.40$ AND Last_Range $<=9.65)$ )

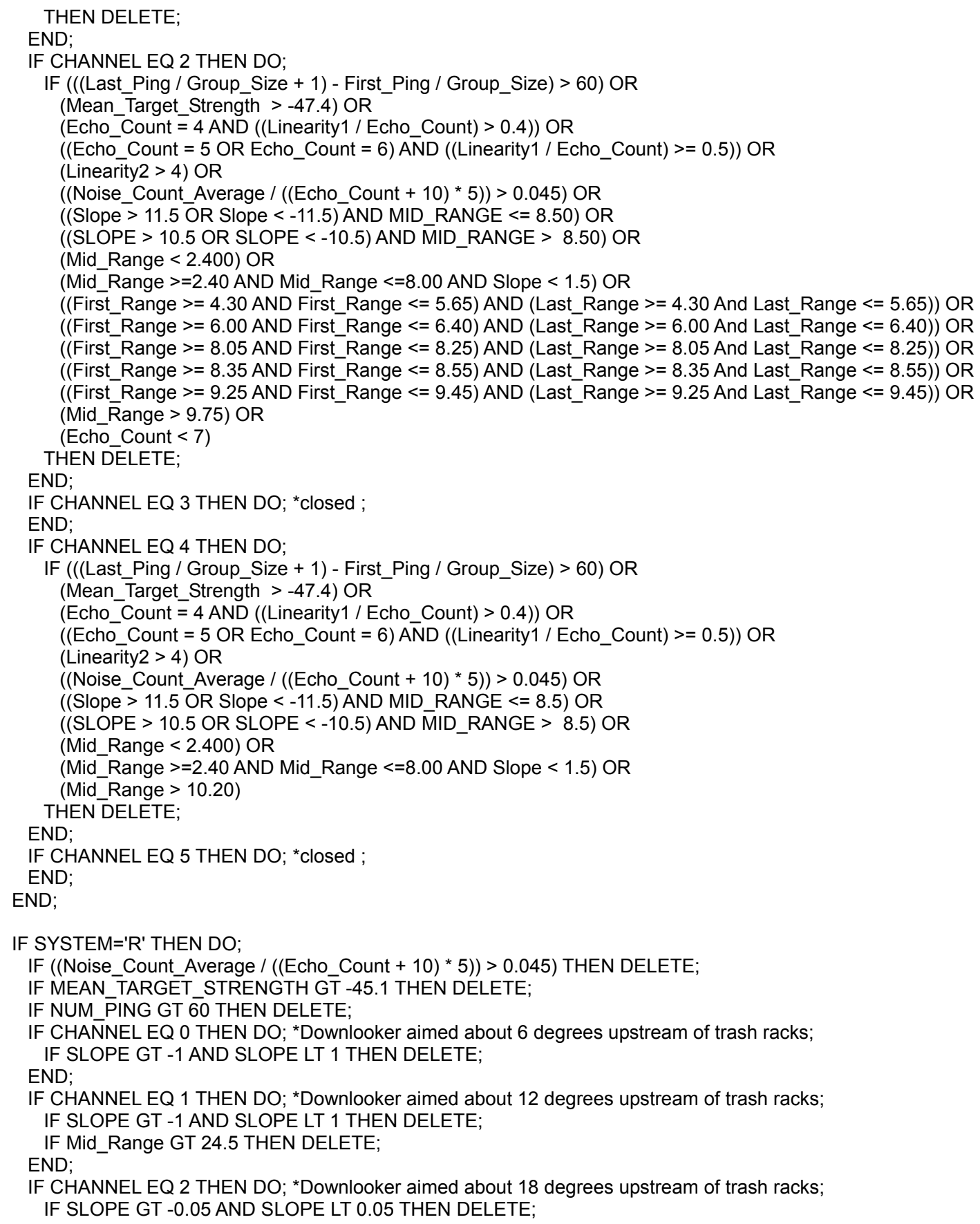

IF CHANNEL EQ 1 THEN DO; *Downlooker aimed about 12 degrees upstream of trash racks; IF SLOPE GT - 1 AND SLOPE LT 1 THEN DELETE; IF Mid_Range GT 24.5 THEN DELETE; END;

IF CHANNEL EQ 2 THEN DO; *Downlooker aimed about 18 degrees upstream of trash racks; IF SLOPE GT -0.05 AND SLOPE LT 0.05 THEN DELETE; 
END;

END;

${ }^{*}$ Ready for 2001;

IF SYSTEM='X' THEN DO;

$O A x=2057$; ${ }^{*}$ These are the average values for the two transducers.

*Both transducers lost phase information, so something was lost from the sounder.;

$\mathrm{OAy}=2054$

$\mathrm{OBx}=2063$

$\mathrm{OBy}=2053$

SAx $=279.5$

$\mathrm{SAy}=278$;

$\mathrm{SBX}=-119950$;

$\mathrm{SBy}=-122150$

$\mathrm{BPF} 2 \mathrm{y}=\left(\left(\mathrm{SAy}^{*}((\mathrm{YANGLE} 1+\mathrm{YANGLE} 2) / 2)+\mathrm{OAy}-\mathrm{OBy}\right)^{* *} 2\right) /-\mathrm{SB}$;

BPF2 $x=\left(\left(\mathrm{SAx}^{*}((\mathrm{XANGLE} 1+\mathrm{XANGLE} 2) / 2)+\mathrm{OAx}-\mathrm{OBx}\right)^{\star *} 2\right) /-\mathrm{SBx}$;

BPF2 $=\left(\text { BPF2 } y^{\star \star} 2+B P F 2 x^{\star \star} 2\right)^{\star \star} 0.5$;

Mean Target Strength=Mean Target Strength-BPF2

IF CHANNEL EQ 0 THEN DO; *Uplooker aimed about 29 degrees downstream of vertical;

IF ((Last Ping / Group_Size + 1) - First Ping / Group_Size) $>60)$ OR

(Mean_Target_Strength > -51.5) OR

(Echo_Count $=4$ AND $(($ Linearity1 $/$ Echo_Count $)>0.25))$ OR

$($ Echo_Count $=5$ AND $(($ Linearity $1 /$ Echo_Count $)>=0.25))$ OR

((Linearity2 / Echo_Count) $>=0.25)$ OR

$((($ Noise_Count_Average $) /(($ Echo_Count +10$) * 5))>0.045)$ OR

(Slope $>=3.35$ OR Slope $<=-3.35)$ OR

(Mid_Range $>=13.55$ )

THEN DELETE;

END;

IF CHANNEL EQ 1 THEN DO; *Downlooker aimed 9 degrees downstream of vertical;

IF ((Last_Ping / Group_Size + 1) - First_Ping / Group_Size ) > 60) OR

(Mean_Target_Strength > -47.4) OR

$($ Echo Count $=4$ AND $(($ Linearity $1 /$ Echo Count $)>0.4))$ OR

$(($ Echo_Count $=5$ OR Echo_Count $=6)$ AND $(($ Linearity $1 /$ Echo_Count $)>=0.5))$ OR

((Linearity2 / Echo_Count) $>0.45)$ OR

$(((($ Noise_Count_Average $) /(($ Echo_Count +10$) * 5))>0.045))$ OR

((Slope > 11.5 OR Slope < -11.5) AND MID_RANGE < < 8.5) OR

((SLOPE > 10.5 OR SLOPE <-10.5) AND MID_RANGE > 8.5) OR

(Mid Range $<10.60$ AND Slope $<3.0$ ) OR

(Mid_Range $>=10.60$ AND Mid_Range $<=17.50$ AND Slope $<2.0$ ) OR

(Mid_Range $>17.50$ AND Mid_Range $<19.00$ AND Slope $<1.5$ ) OR

(Mid_Range $>=19.00$ AND Slope $<=0$ ) OR

(First_Range $>=10.57$ And First_Range $<=10.81$ And Last_Range $>=10.57$ AND Last_Range $<=10.81$ )

THEN DELETE; END;

END;

OUTPUT TRACKED;

END:

RUN; 


\section{Appendix E}

\section{List of Appendix E Tables and Definitions of Variables in Headings of Hourly Fish Passage, Flow, and Forebay Elevation Data on an Accompanying Disk}





\section{Appendix E}

\section{List of Appendix E Tables}

Appendix E-1. List of Appendix Tables on the Accompanying Disk

\begin{tabular}{||l|l||}
\hline \hline Table & Description \\
\hline Appendix E-1 & List of Appendix E Tables on an Accompanying Disk \\
\hline Appendix E-2 & $\begin{array}{l}\text { Definitions of variables in headings of Appendix E tables on the accompanying } \\
\text { disk. }\end{array}$ \\
\hline Appendix E-3 & $\begin{array}{l}\text { Hourly estimates of fish passage (sums, variances, and covariances), unit } \\
\text { discharge, and forebay elevation for Powerhouse 1 in spring 2001. }\end{array}$ \\
\hline Appendix E-4 & $\begin{array}{l}\text { Hourly estimates of fish passage (sums, variances, and covariances), unit } \\
\text { discharge, and forebay elevation for Powerhouse 1 in summer 2001. }\end{array}$ \\
\hline Appendix E-5 & $\begin{array}{l}\text { Hourly estimates of fish passage (sums and variances) and spill-bay discharge for } \\
\text { the spillway in spring 2001. }\end{array}$ \\
\hline Appendix E-6 & $\begin{array}{l}\text { Hourly estimates of fish passage (sums and variances) and spill-bay discharge for } \\
\text { the spillway in summer 2001. }\end{array}$ \\
\hline Appendix E-7 & $\begin{array}{l}\text { Hourly estimates of fish passage (sums, variances, and covariances), unit } \\
\text { discharge, and forebay elevation for Powerhouse 2 in spring 2001. }\end{array}$ \\
\hline Appendix E-8 & $\begin{array}{l}\text { Hourly estimates of fish passage (sums, variances, and covariances), unit } \\
\text { discharge, and forebay elevation for Powerhouse 2 in summer 2001. }\end{array}$ \\
\hline
\end{tabular}


E.2 
Appendix E-2. Definitions of Variables in Headings of Appendix E Tables on the Accompanying Disk

\begin{tabular}{|c|c|}
\hline Variable & Definition \\
\hline Begins with S & Hourly sum of spatially and temporally expanded estimates of fish passage \\
\hline Begins with V & Hourly sum of temporally expanded variances \\
\hline Begins with C & Hourly sum of temporally expanded covariances for guided and unguided fish at powerhouses \\
\hline Ends with $\mathrm{M} 3 \mathrm{H}$ & Discharge in millions of cubic meters \\
\hline Contains INT & Interpolated hourly estimates (applies only to spill bays 3 and 16) \\
\hline Contains I1BG & Intake 1B guided \\
\hline Contains I1BU & Intake 1B unguided \\
\hline Contains I2AG & Intake $2 \mathrm{~A}$ guided \\
\hline Contains I2AU & Intake 2B unguided \\
\hline Contains I3CG & Intake $3 \mathrm{C}$ guided \\
\hline Contains I3CU & Intake $3 \mathrm{C}$ unguided \\
\hline Contains I4AG & Intake 4A guided \\
\hline Contains I4AU & Intake 4A unguided \\
\hline Contains I5BG & Intake 5B guided \\
\hline Contains I5BU & Intake 5B unguided \\
\hline Contains I6CG & Intake $6 \mathrm{C}$ guided \\
\hline Contains I6CU & Intake $6 \mathrm{C}$ unguided \\
\hline Contains I7AG & Intake $7 \mathrm{~A}$ guided \\
\hline Contains I7AU & Intake 7A unguided \\
\hline Contains I8BG & Intake 8B guided \\
\hline Contains I8BU & Intake 8B unguided \\
\hline Contains I9CG & Intake 9C guided \\
\hline Contains I9CU & Intake 9C unguided \\
\hline Contains I10BG & Intake 10B guided \\
\hline Contains I10BU & Intake 10B unguided \\
\hline Contains I11CG & Intake $11 \mathrm{C}$ guided \\
\hline Contains I11CU & Intake 11C unguided \\
\hline Contains I12AG & Intake 12A guided \\
\hline Contains I12AU & Intake $12 \mathrm{~A}$ unguided \\
\hline Contains I13BG & Intake 13B guided \\
\hline Contains I13BU & Intake 13B unguided \\
\hline Contains I14BG & Intake 14B guided \\
\hline Contains I14BU & Intake 14B unguided \\
\hline Contains I15BG & Intake 15B guided \\
\hline Contains I15BU & Intake 15B unguided \\
\hline Contains I15CG & Intake $15 \mathrm{C}$ guided \\
\hline Contains I15CU & Intake $15 \mathrm{C}$ unguided \\
\hline Contains I16BG & Intake 16B guided \\
\hline Contains I16BU & Intake 16B unguided \\
\hline Contains I17BG & Intake 17B guided \\
\hline Contains I17BU & Intake 17B unguided \\
\hline Contains I18BG & Intake 18B guided \\
\hline Contains I18BU & Intake 18B unguided \\
\hline Contains SB2 & Spillway bay 2 \\
\hline Contains SB3 & Spillway bay 3 \\
\hline Contains SB4 & Spillway bay 4 \\
\hline Contains SB5 & Spillway bay 5 \\
\hline Contains SB6 & Spillway bay 6 \\
\hline Contains SB7 & Spillway bay 7 \\
\hline Contains SB8 & Spillway bay 8 \\
\hline Contains SB10 & Spillway bay 10 \\
\hline Contains SB12 & Spillway bay 12 \\
\hline Contains SB14 & Spillway bay 14 \\
\hline Contains SB15 & Spillway bay 15 \\
\hline Contains SB16 & Spillway bay 16 \\
\hline Contains SB17 & Spillway bay 17 \\
\hline
\end{tabular}


Appendix F

Statistical Analysis System Code for Estimating Effective Beam Angle based Upon Range from a Transducer 



\section{Appendix $F$}

\section{Statistical Analysis System Code for Estimating Effective Beam Angle based Upon Range from a Transducer}

Appendix F-1. Definitions of Variables and Operators

\begin{tabular}{|l|l|}
\hline \multicolumn{1}{|c|}{ Variable or Operator } & \\
\hline$*$ & Begins a comment when placed first in a statement or is a multiplication operator within statements \\
\hline$* *$ & Exponential operator \\
\hline+ & Addition operator \\
\hline- & Subtraction operator \\
\hline$;$ & End of statement \\
\hline$\cdot$ & Missing value symbol \\
\hline LT & Less than operator \\
\hline System & $\begin{array}{l}\text { Corresponds to an echosounder and associated transducers. Echosounder channels and transducer locations are described } \\
\text { in Appendix B. }\end{array}$ \\
\hline Channel & Corresponds to a single transducer attached to one specific echosounder channel. \\
\hline Mid_Range & The average of the ranges of the first and last echoes in an echo trace. \\
\hline N_Angle & Nominal beam angle measured at the -3dB point \\
\hline E_Angle & Effective beam angle estimated from a polynomial derived during detectability modeling \\
\hline Angle & Effective beam angle based upon nominal beam angle (if E_Angle is missing) or the effective beam angle \\
\hline & \\
\hline
\end{tabular}


Appendix F-2. Statistical Analysis System (SAS) Code for Calculating Effective Beam Angle Based upon Range from Transducers in Spring 2001

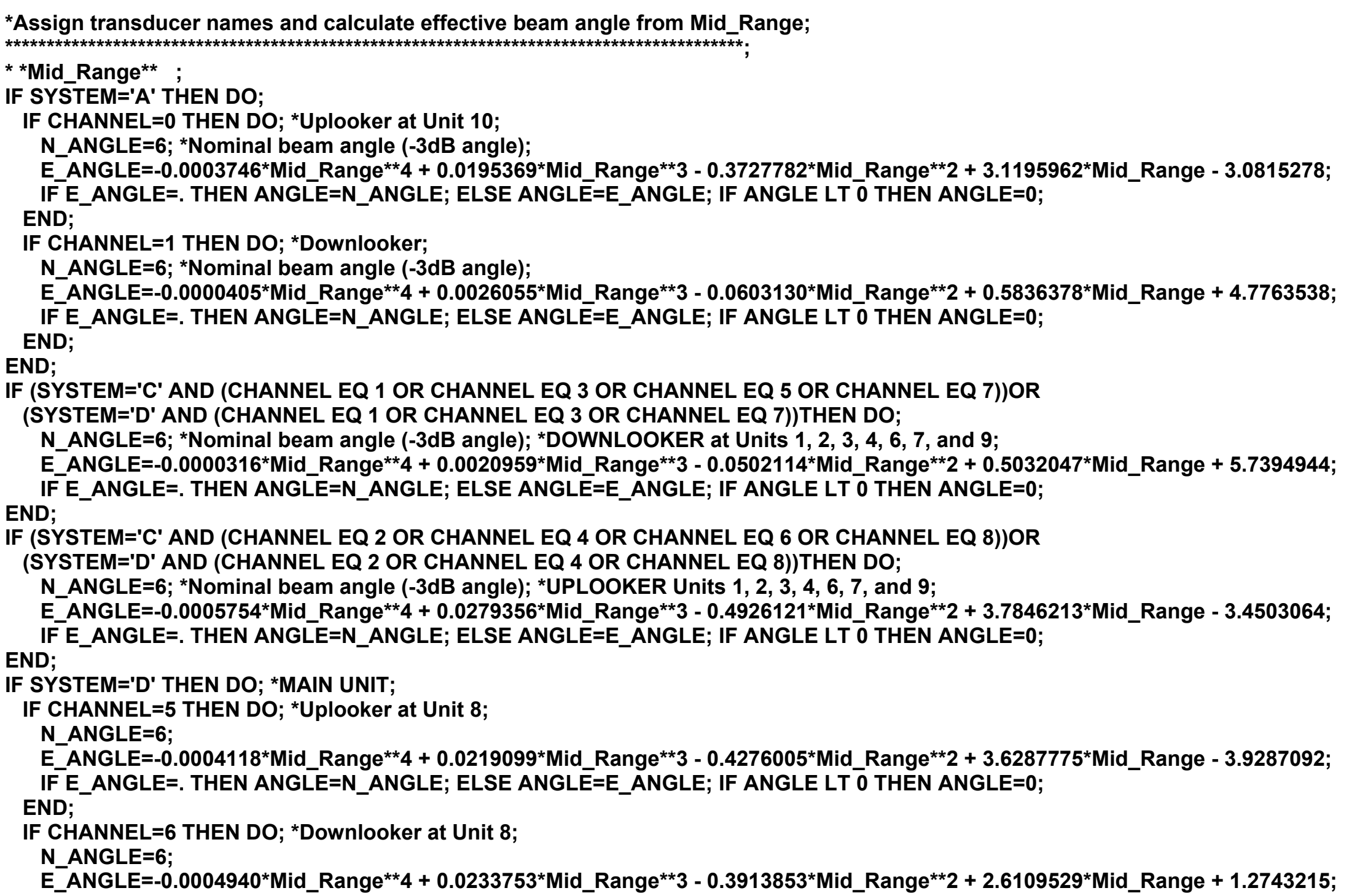


IF E_ANGLE=. THEN ANGLE=N_ANGLE; ELSE ANGLE=E_ANGLE; IF ANGLE LT 0 THEN ANGLE=0; END;

END;

IF SYSTEM='O' THEN DO; *Downlooker at Spill bay 17;

N_ANGLE=10;

E_ANGLE $=-0.0014583^{*}$ Mid_Range ${ }^{* *} 4+0.0526578^{*}$ Mid_Range ${ }^{* *} 3-0.6548105^{*}$ Mid_Range ${ }^{* *} 2+3.2577928^{*}$ Mid_Range +7.7069431 ; IF E_ANGLE=. THEN ANGLE=N_ANGLE; ELSE ANGLE=E_ANGLE; IF ANGLE LT 0 THEN ANGLE=0; END;

IF SYSTEM='P' OR SYSTEM='Q' THEN DO; *Downlookers at spill bays 8, 10, 14, 15, 2, 5, 6, and 7;

N ANGLE=10;

E_ANGLE $=-0.0014580^{*}$ Mid_Range ${ }^{* *} 4+0.0528453^{*}$ Mid_Range ${ }^{* *} 3-0.6570207^{*}$ Mid_Range ${ }^{* *} 2+3.2510723^{*}$ Mid_Range +4.6469364 IF E ANGLE=. THEN ANGLE=N ANGLE; ELSE ANGLE=E ANGLE; IF ANGLE LT 0 THEN ANGLE=0;

$$
\text { END; }
$$

IF (SYSTEM='P' AND CHANNEL=3) OR (SYSTEM='Q' AND CHANNEL=2) THEN DO; *Downlooker at spill bays 12 and 4;

N_ANGLE=10;

E_ANGLE $=0.0036436^{*}$ Mid_Range ${ }^{* *} 5-0.1108587^{*}$ Mid_Range ${ }^{* *} 4+1.2931812^{*}$ Mid_Range ${ }^{* *} 3-7.2245644^{*}$ Mid_Range ${ }^{\star *} 2+$ 19.3212369*Mid_Range - 10.8636667;

IF E_ANGLE=. THEN ANGLE=N_ANGLE; ELSE ANGLE=E_ANGLE; IF ANGLE LT 0 THEN ANGLE=0; END;

IF SYSTEM='I' THEN DO;

IF CHANNEL=10 THEN DO; *Uplooker at Unit 18;

\section{N ANGLE $=6$;}

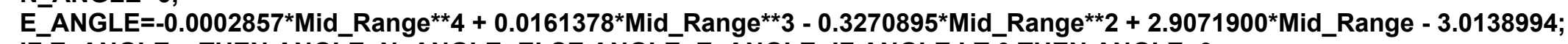
IF E ANGLE=. THEN ANGLE=N ANGLE; ELSE ANGLE=E ANGLE; IF ANGLE LT 0 THEN ANGLE=0; END;

IF CHANNEL=0 THEN DO; *Downlooker at Unit 18;

\section{N_ANGLE $=6$;}

E_ANGLE $=-0.0001427^{*}$ Mid_Range ${ }^{* *} 4+0.0084217^{*}$ Mid_Range ${ }^{\star *} 3-0.1741949 *$ Mid_Range ${ }^{* *} 2+1.4989812^{*}$ Mid_Range +2.0136265

IF E_ANGLE=. THEN ANGLE=N_ANGLE; ELSE ANGLE=E_ANGLE; IF ANGLE LT 0 THEN ANGLE=0; END;

$$
\text { END; }
$$

IF (SYSTEM='G' AND (CHANNEL EQ 2 OR CHANNEL EQ 4 OR CHANNEL EQ 6 OR CHANNEL EQ 8)) OR

(SYSTEM='H' AND (CHANNEL EQ 2 OR CHANNEL EQ 4 OR CHANNEL EQ 6 OR CHANNEL EQ 8)) THEN DO;

*Uplookers at units $11,12,13,14,15,16$, and 17 ;

N_ANGLE $=6.5$;

E_ANGLE $=-0.0001185^{*}$ Mid_Range ${ }^{* *} 4+0.0086176^{*}$ Mid_Range ${ }^{\star *} 3-0.2229570^{*}$ Mid_Range ${ }^{\star *} 2+2.4378017^{*}$ Mid_Range -2.0871320 ; *Effective beam angle (from 2001 detectability modeling); END;

IF E_ANGLE=. THEN ANGLE=N_ANGLE; ELSE ANGLE=E_ANGLE; IF ANGLE LT 0 THEN ANGLE=0;

IF (SYSTEM='G' AND (CHANNEL EQ 1 OR CHANNEL EQ 3 OR CHANNEL EQ 5 OR CHANNEL EQ 7)) OR 
(SYSTEM='H' AND (CHANNEL EQ 1 OR CHANNEL EQ 3 OR CHANNEL EQ 5 OR CHANNEL EQ 7)) THEN DO;

*Downlookers at units $11,12,13,14,15,16$, and 17;

N ANGLE $=6.5$;

E_ANGLE $=-0.0001262^{*}$ Mid_Range ${ }^{* *} 4+0.0074729 *$ Mid_Range ${ }^{* *} 3-0.1554771^{*}$ Mid_Range ${ }^{* *} 2+1.3516580^{*}$ Mid_Range +2.9217253 *Effective beam angle (from 2001 detectability modeling); END;

IF E_ANGLE=. THEN ANGLE=N_ANGLE; ELSE ANGLE=E_ANGLE; IF ANGLE LT 0 THEN ANGLE=0;

IF SYSTEM='R' AND CHANNEL EQ 0 THEN DO; *1 ${ }^{\text {st }}$ Downlooker upstream of Intake 15ㅁ;

N_ANGLE $=6$;

E ANGLE $=-0.0001132{ }^{*}$ Mid Range ${ }^{* *} 4+0.0081442 *$ Mid Range ${ }^{* *} 3-0.2078268 *$ Mid Range ${ }^{* *} 2+2.2352430 *$ Mid Range -1.8956107 END;

IF E_ANGLE=. THEN ANGLE=N_ANGLE; ELSE ANGLE=E_ANGLE; IF ANGLE LT 0 THEN ANGLE=0;

IF SYSTEM='R' AND CHANNEL EQ 1 THEN DO; *2nd Downlooker upstream of Intake 15ㅁ;

N_ANGLE $=6$;

E_ANGLE $=-0.0001220^{*}$ Mid_Range ${ }^{* *} 4+0.0086234^{*}$ Mid_Range $^{* *} 3-0.2155319^{*}$ Mid_Range $^{* *} 2+2.2584577^{*}$ Mid_Range $-1.6517694 ;$ END;

IF E ANGLE=. THEN ANGLE=N_ANGLE; ELSE ANGLE=E_ANGLE; IF ANGLE LT 0 THEN ANGLE=0;

IF SYSTEM='R' AND CHANNEL EQ 2 THEN DO; *3rd Downlooker upstream of Intake 15ㅁ;

N_ANGLE=6;

E ANGLE $=-0.0001222^{*}$ Mid Range ${ }^{* *} 4+0.0086013^{*}$ Mid Range ${ }^{* *} 3-0.2127203^{*}$ Mid Range ${ }^{\star *} 2+2.18714344^{*}$ Mid Range -1.1267870 END;

IF E_ANGLE=. THEN ANGLE=N_ANGLE; ELSE ANGLE=E_ANGLE; IF ANGLE LT 0 THEN ANGLE=0;

IF SYSTEM='X' THEN DO;

IF CHANNEL EQ 0 THEN DO; *uplooker at Unit 5;

N_ANGLE=6;

E ANGLE $=-0.0000178^{*}$ Mid_Range ${ }^{* \star} 5+0.0004271^{*}$ Mid_Range ${ }^{\star *} 4+0.0067419^{*}$ Mid_Range ${ }^{* *} 3-0.2884562 *$ Mid_Range ${ }^{\star \star} 2+$ 2.9351549*Mid_Range - 3.0309238;

IF E ANGLE=. THEN ANGLE=N ANGLE; ELSE ANGLE=E ANGLE; IF ANGLE LT 0 THEN ANGLE=0; END;

IF CHANNEL EQ 1 THEN DO; *downlooker at Unit 5;

N_ANGLE $=6$;

E_ANGLE $=0.0000027^{*}$ Mid_Range ${ }^{* \star} 5-0.0002102^{*}$ Mid_Range ${ }^{* *} 4+0.0064627^{*}$ Mid_Range $^{* *} 3-0.0978366^{*}$ Mid_Range ${ }^{* *} 2+$ $0.7253817^{*}$ Mid Range +4.7598874

IF E_ANGLE=. THEN ANGLE=N_ANGLE; ELSE ANGLE=E_ANGLE; IF ANGLE LT 0 THEN ANGLE=0; END; END; 
Appendix F-3. Statistical Analysis System (SAS) Code for Calculating Effective Beam Angle Based upon Range from a Transducer in Summer 2001

*Assign transducer names and calculate effective beam angle;

* *Mid_Range** ;

IF SYSTEM='A' THEN DO;

IF CHANNEL=0 THEN DO; *Uplooker at Unit 10;

N ANGLE $=6$; *Nominal beam angle (-3dB angle);

E_ANGLE $=-0.0001040^{*}$ Mid_Range ${ }^{* *} 4+0.0072551^{*}$ Mid_Range ${ }^{* *} 3-0.1776161^{*}$ Mid_Range ${ }^{* *} 2+1.8695036^{*}$ Mid_Range -2.0218137 ;

IF E_ANGLE=. THEN ANGLE=N_ANGLE; ELSE ANGLE=E_ANGLE; IF ANGLE LT 0 THEN ANGLE=0;

END;

IF CHANNEL=1 THEN DO; *downlooker at Unit 10;

N_ANGLE $=6$; *Nominal beam angle (-3dB angle);

E ANGLE $=-0.0000553^{*}$ Mid Range ${ }^{* *} 4+0.0034783^{*}$ Mid Range ${ }^{* *} 3-0.0780310^{*}$ Mid Range ${ }^{* *} 2+0.7277080^{*}$ Mid Range + 3.4213323;

IF E_ANGLE=. THEN ANGLE=N_ANGLE; ELSE ANGLE=E_ANGLE; IF ANGLE LT 0 THEN ANGLE=0; END; END;

IF (SYSTEM='C' AND (CHANNEL EQ 1 OR CHANNEL EQ 3 OR CHANNEL EQ 5 OR CHANNEL EQ 7))OR

(SYSTEM='D' AND (CHANNEL EQ 1 OR CHANNEL EQ 3 OR CHANNEL EQ 7))THEN DO; *Downlooker Units 1, 2, 3, 4, 6, 7, and 9;

N_ANGLE=6; *Nominal beam angle (-3dB angle); *DOWNLOOKER;

E ANGLE $=-0.0000386^{*}$ Mid Range ${ }^{* *} 4+0.0025442 *$ Mid_Range ${ }^{* *} 3-0.0601729 *$ Mid Range ${ }^{* *} 2+0.5926396 *$ Mid_Range +4.4116049 IF E_ANGLE=. THEN ANGLE=N_ANGLE; ELSE ANGLE=E_ANGLE; IF ANGLE LT 0 THEN ANGLE=0;

END;

IF (SYSTEM='C' AND (CHANNEL EQ 2 OR CHANNEL EQ 4 OR CHANNEL EQ 6 OR CHANNEL EQ 8))OR

(SYSTEM='D' AND (CHANNEL EQ 2 OR CHANNEL EQ 4 OR CHANNEL EQ 8))THEN DO; *Uplooker Units 1, 2, 3, 4, 6, 7, and 9;

N ANGLE=6; *Nominal beam angle (-3dB angle); *UPLOOKER;

E_ANGLE $=-0.0002324^{*}$ Mid_Range ${ }^{* *} 4+0.012790{ }^{*}$ Mid_Rang ${ }^{* *} 3-0.2602051^{*}$ Mid_Range ${ }^{* *} 2+2.3614581^{*}$ Mid_Range -2.3551021 ; END;

IF E ANGLE=. THEN ANGLE=N ANGLE; ELSE ANGLE=E ANGLE; IF ANGLE LT 0 THEN ANGLE=0

IF SYSTEM='D' THEN DO; *MAIN UNIT;

IF CHANNEL=5 THEN DO; *Uplooker at Unit 8;

N_ANGLE=6;

E ANGLE $=-0.0001290^{*}$ Mid Range ${ }^{* *} 4+0.0089621^{*}$ Mid Range ${ }^{* *} 3-0.2187747^{*}$ Mid Range ${ }^{* *} 2+2.2541737^{*}$ Mid Range -2.6229044 IF E_ANGLE=. THEN ANGLE=N_ANGLE; ELSE ANGLE=E_ANGLE; IF ANGLE LT 0 THEN ANGLE=0; END;

IF CHANNEL=6 THEN DO; *Downlooker at Unit 8;

N_ANGLE $=6$; 
E_ANGLE $=-0.0004732^{*}$ Mid_Range ${ }^{* *} 4+0.0224982^{*}$ Mid_Range ${ }^{* *} 3-0.3793284^{*}$ Mid_Range ${ }^{* \star} 2+2.5495810^{*}$ Mid_Range +0.2314783 IF E_ANGLE=. THEN ANGLE=N_ANGLE; ELSE ANGLE=E_ANGLE; IF ANGLE LT 0 THEN ANGLE=0; END;

END;

IF SYSTEM='O' THEN DO; *Downlooker at Spill bay 17;

N_ANGLE $=10$

E_ANGLE $=-0.0013942^{*}$ Mid_Range ${ }^{* *} 4+0.0509931^{*}$ Mid_Range ${ }^{* *} 3-0.6424398^{*}{ }^{M i d}$ Range ${ }^{* *} 2+3.2511507^{*}$ Mid_Range +5.2349284

IF E_ANGLE=. THEN ANGLE=N_ANGLE; ELSE ANGLE=E_ANGLE; IF ANGLE LT 0 THEN ANGLE=0;

$$
\text { END; }
$$

IF (SYSTEM='P' AND CHANNEL NE 3) OR (SYSTEM='Q' AND CHANNEL NE 2) THEN DO; *Downlookers at spill bays 8, 10, 14, 15, 2, 5, 6, N ANGLE=10;

E_ANGLE $=-0.0014064^{*}$ Mid_Range ${ }^{\star *} 4+0.0509348^{*}$ Mid_Range ${ }^{\star *} 3-0.6320100^{*}$ Mid_Range ${ }^{* *} 2+3.1236695^{*}$ Mid_Range $+2.4016384 ;$ IF E_ANGLE=. THEN ANGLE=N_ANGLE; ELSE ANGLE=E_ANGLE; IF ANGLE LT 0 THEN ANGLE=0; END;

IF (SYSTEM='P' AND CHANNEL EQ 3) OR (SYSTEM='Q' AND CHANNEL EQ 2) THEN DO; *Downlookers at spill bays 12 and 4; N ANGLE $=10$

E_ANGLE $=0.0018058^{*}$ Mid_Range ${ }^{* *} 5-0.0525090 *$ Mid_Range ${ }^{* *} 4+0.5934379 *$ Mid_Range ${ }^{* *} 3-3.3193546 *$ Mid_Range ${ }^{* *} 2+$ 9.3739533*Mid_Range - 6.1593333;

IF E_ANGLE=. THEN ANGLE=N_ANGLE; ELSE ANGLE=E_ANGLE; IF ANGLE LT 0 THEN ANGLE=0; END;

IF SYSTEM='I' THEN DO;

IF CHANNEL=10 THEN DO; *Uplooker at Unit 18;

N_ANGLE $=6$;

E_ANGLE $=0.0002954^{*}$ Mid_Range ${ }^{* *} 4-0.0069716 *$ Mid_Range ${ }^{* *} 3-0.0000848^{*}$ Mid_Range ${ }^{* *} 2+1.0032224^{*}$ Mid_Range -1.3114219 ;

IF E_ANGLE=. THEN ANGLE=N_ANGLE; ELSE ANGLE=E_ANGLE; IF ANGLE LT 0 THEN ANGLE=0; END;

IF CHANNEL=0 THEN DO; *Downlooker at Unit 18;

N ANGLE $=6$;

E_ANGLE $=-0.0001359^{*}$ Mid_Range ${ }^{* *} 4+0.0081012^{*}$ Mid_Range ${ }^{* *} 3-0.1698118^{*}$ Mid_Range ${ }^{* *} 2+1.4910183^{*}$ Mid_Range +0.2731265

IF E_ANGLE=. THEN ANGLE=N_ANGLE; ELSE ANGLE=E_ANGLE; IF ANGLE LT 0 THEN ANGLE=0; END;

END;

IF (SYSTEM='G' AND (CHANNEL EQ 2 OR CHANNEL EQ 4 OR CHANNEL EQ 6 OR CHANNEL EQ 8)) OR

(SYSTEM='H' AND (CHANNEL EQ 2 OR CHANNEL EQ 4 OR CHANNEL EQ 6 OR CHANNEL EQ 8)) THEN DO;

*Uplookers at units $11,12,13,14,15,16$, and 17 ;

N_ANGLE $=6.5$;

E_ANGLE $=-0.0000567^{*}$ Mid_Range ${ }^{* *} 4+0.0043644^{*}$ Mid_Range ${ }^{* *} 3-0.1226479^{*}$ Mid_Range ${ }^{\star *} 2+1.5237704^{*}$ Mid_Range -1.7154795 ;

IF E_ANGLE=. THEN ANGLE=N_ANGLE; ELSE ANGLE=E_ANGLE; IF ANGLE LT 0 THEN ANGLE=0; END; 
IF (SYSTEM='G' AND (CHANNEL EQ 1 OR CHANNEL EQ 3 OR CHANNEL EQ 5 OR CHANNEL EQ 7)) OR

(SYSTEM='H' AND (CHANNEL EQ 1 OR CHANNEL EQ 3 OR CHANNEL EQ 5 OR CHANNEL EQ 7)) THEN DO; *Downlookers;

${ }^{*}$ Downlookers at units $11,12,13,14,15,16$, and 17 ;

N_ANGLE $=6.5$;

E_ANGLE $=-0.0001300^{*}$ Mid Range ${ }^{* *} 4+0.0077531 *$ Mid Range ${ }^{* *} 3-0.1628108^{*}$ Mid Range ${ }^{* *} 2+1.4355703^{*}$ Mid_Range +0.8058478

IF E_ANGLE=. THEN ANGLE=N_ANGLE; ELSE ANGLE=E_ANGLE; IF ANGLE LT 0 THEN ANGLE=0; END;

IF SYSTEM='R' AND CHANNEL EQ 0 THEN DO; *1 ${ }^{\text {st }}$ Downlooker upstream of Intake 15ㅁ;

N_ANGLE $=6$;

E ANGLE $=-0.0000759^{*}$ Mid Range ${ }^{* *} 4+0.0055374^{*}$ Mid Range ${ }^{\star *} 3-0.1450202^{*}$ Mid Range ${ }^{\star *} 2+1.6447507^{*}$ Mid Range -1.6279483 END;

IF E_ANGLE=. THEN ANGLE=N_ANGLE; ELSE ANGLE=E_ANGLE; IF ANGLE LT 0 THEN ANGLE=0;

IF SYSTEM='R' AND CHANNEL EQ 1 THEN DO; *2nd Downlooker upstream of Intake 15ㅁ;

N_ANGLE=6;

E_ANGLE $=-0.0000831^{*}$ Mid_Range ${ }^{* *} 4+0.005970{ }^{*}$ Mid_Range ${ }^{* *} 3-0.1532337^{*}$ Mid_Range ${ }^{\star *} 2+1.6886241^{*}$ Mid_Range $-1.4991839 ;$ END;

IF E_ANGLE=. THEN ANGLE=N_ANGLE; ELSE ANGLE=E_ANGLE; IF ANGLE LT 0 THEN ANGLE=0;

IF SYSTEM='R' AND CHANNEL EQ 2 THEN DO; *3rd Downlooker upstream of Intake 15ㅁ;

N_ANGLE $=6$;

E_ANGLE $=-0.0000870^{*}$ Mid_Range ${ }^{* *} 4+0.0062105^{*}$ Mid_Range ${ }^{* *} 3-0.1570675^{*}$ Mid_Range ${ }^{* *} 2+1.6849015^{*}$ Mid_Range $-1.1777958 ;$ END;

IF E_ANGLE=. THEN ANGLE=N_ANGLE; ELSE ANGLE=E_ANGLE; IF ANGLE LT 0 THEN ANGLE=0;

IF SYSTEM='X' THEN DO;

IF CHANNEL EQ 0 THEN DO; *uplooker at Unit 5;

N_ANGLE $=6$;

E_ANGLE $=-0.0001550^{\star}$ Mid_Range ${ }^{\star *} 4+0.0093049^{\star}$ Mid_Range ${ }^{\star *} 3-0.2065035^{\star}$ Mid_Range $^{\star *} 2+2.0395836^{\star}$ Mid_Range -2.2392157 ;

*The revised equation was based upon the average backscattering cross section converted to a TS;

IF E_ANGLE=. THEN ANGLE=N_ANGLE; ELSE ANGLE=E_ANGLE; IF ANGLE LT 0 THEN ANGLE=0;

END;

IF CHANNEL EQ 1 THEN DO; *downlooker at Unit 5;

N ANGLE $=6$;

E_ANGLE $=-0.0000538^{*}$ Mid_Range ${ }^{* *} 4+0.0033987^{*}$ Mid_Range ${ }^{* *} 3-0.0763793^{*}$ Mid_Range ${ }^{* *} 2+0.7104033^{*}$ Mid_Range +3.6292144

*The revised equation was based upon the average backscattering cross section converted to a TS;

IF E_ANGLE=. THEN ANGLE=N_ANGLE; ELSE ANGLE=E_ANGLE; IF ANGLE LT 0 THEN ANGLE=0; END;

END; 